\title{
CHALLENGES TO INCLUSIVE GROWTH
}

\section{A Poverty and Equity Assessment of Djibouti}

\section{FULL REPORT}

\begin{tabular}{l}
$\frac{1}{2}$ \\
$\frac{1}{2}$ \\
$\frac{2}{5}$ \\
$\frac{5}{2}$ \\
$\frac{1}{5}$ \\
$\frac{0}{2}$ \\
$\frac{0}{0}$ \\
$\frac{\pi}{2}$ \\
$\frac{0}{2}$ \\
$\frac{0}{2}$ \\
\hline
\end{tabular} 


\section{CHALLENGES TO INCLUSIVE GROWTH}

A Poverty and Equity Assessment of Djibouti

(4) WORLD BANK GROUP 

TABLE OF

CONTENTS

Acknowledgments

Acronyms

Welfare and poverty are distributed unequally in Djibouti XIV

Location shapes access to services, with large coverage gaps between urban and rural areas, but the labor market opportunities remain low for urban and rural poor alike $\mathrm{XX}$

Economic growth in recent years has been accompanied by an improvement in well-being of households, as measured by nonmonetary indicators XXIII

Looking forward, investments in human capital may contribute to poverty reduction if the government ensures the benefits are evenly distributed in the population $\mathrm{XXVI}$

The full potential of the labor market as a sustainable driver out of poverty is still untapped-over half of the working-age population is not in the labor force

While the public sector continues to draw highly skilled individuals,

the rest of the employed workforce is informal XXXII

The employment profile highlights the need to continue addressing labor demand-side issues XXXV

Djibouti must take full advantage of its growing economy to strengthen the poverty reduction angle in public policies XXXVI 
Introduction and macroeconomic context

Analysis of welfare and monetary poverty ___ 3

Main source of data 3

The welfare aggregate _ 4

Poverty lines __ 7

Poverty in Djibouti in 2017

Poverty profile 13

Location characteristics

Demographic characteristics __ 13

Nonmonetary indicators _ 15

Economic characteristics _ 23

Trends in well-being _ 25

Inequality in Djibouti___ 31

Monetary inequality ___ 31

Deprivation in Djibouti: Human opportunity index

Comparing the urban poor and nonpoor in the capital: The case of Balbala ___ 38

References $\quad 45$

Chapter 2 : Human Capital and Labor Market __ 47

Human capital: Educational outcomes in Djibouti __ 47

Intergenerational transformation in Djibouti___ 49

Labor market outcomes _ 53

References__ 64

Chapter 3 : Selected Topics to Inform Public Policy in Djibouti__ 67

Introducing competition to the telecom sector

Provision of ICT services in Djibouti___ 69

Potential impact of a new entrant on retail prices in Djibouti___ 72

Simulating increased competition in the ICT sector in Djibouti _ 74

$\begin{array}{ll}\text { Conclusion } & 76\end{array}$

Improved targeting of social programs _ 77

A proxy means test (PMT) application using EDAM4-IS __ 79

Conclusion 86

Nomads and pastoralists __ 87

References__ 93 
The Djibouti Household Survey (EDAM4-IS) 95

Sampling and extrapolation coefficients of the EDAM4-IS___ 96

Data collection 97

Sampling weights 97

Does the EDAM represent the actual Djiboutian population? 98

References 100

Appendix B. Note on Poverty Measurement Methodology 101

The aggregate of consumption as a measure of well-being 101

Expenditures on food products 101

Expenditure on nonfood products 104

Durable goods 104

Rent and housing services 106

Analysis of the consumption aggregate 109

Household composition 110

Temporal and spatial adjustment 110

Estimation of poverty line 111

Estimation of the food poverty line 111

Food poverty threshold 113

Extreme poverty threshold 113

Overall poverty threshold 113

References 


\section{FIGURES}

Figure 0.1 Annual Consumption per Capita per Decile (Djiboutian francs, DF) _ XIV

Figure $\mathbf{0 . 2}$ Extreme Poverty Rates, by EDAM4 Representative Domains___ XV

Figure 0.3 Household Characteristics, by Region and Year___ XXII

Figure $\mathbf{0 . 4}$ Literacy Rates by Age Groups, 2017 (percent) ___ XXIV

Figure 0.5 Educational Attainment by Age Cohort, 2017 (percent)___ XXV

Figure 0.6 Educational Mobility of Individuals 25 Years and Older Compared to Their Fathers (percent) _ XXV

Figure $\mathbf{0 . 7}$ Distribution of Population in the Labor Force (percent)___ XXVII

Figure 0.8 Employment Rate Among Labor Market Participants, by Educational Attainment____ XXVIII

Figure B0.2.1 Distribution of Youth (15-24 years) across Education and Labor Force Activities___ XXIX

Figure 1.1 Macroeconomic Indicators in Djibouti___ 2

Figure 1.2 Annual per Adult Equivalent Consumption, by Area and District in Djibouti City (DF) __ 6

Figure 1.3 Share of Expenditure on Each Category ___ 7

Figure 1.4 Extreme Poverty Rates, by EDAM4 Representative Domains__ 10

Figure 1.5 Poverty Rates Based on International (US\$1.90 and US\$3.20 2011 PPP per day) and Societal Poverty Lines __ 12

Figure 1.6 Poverty Rate (percent), by Number of Household Members__ 14

Figure 1.7 Dwelling Characteristics and Access to Services by Population Groups ___ 16

Figure 1.8 Educational Attainment of Adults Age 25 and Older (percent) __ 18

Figure 1.9 Extreme Poverty Rates, by Educational Attainment of Household Head___ 19

Figure 1.10 Education Expenditure per Capita and Share of Expenditure on Education in

Total Household Expenditure, 2017

Figure 1.11 Deprivation score for Population subgroups __ 22

Figure 1.12 Employment Status of All Age 15 and Older, by Poverty Status (percent)___ 23

Figure 1.13 Type and Sector of Employment (percent of those employed, 15 years and older)___ 23

Figure 1.14 Access to Services, by Year (percent of population) _ـ 25

Figure 1.15 Dwelling Characteristics and Access to Goods, by Year (percent of population)___ 26

Figure 1.16 Comparison of Poverty Rates between 2013 and 2017, Djibouti City___ 30

Figure 1.17 Annual Consumption per Capita, per Decile___ 31

Figure 1.18 Annual Consumption per Capita, across Regions and Districts of Djibouti City (DF) __ _ 32

Figure 1.19 Gini Coefficient across the World, circa $2015 \ldots 33$

Figure 1.20 Self-Reported Welfare Category, by Quintiles of Consumption per Capita (percent)___ 35

Figure 1.21 Coverage Rates and Human Opportunity Index for Children's Opportunities ___ 37

Figure 1.22 Inequality Decomposition of Disparities in Access to Opportunities___ 38

Figure 1.23 Household Characteristics by District in Djibouti City __ 39 
Figure 2.1 Literacy Rates among People Age 15 Years and Older, 2017 (percent)

Figure 2.2 Percentage of Population Age 15 Years and Older with at Least Primary Education, 2017 __ 48

Figure 2.3 Literacy Rates, 2017 (percent) __ 49

Figure 2.4 Educational Attainment by Age Cohort, $2017 \_50$

Figure 2.5 Educational Mobility of Individuals 25 Years and Older Compared to Their Fathers' (percent)__ 51

Figure 2.6 Distribution of Population in the Labor Market (percent) __ 53

Figure 2.7 Employment Rate among Labor Market Participants, by Educational Attainment___ 54

Figure 2.8 Distribution of Youth Ages 15-24 Years across Education and Labor Force Activities__ 55

Figure 3.1 Selected ICT World Rankings for MENA and SSA countries __ 68

Figure 3.2 Digital gap between the richest and poorest households by quintile __ 70

Figure 3.3 Digital gap between urban and rural households___ 70

Figure 3.4 Travel Distance from Telephone Service Infrastructure___ 71

Figure 3.5 Social Assistance Expenditure as a Percentage of GDP ___ 77

Figure 3.6 Errors of Inclusion and Exclusion for PMT Model in Djibouti Compared to Other Countries (cutoff point at 30th percentile)___ 82

Figure $\mathbf{3 . 7}$ Average Temperature in Djibouti (Celsius) _ 88

Figure $\mathbf{3 . 8}$ Percentage of Population Owning and/or Raising Animals___ 89

Figure 3.9 Percentage of Population Practicing Transhumance and Is Pastoralist___ 90

Figure 3.10 Extreme (Monetary) Poverty Rate among Various Population Groups__ 91 


\section{TABLES}

Table 0.1

Table 0.2

Table 0.3

Table 0.4

Table BO.2.1

Table 0.5

Table 0.6

Table 0.7

Table 0.8

Table 1.1

Table 1.2

Table 1.3

Table 1.4

Table 1.5

Table 1.6

Table 1.7

Table 1.8

Table 1.9

Table B1.3.1

Table 1.10

Table 1.11

Table 1.12

Table 1.13

Table 1.14

Table 1.15

Table 1.16

Table 1.17

Table 2.1

Table B2.1.1

Table 2.2

Table 2.3

Table 2.4

Table 2.5

Table 2.6

Table 2.7
Characteristics of Households, by Poverty Status $\mathrm{XVII}$

Characteristics of the Population by Poverty Status and Location XIX

Perceptions on the Evolution of Poverty (percent population by response category) $X X I I I$ Education Transition Matrix of Poor Women (25 years and older) $X X V I$

Distribution of Youth (15-24 years old) in and out of the Labor Force XXIX Distribution of Employed Individuals by Branch of Activity and Sector Of Employment (percent)__ XXX Distribution of Employed Individuals by Firm Size and Sector Of Employment (percent) $X X X I$ Distribution of Employed Individuals by Educational Attainment and Sector of Employment__ XXXII Characteristics by Sector Of Employment XXXII

Distribution of the EDAM4 Sample and Estimated Population, by Region 4 Poverty Indicators in Djibouti, 2017 10 Indicators of Poverty in Djibouti City, 2017 11

Distribution of Extreme Poor and Overall Population across Locations (\% population) 14 Demographics and Characteristics of Extreme Poor, Nonpoor, and Overall Population 15 Extreme Poverty Rate, by Population Group 16

Asset Ownership Rates by Poverty Status 17

Education Indicators among the Extreme Poor, Nonpoor, and Overall Population 18 Health Indicators among the Extreme Poor, Nonpoor, and Overall Population 20

Dimensions and Their Corresponding Weights 21

Percentage of Population Deprived on Various Dimensions of the MPI 22

Percentage of Population with Access to Any Source to Finance Consumption 24

Perceptions on the Evolution of Poverty (percent population by response category) 27

Perceptions on the Evolution of Poverty by Location and Year 28 Indicators of Inequality 33

Access to Services, By Quantiles 34

Opportunities and Circumstances Used in Human Opportunity Index Calculation 36

Characteristics of Poor and Nonpoor, by Area of Residence 40

Education Transition Matrices of Individuals 25 Years and Older Based on Their Father's Education 52

DistriDimensions and Their Corresponding Weights 53 Labor Force Participation Rates, by Groups of Population 53

Reasons for Not Wanting to Find Employment, among the Youth 15-24 Years Old (percent) 55 Distribution of Employed Individuals by Branch of Activity and Sector of Employment (percent) _ 56 Distribution of Employed Individuals by Firm Size and Sector of Employment (percent) 57 Distribution of Employed individuals by Educational Attainment and Sector of Employment (percent)_ 58 Wages Earned in Private and Public Enterprises by Status of Employment 59 
Table 2.8

Table 2.9

Table 2.10

Table 3.1

Table 3.2

Table 3.3

Table 3.4

Table 3.5

Table 3.6

Table 3.7

Table 3.8

Table 3.9

Table 3.10

Table 3.11

Table 3.12

Table 3.13
Returns to Education 60

Characteristics by Sector of Employment of Household Heads 61 Share of Various Income Sources in Total Income 61 Djibouti Telecom Costs, by Service (Djiboutian francs, DF)__ 71 Average per Capita Consumption (DF by Quintile___ 72 Summary Statistics on Telecom Expenditures and Users __ 74 WELCOM Simulations 75 Estimated Increase in Probability Due to Welfare Gains 76 Social Safety Net Programs in Djibouti 78 Inclusion and Exclusion Errors 79 Performance of National and Flexible Model 81 Performance of Flexible Model for Subsets of Population 83 Errors of Exclusion and Inclusion for Truncated Model with Predictions for the Whole and for the Restricted Sample 83 Simulation Results on Poverty Rate after Hypothetical Expansion of PNSF 85 Simulation Results on Poverty Rate after Alternative Hypothetical Expansion of PNSF 86 Characteristics of Households in the Regions That Practice Transhumance and Those That Do Not__ 91 


\section{MAPS}

Map 0.1 Djibouti's Location in Africa___ XIII

Map 0.2 Catchment Areas of a One Kilometer Radius of Primary Schools and Hospitals in Djibouti City _ XX

Map 1.1 Catchment Areas of Primary Schools in Djibouti City (One Kilometer) __ 41

Map 1.2 Catchment Areas of Hospitals in Djibouti City (One Kilometer)___ 42

Map 1.3 Clusters and Density of Clusters for Regions Outside Djibouti City _ 43

Map 3.1 Major Livestock Migration Routes in Djibouti___ 87 


\section{BOXES}

Box 0.1 The Fourth Djiboutian Household Survey (EDAM4)__ XVI

Box 0.2 The Djiboutian Youth Needs Support to Fulfill Their Potential___ XXIX

Box 1.1 The Population Covered by EDAM4 __ 5

Box 1.2 Issues with Comparability of Welfare and Monetary Poverty across Time in Djibouti___ 9

Box 1.3 Multidimensional Poverty Index (MPI)__ 21 


\section{ACKNOWLEDGMENTS}

The World Bank greatly appreciates the collaboration with the government of Djibouti through the Ministry of Finance, the Commissariat au Plan Chargé des Statistiques, and the Directorate of Statistics and Demographic Studies (DISED) in the preparation of this report. The team benefitted from an extensive collaboration with DISED that made the implementation of the recent household survey possible. The team also wishes to acknowledge DISED's close partnership in the development and record-breaking publication of the most recent welfare indicators. The report was prepared by the Poverty and Equity Global Practice. The work was led by Gabriel Lara Ibarra and Vibhuti Mendiratta. Marco Santacroce provided inputs and contributed to the analyses, and Walker Bradley produced geospatial analytics included in the report. John Van Dyck, Amr Moubarak, and Xavier Decoster contributed to this report.

The team received guidance and comments from Carolina Sanchez-Paramo, Benu Bidani, Marina Wes, Asad Alam, Poonam Gupta, Tracey Lane, Atou Seck, Mamadou Ndione, Kadar Mouhoumed Omar, Nistha Sinha, Aziz Atamanov, Carlos Rodriguez-Castelán, Eduardo Malasquez, Axel Rifón Perez and Guido Licciardi. The team thanks Samuel Freije Rodriguez and Javier Baez for their support to the team as peer reviewers of the Djibouti Programmatic Poverty Work.

\section{NV Funded by DAN UK Government}




\section{ACRONYMS}

DISED Direction de la Statistiques et des Etudes Démographiques

DF Djibouti francs

DT Djibouti Telecom

EDAM Enquete Djiboutienne Aupres des Menages (Djiboutian Household Survey)

EDAM-IS Enquete Djiboutienne Aupres des Menages- Indicateurs Sociaux (Djiboutian Household Survey)

EDAM-BC Enquete Djiboutienne Aupres des Menages- Budget Consommation (Djiboutian Household Survey)

GDP gross domestic product

GoD government of Djibouti

HOI human opportunity index

ICT information and communication technologies

IPL international poverty line

ITU International Telecommunications Union

MENA Middle East and North Africa

MPI multidimensional poverty index

ONEAD Office National de l'Eau et de l'Assainissement

PMT proxy means test

PNSF Programme National Solidarite Familiale

PPP purchasing power parity

SDG Sustainable Development Goal

SSN social safety net

WDI World Development Indicators 


\section{OVERVIEW}

The objective of this report is to present a snapshot of the welfare landscape in Djibouti that will help stakeholders understand poverty's determinants. Exploiting data from the 2017 household expenditure survey, as well as administrative and geospatial data, it provides a detailed analysis of poverty in the country, its strong link to labor market outcomes, and the differential access to opportunities between urban and rural areas. Djibouti has recently experienced a period of unprecedented economic development, allowing it to grow its economy by an average of 7 percent per year between 2013 and 2016. This report shows that over a fifth of the Djiboutian population continues to live in extreme poverty and that the country has high levels of inequality, ranking 71 out of 95 countries with information on Gini available circa 2015. The report also focuses on the nexus of (monetary) poverty and the labor market. With a dual labor market, divided between the public sector and informality, a large share of the populationespecially those who are vulnerable-continue to face high risks, as they have neither the skills nor opportunities to lift themselves out of poverty. Djibouti needs to double its efforts in pursuing an inclusive growth strategy. This strategy will need to be sustained by a strong labor market that allows individuals to capitalize on recent investments in education and closes the gaps in human capital across all groups of the population.

\section{WELFARE AND POVERTY ARE DISTRIBUTED UNEQUALLY IN DJIBOUTI}

The Republic of Djibouti is located in the east of the Horn of Africa. It shares its borders with Ethiopia in the west and the southwest, Eritrea in the northwest, Somalia in the southeast, and the Gulf of Aden in the east. Its area is 23,200 square kilometers and it is divided into six regions: Ali Sabieh, Dikhil, Tadjourah, Obock, Arta, and the city of Djibouti, the capital (map O.1). Djibouti city comprises five districts. About three-quarters of the population lives in the capital city. Rural areas are the residence of about 15 percent of the population, with significant variation across regions, ranging from 40 percent of the population in Ali
Sabieh to 77 percent in Tadjourah. The remainder live in the country's other cities and towns.

Djibouti is a relatively small, lower-middle income economy with a nominal gross domestic product (GDP) equivalent to US\$2.6 billion in 2016 (DISED). The country, however, has experienced impressive economic growth in recent years. GDP real growth averaged 4.5 percent per year from 2003 to 2013 and 7 percent between 2013 and 2016. Djibouti's growth in each year of 2013-16 surpassed that of countries with similar characteristics, such as Cabo Verde, 
MAP 0.1 Djibouti's Location in Africa

IBRD 33396
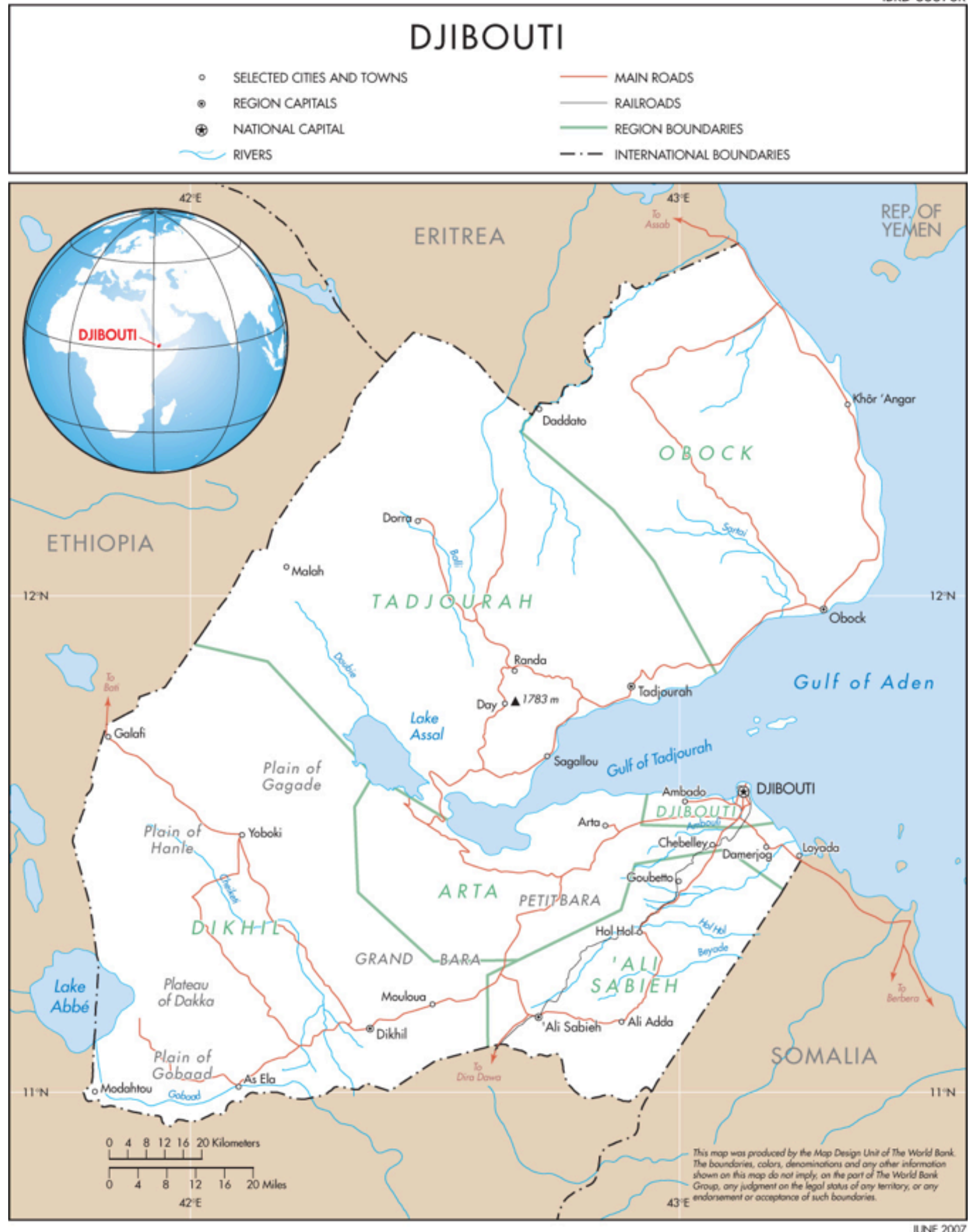

Source: World Bank. 
Comoros, Sao Tome, and Principe. ${ }^{1}$ It also surpassed that of countries that had a similar GDP per capita in 2013, such as Albania, Guinea-Bissau, Mauritius, or Mali. And it surpassed many of its Common Market for Eastern and Southern Africa partners, including Madagascar, Rwanda, and Uganda. Unfortunately, the recent growth spell-as noted, driven mainly by capital intensive investments does not appear to have been inclusive and has had limited strength at eradicating poverty in the country. Nevertheless, pursuing its ambition to position itself as a regional digital hub, the country is re-shifting the growth engine back to exports of transportation and logistics services after a temporary domination of public investment with high import content financed mainly through debt accumulation. It is also increasingly the case that Djibouti's growth is closely tied to Ethiopia's economy.

In 2017, the average consumption per capita in Djibouti was estimated at about DF 208,000 per year, equivalent to about US\$5.08 per day in 2011 purchasing power parity (PPP). ${ }^{2}$ Beyond this average, wide disparities in the levels of well-being of the Djiboutian population are found (figure O.1). Individuals of the richest decile have an estimated per capita consumption level more than 16 times the average per capita consumption in the first decile (over DF 670,000 compared to about DF 40,500). In addition, the richest decile has a per capita consumption twice as high as that of the ninth decile. This distribution leads to an estimated Gini index of 0.42among the highest in the Middle East and North Africa (MENA) region.

The low levels of consumption among certain groups lead to a nonnegligible share of the Djiboutian population not able to cover its basic needs. A little over a fifth (21.1 percent) of the population in Djibouti was considered extremely poor, according to estimates based on the official poverty line (about \$2.18 a day 2011 PPP). Poverty rates based on the international poverty line of $\$ 1.90$ a day (2011 PPP) are similar at 17.1 percent. However, for an economy at Djibouti's level of development, a more informative benchmark can be made using the World Bank's (2018b) poverty line for lower middle-income economies of $\$ 3.20$ a day (2011 PPP). In this case, the poverty rate would be closer to 32 percent.

\section{FIGURE 0.1 Annual Consumption per Capita per Decile (Djiboutian francs, DF)}

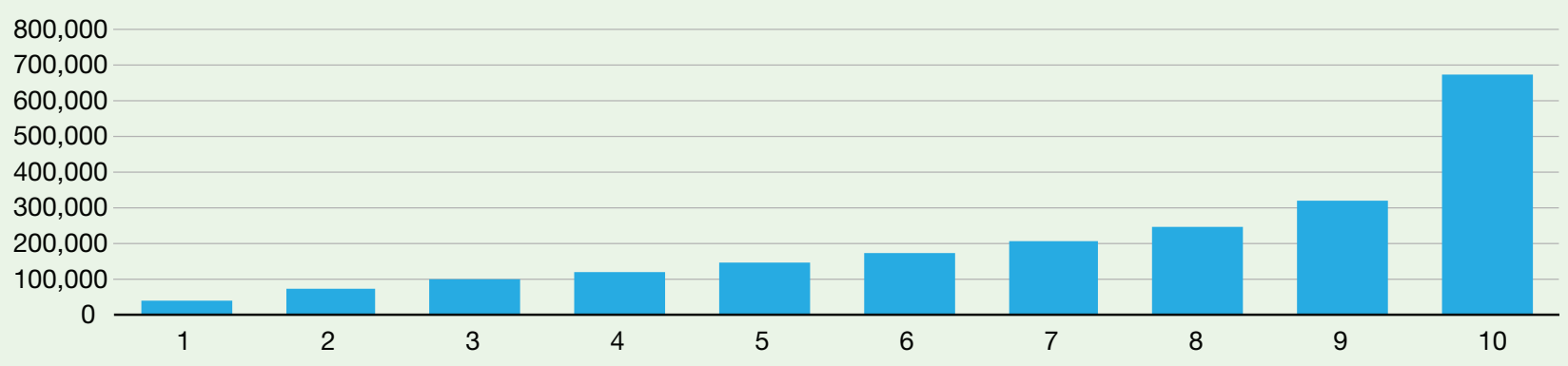

Source: Calculations based on the fourth Enquete Djiboutienne Aupres des Menages- Indicateurs Sociaux (Fourth Djiboutian Household Survey for Social Indicators or EDAM4-IS).

Note: Deciles are calculated based on per capita consumption.

1 Based on World Development Indicators (WDI) and the Find-My-Friends tool developed by the World Bank.

2 Several parts of the analyses in this report are based on the Fourth Djiboutian Household Survey (EDAM4) conducted in 2017. See box 0.1 and Appendix A for details. 
There are significant gaps in welfare between the residents of the capital and those of other regions. In Djibouti city, the extreme poverty rate is estimated at 13.6 percent, while in the other regions, it is more than three times higher at 45 percent (figure 0.2). Spatial differences in Djiboutian households' levels of well-being are evident, with regions further away from the capital showing higher levels of deprivation. Tadjourah region has the highest percentage of population living below the extreme poverty line, followed by the Dikhil region. These two regions in the west side of the country are also hosts of a relatively large rural population. Furthermore, it is notable that this relatively high level of deprivation can also be found across the international border. The adjacent regions of Afar (zone 1) and Somali (Shinile zone) in Ethiopia are classified as a Developing Regional State by the Ethiopian Government-a classification identifying regions where poverty rates are higher and performance on social indicators is poorer than national averages. Large parts of these regions in Ethiopia also face arid or semiarid climatic conditions, much like Djibouti's border regions. Finally, in the capital, disparities are also found: the fourth and fifth districts (jointly known as the community of Balbala) have extreme poverty rates of 18.3 and 15.8 percent, respectively. These rates are more than three times higher than the 1 st district (4.7 percent).

\section{FIGURE 0.2 Extreme Poverty Rates, by EDAM4 Representative Domains}

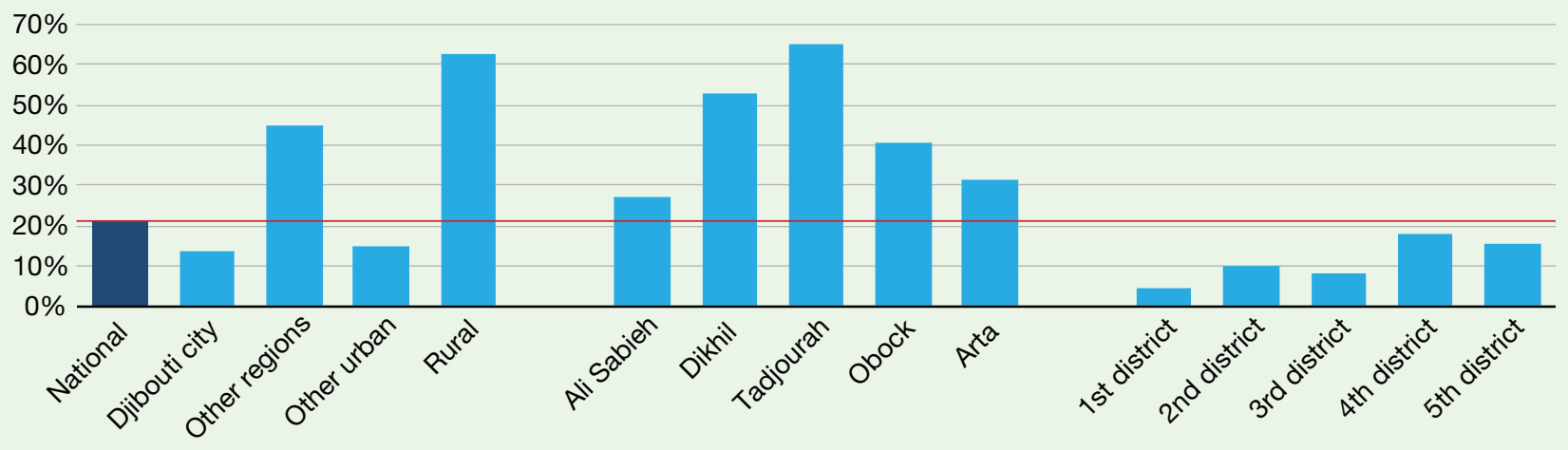

Source: Calculations based on EDAM4-IS.

Note: Line across graph denotes the national extreme poverty rate.

Together with location, several demographic and economic characteristics appear to be correlated with poverty status (table O.1). Compared to the average Djiboutian, and the nonpoor population, households considered to be extreme poor tend to be larger and have more dependents, and their heads have lower literacy rates and have fewer years of education. The dwellings inhabited by poor households are of lesser quality than those among the nonpoor, they don't have (or use) appropriate means to dispose of their garbage, and they have less access to water, electricity, and sanitation services. Poor families are also found to have limited capacity to purchase and own assets: a much lower percentage of them own mobile phones, computers, televisions, refrigerators, air-conditioning units, washing machines, and cars. 


\section{Box 0.1 The Fourth Djiboutian Household Survey (EDAM4)}

The EDAM4 is a nationally representative survey conducted in 2017 in Djibouti. The sampling strategy of the EDAM4-IS was designed to produce representative indicators at several levels: national, urban, rural, by regions and by 5 districts in Djibouti city. In a first for the Djiboutian Statistical Office (DISED), the EDAM4IS collected information on sedentary ordinary households and nomads, with a total of 4,474 households interviewed. As it is common in household surveys, the population in hospitals, prisons, military and homeless were not included.

The survey adopted current best practices in several aspects of questionnaire design and the analytical work subsequently done on welfare and poverty measurement. These changes include better collection of information on food expenditures via the use of a well-crafted list of representative items and better estimation of nonfood expenditures by collecting information on health and education in dedicated modules. The data collected also allowed for the updating of the welfare measure used for poverty estimation in two key ways. First, by incorporating detailed information on purchase of durables and tenure, the calculation of the flow of services of such items was incorporated. Second, a hedonic model was developed to capture the value of housing services (i.e. imputed rent) for owner-occupied dwellings. While the adoption of such changes led to incomparability with earlier surveys, the DISED used this survey as a new baseline from which indicators of well-being will be monitored in the future.

The population in extreme poverty may also face obstacles to escaping poverty, as they lag behind other groups in their capacity to build and sustain human capital. Children in poor households are less likely to attend school at both the primary and lower secondary levels, and a higher percentage of these children ages 6-14 have never attended school (a population sometimes referred to as descolarisés). These findings may be partly explained by the fact that almost 18 percent of the poor population declares it does not have a primary school available. In addition, the extreme poor have lower rates of coverage by health facilities. Higher percentages of the poor population declare that a health center (24.5 percent), hospital (26.8 percent), or maternity clinic (39.1 percent) is not available, as compared to the nonpoor (6.5 percent, 6.7 percent, and 17.5 percent, respectively). 


\section{TABLE 0.1 Characteristics of Households, by Poverty Status}

\begin{tabular}{|c|c|c|c|}
\hline & Nonpoor & Extreme poor & National \\
\hline Household size & 6.2 & 7.0 & 6.4 \\
\hline Dependency ratio $(\%)^{*}$ & 85 & 111 & 90 \\
\hline \multicolumn{4}{|c|}{ Household head characteristics } \\
\hline $\mathrm{Age}^{\star \star}$ & 48.0 & 48.2 & 48.0 \\
\hline Married & $80 \%$ & $84 \%$ & $81 \%$ \\
\hline Female & $21 \%$ & $20 \%$ & $20 \%$ \\
\hline Djiboutian $^{\star \star \star}$ & $96 \%$ & $94.6 \%$ & $95.8 \%$ \\
\hline Literate & $46 \%$ & $12 \%$ & $39 \%$ \\
\hline Years of education & 4.2 & 0.8 & 3.5 \\
\hline
\end{tabular}

\section{Dwelling characteristics}

\begin{tabular}{|c|c|c|c|}
\hline Sheet metal roof & $82 \%$ & $47 \%$ & $74 \%$ \\
\hline Cement floor & $53 \%$ & $31 \%$ & $49 \%$ \\
\hline Open defecation & $5 \%$ & $42 \%$ & $12 \%$ \\
\hline Appropriate garbage disposal & $86 \%$ & $46 \%$ & $78 \%$ \\
\hline Access to electricity & $72 \%$ & $16 \%$ & $60 \%$ \\
\hline Access to water & $96 \%$ & $69 \%$ & $90 \%$ \\
\hline \multicolumn{4}{|l|}{ Asset ownership rate } \\
\hline Mobile phone & $87.1 \%$ & $55.4 \%$ & $80.4 \%$ \\
\hline Laptop/personal computer & $13.3 \%$ & $0.3 \%$ & $10.5 \%$ \\
\hline Television & $61.4 \%$ & $9.4 \%$ & $50.4 \%$ \\
\hline Satellite dish & $39.7 \%$ & $5.8 \%$ & $32.5 \%$ \\
\hline Refrigerator/freezer & $44.6 \%$ & $6.1 \%$ & $36.4 \%$ \\
\hline Air-conditioning & $17.5 \%$ & $0.7 \%$ & $14.0 \%$ \\
\hline Washing machine & $16.0 \%$ & $0.8 \%$ & $12.8 \%$ \\
\hline Private car & $3.8 \%$ & $0.3 \%$ & $3.1 \%$ \\
\hline \multicolumn{4}{|l|}{ Education indicators } \\
\hline Literacy rates among 15-year-olds and older & $58.2 \%$ & $31.8 \%$ & $53.1 \%$ \\
\hline Percentage of children of 6-10 years attending school & $83.8 \%$ & $63.3 \%$ & $78.4 \%$ \\
\hline Percentage of children of $11-14$ years attending school & $88.5 \%$ & $71.1 \%$ & $84.8 \%$ \\
\hline Percentage of 6- to 14-year-olds that never attended school & $11.1 \%$ & $30.8 \%$ & $15.9 \%$ \\
\hline Maximum years of education among all adults in household & 10.0 & 5.3 & 8.3 \\
\hline Percentage of population that declare no primary school is available & $5.7 \%$ & $17.9 \%$ & $8.3 \%$ \\
\hline \multicolumn{4}{|l|}{ Health indicators } \\
\hline Percentage of households that declare no health center is available & $6.5 \%$ & $24.5 \%$ & $10.2 \%$ \\
\hline Percentage of households that declare no hospital is available & $6.7 \%$ & $26.8 \%$ & $10.9 \%$ \\
\hline Percentage of households that declare no maternity clinic is available & $17.5 \%$ & $39.1 \%$ & $22.0 \%$ \\
\hline
\end{tabular}

Source: Calculations based on EDAM4-IS.

Notes: Access to electricity is defined as the use of electricity as the main source of lighting. Access to water is defined as the availability of water in the household in the form of running water (Office National de l'Eau et de l'Assainissement, or ONEAD, indoor connection), direct connection from a borehole, outdoor connection by pipe provided by ONEAD, public fountain, or drilling (with a pump). Appropriate garbage disposal is defined as availability of garbage collector-OVD (public dump), availability of garbage collector-private, and garbage deposited in a designated place.

* Only households with at least one working age (15-64) individual are included. ** The sample comprises 4,359 household heads. For the remaining households, the age of the household head is unknown. ${ }^{* *}$ Nationality is self-declared. 


\section{LOCATION SHAPES ACCESS TO SERVICES, WITH LARGE COVERAGE GAPS BETWEEN URBAN AND RURAL AREAS, BUT THE LABOR MARKET OPPORTUNITIES REMAIN LOW FOR URBAN AND RURAL POOR ALIKE}

Poverty in Djibouti is both a rural and urban phenomenon. Rural areas comprise only 15 percent of the population but are home to 45 percent of the extreme poor population. Meanwhile, the capital city is host to half of the extreme poor, mainly due to its large share of the overall population. The districts that make up the Balbala community in the capital account for 37 percent of the poor population (and 48 percent of the total population). As a comparison, the other districts in Djibouti city are host to 12 percent of the poor, but to 32 percent of the overall population.

Rural poor households are the most deprived group in the population (table O.2). Showing the highest dependency ratios, they have the lowest participation in the labor force (among individuals age 15 and above), and their heads have very low levels of employment, a low likelihood of being employed in the public sector, and very low levels of formality among those working in the private sector. ${ }^{3}$ In terms of access to services, they perform worse than other groups of the population, with 41 percent of the poor population having access to an improved water source, 10 percent having access to sanitation, and a mere 3 percent having access to electricity. A little more than a third of the rural poor are close (less than one kilometer away) to an elementary school and only 10 percent live less than one kilometer away from any health facility. Taking all these elements together, it is no surprise that the deprivation score is 0.83 for this subgroup of the population. ${ }^{4}$
Djibouti city is the wealthiest region in the country, but the disparities among the population living in the capital are multifaceted. In fact, the poor living in Djibouti city have characteristics similar to rural poor households (and sometimes rural households in general) across many dimensions. Individuals in poor households living in both Balbala and other districts of the capital have employment rates as low as the rural poor, although more individuals are participating in the labor force. Heads of poor households in the capital city have similar educational attainment and formality levels in the private sector as the heads of poor households in rural areas. The level of consumption of the poor in the capital city is also much closer to that of the poor in rural areas than to the people living in the same district as they are. The deprivation score among poor urban households is lower than those living in rural areas (reflecting better service coverage), but it still lags their nonpoor neighbors' deprivation score. This evidence suggests that the low levels of human capital and consequently the types of jobs held by the urban poor do not allow them to escape poverty.

A major distinction between the poor in Djibouti city and the rural poor is that the former have better access to public services, perhaps by virtue of being in the capital. Compared to the rural poor, poor in the capital have better coverage rates of water, sanitation, and electricity, and more families live close to an elementary school and a health facility. The urban poor also are more likely to send their children to school. There is much scope for improvement beyond just access, however. Map 0.2

3 The sector of employment is divided into public (when the main branch of activity is public administration) and private (when the main branch of activity is anything except the public administration). Within the private sector, employers, contractors and independent workers are considered working in the formal sector when they have accounting records, a trading license (commonly referred to as "patente") and registration in the chamber of commerce. Within the private sector, salaried individuals, family helpers and apprentices are considered working in the formal sector if the worker has a contract and is registered in social security. All remaining individuals working in the private sector are considered as working in the informal sector.

4 A deprivation score is calculated looking at deprivations along 3 dimensions: monetary poverty, education, and access to services. The final score ranges from 0 to 1 , where a score of 1 indicates deprivation on all 6 indicators and a score 0 indicates no deprivation. 
uses geospatial data to show catchment areas of one kilometer of primary schools and hospitals in Djibouti city. The majority of the city dwellings are covered by at least one primary school (80.6 percent) and a hospital (71.3 percent). ${ }^{5}$ However, the estimated population served by these facilities is expected to be high and may thus call for attention in examining whether these areas are underserved and consequently if the quality of service delivery in these areas is affected. For schools, this is less likely to be a problem as a result of the introduction of double flows in public schools in the capital. Using an alternate catchment area of 1.5 kilometers would increase

\section{TABLE 0.2 Characteristics of the Population by Poverty Status and Location}

\begin{tabular}{|c|c|c|c|c|c|c|}
\hline & \multicolumn{3}{|c|}{ Nonpoor population } & \multicolumn{3}{|c|}{ Extreme poor population } \\
\hline & $\begin{array}{l}\text { Districts } \\
1-2-3\end{array}$ & Balbala & Rural & $\begin{array}{c}\text { Districts } \\
1-2-3\end{array}$ & Balbala & Rural \\
\hline Dependency ratio* & 0.71 & 0.87 & 1.08 & 0.75 & 0.82 & 1.35 \\
\hline $\begin{array}{l}\text { Percentage of population older than } 15 \\
\text { in labor force }\end{array}$ & $48 \%$ & $46 \%$ & $41 \%$ & $49 \%$ & $41 \%$ & $33 \%$ \\
\hline Percentage of individuals employed ${ }^{\star \star}$ & $29 \%$ & $25 \%$ & $22 \%$ & $13 \%$ & $12 \%$ & $13 \%$ \\
\hline Head has no education & $44 \%$ & $61 \%$ & $81 \%$ & $87 \%$ & $87 \%$ & $94 \%$ \\
\hline Head has at least secondary education & $19 \%$ & $15 \%$ & $3 \%$ & $4 \%$ & $2 \%$ & $1 \%$ \\
\hline Head is employed & $57 \%$ & $61 \%$ & $41 \%$ & $31 \%$ & $42 \%$ & $26 \%$ \\
\hline $\begin{array}{l}\text { Head is employed in public sector } \\
\text { (as \% of all employed) }\end{array}$ & $43 \%$ & $48 \%$ & $45 \%$ & $32 \%$ & $46 \%$ & $27 \%$ \\
\hline $\begin{array}{l}\text { Head is employed in private formal sector } \\
\text { (as \% of all employed) }\end{array}$ & $19 \%$ & $10 \%$ & $5 \%$ & $2 \%$ & $3 \%$ & $4 \%$ \\
\hline Access to water & $99 \%$ & $99 \%$ & $66 \%$ & $92 \%$ & $97 \%$ & $41 \%$ \\
\hline Access to sanitation & $48 \%$ & $54 \%$ & $23 \%$ & $28 \%$ & $32 \%$ & $10 \%$ \\
\hline Access to electricity & $90 \%$ & $68 \%$ & $10 \%$ & $59 \%$ & $18 \%$ & $3 \%$ \\
\hline $\begin{array}{l}\text { Household lives less than one kilometer away } \\
\text { from an elementary school }\end{array}$ & $39 \%$ & $41 \%$ & $41 \%$ & $41 \%$ & $47 \%$ & $37 \%$ \\
\hline $\begin{array}{l}\text { Percentage of } 6 \text { - to } 14 \text {-year-olds enrolled } \\
\text { in school }\end{array}$ & $84 \%$ & $87 \%$ & $69 \%$ & $70 \%$ & $79 \%$ & $53 \%$ \\
\hline $\begin{array}{l}\text { Household lives less than one kilometer away } \\
\text { from any health facility }\end{array}$ & $26 \%$ & $25 \%$ & $15 \%$ & $28 \%$ & $29 \%$ & $10 \%$ \\
\hline Average consumption per capita & 323,598 & 212,859 & 151,326 & 69,392 & 67,669 & 49,051 \\
\hline Deprivation score & 0.13 & 0.16 & 0.44 & 0.47 & 0.50 & 0.83 \\
\hline
\end{tabular}

Source: Calculations based on EDAM4-IS.

Notes: Access to electricity is defined as the use of electricity as the main source of lighting. Access to water is defined as the availability of water in the household in the form of running water (Office National de l'Eau et de l'Assainissement, or ONEAD, indoor connection), direct connection from a borehole, ONEAD outdoor connection by pipe provided, public fountain, and drilling (with a pump). Access to sanitation is defined as unshared access to a water closet with flush, or latrine with slab. Private sector comprises all branches of activity except public administration and others (international organizations, military bases, and unspecified categories). Within the private sector, employers, contractors and independent workers are considered working in the formal sector when they have accounting records, a trading license (commonly referred to as "patente") and registration in the chamber of commerce. Within the private sector, salaried individuals, family helpers and apprentices are considered working in the formal sector if the worker has a contract and is registered in social security. All remaining individuals working in the private sector are considered as working in the informal sector.

* Only households with at least one working age (15-64) individual are included. ** Includes all individuals 15 years and older.

5 Recent school openings in Balbala during 2018 are not reflected in the map or calculations. Georeferenced data is currently unavailable to estimate the impact on the estimated coverage rates. Regarding health, coverage rates of other health facilities like community health centers are not included-partly explaining the difference from rates obtained from the survey. 


\section{MAP 0.2 Catchment Areas of a One Kilometer Radius of Primary Schools and Hospitals in Djibouti City}

\section{a. Elementary schools}

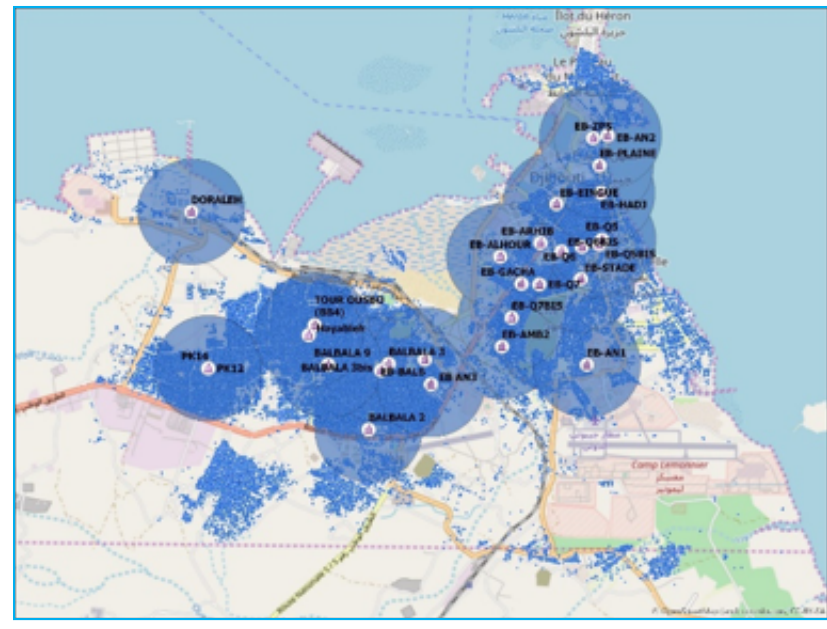

\section{b. Hospitals}

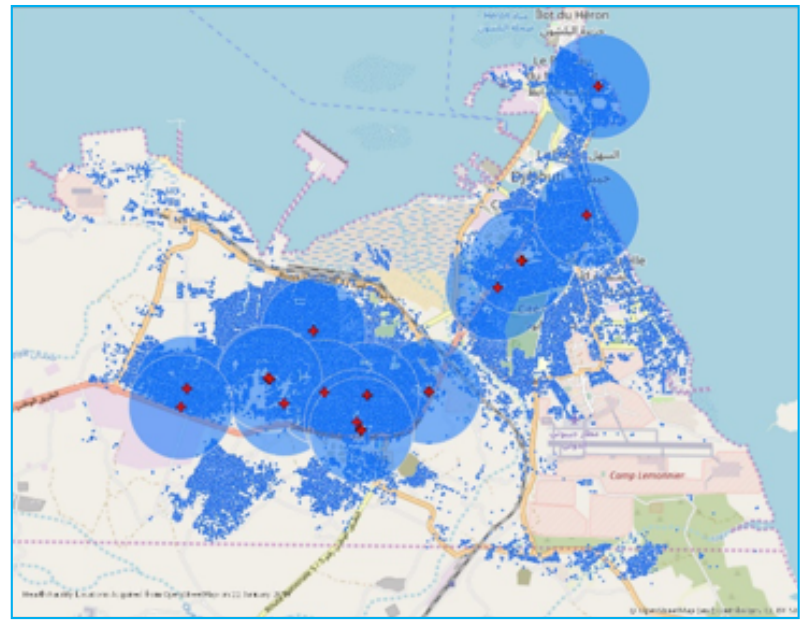

Note: Data on primary schools is obtained from Ministère de l'Education Nationale et de la Formation Professionnelle site. Data on hospitals is obtained from OpenStreetMap and do not include military hospitals or doctor's offices. Data for dwellings (marked as blue dots) are obtained from the building footprint of Djibouti produced by the World Bank.

the coverage of public elementary schools and health facilities to 89.7 percent and 86.8 percent, respectively. These elements point to the need to boost coverage in certain areas of the capital (if the areas are found to be underserved), especially as these areas seem to host poor and vulnerable populations.

Finally, location plays an important role in two other aspects: it poses challenges to implementing public investments in sparsely populated areas and increases the urgency for policies to help high-risk populations due to climate change. On the first aspect, lack of access to several services is evident in rural areas of Djibouti, but a realistic government of Djibouti (GoD) strategy to expand coverage of basic services will need to find innovative ways to reach the populations in the poorest regions, as significant portions of the population live far apart from each other. In Tadjourah, the region with the highest poverty rate, geospatial analysis shows that close to 60 percent of dwellings are in extremely low-density areas (one building per square kilometer) and almost three- quarters (73 percent) are in very low-density areas (two buildings or less per square kilometer). In Dikhil, where extreme poverty is 53 percent, these shares are 77 and 86 percent, respectively.

The second aspect - the rough arid climate-further affects inhabitants of rural areas, as they will require a strategy that supports them in the face of increased climate change risk. Due to the series of droughts that Djibouti has experienced in recent years, the livelihoods of nomadic and pastoralists have come under threat. Moreover, this population is estimated to have dwindled substantially by flight to neighboring countries or becoming sedentary in the outskirts of villages and cities. Still, in 2017, more than half of the population in Tadjourah and Obock practiced some sort of animal husbandry, as did 42, 31, and 25 percent of the population in Arta, Ali Sabieh and Dikhil, respectively. Survey estimates suggest that transhumance or pastoralism is still practiced by 6 percent of the population outside of Djibouti city. Poverty rates in this population appear to be much higher than the national rate. 


\section{ECONOMIC GROWTH IN RECENT YEARS HAS BEEN ACCOMPANIED BY AN IMPROVEMENT IN WELL-BEING OF HOUSEHOLDS, AS MEASURED BY NONMONETARY INDICATORS}

The recent period of economic growth in Djibouti has been capital intensive and driven mostly by large investments, including an investment of US\$3.4 billion on the railroad to Ethiopia (Borgen Project 2017) as well as other port projects $^{6}$ in Doraleh (cost of US\$590 million), Goubet (cost of US\$64 millions) and Tadjourah (US\$160 million). A key policy question is whether the extent to which some of the economic growth has translated into improvements in the well-being of households. Due to the lack of comparable data along monetary indicators, evidence of the potential improvement must be found in nonmonetary indicators. ${ }^{7}$

Survey data from 2012 and 2017 suggest that the Djiboutian population experienced improvements in their well-being. Indicators on access to services, dwelling characteristics, or ownership of assets indicate an increase in households' livelihoods (figure O.3). Unfortunately, regional disparities in such nonmonetary indicators, with regions further away from the capital city performing worse, are an enduring feature. As evidenced by data from 2012 and 2017, improvements of recent years had limited effects in closing the gaps. Tadjourah region is found to have the lowest coverage of services, followed by Obock and Dikhil in both years. Only one-fifth of the population has access to electricity in the regions of Tadjourah, Dikhil, and Obock, and this has hardly changed over time. In Djibouti city, access to water has improved and is almost universal. Djibouti city is followed by Ali Sabieh and Arta-a higher percentage of the population declared having access to water in these regions in 2017 as compared to
2012. Improvements are observed in other regions too, with the exception of Tadjourah. It seems that proximity to the capital and the predominance of rural population are important indicators that can help explain the difference in access to services between regions. In addition, we find that these improvements in access are highest for the bottom two quintiles of the population.

In terms of dwelling characteristics (potentially reflecting the ability to invest in one's residence), it is found that a lower percentage of the Djiboutian population is living in tents or spontaneous dwellings (makeshift dwellings) in 2017 than in 2012. There is also a higher proportion of the Djiboutian population living in houses with sheet metal as roof. These results are largely driven by changes in the capital city, Ali Sabieh, and Arta. It seems that many of these characteristics have not changed in Tadjourah, Dikhil, and Obock. The percentage of the population living in dwellings with a cement floor has also increased, indicating that the precarity of the dwellings has decreased. Higher mobile phone ownership over time is also found across all the regions of Djibouti, with the exception of Tadjourah. Nationally, this percentage increased from 64 percent in 2012 to 80 percent in 2017.

Besides objective nonmonetary indicators that correlate with households' well-being, measures relying on subjective data also point to a relative improvement in living conditions. When asked about their perceptions, members of the Djiboutian population appear to have a positive view of the evolution of poverty in 2017, especially

6 See http://www.portdedjibouti.com/wp-content/uploads/2017/05/Djibouti-Article.pdf, accessed January 16, 2019.

7 Recurrent changes in methodology and survey instruments prevent obtaining a reliable comparison of monetary welfare across years. With the incorporation of current good practices in the latest household survey, the EDAM4-IS is expected to be the start of a new series to track progress on poverty reduction. See chapter 1 and DISED (2018) for more details. 


\section{FIGURE 0.3 Household Characteristics, by Region and Year}

\section{a. Access to electricity}

$$
\text { - } 2012 \quad \text { - } 2017
$$

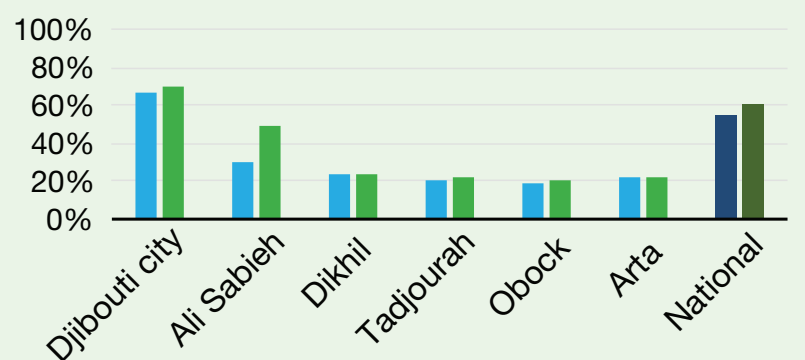

c. Living in a tent, spontaneous habitat, similar

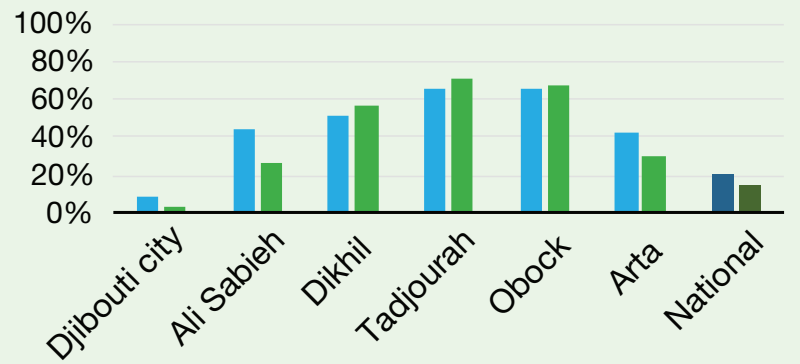

e. Cement as floor material

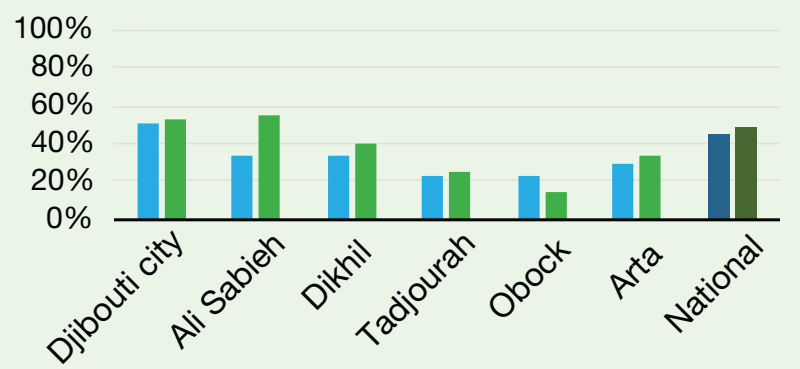

\section{b. Access to improved water sources}

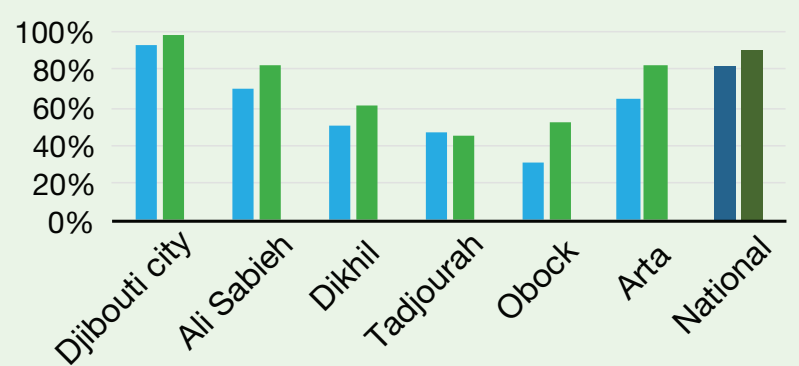

d. Sheet metal as roof material

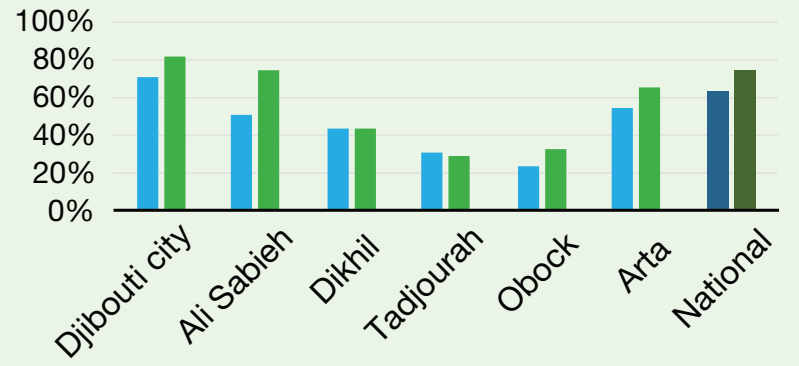

\section{f. Ownership of mobile phone}

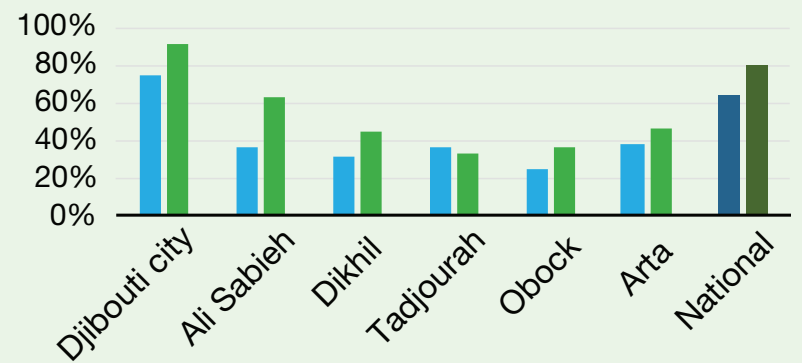

Source: Calculations using EDAM 2012 and EDAM4-IS.

Notes: Access to electricity reflects the use of electricity as the main source of lighting. Access to water in 2017 and 2012 is defined as availability of water in running water (ONEAD indoor connection), ONEAD outdoor connection by pipe, public fountain, and borehole (with a pump). Access to water in 2017 had one additional category not included in 2012-direct connection from a borehole. 
when compared to their sentiment in 2012. About a third of the population perceived a reduction in poverty in the previous five years in 2017 (table O.3). This percentage was only 13 percent in 2012. About 41 percent felt that poverty would decrease in the next five years, while only 25 percent believed so in 2012. Overall, there seems to be a belief that things got better in the period 2012-2017. It is notable that that there is also inequality in people's prospects. Breaking down the indicator on perceptions of poverty by location shows the positive expectations are driven by residents of Djibouti city, with regions showing more tame improvements in their views.

\section{TABLE 0.3 Perceptions on the Evolution of Poverty (percent population by response category)}

\section{a. 2017}

\begin{tabular}{|c|c|c|c|c|c|}
\hline & \multicolumn{5}{|c|}{$\begin{array}{l}\text { "In the next five years, do you think poverty } \\
\text { in your community will ..." }\end{array}$} \\
\hline & & Decrease & Same & Increase & Total \\
\hline \multirow{4}{*}{$\begin{array}{l}\text { "In the past five years, do you } \\
\text { think that in your community } \\
\text { poverty has . . ." }\end{array}$} & Decrease & 31 & 3 & 1 & 35 \\
\hline & Same & 5 & 23 & 3 & 31 \\
\hline & Increase & 4 & 6 & 23 & 33 \\
\hline & Total & 41 & 32 & 27 & 100 \\
\hline
\end{tabular}

\section{b. 2012}

\begin{tabular}{|c|c|c|c|c|c|}
\hline & \multicolumn{5}{|c|}{$\begin{array}{l}\text { "In the next five years, do you think poverty } \\
\text { in your community will . . ." }\end{array}$} \\
\hline & & Decrease & Same & Increase & Total \\
\hline \multirow{4}{*}{$\begin{array}{l}\text { "In the past five years, do you } \\
\text { think that in your community } \\
\text { poverty has . . ." }\end{array}$} & Decrease & 13 & 3 & 1 & 17 \\
\hline & Same & 4 & 14 & 6 & 24 \\
\hline & Increase & 7 & 7 & 45 & 59 \\
\hline & Total & 25 & 23 & 52 & 100 \\
\hline
\end{tabular}

Source: Calculations based on EDAM 2012 and EDAM-IS 2017.

Notes: For 2017, only households who answered both questions were included (3,480 households). For 2012, only households who answered both questions were included (3,436 households). 


\section{LOOKING FORWARD, INVESTMENTS IN HUMAN CAPITAL MAY CONTRIBUTE TO POVERTY REDUCTION IF THE GOVERNMENT ENSURES THE BENEFITS ARE EVENLY DISTRIBUTED IN THE POPULATION}

The GoD has made significant efforts to increase access to schooling in recent years. The number of public primary schools increased from 84 in 2004-05 to 113 in 2010-11 and to 136 in 2016-17 (DISED 2012a, 2014a, 2017a). At the same time, the number of public middle and secondary schools also increased threefold, from 11 in 2004-5 to 29 in 2010-11 and to 36 in 2016-17 (DISED 2012, 2014, 2017). ${ }^{8}$ These investments appear to be bearing fruit by boosting the educational attainment of younger cohorts as compared to previous generations.

Cohorts of individuals 10-14 years old and 15-24 years old have remarkably higher literacy rates as compared to older age groups (figure 0.4). Not only that, the cohort of 15-24 years old has a literacy rate of 80 percent which is significantly higher than the national average of 53 percent though still lower than the average of the MENA region of 91 percent for the same cohort (UNESCO 2018). The gains in literacy have benefitted both boys and girls and the gender gap in literacy rates that is observed for those born around the mid-1950s and mid-1970s has mostly closed. Among the population of 40-60 years, there is a 24 percentage point (p.p.) difference between men's and women's literacy rates. This gap is only 10 p.p. and nearly 2 p.p. for 15-24 years and 10-14 years old, respectively. Improvements in educational attainment beyond basic literacy have also accumulated. A quarter of those 15-24 years old have attained some secondary education, compared to less than 3 percent among the 61+ years old and above (figure 0.5). Gender disparities are evident as women are more likely to have no formal education and only 38 percent have completed at least primary education as opposed to 57 percent of the men.

FIGURE 0.4 Literacy Rates by Age Groups, 2017 (percent)

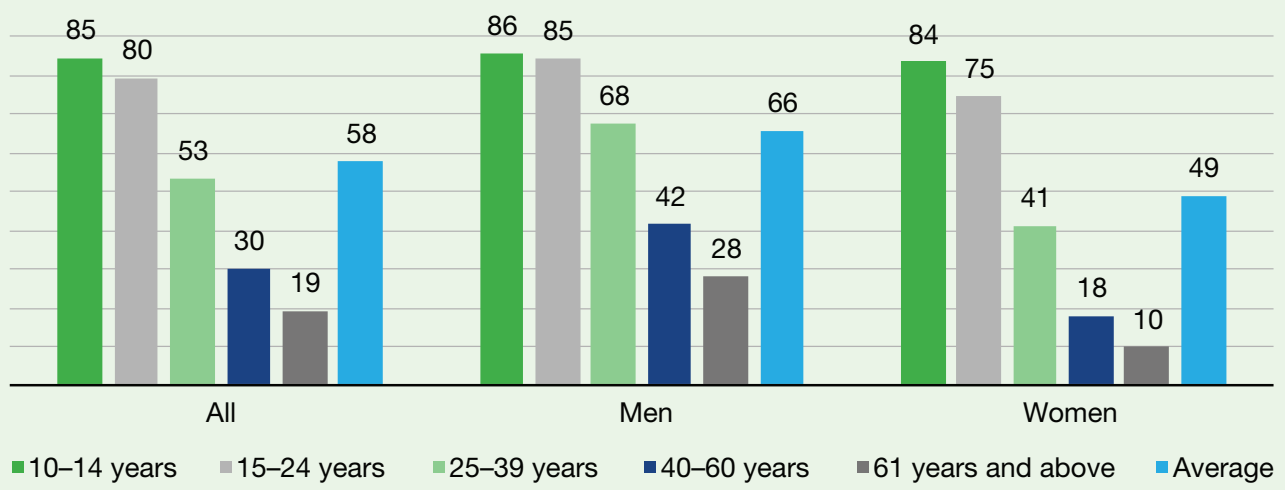

Source: Calculations based on EDAM4-IS.

8 According to WDI (n.d.), the GoD spent 12.3 percent of its total expenditure (or 4.5 percent of GDP) in education in 2010-both shares lower than in 2007 (22.5 and 8.4 percent, respectively). More recent estimates are not available. 
FIGURE 0.5 Educational Attainment by Age Cohort, 2017 (percent)

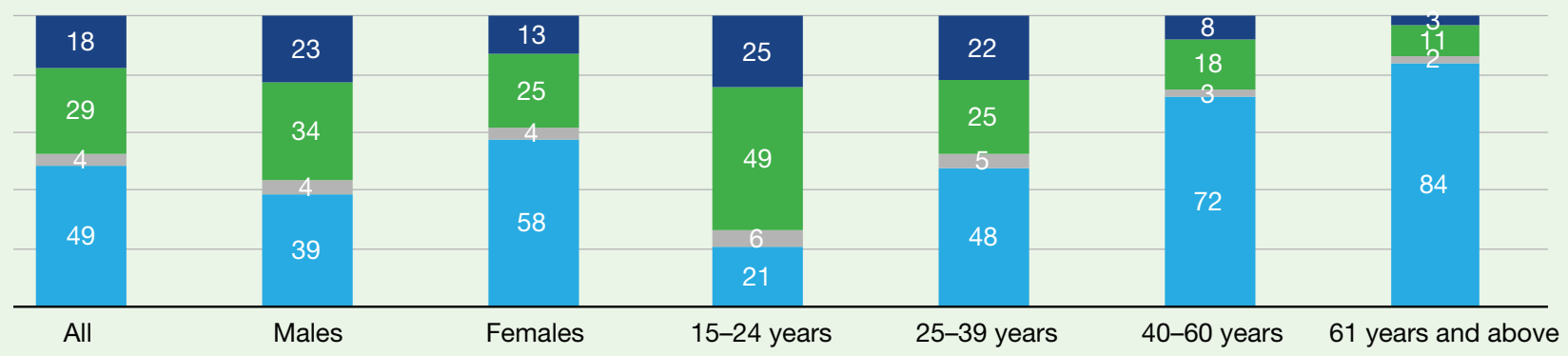

- Secondary and above - Primary and above, but less than secondary $\quad$ Less than primary $\quad$ No education/ own education

Source: Calculations based on EDAM4-IS.

Note: Only individuals above the age of 15 years are included.

Educational mobility, or the rate at which a group of individuals is able to attain a higher level of education than their parents, is positive for the overall population. Using the population 25 years old and older as reference, the share of individuals with higher educational qualifications than their fathers' is 36 percent in Djibouti (figure O.6).
At the same time, about 60 percent attained the same level, and a mere 4 percent performed worse than their father: overall, leading to a net gain in the population's educational attainment. The upward mobility phenomenon was not evenly distributed among all groups, however.

Nonpoor men experienced the largest gains in education:

FIGURE 0.6 Educational Mobility of Individuals 25 Years and Older Compared to Their Fathers (percent)

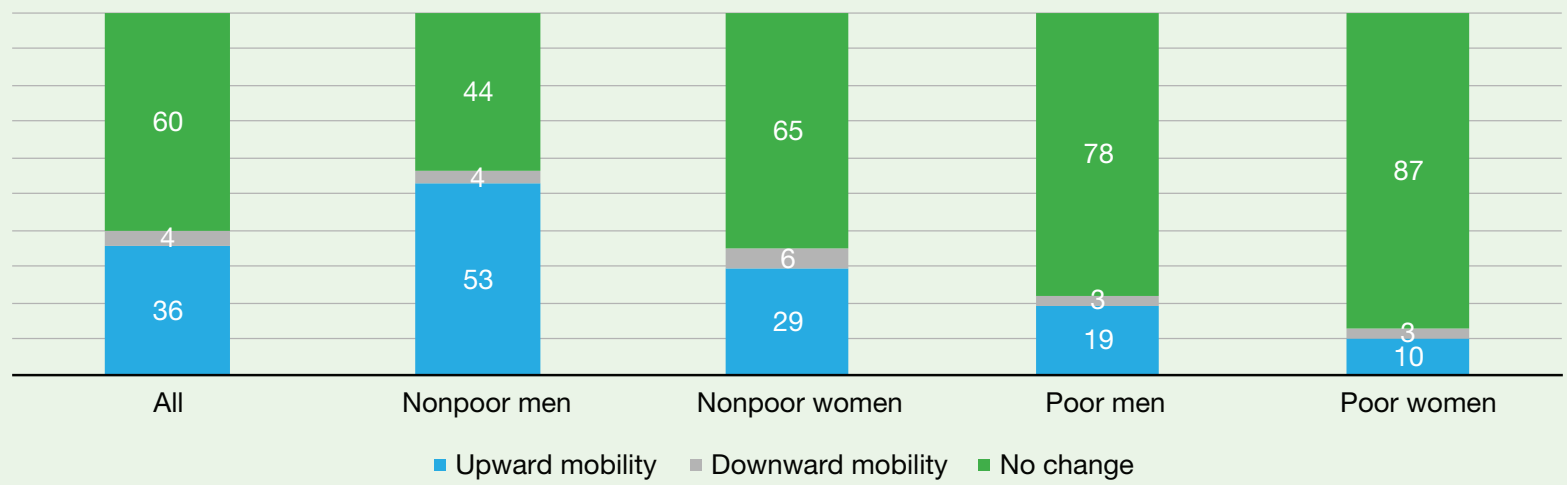

Source: Calculations based on EDAM4-IS.

Notes: We use educational attainment divided into four categories: no education, primary education or less, between primary education and secondary education, and secondary education or more. If the educational attainment of the child is higher than that of the father, he or she is considered upwardly mobile. Shares below 3 percent are not labeled. Data on education of self or father were missing for 7 percent of all individuals. 
over half were able to surpass their father's education level. In contrast, poor women are found to be the group with the lowest upward mobility (10 percent). To put this gap in context, a recent study (Narayan et al. 2018) on intergenerational educational mobility with upward mobility estimates for close to 150 economies can provide informative benchmarks. Upward mobility among Djiboutian nonpoor men is around the median of the distribution with countries like Egypt, Hungary, or China. Poor women's mobility is close to the bottom and similar to those in Mali and South Sudan. The poor women were found to least mobile, even though none of this group's fathers had more than primary education (table 0.4). At this rate, in the absence of better targeted interventions, it would take several generations for poor women to catch up to the national average in educational attainment.

\section{TABLE 0.4 Education Transition Matrix of Poor Women (25 years and older)}

\begin{tabular}{|c|c|c|c|c|c|}
\hline \multirow[b]{2}{*}{ Individual's education } & \multicolumn{5}{|c|}{ Father's education } \\
\hline & $\begin{array}{c}\text { No } \\
\text { education }\end{array}$ & $\begin{array}{c}\text { Primary } \\
\text { or less }\end{array}$ & $\begin{array}{l}\text { More than } \\
\text { primary or } \\
\text { secondary }\end{array}$ & $\begin{array}{l}\text { More than } \\
\text { secondary }\end{array}$ & Total \\
\hline No education & 87 & 2 & 0 & 0 & 89 \\
\hline Primary or less & 7 & 0 & 0 & 0 & 7 \\
\hline More than primary or secondary & 3 & 0 & 0 & 0 & 3 \\
\hline More than secondary & 0 & 0 & 0 & 0 & 0 \\
\hline Total & 97 & 3 & 0 & 0 & 100 \\
\hline
\end{tabular}

Source: Calculations based on EDAM4-IS.

Note: Numbers represent the distribution of the population 25 years and older in percent. Data on education of self or father were missing for 7 percent of all individuals.

Economic growth experienced by Djibouti in recent years has been accompanied by investments that contributed to human capital accumulation, ${ }^{9}$ although these have not been inclusive. Still, the marked improvements in educational attainment can play a pivotal role in allowing individuals to access better jobs, improve their well-being, and ultimately support breaking the intergenerational transmission of poverty. A better educated workforce presents a good opportunity to transform the labor market and further contribute to economic development and poverty reduction in the country. Unfortunately, the country still faces challenges to unleashing this potential.

9 There is mixed evidence of improvements in other human capital indicators, such as health. Projections for infant mortality, for instance, show a continuous decline, dropping to 51.5 in 2017 from 80.3 in 2000. However, indicators on stunting rates appear to be unchanged, and wasting rates appear to have increased between 1996 and 2012 (World Bank 2018a). Thus, the gains in education may not fully translate into gains in productivity among the labor force. 


\section{THE FULL POTENTIAL OF THE LABOR MARKET AS A SUSTAINABLE DRIVER OUT OF POVERTY IS STILL UNTAPPED- OVER HALF OF THE WORKING-AGE POPULATION IS NOT IN THE LABOR FORCE}

The trickle-down effect of high economic growth leading to the creation of a dynamic labor market and a jobgenerating private sector is yet to be seen in Djibouti. Labor force participation rates in Djibouti are low. Overall, among the population of 15 years and above, about 45 percent participate in the labor market - a ratio practically unchanged from the earlier estimate of 46.3 percent in 1996 (World Bank 1997) despite the positive economic growth during the past 20 years. Labor force participation shows substantial variation across gender and age, with patterns similar to those encountered in other MENA countries. Men's labor force participation stands at 59 percent, whereas for women it is only 32 percent. Less than a third of individuals in the 15-24 year age range participate in the labor market. Among people in prime working years of age - 25-39 and 40-60 years - the participation rate is 55 and 53 percent, respectively.

A sluggish labor market is evidenced not only by the low levels of labor market attachment but also by the high rates of unemployment. Furthermore, the distribution of job opportunities across the active population (among those 15 years and older) varies substantially between men and women and across age groups (figure 0.7). Women and the youngest cohort (15-24 years) are the groups less likely to be employed. Unemployment rates are also high among prime-age workers, with about half of them not having a job.

\section{FIGURE 0.7 Distribution of Population in the Labor Force (percent)}

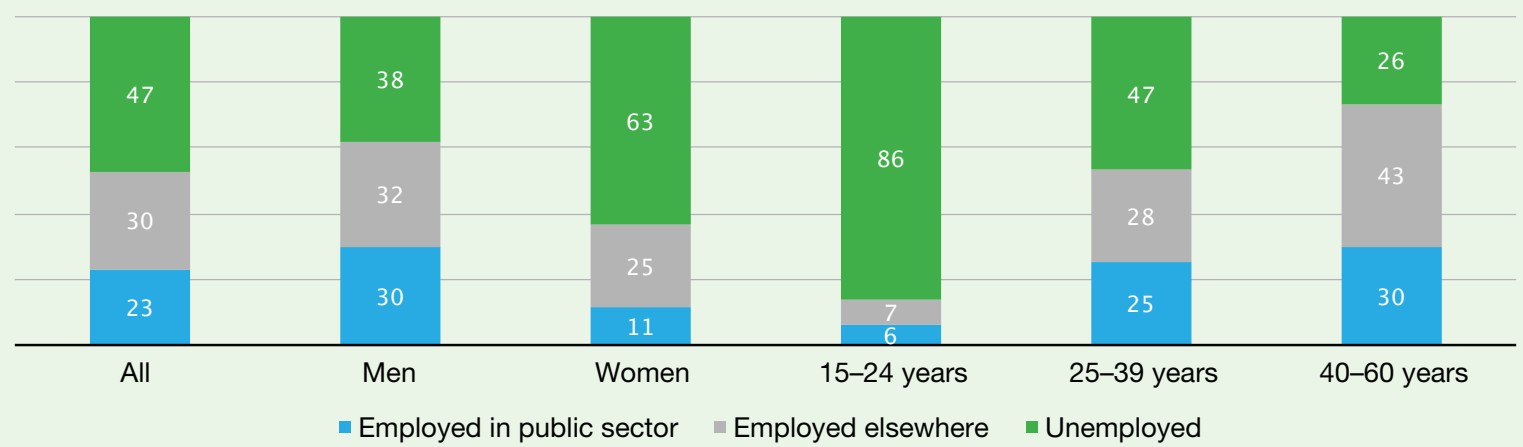

Source: Calculations based on EDAM4-IS.

Notes: Only the population 15 years and older is included. Public sector includes those employed declaring public administration as the main branch of activity. 
Employment rates and education levels show a slight positive correlation in Djibouti but attaining higher levels of education does not guarantee more opportunities in the labor market. Individuals with a secondary education or more show higher employment rates than those with no education. However, the differences in employment between those with no education and individuals that attain only primary education are not always substantial. The employment-education patterns are similar across men and women, but men have much higher employment rates. Two-thirds of men are employed, while only one- third of women are. This is true across all educational levels. Employment rates are positively correlated with age, although even among individuals between 40 and 60 years of age, only about three-quarters are employed (figure 0.7 and figure 0.8). The lowest rates are found among the youngest cohorts, with only 14 percent being employed. While in some contexts this result points to a delay in the school-to-work transition, it appears that there is a nonnegligible share (28 percent) of Djiboutian youth that are disconnected from both the education system and the labor market (see box 0.2).

\section{FIGURE 0.8 Employment Rate Among Labor Market Participants, by Educational Attainment}

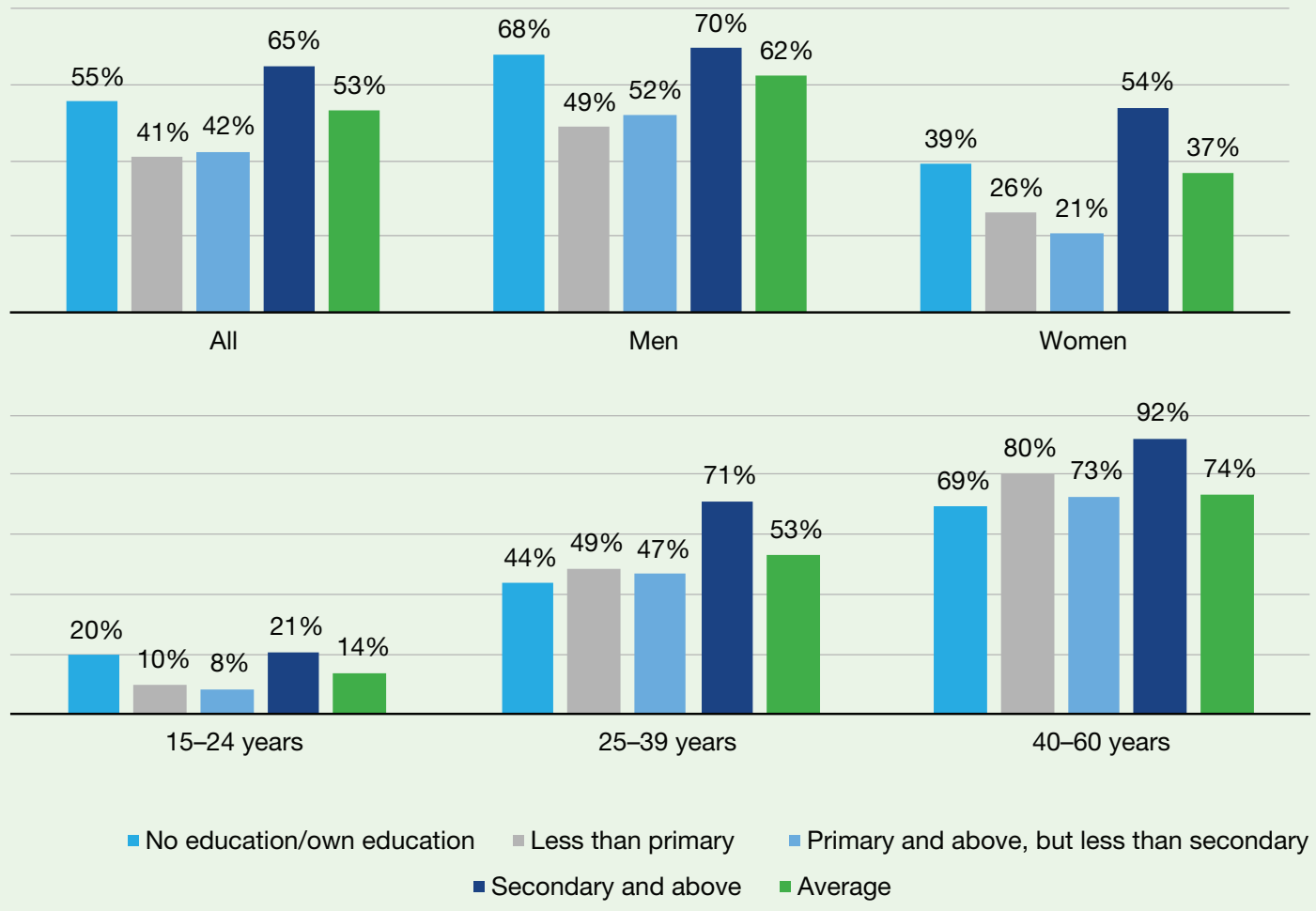

Source: Calculations based on EDAM4-IS.

Notes: Employment rate is defined as those employed among those active in the labor force. Both employed and unemployed individuals are considered active in the labor force. 


\section{Box 0.2 The Djboutian Youth Needs Support to Fulfill Their Potential}

Djibouti is a young country, with slightly less than 28 percent of its population between 16 and 30 years old (and over 35 percent under 15 years old). Thus, capitalizing on the improved human capital investments the country has made presents a great opportunity to promote poverty reduction and boost shared prosperity. The cohort of 15-24 years has higher rates of literacy and a greater share of individuals with at least primary education than any other age group in the country. Nonetheless, their low labor participation and employment rates highlight the hardships they face in transitioning from school to work. On average, about 45 percent of those age 15-24 years are studying and about 5 percent are engaged in work (figure BO.2.1). Close to a fifth of the youth (22 percent) are unemployed. Worryingly, nearly 28 percent are not in education, employment, or in training (NEET). This distribution of activities and lack of engagement is replicated across gender, although women show slightly higher rates of disconnection to productive activities. Among young women, a third are NEET, implying that they are neither active in the labor force nor studying. Youth in the regions are estimated to have worse outcomes than in Djibouti city, with about 43 percent of them considered to be NEET.

\section{FIGURE BO.2.1 Distribution of Youth (15-24 years) across Education and Labor Force Activities}

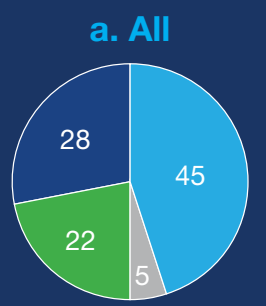

$\square$ Studying

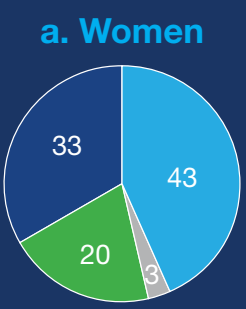

口Employed/ in training
口Unemployed $\square$ NEET
Source: Calculations based on EDAM4-IS.

Note: NEET refers to youth not in employment, education or training and not "unemployed" (those individuals who are seeking a job). Employed/ training and studying shares are negligible.

Young women's labor force participation decreased between 2012 and 2017 (table BO.2.1). This drop in labor force participation is driven mostly by a higher percentage of women reporting familial obligations as a reason to stay out of the labor force in 2017 as compared to 2012. That said, the main reason for not seeking participation in the labor market is the pursuit of education-about 40 percent report studying as the main reason. For men, there has been a drop in the percentage reporting studying as the main reason for not being active in the labor force. These results highlight a need for stronger policy efforts to keep the Djiboutian youth engaged. While some of the shifts observed may be attributed to changes in preferences, the lack of human capital accumulation or stagnant labor market experience can only increase the dependency of these young individuals in the future. Without tools to attain and keep a good job and generate income by themselves, this group will be dependent on help from private or public sources to be able to stay out of poverty.

\section{TABLE BO.2.1 Distribution of Youth (15-24 years old) in and out of the Labor Force}

\begin{tabular}{l|c|c|c|c|} 
& \multicolumn{2}{|c|}{2017} & \multicolumn{2}{c}{2012} \\
\hline In the labor force & Males & Females & Males & Females \\
\hline Out of the labor force & 32 & 26 & 33 & 33 \\
\hline$\quad$ Studying & 44 & 40 & 53 & 42 \\
\hline Family obligations & 7 & 19 & 4 & 13 \\
\hline Others / missing & 17 & 16 & 10 & 13 \\
\hline Total & 100 & 100 & 100 & 100 \\
\hline
\end{tabular}

Source: Calculations based on EDAM 2012 and EDAM4-IS.

Notes: Students seeking employment are counted as part of the labor force. Trainees without other activity are counted out of the labor force. Shares may differ slightly from figure BO.2.1. 


\section{WHILE THE PUBLIC SECTOR CONTINUES TO DRAW HIGHLY SKILLED INDIVIDUALS, THE REST OF THE EMPLOYED WORKFORCE IS INFORMAL}

The working population in Djibouti faces a markedly dual labor market. Workers are largely concentrated in the private informal sector or public administration (Table O.5). These two sectors host 90 percent of those employed, with 43 percent working in the public sector. Meanwhile, the formal sector employs the remaining 10 percent. In the private sector, agriculture and manufacturing play a relatively small role, as the services sector employs the large majority of individuals. Formal labor market opportunities are less available for working women than for working men. Informal private sector employs 63 percent of women, while a third of women work in the public administration (in contrast to the 48 percent estimated for men).

Half of Djiboutian workers are employed in small firms with 10 or fewer employees, but informal workers and women and overrepresented in this category (table O.6).

\section{TABLE 0.5 Distribution of Employed Individuals by Branch of Activity and Sector Of Employment (percent)}

\begin{tabular}{l|c|c|c|c|} 
& $\begin{array}{c}\text { Private } \\
\text { informal }\end{array}$ & \multicolumn{2}{c|}{$\begin{array}{c}\text { Public } \\
\text { Private formal }\end{array}$} & $\begin{array}{c}\text { Total of } \\
\text { administration }\end{array}$ \\
\hline Overanch activity
\end{tabular}

Source: Calculations based on EDAM4-IS.

Notes: The sample includes 3,139 individuals that answered to all corresponding questions. Private sector comprises all branches of activity except public administration: agriculture, manufacturing, services (including private administration), and others (international organizations, military bases and unspecified categories). Within the private sector, employers, contractors and independent workers are considered working in the formal sector when they have accounting records, a trading license (commonly referred to as "patente") and registration in the chamber of commerce. Within the private sector, salaried individuals, family helpers and apprentices are considered working in the formal sector if the worker has a contract and is registered in social security. All remaining individuals working in the private sector are considered as working in the informal sector. . 
Individuals working in the informal private sector are predominantly one-person firms, pointing to largely selfemployed individuals working as microentrepreneurs. These numbers for women are even higher (47 percent). In the informal sector, firms with 10 or fewer employees account for slightly more than three-quarters of workers working. In the case of women, 71 percent work in (or own) a firm that has at most 10 employees. In the informal sector, however, micro- and small firms account for 9 of every 10 jobs held by women.

The public sector continues to have enormous appeal to highly qualified individuals (table 0.7). About half of the public employees (45 percent) have at least a secondary

\section{TABLE 0.6 Distribution of Employed Individuals by Firm Size and Sector Of Employment (percent)}

\begin{tabular}{l|c|c|c|c|} 
& $\begin{array}{c}\text { Private } \\
\text { informal }\end{array}$ & $\begin{array}{c}\text { Private } \\
\text { formal }\end{array}$ & $\begin{array}{c}\text { Public } \\
\text { administration }\end{array}$ & Size total \\
\hline Overall population & 20.8 & 0.6 & 1.1 & 22.5 \\
\hline 1 worker & 8.7 & 0.5 & 2.2 & 11.4 \\
\hline $2-3$ & 7.8 & 2.1 & 6 & 15.9 \\
\hline $4-10$ & 9.9 & 7.2 & 33 & 50.2 \\
\hline $11+$ & 47.3 & 10.4 & 42.3 & 100 \\
\hline Total & 46.8 & & & 48 \\
\hline Women population & 8.8 & 0.7 & 0.5 & 11.5 \\
\hline 1 worker & 5.5 & 0.3 & 5.4 & 11.8 \\
\hline $2-3$ & 4.3 & 1 & 20.5 & 28.6 \\
\hline $4-10$ & 65.4 & 3.9 & 28.7 & 100 \\
\hline $11+$ & & 5.9 & & \\
\hline Total & & & & \\
\hline
\end{tabular}

\section{Source: Calculations based on EDAM4-IS.}

Notes: The sample includes 2,806 individuals with complete information. Private sector comprises all branches of activity except public administration: agriculture, manufacturing, services (including private administration), and others (international organizations, military bases, and unspecified categories). Within the private sector, employers, contractors and independent workers are considered working in the formal sector when they have accounting records, a trading license (commonly referred to as "patente") and registration in the chamber of commerce. Within the private sector, salaried individuals, family helpers and apprentices are considered working in the formal sector if the worker has a contract and is registered in social security. All remaining individuals working in the private sector are considered as working in the informal sector

education. Moreover, the public administration hires 7 out of every 10 Djiboutian workers with at least secondary education. Thus, the pool of available talent in the private sector is constituted of a population where individuals with low skills are overrepresented. The high wages offered by the public sector help explain the skewed distribution of educated workforce between the private and public sectors. On average, workers in the public sector earn DF 104,161 per month while those in the (informal) private sector earn DF 84,221 per month (table 0.8). Controlling for factors such as education and experience, it is estimated that on average, one more year of formal education increases labor earnings by about 7 percent. Nonetheless, working in the public sector still carries a premium of 18 percent even after controlling for other factors. 


\section{TABLE 0.7 Distribution of Employed Individuals by Educational Attainment and Sector of Employment}

\begin{tabular}{l|c|c|c|c|} 
& $\begin{array}{c}\text { Private } \\
\text { informal }\end{array}$ & $\begin{array}{c}\text { Private } \\
\text { formal }\end{array}$ & $\begin{array}{c}\text { Public } \\
\text { administration }\end{array}$ & Total \\
\hline No education/own education & 30.8 & 2.5 & 11.5 & 44.8 \\
\hline Less than primary & 2.5 & 0.4 & 1.3 & 4.2 \\
\hline Primary but less than secondary & 9.1 & 3.2 & 11.0 & 23.3 \\
\hline Secondary and above & 3.9 & 3.9 & 19.9 & 27.6 \\
\hline Total & 46.3 & 9.9 & 43.8 & 100 \\
\hline
\end{tabular}

Source: Calculations based on EDAM4-IS.

Note: The sample includes 3,132 individuals with complete information. Private sector comprises all branches of activity except public administration: agriculture, manufacturing, services (including private administration), and others (international organizations, military bases, and unspecified categories). Within the private sector, employers, contractors and independent workers are considered working in the formal sector when they have accounting records, a trading license (commonly referred to as "patente") and registration in the chamber of commerce. Within the private sector, salaried individuals, family helpers and apprentices are considered working in the formal sector if the worker has a contract and is registered in social security. All remaining individuals working in the private sector are considered as working in the informal sector. Cells show the percentage of the working population.

\section{TABLE 0.8 Characteristics by Sector Of Employment}

\begin{tabular}{l|c|c|c|} 
& $\begin{array}{c}\text { Private } \\
\text { informal }\end{array}$ & $\begin{array}{c}\text { Private } \\
\text { formal }\end{array}$ & $\begin{array}{c}\text { Public } \\
\text { administration }\end{array}$ \\
\hline National average monthly wages of those employed (DF) & 84,221 & 118,442 & 104,161 \\
\hline
\end{tabular}

Based on sector of employment of household head

\begin{tabular}{|c|c|c|c|}
\hline Average monthly wages of head (DF) & 87,081 & 121,576 & 101,077 \\
\hline Extreme poverty rate & $18 \%$ & $3 \%$ & $11 \%$ \\
\hline Extreme poverty rate when poverty line is $5 \%$ higher & $20 \%$ & $6 \%$ & $12 \%$ \\
\hline Extreme poverty rate when poverty line is $10 \%$ higher & $22 \%$ & $6 \%$ & $13 \%$ \\
\hline Percentage of households that experienced a health problem & $28 \%$ & $24 \%$ & $27 \%$ \\
\hline Health expenses as a percentage of total: average & $3 \%$ & $2.5 \%$ & $1.9 \%$ \\
\hline Health expenses as a percentage of total: 90th percentile & $7.2 \%$ & $6.7 \%$ & $4.9 \%$ \\
\hline
\end{tabular}

Source: Calculations based on EDAM4-IS.

Notes: Wage information is available for 2,415 individuals and 1,531 heads. Private sector comprises all branches of activity except public administration: agriculture, manufacturing, services (including private administration), and others (international organizations, military bases and unspecified categories). Within the private sector, employers, contractors and independent workers are considered working in the formal sector when they have accounting records, a trading license (commonly referred to as "patente") and registration in the chamber of commerce. Within the private sector, salaried individuals, family helpers and apprentices are considered working in the formal sector if the worker has a contract and is registered in social security. All remaining individuals working in the private sector are considered as working in the informal sector. Cells show the percentage of the working population 
Djibouti's high economic growth rate has not been accompanied by the creation of a dynamic formal private sector. A lagging formal private sector may have important negative consequences for the economy going forward, according to the relevant literature. In fact, it has been argued that formal firms are the driver of economic development, while informal firms are a by-product of poverty (Rauch 1991; La Porta and Schleifer 2014). The literature points out that as an economy modernizes, formal firms grow, and informality becomes less prevalent. Countries with an abundance of informal firms suffer from low aggregate productivity, too. Thus, efforts to encourage the growth of the formal sector in Djibouti may be important to stimulate job-driven growth.

Tackling informality directly can also have positive effects on the population. In Djibouti, informality is correlated to poverty and vulnerability. Poverty rates are six times higher when the household head is employed in the informal private sector as compared to when s/he works in the formal sector (table O.8). Households with a head employed informally also spend more on health-related expenses, although they fall ill at the same rate as other groups, pointing to vulnerability to health shocks. Vulnerability is higher among those with a head working in the informal sector, as evidenced by the higher poverty rates found after small changes to the poverty line. Finally, among households in the bottom of the distribution, the vulnerability of informal incomes is further compounded by the variability of other unpredictable sources of income. The income of households in the bottom quintile includes of 40 percent from informal work, 20 percent from transfers (public or private), and another 14 percent from agricultural activity. Formal work (including the public sector) accounts for a quarter of total income, on average. For the overall population, half of income comes from formal or public sector jobs.

\section{THE EMPLOYMENT PROFILE HIGHLIGHTS THE NEED TO CONTINUE ADDRESSING LABOR DEMAND-SIDE ISSUES}

\begin{abstract}
A sustainable path of economic growth accompanied with poverty reduction cannot continue to rely on a labor market where about 80 percent of individuals are working either in the public sector or in micro/small informal firms. Djibouti's economic growth rate has had limited spillovers into the creation of a dynamic formal private sector with competitive wages. Recent investments in education seem to be paying off in building the human capital and, ultimately, boosting the quality of the labor supply. However, to develop the labor market and absorb this increasingly educated population, obstacles in the labor demand side should also be studied and addressed.
\end{abstract}

According to the enterprise survey conducted in 2013, ${ }^{10}$ among formal firms in Djibouti, certain aspects of the regulatory environment and quality of service were flagged as barriers for development of business. For instance, high tax rates were found to be a hindrance for 15 percent of the small and medium-size firms, while the paucity and quality of electricity as well as corruption were also cited as constraints among a third of large firms. Per the Doing Business (DB) 2014 report, Djibouti ranked 160th of all countries evaluated, with several areas of improvement identified: procedures for starting a business (a rank of 127), getting electricity (144), registering property (133), and getting credit (180), among others (World Bank 2014).

10 The sample comprised 266 formal nonagricultural private firms. Public utilities, government services, health care, and financial services sectors are not included in the sample. 
Regarding the process of setting up a (formal) business and getting it up and running, there were two areas that deserved particular attention. First, the costs associated with starting a business was estimated at 184.7 percent of the country's income per capita for all the permits required for the benchmark case. Second, securing an electrical connection to a business took 180 days at a cost of 7,487 percent of income per capita. It shouldn't be a surprise that informality remains pervasive throughout the economy.

There is, however, more recent evidence that the GoD has begun tackling some of these issues. In the DB 2019 report, Djibouti made significant strides, jumping 55 places to 99th, as opposed to 154th a year before World Bank 2019). The largest gains came from changes in protecting minority investors, registering property, and getting electricity. Other improvements were seen in resolving insolvency and starting a business. The current cost of opening the business was estimated at 41.9 percent of income per capita. ${ }^{11}$ Nonetheless, there is still room for improvement. The DB 2019 report notes that the costs of starting a business in the MENA region average 22.6 percent (as a share of income per capita) and that of OECD high-income countries is at 3.1 percent. Steps in the right direction have been taken, but there is more to be achieved to maximize the potential of Djibouti's labor market.

\section{DJIBOUTI MUST TAKE FULL ADVANTAGE OF ITS GROWING ECONOMY TO STRENGTHEN THE POVERTY REDUCTION ANGLE IN PUBLIC POLICIES}

Djibouti's policies need to take better advantage of the growing economy to eradicate poverty and boost shared prosperity in the country. No comparable estimates for monetary poverty from previous years are available. However, despite the strong economic growth of recent years, extreme poverty still affects more than a fifth of the population and about two-thirds of rural households. Inequality is also high - and among the highest in the world. The richest decile in Djibouti enjoys 32 percent of the total consumption and shows more than 16 times the level of consumption of the poorest bottom 10 percent (whose consumption share is 1.9 percent). There is suggestive evidence of improvements in certain nonmonetary indicators and individual's perceptions. Still, Djibouti seems to have significant scope at leveraging their booming economy into a poverty-reducing strategy.

The heterogeneous Djiboutian population requires a broad variety of supports. A multifaceted welfare-enhancing strategy that cuts across the policies implemented by the government needs to be adopted. The large potential of Djibouti, given its geostrategic location coupled with the GoD's objective to become a regional hub for trade and commerce, sets up a natural environment where priority should be given to investments in service provision and human capital of the population, and the provision of incentives to develop a dynamic labor market.

Rural and urban poor face a distinct set of concerns, and separate, targeted sets of policies must be considered for each of these subgroups. Rural areas require a comprehensive strategy that invests in infrastructure and service provision. Rural Djibouti is the residence of 15 percent of the population yet hosts close to 45 percent of the poor population. Households in these areas suffer from low access to public services such as electricity, water, and sanitation. Electricity access - a key service that has been shown to stimulate consumption and income and enable better education and healthespecially needs to be addressed, as only 6 percent of

11 Roughly, the costs summed to about DF 129,000, not including costs for stamp duties. 
the rural population has access to it. Meanwhile, open defecation rates are high in regions with high poverty rates and with a high rural presence, such as Tadjourah and Dikhil (69 and 48 percent, respectively). These call for strong investments in sanitation services as well as disease management, especially as these areas are also affected by low coverage of health facilities. Achieving universal coverage in these areas will face the obstacle of reaching a very sparsely populated region.

The urban poor are more numerous and have much lower consumption than others in their community. Crucially, they also show lower educational attainment and worse employment outcomes. The estimated population served by schools and hospitals is expected to be high in these areas and may thus call for attention in examining whether these areas are underserved and consequently if the quality of service delivery in these areas is affected. For schools, this is less likely to be a problem as a result of the introduction of double flows in public schools in the capital. A policy tool kit to promote better education and a boost in employment opportunities in the country is critical, going forward.

Education policies need to reinforce recent public investments to help close the disparities that persist. GoD investments in education have paid off in increasing the literacy rates and educational attainment among the younger generation. These investments need to be more balanced and allow the poor to catch up. Women in poverty are a particularly vulnerable group in terms of human capital accumulation and low mobility. More schools have opened in the poorer areas of Djibouti city and double classes have been introduced in schools in the capital but there is a gap that needs to be filled in understanding how the increased educational attainment reflects actual learning. Learning based on acquired skills promotes employment, income, health, and poverty reduction (World Bank 2018c). Djibouti is among the few countries that do not participate in internationally comparable testing efforts of students, such as the
Programme for International Student Assessment or Trends in International Mathematics and Science Study.

Employment policies need to be rethought as an essential part of the GoD's poverty reduction strategy. Expanding employment opportunities will be key to unlocking the potential of the Djiboutian population. With just 45 percent of the working-age population participating in the labor market, a push must be made to increase the incentives of the population to join the labor force. This detachment may be partly explained by the distinct dual market Djiboutian individuals face. This report shows that in Djibouti's labor market, an individual's employment sector is highly determined by the individual's skill level. On the one side, there is the public administration. The public sector hires two-fifths of employed individuals, with a large share of them being highly skilled workers. These individuals are likely to be drawn to the public sector due to the high wages this sector offers: even controlling for other characteristics such as education and experience, public administration pays an average 18 percent more than the private sector. On the other side, workers with low skills are mostly left with the option of working in the informal sector. More than 40 percent of employed individuals are informal, as are two-thirds of employed women.

Boosting employment in the country will require ensuring the elements of a vibrant private sector exist. The improvements on measures such as the Doing Business Index are steps in the right direction, but there is more to be done. On the labor supply side, a better educated workforce would be able to fill vacancies from new investments. On the labor demand side, the pervasiveness of the informal sector suggests that barriers for formalization are varied. Firms (or small entrepreneurs) may be showing a preference for staying informal or reacting to a simple cost-benefit analysis showing the large costs of registering, getting basic services like electricity, and strong competition from those who decide to stay informal and avoid the increased overhead. However, the corresponding variability of income and 
vulnerability to shocks (in both short and long terms) may not be fully internalized in such decisions. A broad range of policies that spurs a better business climate (including taxation, labor regulations, and costs of key inputs such as electricity or telecom services) and investment in laborintensive sectors are the best bet. The youth in Djibouti present a particularly vulnerable group and will need support from private (or public) networks if they continue to be detached from studying or working.

This assessment explores three themes that should be considered in the design of the GoD's public policy strategy going forward. The first topic that we investigate is the strengthening of social safety net (SSN) programs, such as cash transfer programs. SSN is a powerful policy tool to support the poor and vulnerable population.

Recently, Djibouti has made efforts to move away from a largely donor-driven initiative, which was mainly focused on providing food to vulnerable populations, and to investing in adaptive social safety nets and incentivizing households to invest in human development. Moreover, Djibouti has begun laying the groundwork for a social protection system through the national expansion of the Programme National Solidarite Familiale (PNSF) and the establishment of a social registry. Simulations show that with increasing efforts in targeted programs such as the PNSF, either through the application of a proxy means test (PMT) to identify and target households that experience a high level of deprivation, or a combination of a PMT with geographic targeting, there is strong potential for poverty reduction, especially among rural households. Programs that connect those in beneficiary households with the opportunity to work will also help, provided there are work opportunities available.

The second topic studied in this report is the continuous development of information and communication technologies (ICT) services, which hold enormous potential for economic growth and poverty alleviation. For example, in rural Peru, the expansion of mobile network coverage boosted household real consumption by 11 percent (Beuermann, McKelvey, and Vakis 2012). The ICT sector has a great capability to enable job creation and innovation in the private sector, with a corresponding increase in economic opportunities for the population. Moreover, the Internet is also an enabler of higher labor productivity by lowering information and search costs. For example, the introduction of mobile phones in the grain markets of Niger led to farmers obtaining grain price information over the phone, thereby reducing search costs by 50 percent (Aker 2010) and reduced dispersion of grain prices across markets by 10 percent (Aker and Mbiti 2010). People's perceptions also reveal that the Internet has led to an increase in consumer welfare by making several products and services available digitally. From the standpoint of both the government and the private sector, the Internet can bring major benefits to the provision and delivery of services. Digital identification can also improve participation of disadvantaged groups and help them integrate into the economy. The advantages of a welldeveloped ICT sector are manifold and transformational.

Djibouti is particularly well placed to take advantage of the digital economy with its regional comparative advantage as the landing site of the undersea fiber optic cables. Unfortunately, Djibouti Telecom's (the single ICT operator) outward strategy has not exploited the full development potential of the sector, leading to lower than expected penetration rates of ICT services, very low ownership rates among rural households, and prices for broadband services that are considered higher than in comparator countries. Based on international case studies, we hypothesize that increased competition in the telecom sector could help improve service delivery, productivity and innovation, and overall performance in Djibouti's ICT sector. Simulations of the welfare effects of price changes in the telecom sector (that could result from more competition in the sector) show there are potential welfare gains for the population and an increase in the likelihood of adoption of new technologies. In view of 
this, an extraordinary collective, national effort must be considered in Djibouti to achieve the goal of expanding affordable access to the Internet and transmission of data. This should be accompanied by the promotion of modern finance and payment systems supporting financial transactions that can be carried out electronically. Such a large-scale effort is likely to foster productivity, competition, entrepreneurship, and growth of businesses. This would especially be an appealing prospect for the youth, who are more Internet savvy and currently seem not able to find jobs or are stuck in low wage employment.

The final theme investigated is the livelihoods of pastoralists in Djibouti. About 20 percent of the Djiboutian population was found to be nomadic in 2009, according to the country's 2009 census. Due to the series of droughts that Djibouti has experienced in recent years, the nomadic population is estimated to have dwindled substantially because of flight to neighboring countries or by becoming sedentary on the outskirts of villages and cities. Survey estimates suggest that transhumance or pastoralism is practiced by only 6 percent of the population outside of Djibouti city. Poverty rates in this population appear to be much higher than the national rate. Individuals living in households practicing transhumance also have fewer years of education and are more likely to be illiterate. It, thus, becomes imperative to protect this vulnerable group, especially in light of the persistent threat of climate change. Equally importantly, the statistical systems in Djibouti must redouble efforts to be able to better observe this population. The upcoming population census (expected to be conducted in 2020) is an opportunity that should not be missed to improve our understanding of this important subgroup of the population. It would also be worthwhile to investigate resilience strategies that could be employed by this population as well as the policy actions that may facilitate the promotion of these strategies and alternative livelihoods. 
Aker, J. C. 2010. "Information from Markets Near and Far: Mobile Phones and Agricultural Markets in Niger." American Economic Journal: Applied Economics 2 (3): 46-59.

Aker, J. C., and I. M. Mbiti. 2010. "Mobile Phones and Economic Development in Africa." Journal of Economic Perspectives 24 (3): 207-32.

Beuermann, D. W., C. McKelvey, and R. Vakis. 2012. "Mobile Phones and Economic Development in Rural Peru." Journal of Development Studies 48 (11): 1617-28.

Borgen Project. 2017. "Ethiopia-Djibouti Water Pipeline." Borgen blog. Seattle, WA. December. https:// borgenproject.org/tag/ethiopia-djibouti-water-pipeline/.

DISED (Direction de la Statistiques et des Etudes Démographiques). 2012a. Annuaire Statistique 2012.

DISED. 2012b. EDAM 3-IS. Djibouti: DISED.

DISED. 2014a. Annuaire Statistique 2014. Djibouti: DISED.

DISED. 2014b. "Mesures de la pauvreté et des inégalités" Photocopy. Djibouti: DISED.

DISED. 2017a. Annuaire Statistique 2017. Djibouti: DISED.

DISED. 2017b. EDAM4-IS. Djibouti: DISED.

DISED (Direction de la Statistiques et des Etudes Démographiques.) 2018. Résultats de la Quatrième Enquête Djiboutienne Auprès de Ménages pour les Indicateurs Sociaux (EDAM4-IS). Djibouti city: DISED. http://www.dised.dj/Rapport1_resultats_EDAM4.pdf.

Financial Times. 2018. Djibouti ready to pay compensation to settle DP World dispute.
La Porta, R., and A. Shleifer. 2014. "Informality and Development." Journal of Economic Perspectives 28 (3): 109-26.

Ministere de l'Education Nationale et de la Formation Professionnelle. 2018. "Cartographie des ecoles de base." http://qgiscloud.com/Destini/projet_ETS_djibouti/ ?bl=mapnik\&st=\&l=ecole-djibouti\%2Cregion-djibouti\&t= projet_ETS_djibouti\&e=4790662\%2C1291018\%2C48109 $82 \% 2 C 1300946$.

Narayan, Ambar, Roy Van der Weide, Alexandru Cojocaru, Christoph Lakner, Silvia Redaelli, Daniel Gerszon Mahler, Rakesh Gupta N. Ramasubbaiah, and Stefan Thewissen. 2018. Fair Progress?: Economic Mobility Across Generations Around the World. Washington, DC: World Bank. https://openknowledge.worldbank.org/ handle/10986/28428.

Rauch, J. E. 1991. "Modelling the Informal Sector Formally." Journal of development Economics 35 (1): 33-47.

UNESCO Institute for Statistics. 2018a. "Literacy Rate, Adult Total (\% of People Ages 15 and Above)." World Bank Open Data. https://data.worldbank.org/indicator/SE.ADT. LITR.ZS.

UNESCO Institute for Statistics. 2018b. "Literacy Rate, Youth Total (\% of People Ages 15-24)." World Bank Open Data. https://data.worldbank.org/indicator/ SE.ADT.1524.LT.ZS.

WDI (World Development Indicators). n.d. Database. Washington, DC: World Bank. https://datacatalog. worldbank.org/dataset/world-development-indicators. 
World Bank. 1997. Djibouti: Crossroads of the Horn of Africa. Poverty Assessment Report 16543-DJl. Washington, DC: World Bank. http://documents. worldbank.org/curated/en/557421468748480282/ Djibouti-Crossroads-of-the-Horn-of-Africa-povertyassessment

World Bank. 2014. Doing Business. Washington, DC: World Bank.

World Bank. n.d. "Tables, Charts, and Technical Notes." Global Consumption Database. http://datatopics. worldbank.org/consumption/detail.

World Bank. 2018a. Economic Transformation in Djibouti: Systematic Country Diagnostic. Washington, DC: World Bank.

World Bank. 2018b. Poverty and Shared Prosperity 2018: Piecing Together the Poverty Puzzle. Washington, DC: World Bank.

World Bank. 2018c. World Development Report 2018: Learning to Realize Education's Promise. Overview booklet. Washington, DC: World Bank.

World Bank and OECD (Organisation for Economic Co-operation and Development). 2018. "GDP Growth (Annual \%)." World Bank Open Data. https://data. worldbank.org/indicator/NY.GDP.MKTP.KD.ZG.

World Bank. 2019. Doing Business. Washington, DC: World Bank. 


\section{WELFARE AND POVERTY IN DJIBOUTI}

\section{INTRODUCTION AND MACROECONOMIC CONTEXT}

The Republic of Djibouti is located in the east of the Horn of Africa. It shares its borders with Ethiopia in west and southwest, Eritrea in the northwest, Somalia in the southeast, and the Gulf of Aden in the east. Its area is 23,200 square kilometers. Djibouti is divided into six regions: five regions of the interior (Ali Sabieh, Dikhil, Tadjourah, Obock, and Arta) and the city of Djibouti, the capital. Djibouti city comprises three municipalities (Rasdika, Boualos, and Balbala), which are further subdivided into five districts.

Djibouti is situated in a very important geostrategic location for trade and security in the region. The port in Djibouti is located at the Red Sea and serves as an important connection point between Asia, Europe, and Africa. It is estimated that about 30 percent of world shipping cargo transits through the Red Sea basin (Financial Times, 2018). The country also serves as the main gateway of trade for Ethiopia, its landlocked neighbor. Indeed, about 70 percent of the cargo at the port of Djibouti is shipped from or to Ethiopia (Meseret 2016). What's more, it accounts for 95 percent of Ethiopia's foreign trade (Maasho 2011). ${ }^{1}$ The port's location at the Gulf of Aden has also made it an important military outpost for the French navy, the US navy, Japan's only foreign military base, an Italian base, and more recently the Chinese navy. The country also plays an important security role in the region, hosting refugees fleeing conflicts and environmental risks in neighboring countries. According to United Nations High Commissioner for Refugees, the population of concern (refugees, asylum seekers, and others) was 27,000 in $2017 .{ }^{2}$

Djibouti is a relatively small lower-middle income economy with a nominal gross domestic product (GDP) equivalent to US\$2.6 billion in 2016 (DISED). The country, however, has experienced impressive economic growth in recent years. GDP real growth has averaged 4.5 percent per year from 2003 to 2013 and 7 percent between 2013 and 2016. Djibouti's growth in each year of 2013-16 surpassed that of countries that are similar in characteristics, such as Cabo Verde, Comoros, Sao Tome and Principe; ${ }^{3}$ countries that had a similar GDP per capita in 2013, such as Albania, Guinea-Bissau, Mauritius, Mali, Jamaica, and Republic of the Congo; and many of its Common Market for Eastern and Southern Africa partners, including Madagascar, Rwanda, Uganda, Tunisia and Egypt.

Several large investments on infrastructure projects (such as a railway line connecting to Ethiopia) have propelled Djibouti's growth. From 2014 to 2016, the fast implementation of large public infrastructure projects added 3 to 5 percentage points to real growth. As many

1 Ethiopia's and Djibouti's economies are reliant on each other, with about 70 percent of all trade through Djibouti's port coming from its landlocked neighbor.

2 This number could underestimate the true magnitude of this population, as some immigrants are not registered in camps. Other estimates (IMF 2017) suggest that there are about 60,000 refugees, asylum seekers, and migrants. According to estimates from the Ministry of Social Affairs, the population of unregistered migrants and refugees in the country is 150,000, and this may have consequences for the socio-economic situation in the country as well as for public policy decisions.

3 Based on WDI (n.d.) and Find-My-Friends tool developed by the World Bank. 


\section{FIGURE 1.1 Macroeconomic Indicators in Djibouti}

\section{a. GDP growth (\%)}

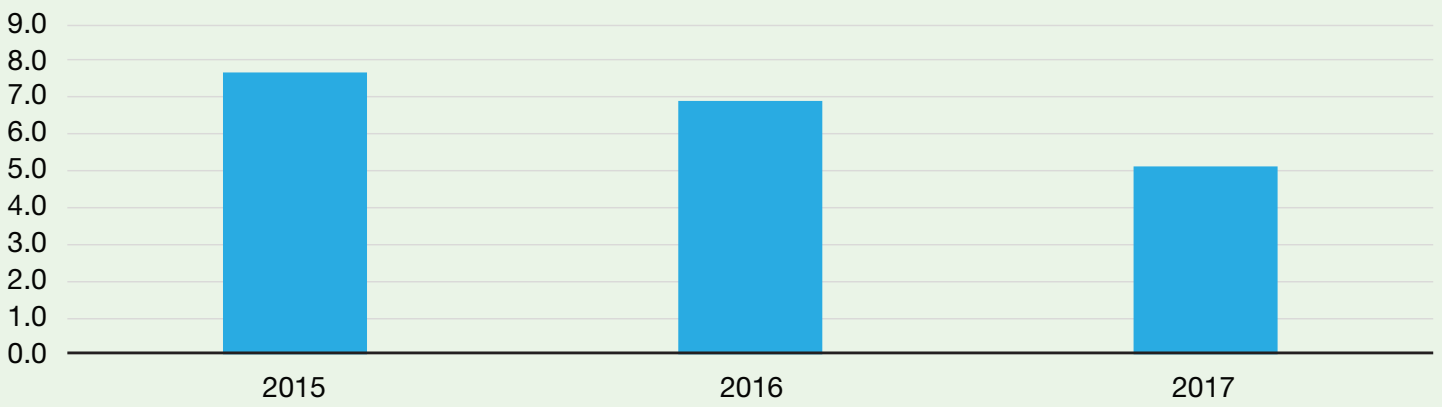

b. Share of economic sectors in GDP (\%)

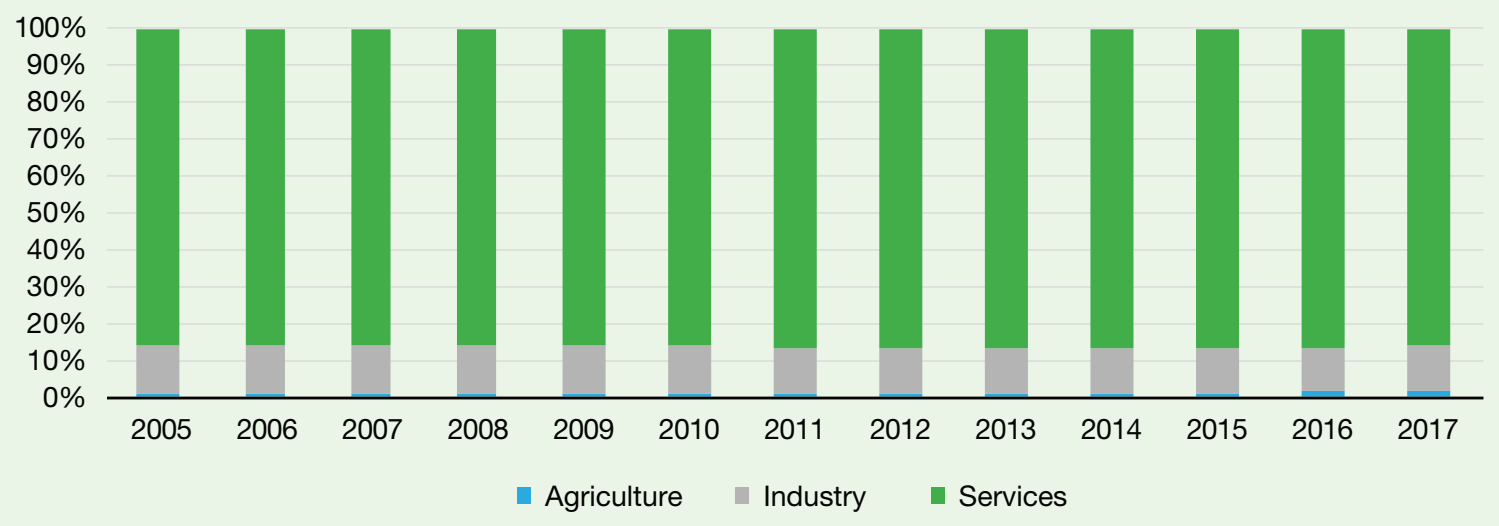

Source: DISED.

infrastructure projects come to an end, the rate of GDP growth slowed to 4.1 percent in 2017 . Output is expected to increase by 7 percent in 2019 as international trade normalizes in Ethiopia following the successful political transition and the devaluation of the birr by 15 percent, the Ethiopian currency, in October 2017. Growth will be driven by export of transportation and logistics services supported by the newly commissioned infrastructures (railway, port, and free zone). The tertiary sector dominates economic activity in Djibouti with an estimated share of more than 80 percent of GDP in 2017. This share has also been gradually increasing over time. Meanwhile, agriculture plays an insignificant role in Djibouti's economy, given the arid climatic conditions in the country (Figure 1.1).

This impressive economic growth has been highly capital intensive such as an investment of US\$3.4 billion on the railroad to Ethiopia (Borgen Project, 2017). According to the Port of Djibouti website, ${ }^{4}$ the country's investments in large-scale projects have included the construction of several new ports, such as the port of Doraleh (cost of US\$590 million), port of Goubet (US\$64 million) and port of Tadjourah (US\$160 million). Finally, Djibouti's revenues

4 See http://www.portdedjibouti.com/wp-content/uploads/2017/05/Djibouti-Article.pdf, accessed January 16, 2019. 
are also dependent on port activities and military bases. ${ }^{5}$ However, pursuing its ambition to position itself as a regional digital hub, the country is re-shifting the growth engine back to exports of transportation and logistics services after a temporary domination of public investment with high import content, financed mainly through debt accumulation. It is also increasingly the case that Djibouti's growth is closely tied to Ethiopia's economy. Past growth driven by capital intensive investments is likely to not have been conducive of an inclusive growth path, as large-scale infrastructure and logistics investments are more likely to create demand for skilled workers.

It is against this macroeconomic backdrop that this chapter presents a detailed update of welfare and poverty in
Djibouti. Relying on a household consumption survey fielded in 2017, this chapter fills a knowledge gap by shedding light on the most recent state of affairs for the Djiboutian population. We introduce the household expenditure survey conducted in 2017 and the poverty measurement methodology for Djibouti. A full demographic and economic profile of the poor population and how it compares to that of the nonpoor population follows. The report then explores the evolution of welfare in the country by comparing several indicators of well-being between 2013 and 2017. The main objective of this chapter is to help understand whether the high economic growth that Djibouti has experienced has percolated down to the population and consequently led to improvements in welfare.

\section{ANALYSIS OF WELFARE AND MONETARY POVERTY}

One of the main components to designing programs and policies that help alleviate poverty is to identify the poor and vulnerable population in the country. This section presents results on welfare and poverty in Djibouti. Most of the information presented is drawn from the Enquete Djiboutienne Aupres des Menages- Indicateurs Sociaux (henceforth referred to as EDAM4-IS) conducted in 2017 by the Directorate of Statistics and Demographic Studies (DISED) under the supervision of the Planning Commission for Statistics. The structure of this section is as follows: we first elaborate on the (monetary-based) estimate of consumption that is used as the measuring bar of households' well-being (Deaton and Zaidi 2002), followed by a brief presentation of the estimation of the poverty line. The main results on poverty in Djibouti close this section.

\section{MAIN SOURCE OF DATA}

Several parts of analysis in this report are based on the EDAM4-IS survey from 2017. ${ }^{6}$ This survey was designed to provide recent data on household consumption and living conditions, to monitor and evaluate social development and poverty alleviation policies, and to monitor progress toward the Sustainable Development Goals (SDGs). A key implication of these objectives is the ability to provide an updated profile of poverty and well-being of the Djiboutian population.

The EDAM4-IS integrates several themes: demographic characteristics of household members, education, health, employment, migration, housing characteristics, possession of livestock, food expenses (consumed at home and meals taken outside), nonfood expenses, sources of income (private and public transfers), shocks and survival mechanisms, perceptions of poverty, governance, access to services, and income from agricultural and livestock activities.

The sampling strategy of the EDAM4-IS was designed to produce indicators at several levels of representativeness: national, urban, rural, regional, and by districts in Djibouti city. The EDAM4-IS collected information on both

5 For instance, about US\$63 million is received annually from the United States and US\$20 million from China (Jacobs and Perlez 2017).

6 See appendix A for a more detailed description of the survey. 


\section{TABLE 1.1 Distribution of the EDAM4 Sample and Estimated Population, by Region}

\section{a. Distribution of sampled households}

\begin{tabular}{l|c|} 
Region & $\begin{array}{c}\text { Households } \\
\text { interviewed }\end{array}$ \\
\hline Djibouti city & 2,035 \\
\hline Ali Sabieh & 495 \\
\hline Dikhil & 496 \\
\hline Tadjourah & 493 \\
\hline Obock & 475 \\
\hline Arta & 480 \\
\hline National & 4,474 \\
\hline
\end{tabular}

\section{b. Distribution of population using sampling weights}

\begin{tabular}{l|c||c|} 
Region & $\begin{array}{c}\text { Population } \\
\text { weighted } \\
\text { representation }\end{array}$ & $\begin{array}{c}\text { Population in } \\
\text { rural areas }\end{array}$ \\
\hline Djibouti city & $76 \%$ & $0 \%$ \\
\hline Ali Sabieh & $5.4 \%$ & $40 \%$ \\
\hline Dikhil & $6.6 \%$ & $64.2 \%$ \\
\hline Tadjourah & $5.5 \%$ & $77 \%$ \\
\hline Obock & $2.4 \%$ & $63.7 \%$ \\
\hline Arta & $4.2 \%$ & $73.5 \%$ \\
\hline National & $100 \%$ & $15.2 \%$ \\
\hline
\end{tabular}

Source: Calculations based on EDAM4-IS.

sedentary ordinary households and nomads. A total of 4,474 households were interviewed. Table 1.1 shows the decomposition of the total sample size. The sampling weights were obtained from a two-step sampling approach and corrected for nonresponse.

The EDAM4 relied for its framework on (i) the distribution of the population according to the 2009 census, (ii) the listing exercise of all the enumeration areas that were selected for the survey data collection, and (iii) the population projections made by DISED. Finally, the population that was covered in the survey could be drawn only from those households that could be listed and whose members were likely to be found during the interview. Thus, a direct implication is that there will be a gap between the population that is represented in the survey and the overall population in the country. Current estimates of the Djiboutian population are about 1 million, but it includes subgroups such as homeless people and refugees living in camps that are not part of the survey. Moreover, these estimates are based on extrapolations of the distribution of the population from the 2009 census that may overestimate the evolution of the nomadic population (see Box 1.1). While there is evidence that several statistics from the EDAM4 replicate the patterns of other official data sources (see appendix A), this difference should be kept in mind while reading the results.

\section{THE WELFARE AGGREGATE}

The measure of a household's standard of living - its welfare-is typically based on an estimate of the level consumption or income of a household. The choice between the two depends on many factors, such as the availability of data, the design of the survey, as well as the context of the country. Consumption is preferred to income due to several reasons. Consumption is typically smooth over the duration of the year, while income may be subject to more variability and patterns of seasonality. It may also be difficult to gather accurate data on income when there is a high level of informality. Thus, the income observed in a survey (over a short time frame) is less likely to reflect accurately the living standard of the household, or the average level of well-being the household enjoys by smoothing their consumption throughout the year. In the case of a country like Djibouti, the recording of income is difficult because of underreporting, the informality of the labor market, and the high variation in labor income. A measure that relies on consumption expenditure can then be considered as a better approximation of well-being than income.

The calculation of the welfare aggregate in EDAM4-IS is based on the addition of several components of household consumption (measured by associated expenditures). The included components of well-being are food 


\section{Box 1.1 The Population Covered by EDAM4}

There are two important points to make in understanding the population covered by the EDAM4 and how this estimation may not be comparable to total population estimates. The first is that, due to the nature of a data collection exercise of surveys, households that are included in the survey must be identifiable during the listing exercise, and they must be available in the same physical place during the survey interview. Thus, the homeless population is not covered in the survey, nor is the population that is living in very precarious dwellings. Other populations are also not typically included in surveys. The EDAM4 did not include individuals in boarding schools, orphanages, prisons, hospitals, hotels, military and paramilitary camps, housing for foreign laborers, and refugees in camps.

The second point worth highlighting is that unlike earlier surveys (2012 EDAM3-IS, the 2012 EDSF/ PAPFAM, and the 2015 Employment and Informal Sector Survey), the EDAM4 also covered the nomadic population. Incorporating appropriate estimates of this population required several sources of information. Since 2008, Djibouti has been experiencing longer and more frequent cycles of drought, accompanied by continued desertification and significant losses of livestock and pastures (map B.1.1). In 2009, the government of Djibouti adopted (Décret n²009-0113/PRE) the National Strategy for Food and Nutrition Security. In volume 1 of that strategy's report, it is mentioned that "[due to the drought] . . nomadic pastoralists are led to move their animals ... in the interior of the country, especially to high-altitude pastures and to other countries in the region. . . . More substantial and more regular humanitarian aid to Ethiopian pastoralists has helped set up pastoralists in Ethiopia, whose home lands were traditionally in Djibouti. Therefore, there is a double hemorrhage of the rural population," Thus, resilience strategies developed by the nomadic populations against the negative effects of the drought have been (i) to migrate to regions, sometimes beyond the country's borders, or (ii) to settle around villages or other points, abandoning traditional transhumance in favor of nearby pastures.

\section{MAP B1.1.1 Djlbouti Vegetation and Urbanization}

\section{a. Djibouti 2007}

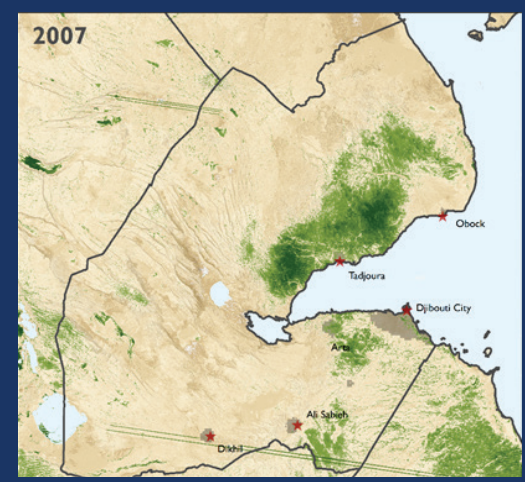

\section{a. Djibouti 2012}

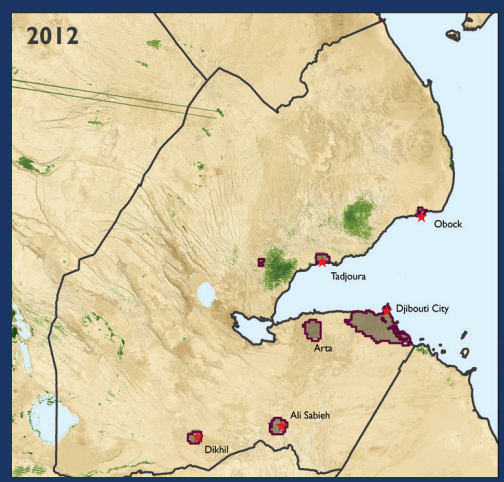

Source: DISED 2018.

For EDAM4, DISED's listings were complemented with information from the National Strategy for Food and Nutritional Security and thus estimated a decrease in the nomadic population (as defined in the 2009 General Population and Housing Census and excluding settled pastoralists households). This decrease was estimated at nearly three quarters between 2009 and 2017. 
expenditures, housing expenditures such as water and electricity services, transportation and communications, clothing purchases, hotel and food purchases, purchase of household items, khat, tobacco and alcohol purchases, education, health, recreation, and general services. In order to better capture well-being derived from durable goods, the flow of services based on the current market value of each property and the depreciation rate for each durable good is estimated. Finally, a hedonic model was estimated to allocate the rental value of the dwellings among home owners. ${ }^{7}$ Expenses for ceremonies, transfers, or investments were not taken into account.

Temporal adjustments must be made to household consumption to ensure that poverty measures are comparable across different data collection periods. Thus, the national monthly consumer price index in 2017 is used to adjust the expenditures recorded in the survey and express all expenditures in May 2017 prices. Finally, to take into account the possible differences in needs across members of the household by age, as well as the potential for economies of scale, the welfare aggregate is calculated in per adult equivalent terms. Appendix B provides more details on the construction of the consumption aggregate for Djibouti using EDAM4-IS.

Results from the survey show that the estimated per adult equivalent consumption at the national level is DF 261,391 per year, or approximately US\$1,468 per year. $^{8}$ In line with previous studies, Djibouti city is found to be a relatively richer zone than the five other regions in Djibouti (Figure 1.2). In the regions, consumption is about 57 percent of the amount spent in Djibouti city on average, while per adult equivalent consumption in rural areas is very low (DF 114,909). Among the five districts of the city of Djibouti, the fourth and fifth districts have the lowest levels of consumption.

\section{FIGURE 1.2 Annual per Adult Equivalent Consumption, by Area and District in Djibouti City (DF)}

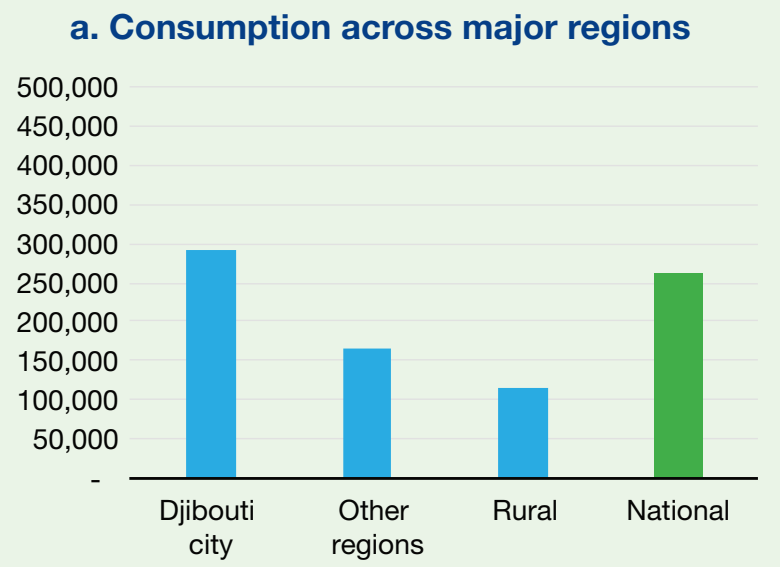

\section{b. Consumption across Djibouti city districts}

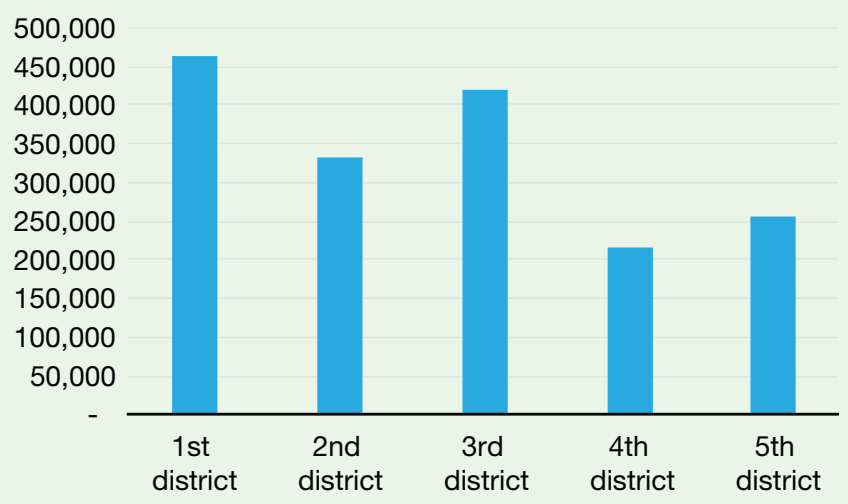

Source: Calculations based on EDAM4-IS.

7 Imputations were done according to two hedonic models: one for Djibouti city and another for regions. Imputations for rental values among tenants that were considered outliers were also carried out.

8 The exchange rate assumed is US $\$ 1=$ DF 178. A simple transformation using the household size and welfare aggregate at the household level suggest that the average consumption per capita is about US $\$ 5.08$ per day in 2011 purchasing power parity. 
The distribution of expenditures of the basket of goods consumed in Djibouti is in line with other international examples. The Djiboutian population spends about 40 percent of its expenditures on food (Figure 1.3). This percentage is higher for households in the interior regions (47 percent) and in rural areas (56 percent), while that of Djibouti city is 39 percent. According to World Bank's Global Consumption Database, ${ }^{9}$ it is found that food share in total consumption at the national level in Djibouti is lower than some countries in the region such as Egypt (48 percent), Yemen (49 percent), or neighboring Ethiopia (58 percent), as well as other comparable countries such as Sao Tome (68 percent) and Cabo Verde (50 percent). Nonetheless, such national differences may follow the varying degrees of the countries' urbanization. The food share of Djibouti city compares reasonably well with the food share in urban areas of other countries in the region such as Egypt (44 percent) and Yemen (40 percent). The differences in the food expenditure share between urban and rural areas in Djibouti is roughly in line with the results in Anker (2011) where the average gap is 20.6 percentage points among 11 countries analyzed. ${ }^{10}$ Nonfood consumption per capita spending is higher in Djibouti city (61 percent) as compared to the interior regions (52 percent) and rural areas in the regions (44 percent), mainly due to rents, electricity, and water costs. Rents are a large component of the overall consumption expenditures, especially in Djibouti city.

\section{POVERTY LINES}

The second component to calculate poverty rates is the poverty threshold or poverty line. The poverty lines are based on the consumption basket of the Djiboutian population in 2017 , and therefore they reflect a reliable estimate of the minimum cost needed to cover the needs of Djiboutian households. To estimate the overall poverty line and the extreme poverty line, the approach suggested by Ravallion (1998) was used. This consists of estimating

\section{FIGURE 1.3 Share of Expenditure on Each Category}

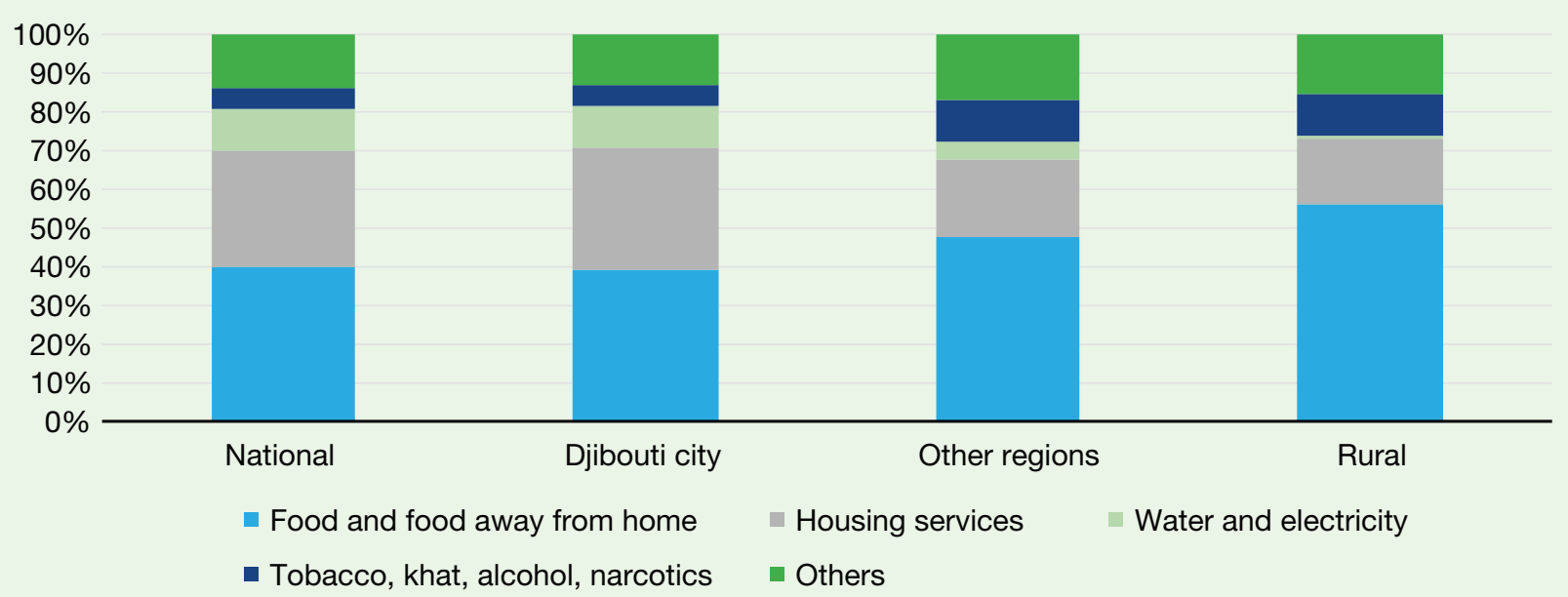

Source: Calculations based on EDAM4-IS.

Notes: Other expenditures include those on education, health, flow of services from durables, fuel, transportation, communication, well-being, housing repair, clothing and footwear, and services.

9 See http://datatopics.worldbank.org/consumption/detail, accessed November 21, 2018.

10 They use data for 11 developing countries, including Bangladesh, Pakistan, Samoa, and Vietnam, for which both national and urban expenditure weights are available. 
a food poverty line to then construct an extreme or "lower" poverty line, followed by an overall or "upper" poverty line.

The food threshold or poverty line is defined as the product of the minimum caloric intake that a basket of food consumption must guarantee by the unit cost of acquiring a kilocalorie. This is to estimate the cost of a basket of food items necessary to maintain day-to-day activities. Using the cost-of-basic-needs methodology, 2,115 kilocalories per day is considered the minimum necessary to meet nutritional needs. A representative basket of the consumer distribution community was used to obtain the cost per calorie that determines the food poverty line. Adjustments to obtain the structure of the household members were based on an adult equivalent formula.

Once the food poverty line is set, Ravallion's (1998) approach allows us to determine a poverty line, referred to as the extreme poverty line. The nonfood component of the extreme threshold is calculated by considering only households whose total consumption corresponds to the food poverty line. Based on this, nonfood expenditures of these households are observed. Although these households have a total consumption equal to the food threshold that would enable them to meet their basic food needs, these households nevertheless choose to divide their consumption between food and nonfood. As a result, these households consider that the part of the expenditure devoted to the acquisition of nonfood items further improves their level of satisfaction. These nonfood expenses are then considered indispensable as households end up sacrificing meeting their food needs in order to cover for these nonfood items. This level of nonfood expenditure is added to the food threshold to obtain the extreme poverty line.

As in many countries, the extreme poverty line is used in Djibouti to present the official poverty rates. The information from the survey, however, allows the estimation of an overall poverty line. This line represents the value that would enable households to cover, without sacrifice, all essential food and nonfood needs. A complementary measure of poverty is obtained by calculating the overall poverty line. To obtain this line, we first identify households whose food expenditures are close to the food poverty line. Thus, the nonfood expenditure of this group is considered to indicate the spending required to meet a household's nonfood needs. Adding the food poverty line and this nonfood component yields the overall poverty line. In earlier DISED reports, this upper threshold has been referred to as a global poverty line. To avoid confusion with other international indicators, we will refer to it as the overall poverty line.

The main parameters and results of the exercise concerning the estimation of the poverty line are as follows. Using the EDAM4-IS survey and the reference consumption basket, the extreme poverty line is estimated at DF 111,783 per year (DF 306 per day) and the overall poverty line is estimated at DF 151,391 per year (DF 415 per day). These lines translate to US\$2.17 in 2011 purchasing power parity (PPP) and US\$2.96 in 2011 PPP per day, respectively. ${ }^{11}$

\section{POVERTY IN DJIBOUTI IN 2017}

\section{DJIBOUTI POVERTY RATES BASED ON THE NATIONAL POVERTY LINE}

Using the adult equivalent consumption expenditure as a measure of household welfare and poverty line just described, various indicators of poverty can be obtained. Table 1.2 presents the results. Measured by consumption per adult equivalent, the extreme poverty rate for the whole country is estimated at 21.1 percent in 2017. In line with previous years' studies (Box 1.2 nevertheless highlights that the welfare aggregate and consequently poverty are not comparable over time), there appears to be a significant gap between the well-being of the capital and other regions. Indeed, in Djibouti city, the extreme poverty rate is estimated at 13.6 percent, while in the other regions, at 45 percent, it is more than two times higher than the national rate. Using the overall poverty

11 To go from an adult equivalent scale to a per capita scale, the poverty line in adult equivalent is adjusted by dividing it by the mean adult equivalent and multiplying it by the average household size as obtained from EDAM4. 


\section{Box 1.2 Issues with Comparability of Welfare and Monetary Poverty across Time in Dfibouti}

In 2013, DISED revised the methodology for monitoring poverty. Using data from Enquete Djiboutienne Aupres des Menages- Budget Consommation (EDAM-BC) 2013, a basic-cost-of-needs approach was adopted to define food and total poverty lines. After defining the threshold, conventional price adjustments were done to find poverty lines corresponding to the previous 2002 and 2012 EDAMs. Estimated extreme poverty rates were 24.1 percent in 2002, 16 percent in 2012, and 23 percent in 2013 . Such figures should not be used together with the results presented here. Previous EDAMs have gone through significant methodological changes, including changes to the consumption aggregate used to measure well-being, thus rendering it not strictly comparable across surveys. Three key components of the aggregate of wellbeing must be highlighted:

1. Food component: Over time, EDAM's consumption data collection efforts have evolved by increasing the level of detail of the questions. These variations between the EDAMs limit temporal comparability. In EDAM2-IS 2002, the food component of household well-being was identified using a single question. For the 2012 EDAM3-IS, a 21-question module was developed to improve the data collected on food consumption. In addition, the recall period had been set at a week or a month. For EDAM-BC 2013, a log was used to collect consumption data instead of the recall. At the same time, information on a much more detailed list of articles was collected during the data collection. (It was possible to register 208 food items.)

2. Nonfood components: Like the food aggregate, there were significant differences in the data collection method and the level of detail of nonfood items. For example, in EDAM2-IS 2002, household nonfood expenditures were captured for about 10 items, while the list in EDAM3-IS 2012 comprised about 90 items. In EDAM-BC 2013, more than 500 nonfood items were collected at different recall periods.

3. Housing services: the well-being of neighborhoods where households live is one of the key elements in understanding their living conditions. In addition, the share of housing services in household welfare becomes more important as countries develop. In the case of Djibouti, the EDAM surveys of 2002 and 2012 have collected information on actual rent and shadow rent that are considered for housing services. For EDAM-BC 2013, the approach was very different, because housing and household characteristics were used to estimate a hedonic model. This model predicted housing services for owner occupied households.

The EDAM4-IS 2017 questionnaire incorporated improvements based on current good practices to better capture household food and nonfood expenditures and turn it into a true multitopic tool. Despite the loss of comparability over time, DISED decided to seize the opportunity of the survey and to estimate wellbeing with the most recent methodologies. EDAM4-IS 2017 will become the baseline for monitoring the evolution of poverty in the country.

Source: Adapted from DISED, 2018. 
TABLE 1.2 Poverty Indicators in Djibouti, 2017

\begin{tabular}{l|c|c|c|c|c|} 
& National & Djibouti city & Other regions & Other urban & Rural \\
\hline \multirow{2}{*}{ Extreme poverty } & $21.1 \%$ & $13.6 \%$ & $45.0 \%$ & $14.8 \%$ & $62.6 \%$ \\
& $(0.90)$ & $(1.10)$ & $(1.25)$ & $(2.04)$ & $(1.33)$ \\
\hline \multirow{2}{*}{ Poverty gap } & $7.1 \%$ & $3.5 \%$ & $18.6 \%$ & $5.2 \%$ & $26.4 \%$ \\
& $(0.34)$ & $(0.38)$ & $(0.68)$ & $(1.07)$ & $(0.80)$ \\
\multirow{2}{*}{ Severity of poverty } & $3.4 \%$ & $1.3 \%$ & $10.1 \%$ & $2.6 \%$ & $14.4 \%$ \\
& $(0.19)$ & $(0.49)$ & $(0.19)$ & $(0.78)$ & $(0.60)$ \\
\hline \multirow{2}{*}{ Overall poverty } & $35.8 \%$ & $28.2 \%$ & $59.8 \%$ & $27.6 \%$ & $78.4 \%$ \\
& $(1.08)$ & $(1.37)$ & $(1.24)$ & $(2.32)$ & $(1.07)$ \\
\hline
\end{tabular}

Source: Calculations based on EDAM4-IS.

Note: Standard errors in parentheses.

line, the proportion of the population considered poor increases considerably. Across the country, 35.8 percent are unable to cover their food and nonfood needs. Among households in other regions, this rate is even higher, at 59.8 percent.

Figure 1.4 shows spatial differences in Djiboutian population's levels of well-being. Tadjourah region has the highest percentage of population living below the extreme poverty line, followed by the Dikhil region. In the capital, disparities are also highlighted: the fourth and fifth districts have extreme poverty rates three times higher than the 1st district. Overall, poverty also remains high in the fourth and fifth districts of the capital city, with nearly a third of the population living below the overall poverty line in these districts (Table 1.3). Tadjourah and Dikhil are the regions that show the highest estimated extreme poverty rates. This could be partly explained by the large share

\section{FIGURE 1.4 Extreme Poverty Rates, by EDAM4 Representative Domains}

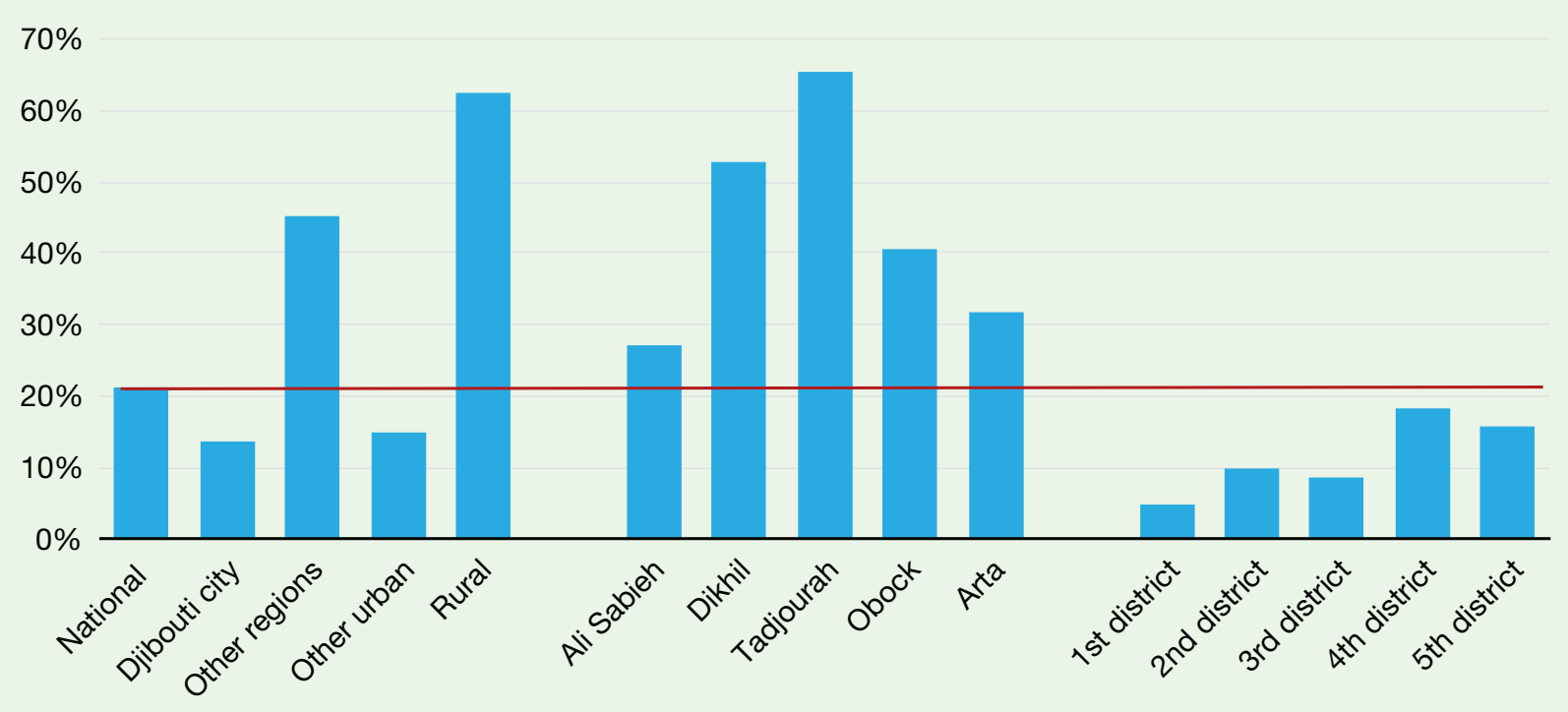

Source: Calculations based on EDAM4-IS.

Note: Line across graph denotes the national extreme poverty rate. 


\section{TABLE 1.3 Indicators of Poverty in Djibouti City, 2017}

\begin{tabular}{l|c|c|c|c|c|c|} 
& Djibouti city & 1st dist. & 2nd dist. & 3rd dist. & 4th dist. & 5th dist. \\
\hline \multirow{2}{*}{ Extreme poverty } & $13.6 \%$ & $4.7 \%$ & $9.8 \%$ & $8.5 \%$ & $18.3 \%$ & $15.8 \%$ \\
& $(1.10)$ & $(2.21)$ & $(1.81)$ & $(1.78)$ & $(2.34)$ & $(2.26)$ \\
\hline \multirow{2}{*}{ Poverty gap } & $3.5 \%$ & $1.0 \%$ & $2.3 \%$ & $2.1 \%$ & $4.8 \%$ & $4.2 \%$ \\
& $(0.38)$ & $(0.51)$ & $(5.63)$ & $(0.58)$ & $(0.89)$ & $(0.81)$ \\
\multirow{2}{*}{ Overall poverty } & $28.2 \%$ & $13.0 \%$ & $22.0 \%$ & $15.4 \%$ & $35.2 \%$ & $33.6 \%$ \\
& $(1.37)$ & $(2.92)$ & $(2.64)$ & $(2.20)$ & $(2.71)$ & $(2.72)$ \\
\hline
\end{tabular}

Source: Calculations based on EDAM4-IS.

Note: Standard errors in parentheses.

of population living in rural areas in these two regions (77 percent and 64 percent, respectively) and consequently the limited income opportunities that their residents have access to. In fact, it is notable that this relatively high level of deprivation can also be found across the international border in Ethiopia. The regions of Afar (zone 1) and Somali (Shinile zone) in Ethiopia share the national border with the regions of Tadjourah and Dikhil in Djibouti. Both the Afar and Somali regions are classified as a "developing regional state" by the Ethiopian Government. This classification identifies regions where poverty rates are higher and performance on social indicators is poorer as compared to national averages. Indeed, the poverty rate using national poverty line is higher than the national average of 23.4 percent-38.5 percent in the Shinile zone of Somali region and 24.2 percent in zone 1 of Afar region in 2016. This is not surprising, however, given the similar characteristics of border regions in the two countries. In Afar and Somali regions, about 60 percent and 38 percent respectively rely on livestock as the main occupation of household head. ${ }^{12}$ Large parts also face arid or semiarid climatic conditions, much like Djibouti's border regions.

\section{DJIBOUTI POVERTY RATES BASED ON INTERNATIONALLY DEFINED POVERTY LINES}

The results on poverty presented thus far are based on national poverty lines calculated to reflect in the best way possible the realities and costs of basic needs among the Djiboutian population. The approach to estimate the extreme and overall poverty lines relied heavily on the expertise of DISED. These national poverty lines are calculated using the basket of goods that are reflective of the consumption patterns of the Djiboutian population in 2017 using data from EDAM4-IS. Nonetheless, to gain a broader view of the state of poverty in the country, it is important to use complementary benchmarks that help contextualize the results already shown. Here we present results by applying alternative poverty lines to the distribution of consumption in Djibouti in 2017.

A key target of SDG 1 of ending poverty in all its forms everywhere is the eradication of extreme poverty by 2030. In order to assess the progress made against this SDG, it is necessary to monitor poverty based on an internationally comparable benchmark. The global poverty rate is defined as the percentage of the population living below the international poverty line (IPL). The IPL was originally based on the International Comparison Program's (ICP's) 2005 PPP and valued at US $\$ 1.25$ per person per month. Recently, the ICP's revision of 2011 PPP and new data led to the updated value of the IPL. ${ }^{13}$ Currently, the IPL is estimated to be US\$1.90 (in 2011 PPP) per person per day. ${ }^{14}$

The World Bank's (2018a) Poverty and Shared Prosperity 2018 report recognizes that while the IPL is informative,

12 Comprehensive Food Security and Vulnerability Analysis (CFSVA), Ethiopia, March 2014

13 See Ferreira and Sánchez-Páramo (2017) for a review and a brief discussion.

14 The International Comparison Program adjustment factor in 2011 is 101.4806 . This means that in 2011, US\$1 was equivalent in purchasing power as DF 101.48. 
the analytical underpinnings are derived from surveys conducted before 2005 . The relatively outdated foundation (of average assessments of basic needs in low-income countries) can limit its ability to measure poverty in a world where a high proportion of the population and global poor are now living in middle- and high-income countries. To account for these factors, the report develops additional higher value lines, including the poverty line for lowermiddle-income countries, the poverty line for uppermiddle-income countries, and a societal poverty line.

Two more thresholds are explored to complement the picture of poverty in Djibouti. First, as the country is classified as a lower middle-income country by the World Bank, the lower middle-income class poverty line with a value of US $\$ 3.20$ (2011 PPP) becomes a relevant threshold. Second, in using the IPL, one assumes that the cost of basic needs is the same across all countries. However, that is empirically shown not to be the case. ${ }^{15}$ As countries progress, US\$1.90 in 2011 PPP may no longer reflect the cost of basic needs. Due to these reasons, Poverty and Shared Prosperity (2018a) develops another metric called the societal poverty line, which helps take these considerations into account. The measure of societal poverty line is equal to US\$1.90 in 2011 PPP per day or US\$1 in 2011 PPP plus half of the median consumption of a person in the country, whichever is greater. The societal poverty line accounts for extreme poverty, which is fixed for everyone at US\$1.90 in 2011 PPP and adds a relative dimension of welfare. As a country progresses and the median consumption per person increases, the societal poverty line would increase as well, reflecting the change in the cost of basic needs. In the case of Djibouti, the societal poverty line is estimated at US\$2.82 in 2011 PPP. Djibouti's societal poverty line is greater than the IPL, which reflects that the IPL may longer adequately reflect the cost of basic needs in Djibouti.

Figure 1.5 presents the poverty rates associated with the IPL, the lower middle-income class poverty line, and the societal poverty line for Djibouti and its regions. ${ }^{16}$ About 17 percent of the Djiboutian population is found to live below the IPL, and 40 percent has consumption per capita below US\$3.2 in 2011 PPP. As expected, the pattern of poverty

\section{FIGURE 1.5 Poverty Rates Based on International (US\$1.90 and US\$3.20 2011 PPP per day) and Societal Poverty Lines}

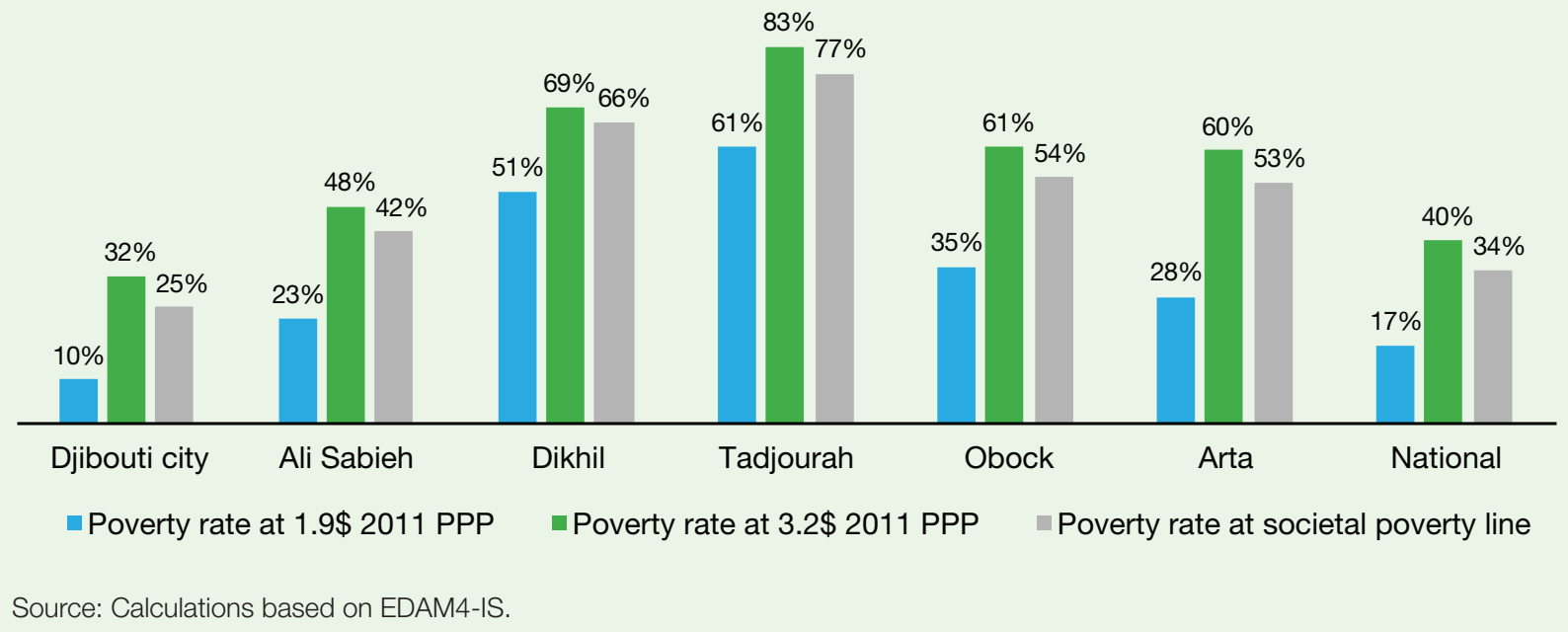

15 Refer to Poverty and Shared Prosperity (World Bank 2018b) for more details

16 Note that the welfare aggregate used in this exercise is in per capita terms and adjusted to 2011 PPP. 
rates using these poverty lines across regions is the same as poverty rates calculated using the national poverty line. Tadjourah registers the highest percentage of population living below the IPL, followed by Dikhil. About two-fifths of the population lived below US\$3.2 in 2011 PPP nationally in 2017. Meanwhile, about a third of the population suffers

\section{POVERTY PROFILE}

The multitopic nature of the EDAM4-IS makes it is possible to create a detailed profile of different groups of the population. In this section, we present results concerning the poorest population, those considered as extreme poor: the 21.1 percent of the Djiboutian population with a level of annual consumption below the extreme poverty line. The location of the poor population, the kind of dwellings they live in, and their educational and employment outcomes are emphasized. We contrast the outcomes of poor and nonpoor populations in order to assess the key distinguishing characteristics of the former in Djibouti.

\section{LOCATION CHARACTERISTICS}

Table 1.4 shows the distribution of the poor and overall population across the country. About 12 percent of country's population lives in Tadjourah and Dikhil but these regions host a disproportionate share of the country's poor. A third of the country's extreme poor reside in these two regions. Based on the distribution of the population from EDAM4, the rural population represents 15 percent of the total population, but it hosts about 45 percent of the population considered as extreme poor. On the other hand, 76 percent of the total population lives in Djibouti city and 49 percent of the poor population lives in Djibouti city. Finally, in terms of magnitude, we find a high concentration of the extreme poor population in some districts of the capital. The fourth and fifth districts-belonging to the community of Balbala-are the residence of nearly 37 percent of the poor population in Djibouti. Taken together, the poor population of the country is concentrated in rural areas (45 percent) and Balbala (37 percent). The section from societal poverty in Djibouti, and the patterns across regions persist. Taken together, these results suggest that the poverty-reducing agenda in Djibouti is still important. Despite the strong period of economic growth of recent years, welfare levels are low, especially in certain regions with a large rural population.

on inequality presents more details about the differences in the poor living in Balbala and the poor living in rural areas.

The strong correlation between welfare and location (especially where areas with rural populations are more prominent) will become a common thread in the different pieces of analysis considered in this report. Djibouti city is entirely urban and constitutes three-fourths of the country's population. Tadjourah has the bulk of the population living in rural areas, followed closely by Dikhil and Obock. Since the urban environment is more affluent than rural areas, regions with a high proportion of the population living in rural areas will be shown to have weaker monetary and nonmonetary indicators when compared to more urbanized regions.

\section{DEMOGRAPHIC CHARACTERISTICS}

Nonpoor households differ in demographic characteristics from the extreme poor households. The latter households tend to be bigger, with an average of 7 household members, and have a higher dependency ratio than the nonpoor households. In fact, household size seems to be highly correlated with poverty. Figure 1.6 shows that as the household size increases, the poverty rate of the population living in these households is also higher. Households living in extreme poverty are also younger and comprise a larger share of children (younger than 15 years of age). Among the extreme poor, this group constitutes 39 percent, whereas it is 35 percent among the nonpoor (Table 1.5). Extreme poor households also have much higher dependency ratios (111 percent) than nonpoor households. 
TABLE 1.4 Distribution of Extreme Poor and Overall Population across Locations (\% population)

\begin{tabular}{l|c|c|} 
& Extreme poor & Overall population \\
\hline $\begin{array}{l}\text { By regions } \\
\text { (outside Djibouti city) }\end{array}$ & \multicolumn{2}{|c}{} \\
\hline Djibouti city & 49 & 5 \\
\hline Ali Sabieh & 7 & 7 \\
\hline Dikhil & 16 & 5 \\
\hline Tadjourah & 17 & 2 \\
\hline Obock & 5 & 4 \\
\hline Arta & 6 & 100 \\
\hline National & 100 & 5 \\
\hline
\end{tabular}

\begin{tabular}{l|c|c|}
\hline By location & 55 & 85 \\
\hline Urban & 45 & 15 \\
\hline Rural & 100 & 100 \\
\hline National & 49 & 76 \\
\hline Within Djibouti city & 2 & 8 \\
\hline Overall & 8 & 17 \\
\hline 1st district & 2 & 5 \\
\hline 2nd district & 20 & 24 \\
\hline 3rd district & 17 & 22 \\
\hline 4th district & & \\
\hline 5th district & & \\
\hline
\end{tabular}

Source: Calculations based on EDAM4-IS.

FIGURE 1.6 Poverty Rate (percent), by Number of Household Members

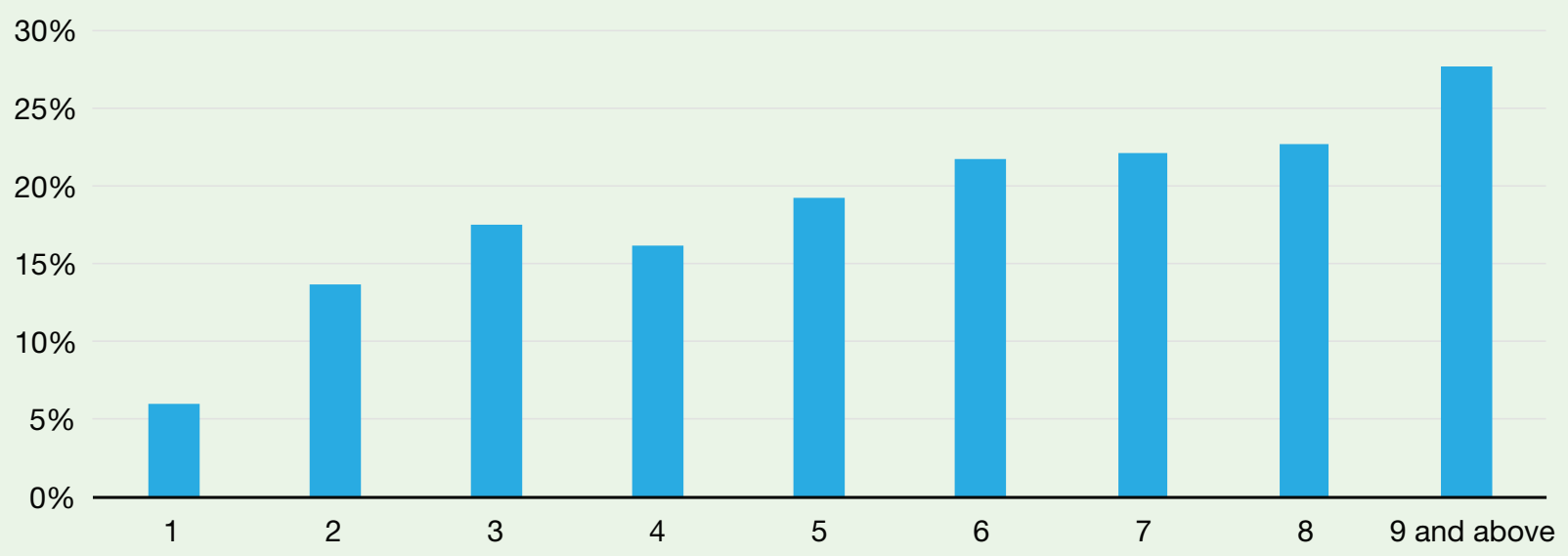

Source: Calculations based on EDAM4-IS. 
In terms of age, marital status, and gender, household heads in extreme poor and nonpoor households do not seem to differ substantially. Extreme poor households are slightly more likely to have a non-Djiboutian head. In contrast, characteristics of heads are found to be different on other dimensions. Nonpoor household heads have an average literacy rate of 46 percent as compared to 12 percent of the poor household heads. Not only that, the former also have an average of 4.2 years of education as compared to 0.8 years among the latter.

Table 1.6 presents extreme poverty rates of children $(0-17$ years) and men and women (18 years and over). ${ }^{17}$ There are slight disparities between the population groups analyzed. In particular, children do not seem to have a higher level of deprivation than adults in Djibouti city. Outside Djibouti city, however, the differences are slightly larger. For example, in rural areas, the poverty rate among children is 67 percent and that among adults is about 58 percent. No gender differences in poverty rates are found among adults.

\section{NONMONETARY INDICATORS}

There are marked differences in access to services across different groups of the population. Figure 1.7 shows the differences between the extreme poor and the nonpoor population, as well as the indicators of the overall population. The dwellings inhabited by the poor seem to be more precarious that those occupied by the nonpoor. The poor population, as compared to nonpoor, is more likely to live in a tent and less likely to live in a house with brick walls, sheet metal roof, and cement floor. Among the very poor, the percentage with access to electricity is 16 percent, while for the rest of the population it is estimated at 72 percent. The gap in access to water is less pronounced: 69 percent and 96 percent, respectively. Finally, disparities in access to garbage disposal services and toilets services are also evident. Among the very poor population, 42 percent practices open defecation, compared with just 5 percent among the nonpoor population. Access to services such as electricity and

\section{TABLE 1.5 Demographics and Characteristics of Extreme Poor, Nonpoor, and Overall Population}

\begin{tabular}{l|c|c|c|} 
& Nonpoor & Extreme Poor & Total \\
\hline Household size & 6.2 & 7.0 & 6.4 \\
\hline Dependency ratio (\%)** & 85 & 111 & 90 \\
\hline
\end{tabular}

Percentage in each group

\begin{tabular}{l|l|l|l|}
\hline Children ages $0-14$ years & 35 & 39 & 36 \\
\hline Individuals ages $15-39$ years & 45 & 42 & 44 \\
\hline Individuals ages 40 years and older & 21 & 19 & 20 \\
\hline
\end{tabular}

Household head characteristics

\begin{tabular}{l|c|c|c}
\hline Age $^{\star}$ & 48.0 & 48.2 & 48.0 \\
\hline Married & $80 \%$ & $84 \%$ & $81 \%$ \\
\hline Female & $21 \%$ & $20 \%$ & $20 \%$ \\
\hline Djiboutian** & $96 \%$ & $95 \%$ & $96 \%$ \\
\hline Literate & $46 \%$ & $12 \%$ & $39 \%$ \\
\hline Years of education & 4.2 & 0.8 & 3.5 \\
\hline
\end{tabular}

Source: Calculations based on EDAM4-IS.

* The sample comprises 4,359 household heads. For the remaining households, the age of the household head is unknown.

${ }^{* \star}$ Only households with at least one working age (15-64) individual are included. ${ }^{* \star *}$ Self-declared. 
TABLE 1.6 Extreme Poverty Rate, by Population Group

\begin{tabular}{l|c|c|c|c|} 
& National & Djibouti city & Other regions & Rural \\
\hline Poverty rate among children (0-17 years) & $23 \%$ & $14 \%$ & $48 \%$ & $67 \%$ \\
\hline Poverty rate among men (18+ years) & $19 \%$ & $14 \%$ & $42 \%$ & $59 \%$ \\
\hline Poverty rate among women (18+ years) & $19 \%$ & $13 \%$ & $41 \%$ & $58 \%$ \\
\hline Global population & $21.1 \%$ & $13.6 \%$ & $45.0 \%$ & $62.6 \%$ \\
\hline
\end{tabular}

Source: Calculations based on EDAM4-IS.

\section{FIGURE 1.7 Dwelling Characteristics and Access to Services by Population Groups}

\section{a. Extremely Poor, Nonpoor, and Total Population}

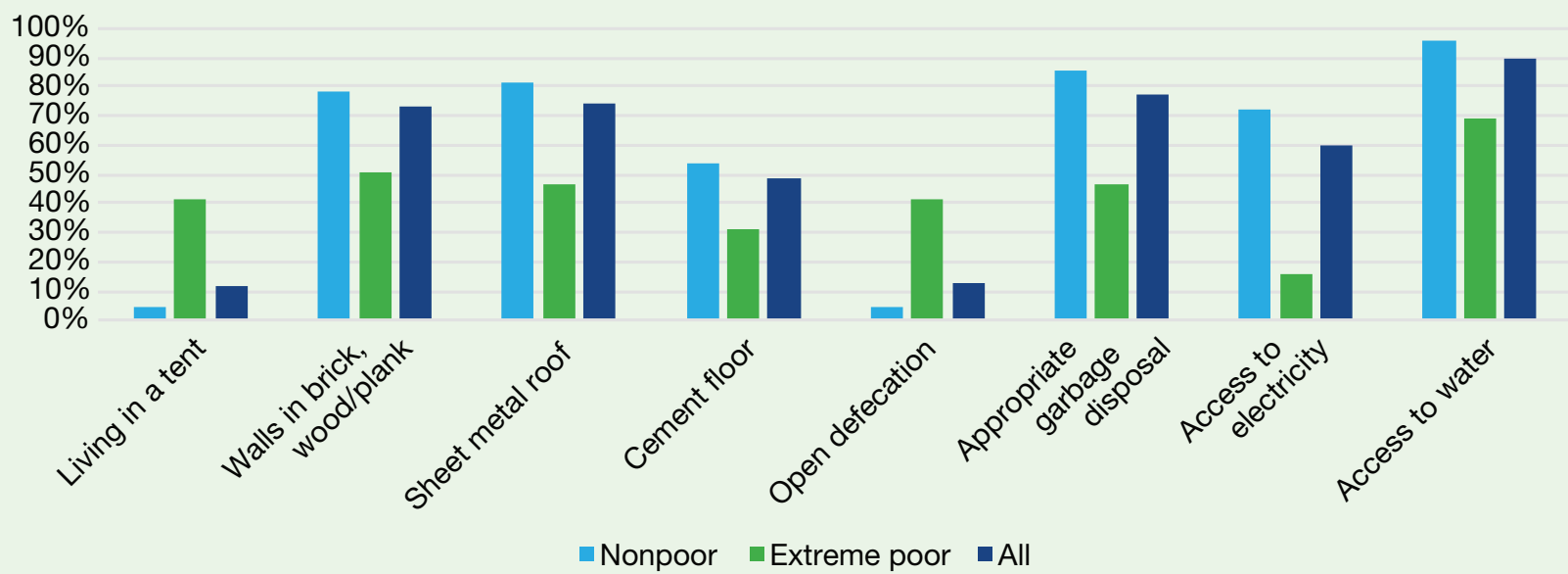

a. Urban, Rural and Total Population

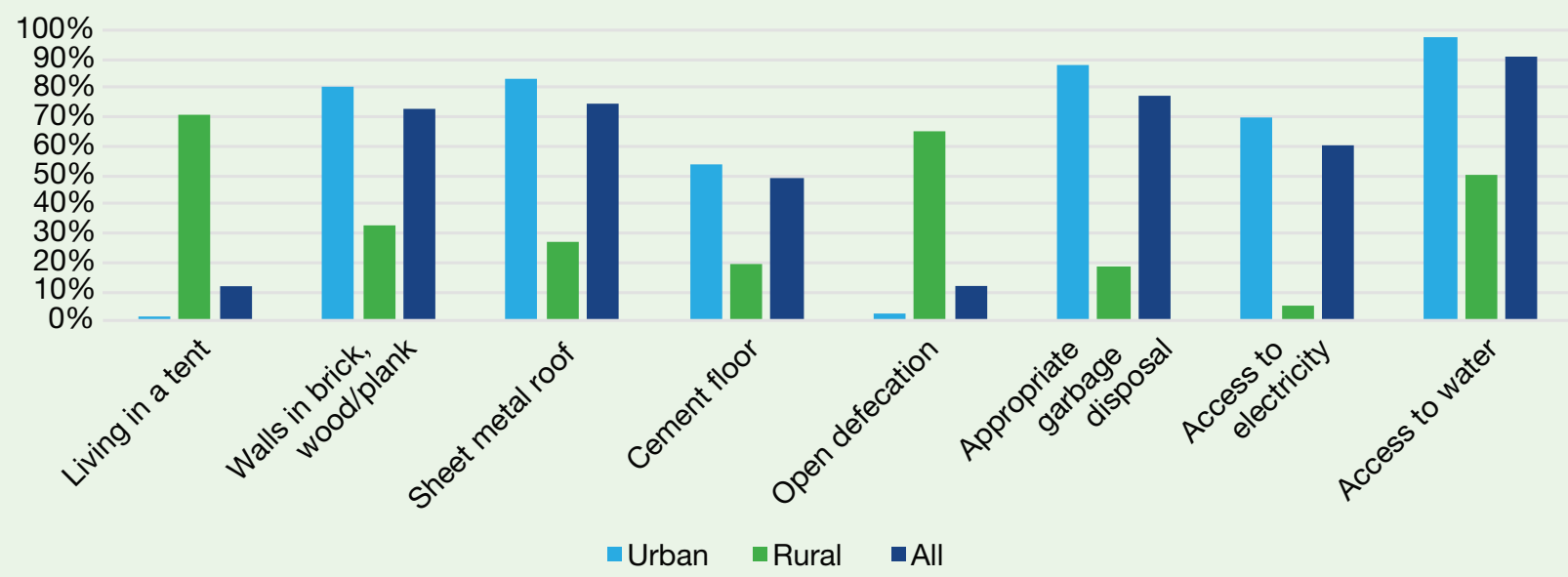

Source: Calculations based on EDAM4-IS.

Note: Walls in brick, wood/ plank include 3 categories: adobe bricks (cement block) in cement, wood/plank and brick/ wood. Access to electricity is defined as the use of electricity as the main source of lighting. Access to water is defined as the availability of water in the household in the form of running water (Office National de l'Eau et de l'Assainissement [ONEAD] indoor connection), direct connection from a borehole, and ONEAD outdoor connection by pipe, public fountain, and drilling (with a pump). Appropriate garbage disposal is defined as availability of garbage collector-OVD (public dump), availability of garbage collector-private, and garbage deposited in a designated place. 
TABLE 1.7 Asset Ownership Rates by Poverty Status

\begin{tabular}{l|c|c|c|} 
& Nonpoor & Extreme poor & Overall \\
\hline Mobile phone & $87.1 \%$ & $55.4 \%$ & $80.4 \%$ \\
\hline Laptop/Personal computer & $13.3 \%$ & $0.3 \%$ & $10.5 \%$ \\
\hline Tablet & $2.8 \%$ & $0.0 \%$ & $2.2 \%$ \\
\hline Radio & $13.3 \%$ & $8.0 \%$ & $12.2 \%$ \\
\hline Television & $61.4 \%$ & $9.4 \%$ & $50.4 \%$ \\
\hline Satellite dish & $39.7 \%$ & $5.8 \%$ & $32.5 \%$ \\
\hline Refrigerator/freezer & $44.6 \%$ & $6.1 \%$ & $36.4 \%$ \\
\hline Air conditioning & $17.5 \%$ & $0.7 \%$ & $14.0 \%$ \\
\hline Washing machine & $16.0 \%$ & $0.8 \%$ & $12.8 \%$ \\
\hline Microwave/oven & $1.5 \%$ & $0.0 \%$ & $1.2 \%$ \\
\hline Private car & $3.8 \%$ & $0.3 \%$ & $3.1 \%$ \\
\hline
\end{tabular}

Source: Calculations based on EDAM4-IS.

sanitation seem to be a priority focus area for public policy, going forward. Electricity access has been shown to contribute to well-being in various ways. It has been shown to stimulate consumption and income (Chakravorty, Pelli, and Marchand 2014; Van de Walle et al. 2017), promote income generating activities and entrepreneurship (Chowdhury 2010; Dinkelman 2011), enable better education (Chandrasekhar and Amin 2012), and enable better health (World Bank 2008).

It must be kept in mind that about 45 percent of the poor live in rural areas while another 37 percent live in Balbala area of the capital. Thus, these results on extreme poor are driven by those living in rural areas (Figure 1.7). For example, the open defecation rates among those living in rural areas is 65 percent, while only 3 percent for urban areas. Similarly, about 70 percent of rural residents are found to be living in tents while only 1 percent in the urban areas are found to be doing so.

There are also marked differences in the assets owned by households based on their poverty status (Table 1.7). Likely a reflection of the low capacity to save and purchase durable goods, or have access to loans for credit purchases, the poor have much lower rates of ownership of radios, TVs, refrigerators, and even mobile phones. It is notable that among the extreme poor, the estimated ownership rate is less than one percent for the following items: laptops, tablets, air conditioning units, washing machines, and cars.

In terms of human capital accumulation and the ability of individuals to progress economically, differences between the extreme poor population and the rest of the population are also evident. There is a 20 percentage point difference in the literacy rates of extreme poor and nonpoor (Table 1.8). Large differences are also found in attendance at school among those 6-14 years old (corresponding to primary and secondary school ages) between the poor and nonpoor population groups. The poor of 6-14 years are much more likely to have never attended school. There are also gaps in access to primary school, with only 6 percent of the nonpoor and 18 percent of the poor declaring unavailability of school. Additionally, 45 percent declare having a primary school less than 1 kilometer away. About a third among the extreme poor declare that a high school does not exist, while only 7 percent of the nonpoor declare so. The nonpoor spend nearly four times on education per capita as compared to the poor.

About 85 percent of individuals older than 25 years in the very poor population have no education, and 2 percent of this population has attended school but not attained primary education (Figure 1.8). Among the nonpoor population, the 
corresponding percentages are 55 percent and 4 percent. In addition, 18 percent of the nonpoor population has at least completed high school education. Figure 1.9 presents the poverty rate of the household head by educational attainment. There is again evidence of a strong correlation between education and poverty status: the poverty rate stands at 30 percent when the head has no education whatsoever and drops sharply for heads with less than

\section{TABLE 1.8 Education Indicators among the Extreme Poor, Nonpoor, and Overall Population}

\begin{tabular}{|c|c|c|c|}
\hline & Nonpoor & Extreme poor & Total \\
\hline Literacy among those age 15 years and older & $58.2 \%$ & $31.8 \%$ & $53.1 \%$ \\
\hline Percentage of children of $6-10$ years attending school & $83.8 \%$ & $63.3 \%$ & $78.4 \%$ \\
\hline Percentage of children of 11-14 years attending school & $88.5 \%$ & $71.1 \%$ & $84.8 \%$ \\
\hline Percentage of children of 15-17 years attending school & $72.2 \%$ & $52.5 \%$ & $68.2 \%$ \\
\hline Percentage of children of 6-14 years that never attended school & $11.1 \%$ & $30.8 \%$ & $15.9 \%$ \\
\hline $\begin{array}{l}\text { Percentage of households where household head has less than } \\
\text { primary (including no) education }\end{array}$ & $61.8 \%$ & $93.3 \%$ & $67.8 \%$ \\
\hline Maximum years of education among all adults in household & 10.0 & 5.3 & 8.3 \\
\hline Percentage of population that declares no primary school is available & $5.7 \%$ & $17.9 \%$ & $8.3 \%$ \\
\hline Percentage of population with a primary school within one kilometer & $41.8 \%$ & $41.7 \%$ & $41.8 \%$ \\
\hline Percentage of population that declares no high school is available & $7.4 \%$ & $31.1 \%$ & $12.3 \%$ \\
\hline Percentage of population with a high school within one kilometer & $21.8 \%$ & $13.7 \%$ & $20.1 \%$ \\
\hline Annual per capita spending on education (DF) & 9,126 & 2,197 & 7,662 \\
\hline Share of consumption expenditure on education & $4.4 \%$ & $3.5 \%$ & $4.2 \%$ \\
\hline
\end{tabular}

Source: Calculations based on EDAM4-IS.

Notes: Education expenditures reflect households' expenses on school subscription fee, cost of books and furniture associated with schooling, school and sports uniform, transport to and from school, and others (cost of accommodation, repetitions of class, special courses, and other services).

\section{FIGURE 1.8 Educational Attainment of Adults Age 25 and Older (percent)}

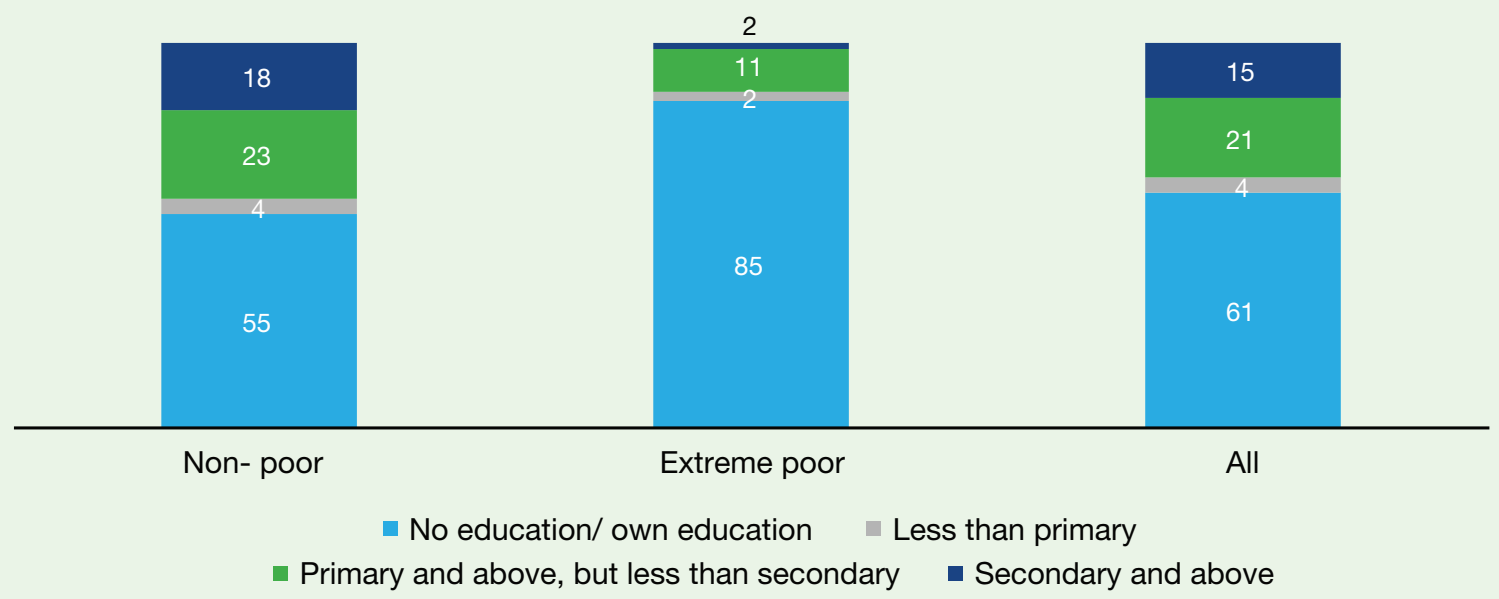

Source: Calculations based on EDAM4-IS. 


\section{FIGURE 1.9 Extreme Poverty Rates, by Educational Attainment of Household Head}

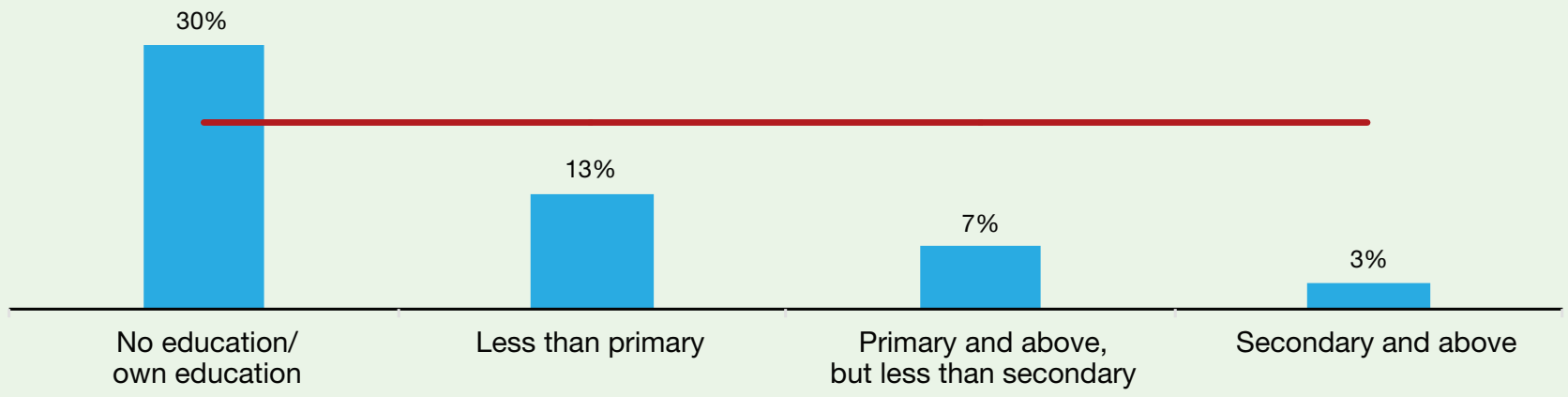

Source: Calculations based on EDAM4-IS.

Notes: Line indicates national poverty rate.

primary education. The poverty rate is extremely low when the head has completed at least secondary education.

These significant disparities across the poor and nonpoor on educational outcomes is important and must be kept in mind when we explore labor market outcomes.

A majority of children (95 percent) attending school in Djibouti go to public schools. However, inequities in educational outcomes may occur insofar as private, school-related expenditures affect children's learning. This is due to the fact that regional disparities seen in monetary indicators are mirrored by households' education expenditures (Figure 1.10). The average household in Djibouti city spends slightly more than DF 9,000 per capita on education, and in Tadjourah, about DF 1,200. Not only is the difference in the levels of per capita education

\section{FIGURE 1.10 Education Expenditure per Capita and Share of Expenditure on Education in Total Household Expenditure, 2017}

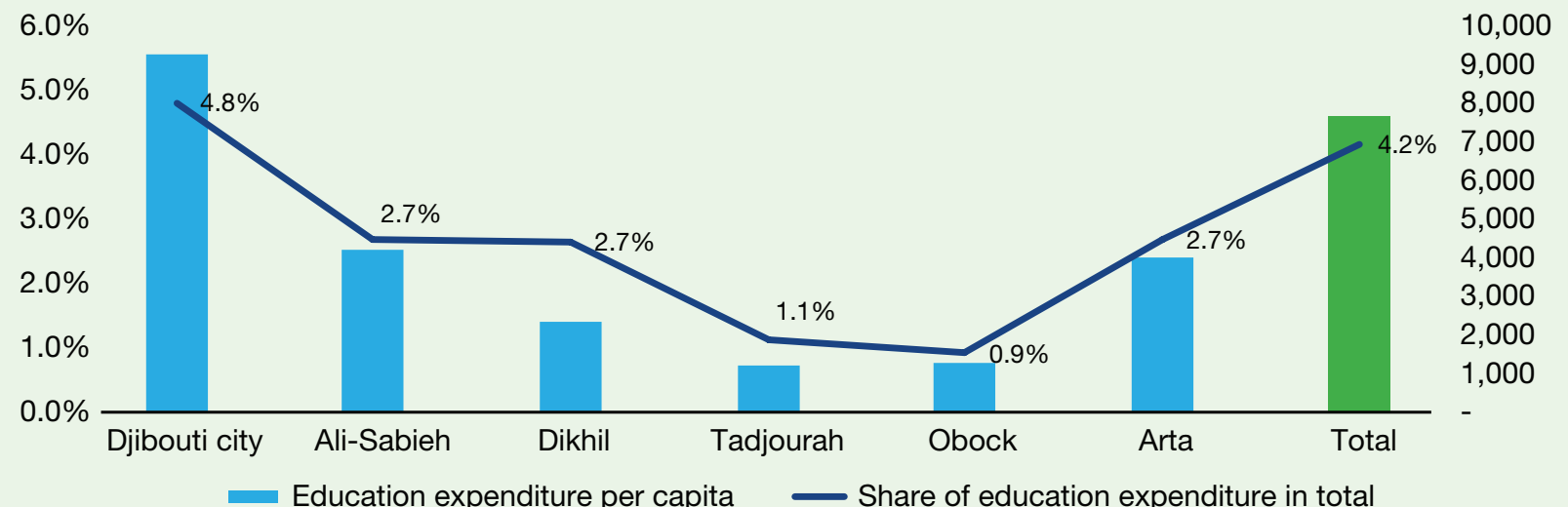

Source: Calculations using EDAM4-IS

Notes: Education expenditures reflect households' expenses on school subscription fee, cost of books and furniture associated with schooling, school and sports uniform, transport to and from school and others (cost of accommodation, repetitions of class, special courses, and other services). 
expenditure highest across regions, but also the share of these expenditures in total follows the same trend. It is thus not surprising that an average household spends 5 percent of their total expenditure on education in Djibouti city and only 1 percent in Tadjourah.

About 8 percent of the population reports having had an illness during the preceding year, with a lower share of the extreme poor reporting being ill (Table 1.9). Meanwhile, the percentage of people that declared having certain physical limitations is essentially the same across poor and nonpoor. ${ }^{18}$ Access to health centers and hospitals appears to be limited among the poor population, with nearly a fourth of them declaring that a health center does not exist nearby. About 40 percent of the poor declare that a maternity clinic does not exist nearby, while only 18 percent of the nonpoor do so. In addition to primary schools, access to health facilities such as health centers, hospitals, and maternity clinics is another public facility for which the poor show lower coverage rates. Finally, disparities emerge when we look at households spending (and their ability to spend) to treat their ailments. While over 77 percent of people reporting being ill go to a public health facility for consultation, the nonpoor spend nearly three times as much on health per capita than the poor do.

The preceding sections have explored the concept of monetary poverty or the cost for a household to achieve a level of well-being considered as the minimum necessary and that allows the members to satisfy their food and nonfood needs. Separately, we explore its correlation with other nonmonetary indicators. As a way to track several margins of deprivation and broaden our understanding of poverty, it is important to supplement the monetary measure of well-being with nonmonetary measures that may improve welfare. In light of this, a deprivation score is calculated based on three dimensions (poverty, access to education and access to services), and a total of six potential deprivations that households can face (see Box 1.3). The deprivation score ranges from 0 to 1 : a score of 1 indicates deprivation on all 6 indicators and a score pf 0 indicates no deprivation.

\section{TABLE 1.9 Health Indicators among the Extreme Poor, Nonpoor, and Overall Population}

\begin{tabular}{|c|c|c|c|}
\hline & Nonpoor & Extreme poor & Total \\
\hline Percentage of population reporting being ill in the prior 30 days & $5.9 \%$ & $4.4 \%$ & $5.6 \%$ \\
\hline Percentage of population reporting being ill in the past year & $8.4 \%$ & $6.7 \%$ & $8 \%$ \\
\hline $\begin{array}{l}\text { Percentage of population declaring certain limitations (visual, } \\
\text { listening, walking, memory, and/or understanding) }\end{array}$ & $8.7 \%$ & $8.6 \%$ & $8.7 \%$ \\
\hline Percentage of households that declare no health center is available & $6.5 \%$ & $24.5 \%$ & $10.2 \%$ \\
\hline Percentage of households with a health center within one kilometer & $34.0 \%$ & $31.1 \%$ & $33.4 \%$ \\
\hline Percentage of households that declare no hospital is available & $6.7 \%$ & $26.8 \%$ & $10.9 \%$ \\
\hline Percentage of households with a hospital within one kilometer & $23.1 \%$ & $19.3 \%$ & $22.3 \%$ \\
\hline Percentage of households that declare no maternity clinic is available & $17.5 \%$ & $39.1 \%$ & $22.0 \%$ \\
\hline Percentage of households with a maternity clinic within one kilometer & $21.8 \%$ & $15.8 \%$ & $20.6 \%$ \\
\hline Annual health expenditures per capita ('000s DF) & 1,517 & 538 & 1,310 \\
\hline Share of household expenditure on health & $0.6 \%$ & $0.9 \%$ & $0.7 \%$ \\
\hline
\end{tabular}

Source: Calculations based on EDAM4-IS.

Notes: Health expenditures include households' expenses on consultation fees, medical exams, medications, hospitalization, and vaccination.

18 This estimate is based on the set of questions used by Washington Group on Disability Statistics to identify disability statistics. 


\section{Box 1.3 Multidimensional Poverty Index (MPI)}

Following the methodology proposed in Poverty and Shared Prosperity 2018 (World Bank 2018a), the dimensions used in the estimation of the deprivation score are given in table B1.3.1 below. The EDAM4IS captures information for each of the indicators required. Thus, we first calculate each of the six indicators for all households surveyed in Djibouti. In the education component, the first indicator is a check on school attendance of all children ages 6-14 in the household. The second indicator is a check on whether any adult age 15 years and older in the household has completed primary school education. Access to electricity reflects the use of electricity as the main source of lighting. Access to water reflects the availability of water via running water (ONEAD indoor connection), direct connection from a borehole, ONEAD outdoor connection by pipe, public fountain. and borehole (with a pump). Improved sanitation services are defined as a water closet with flush and latrines with slab, as long as these are not shared with other households.

Next, we apply the corresponding weights to each of the indicators. Finally, the summation of all the weighted components produces the deprivation score.

\section{TABLE B1.3.1 Dimensions and Their Corresponding Weights}

\begin{tabular}{l|l|c} 
Dimensions & Indicators & Weight \\
\hline Monetary poverty & Daily consumption per capita less than US\$1.9 & $1 / 3$ \\
\hline Education & Any school aged child up to age of grade 8 is not attending school & $1 / 6$ \\
\hline & No adult of grade nine and above has completed primary education & $1 / 6$ \\
\hline Access to services & No access to improved water sources & $1 / 9$ \\
\hline & No access to improved sanitation facilities & $1 / 9$ \\
\hline & No access to electricity & $1 / 9$ \\
\hline
\end{tabular}

Source: Poverty and Shared Prosperity 2018 (World Bank 2018a).

Monetary poverty, children not attending school, adults without primary education, and lack of access to water, sanitation, or electricity constitute the six deprivations included in the deprivation score. In Djibouti, only about a fourth of the population lives in households that face none of these deprivations, and about 30 percent lives in households deprived in one of the indicators (Table 1.10). The most common deprivations are access to sanitation and electricity, as 56 and 40 percent of the population does not have access to these services, respectively. There is close to 30 percent of the population that is deprived on three or more indicators, thus highlighting the need to establish a multipronged strategy to address poverty in Djibouti.
Aggregating the information on all dimensions, we find that richer households and richer regions have a lower deprivation score, but certain deprivations remain (Figure 1.11). Among the richest 20 percent of the population, the deprivation score stands at 0.1 . The results by region show a similar pattern as that of monetary poverty. Thus, not only do the regions of Tadjourah and Obock have the highest percentage of extreme (monetary) poor population, they also have the highest deprivation score. This implies that coverage of basic services and education outcomes (proxied by attainment) are worse in these regions. In line with the results shown earlier, we find lower deprivation more typically in urban than rural settings. Notably, we find strong evidence supporting the importance of education in 
reducing poverty and deprivation. Households headed by a highly educated person (secondary to tertiary education) show a fivefold reduction in the deprivation score compared to uneducated ones and exhibit a near perfect lack of deprivation (0.09). The gender of the household head does not appear to be linked to the households' level of deprivation. These findings point to the relevance of disparities in education, labor opportunities, and location in explaining the level of poverty across Djiboutian households.

\section{TABLE 1.10 Percentage of Population Deprived on Various Indicators of the MPI}

\begin{tabular}{l|c|}
$\begin{array}{l}\text { Number of } \\
\text { deprivations }\end{array}$ & $\begin{array}{c}\text { Percentage of } \\
\text { population }\end{array}$ \\
\hline 0 & 24.7 \\
\hline 1 & 30.3 \\
\hline 2 & 15.8 \\
\hline 3 & 11.5 \\
\hline 4 & 7.8 \\
\hline 5 & 5.6 \\
\hline 6 & 4.3 \\
\hline
\end{tabular}

\section{FIGURE 1.11 Deprivation score for Population Subgroups}

\section{a. By quintiles of consumption per capita}

0.8

0.6

0.4

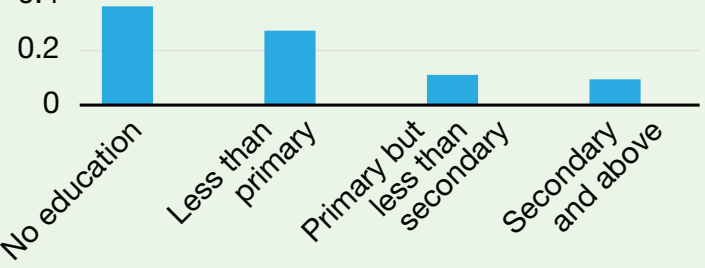

c. By education of household head

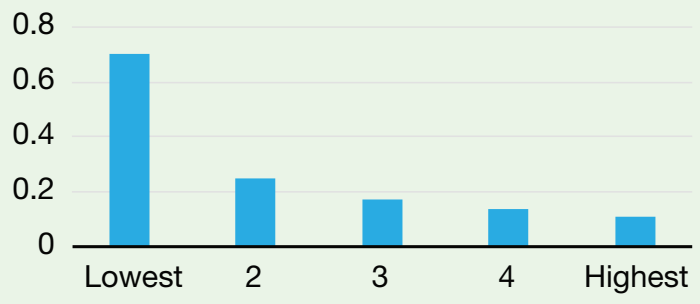

b. By gender of the household head

0.8

0.6

0.4

0.2

0

Female $\mathrm{HHH}$

d. By region

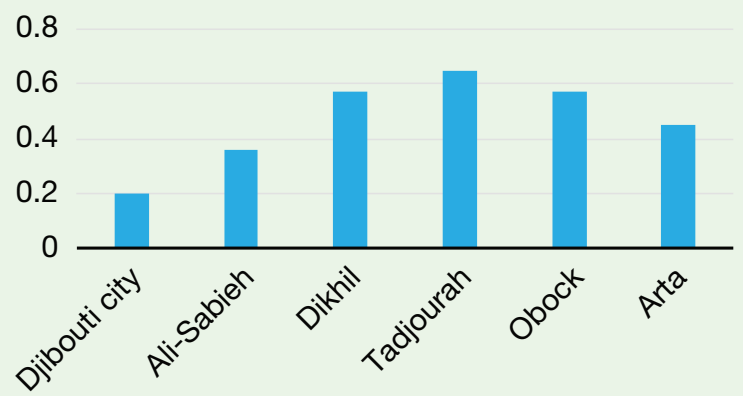

Source: Calculations based on EDAM4-IS.

Note: Analysis is restricted to 4,418 households for which information was found on all 6 dimensions. $\mathrm{HHH}=$ head of household. Deprivation scores on y-axis. 


\section{ECONOMIC CHARACTERISTICS}

The nonpoor population differs in important ways from the poor population in economic characteristics. An individual living in a poor household, on average, incurs a per capita consumption expenditure of about DF 59,000 annually, less than a quarter of the corresponding level of a nonpoor individual, which is closer to DF 250,000. This low consumption expenditure could be directly linked to the household earnings, particularly employment outcomes. Looking at the composition of the labor for all individuals of or older than the age of 15 years, we find that almost double of the nonpoor population is employed as compared to the extreme or very poor population
(Figure 1.12). About 54 percent of the nonpoor are out of the labor force, compared to 62 percent of the poor.

Among those employed, about a half of the nonpoor population work as salaried employees. Nearly 35 percent of the poor are self-employed, and another third work as salaried employees (Figure 1.13). Among both the poor and nonpoor population, employment is primarily in the tertiary or services sector. Nonpoor individuals work in the public sector almost at the same rate as the overall working population (46 percent and 44 percent, respectively), whereas among the extreme poor only 31 percent have a job in the public sector.

\section{FIGURE 1.12 Employment Status of All Age 15 and Older, by Poverty Status (percent)}

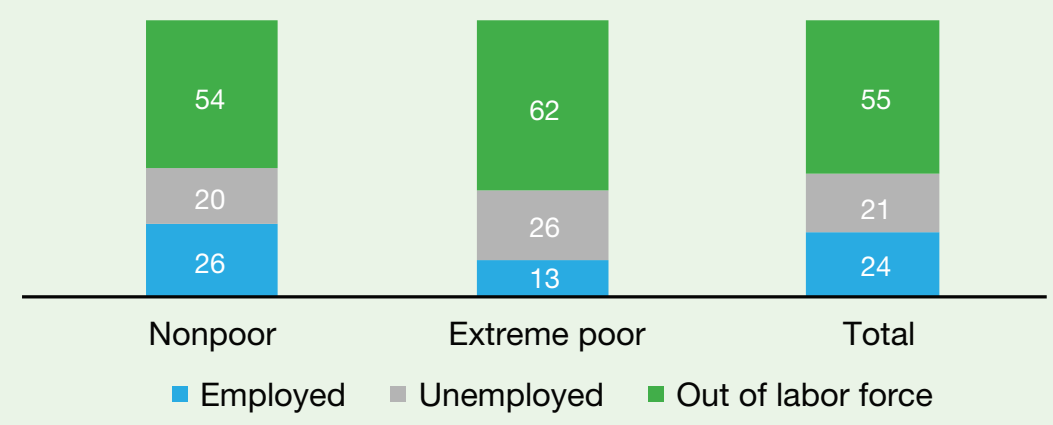

Source: Calculations based on EDAM4-IS.

FIGURE 1.13 Type and Sector of Employment (percent of those employed, 15 years and older)

\section{a. Type of employment activity}

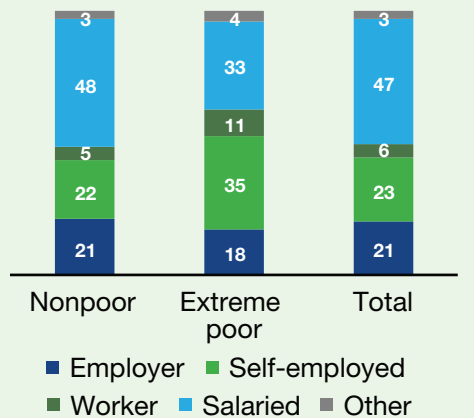

b. Sector of employment

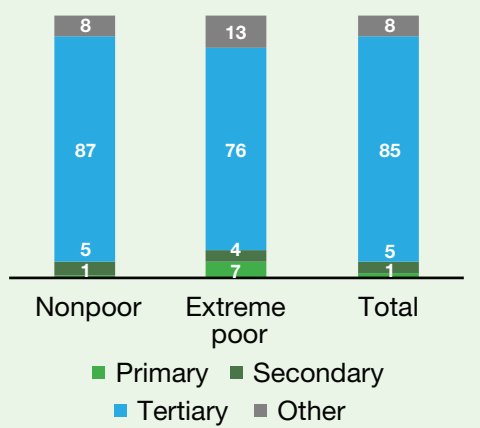

c. Percentage working in public sector

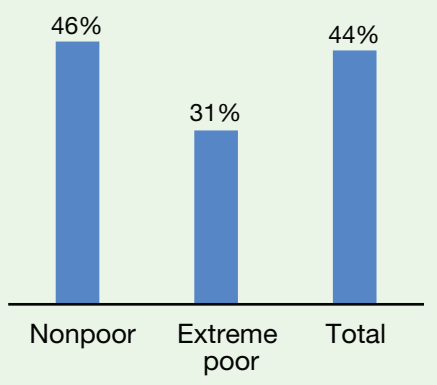

Source: Calculations based on EDAM4-IS.

Note: Salaried employment is comprised of several types of employment. The sector of employment is calculated based on the branch of activity declared by the individual. Public sector includes those employed declaring public administration as the main branch of activity. 
The low levels of labor market participation and employment raise the question of what other sources of monetary and in-kind resources are available to both poor and nonpoor populations. It is particularly important to understand the income-generating activities of the poor population and the networks on which they rely to finance their consumption and day-to-day activities. The information collected in the EDAM4-IS questionnaire on a variety of topics provides a good starting point to explore the sources and ways people in Djibouti finance their consumption.

The typical channel through which to finance day-to-day needs is income generated from employment. Another potential source could be transfers. Private transfers can take the form of cash and gifts received from family and friends or income earned from physical and financial assets. Public transfers include aid received from any of the social programs listed in the questionnaire. This population could also be adopting other measures to make ends meet, such as self-production of food or receiving food in the form of gifts from family or friends, highlighting the importance of solidarity in the community. Finally, a possibility also exists that the household engages in primary sector economic activities such as agriculture, rearing of animals, collecting wood or performing other forestry activities, and fishing. Table 1.11 shows each of these different possibilities and sources. Results indicate that 72 percent of the nonpoor and 46 percent of poor rely on labor income, as one or more of its members is employed. Primary sector activities such as agriculture, forestry and fishing are less prevalent than owning and/or raising animals. About 30 percent of the poor population own animals, whose by-products are presumably consumed directly by them and/or sold. About 11 percent of the poor also produce their own food. In terms of transfers, the poor are more likely to rely on both private and public transfers to finance their consumption than nonpoor households. Overall, about 81 percent of the nonpoor and 72 percent of the poor engage in any income generating activities.

\section{TABLE 1.11 Percentage of Population with Access to Any Source to Finance Consumption}

\begin{tabular}{|c|c|c|c|}
\hline Sources of income & Nonpoor & Extreme poor & Total \\
\hline Any adult (15 years and older) employed in household & $72 \%$ & $46 \%$ & $67 \%$ \\
\hline Engages in agriculture, gardening, forestry, or fishing & $1 \%$ & $5 \%$ & $2 \%$ \\
\hline Owns animals/engages in animal rearing & $6 \%$ & $30 \%$ & $11 \%$ \\
\hline Food is self-produced & $10 \%$ & $11 \%$ & $10 \%$ \\
\hline Public transfer & $5 \%$ & $7 \%$ & $6 \%$ \\
\hline Private transfers & $10 \%$ & $9 \%$ & $10 \%$ \\
\hline Any of the above income-generating activities & $81 \%$ & $72 \%$ & $79 \%$ \\
\hline \multicolumn{4}{|l|}{ Other sources and coping strategies } \\
\hline Any household member retired or recently unemployed & $6 \%$ & $3 \%$ & $6 \%$ \\
\hline Food received as gift & $5 \%$ & $8 \%$ & $6 \%$ \\
\hline Employing money-generating coping strategies & $8 \%$ & $19 \%$ & $10 \%$ \\
\hline \multicolumn{4}{|l|}{ Any of the above } \\
\hline Sources of income, other sources and coping strategies & $84 \%$ & $78 \%$ & $83 \%$ \\
\hline
\end{tabular}

Source: Calculations using EDAM4-IS

Note: The variable "any of the above sources" includes several sources: any adult (15 years and older) employed in the household; any household member who is retired or has become unemployed in the past two months; household using other money-generating coping strategy; households receiving private transfers or transfers from government social programs; households engaging in self-production of food or receiving it as a gift; households engaging in agriculture, gardening, forestry, or fishing activities; and households owning or engaging in animal rearing. 
In addition to income-generating activities, other monetary and in-kind resources may be available to the population. A household might finance consumption by relying on income from retired members and/or from severance payments of those who recently became unemployed. Only a small percentage of households use this source of income. Some households may also resort to informal networks and certain coping mechanisms to generate money. About 8 percent of the poor population declare receiving food as gifts. At the same time, an important share of the poor population appears to rely on such coping strategies as selling assets, borrowing, buying food on credit, and begging, among others, to generate income, providing further evidence of their vulnerability. No explanation regarding the source of financing is found for about 22 percent of the poor population in the different sections covered by EDAM4IS survey. These results likely underrepresent the set of available income sources for households. Other potential ways to make ends meet that may not have been accurately captured in the survey due to underreporting include pursuing illegal activities, having children earn income (child labor), or performing very infrequent tasks or jobs.

\section{TRENDS IN WELL-BEING}

In this section, the evolution of welfare in Djibouti in recent years is investigated as a way to understand whether economic growth - through capital accumulation, mostlyhas led to tangible improvements in the livelihood of the Djiboutian population. The main results use information from the EDAM 2012-the most recent nationwide data collection effort for a household consumption survey. The focus is on nonmonetary dimensions and the perceptions of the population on what is happening in their community. Regarding monetary welfare, an attempt is made to compare poverty rates using EDAM-BC 2013 and 2017. However, given the differences in the questionnaire and the poverty measurement methodology, this exercise faces issues and should be considered suggestive at best.

\section{COMPARING NONMONETARY INDICATORS OVER TIME}

While monetary measures may be hard to compare across survey rounds, due to changes made to the questionnaire as well as the change in methodology to calculate poverty, it is still possible to compare nonmonetary indicators of well-being, such as access to services, amenities, and assets. The similar coverage of the surveys, as well as the ability to define the indicators in a similar way, provide confidence on their comparability across time. The evolution of these nonmonetary indicators would help us emphasize the trends in the evolution of welfare of the Djiboutian population in the context of high economic growth that the country has experienced in recent years.

Survey data from 2012 and 2017 suggest that the Djiboutian population experienced improvements in wellbeing. Unfortunately, regional disparities that emerged previously are also found among nonmonetary indicators, with regions further away from the capital city performing worse. Furthermore, as evidenced by data from 2012 and 2017, improvements of recent years had limited effects in closing the gaps (Figure 1.14). The Tadjourah region appears to have the worst access to services, followed by Obock and Dikhil in both years. Only onefifth of the population has access to electricity in the regions of Tadjourah, Dikhil, and Obock, and this has hardly changed over time. In Djibouti city, access to water has improved and is almost universal. Djibouti city is followed by Ali Sabieh and Arta-a higher percentage of the population declared having access to water in these regions in 2017 as compared to 2012, too. Improvements are observed in other regions, also, with the exception of Tadjourah. It seems that proximity to the capital and the predominance of a rural population are important indicators that can help explain the difference in access to services between regions. In addition, it is found that these improvements in access are highest for the bottom two quintiles of the population. 


\section{FIGURE 1.14 Access to Services, by Year (percent of population)}

a. Access to electricity

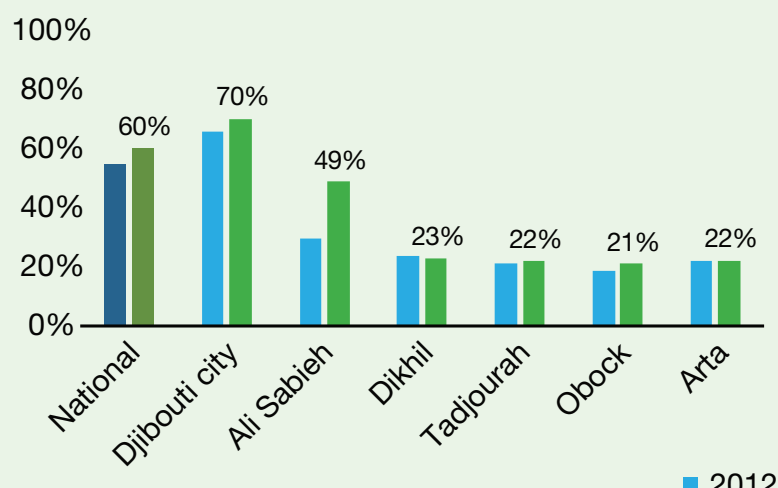

b. Access to improved water sources

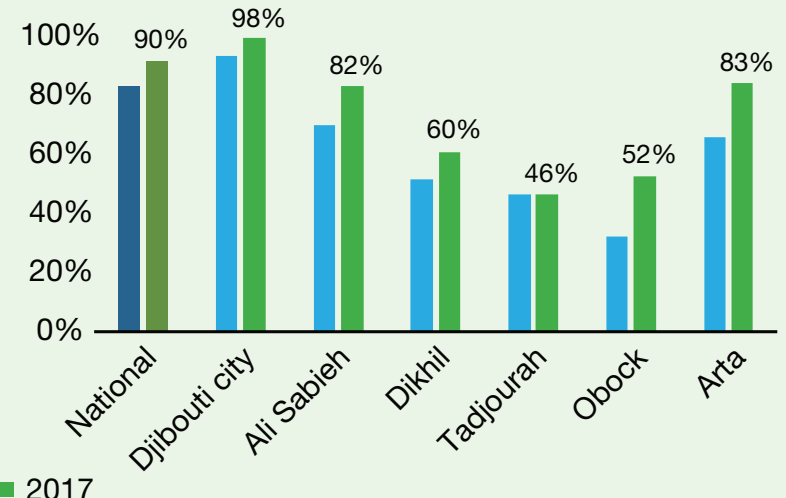

Source: Calculations based on EDAM 2012 and EDAM4-IS.

Note: Access to electricity reflects the use of electricity as the main source of lighting. Access to water in 2017 and 2012 is defined as availability of water in running water (ONEAD indoor connection) and ONEAD outdoor connection by pipe, public fountain, and borehole (with a pump). Access to water in 2017 had one additional category that was not included in 2012-direct connection from a borehole.

\section{FIGURE 1.15 Dwelling Characteristics and Access to Goods, by Year (percent of population)}

a. Living in a tent, spontaneous habitat, others

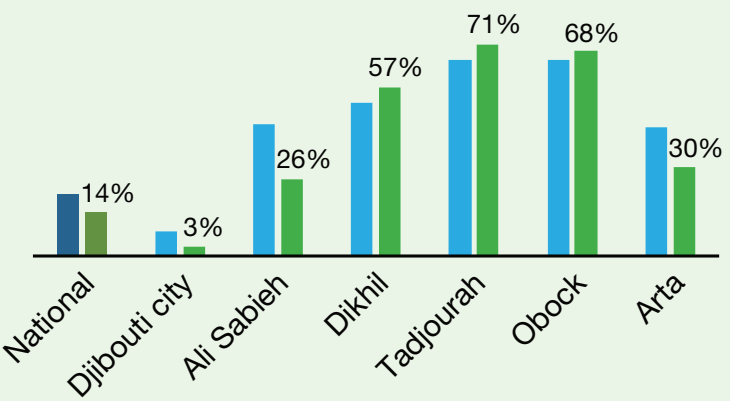

c. Cement as material of floor

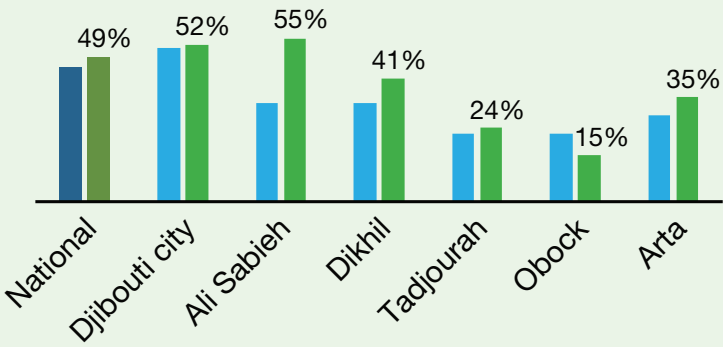

b. Sheet metal as material of roof

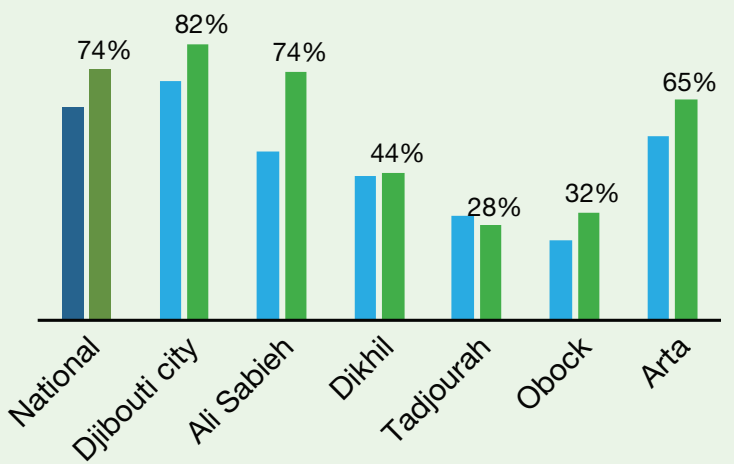

d. Ownership of mobile phone

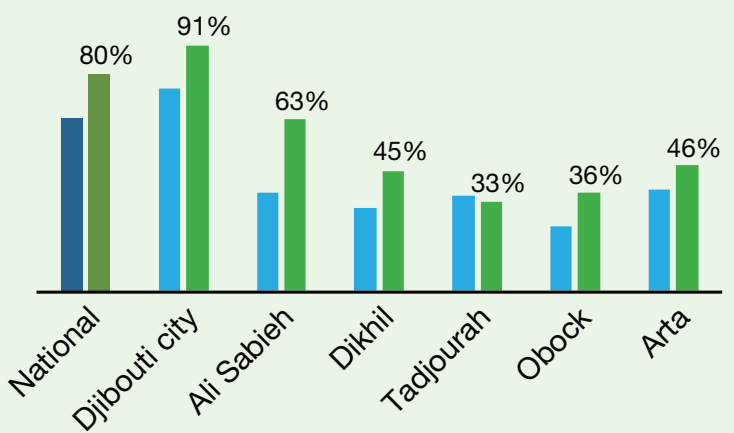

- 2012 - 2017 
Dwelling characteristics also reflect improvements over time and are consistent with earlier regional patterns (Figure 1.15). It is found that a lower percentage of the Djiboutian population is living in tents or spontaneous habitats in 2017 as compared to 2012. There is also a higher proportion of the Djiboutian population living in houses with sheet metal roofs. These results are largely driven by the capital city, Ali Sabieh, and Arta. It seems that many of these characteristics have not changed in Tadjourah, Dikhil, and Obock. The percentage of the population living in dwellings with a cement floor has also increased, pointing to the fact that the precarity of the dwellings has decreased. A higher penetration of mobile phones is also found across all the regions of Djibouti, with the exception of Tadjourah. This percentage increased from 64 percent in 2012 to 80 percent in 2017.
To complement this section, we explore whether the improvements observed in access to services, dwelling characteristics, and to some extent accumulation of assets are also reflected in people's perceptions. We exploit a perception question related to the evolution of poverty in a household's community that was asked both in a 2012 survey and in EDAM4 in 2017. Along the lines of the indicators just shown, there seems to be a positive perception about the evolution of poverty in 2017 as compared to 2012 (Table 1.12). About a third of the population perceived a reduction in poverty in the previous five years and expected continuing improvement in the next five years in 2017, as compared to 13 percent in 2012.

About 41 percent perceived that poverty would decrease in the next five years, while only 25 percent believed so in 2012. Thus, overall, there seems to be an expectation or perception of things getting better in 2017, compared to 2012.

\section{TABLE 1.12 Perceptions on the Evolution of Poverty (percent population by response category)}

\section{a. 2017}

\begin{tabular}{|c|c|c|c|c|c|c|} 
& \multicolumn{3}{|c|}{ "In the next five years, do you think poverty } \\
in your community will .."
\end{tabular}

\section{b. 2012}

\begin{tabular}{|c|c|c|c|c|c|}
\hline & \multicolumn{5}{|c|}{$\begin{array}{l}\text { "In the next five years, do you think poverty } \\
\text { in your community will ...." }\end{array}$} \\
\hline & & Decrease & Be the same & Increase & Total \\
\hline \multirow{4}{*}{$\begin{array}{l}\text { "In the past five years, do you } \\
\text { think that in your community } \\
\text { poverty has. . ." }\end{array}$} & Decreased & 13 & 3 & 1 & 17 \\
\hline & Not changed & 4 & 14 & 6 & 24 \\
\hline & Increased & 7 & 7 & 45 & 59 \\
\hline & Total & 25 & 23 & 52 & 100 \\
\hline
\end{tabular}

Source: For panel a, calculations based on EDAM4-IS. For panel b, calculations are based on EDAM 2012.

Notes: Only households that answered both questions were included: for panel a, 3,480 households; for panel b, 3,436 households. 
The positive expectations of the population, as reflected by subjective indicators could be driven by the known improvements in access to services, dwellings characteristics, and certain spillovers from the high growth rates Djibouti experienced in recent years. Thus, perceptions at the national level may also be composed of heterogeneous views across groups of the population. If economic growth has been concentrated in only certain groups (as it can happen in high-inequality contexts), then one could expect that expectations in the bottom of the distribution may be less optimistic than the average. Breaking down the indicator on perceptions of poverty by location shows evidence of these disparities. The positive prospects about poverty between 2012 and 2017 are driven by residents of Djibouti city (Table 1.13). In 2012, 53 percent of those residing in Djibouti city thought that poverty would increase in the next five years. However, in 2017, this share had halved to 24 percent. Much less improvement in positive perceptions was seen for those living in regions.

\section{TABLE 1.13 Perceptions on the Evolution of Poverty by Location and Year}

\section{In the next five years, do you think poverty in your community will . . .}

\begin{tabular}{|c|c|c|c|c|c|c|c|c|c|}
\hline \multicolumn{10}{|c|}{$\begin{array}{ll}\text { a. } 2017\end{array}$} \\
\hline & & \multicolumn{4}{|c|}{ Djibouti city } & \multicolumn{4}{|c|}{ Regions } \\
\hline & & 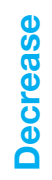 & 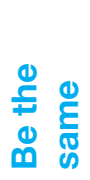 & 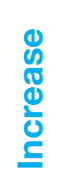 & $\begin{array}{l}\overline{\sqrt{0}} \\
\text { 음 }\end{array}$ & 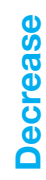 & 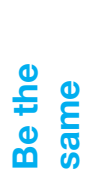 & 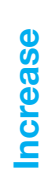 & $\begin{array}{l}\overline{\widetilde{\pi}} \\
\text { 으 }\end{array}$ \\
\hline \multirow{4}{*}{$\begin{array}{l}\text { "In the past five } \\
\text { years, do you } \\
\text { think that in } \\
\text { your community } \\
\text { poverty has. . . ." }\end{array}$} & Decreased & 37 & 3 & 0 & 40 & 13 & 4 & 3 & 20 \\
\hline & Not changed & 4 & 23 & 3 & 30 & 9 & 19 & 5 & 33 \\
\hline & Increased & 4 & 5 & 20 & 29 & 6 & 9 & 32 & 47 \\
\hline & Total & 45 & 30 & 24 & 99 & 27 & 33 & 40 & 100 \\
\hline
\end{tabular}

\section{b. 2012}

\begin{tabular}{|c|c|c|c|c|c|c|c|c|c|}
\hline & & \multicolumn{4}{|c|}{ Djlbouti city } & \multicolumn{4}{|c|}{ Regions } \\
\hline & & 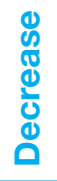 & 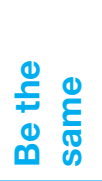 & 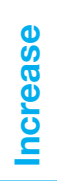 & $\begin{array}{l}\bar{\Phi} \\
\text { 믐 }\end{array}$ & 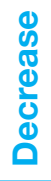 & 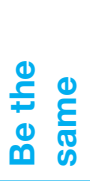 & 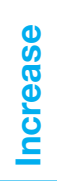 & $\begin{array}{l}\text { त्ञ } \\
\text { 음 }\end{array}$ \\
\hline \multirow{4}{*}{$\begin{array}{l}\text { "In the past five } \\
\text { years, do you } \\
\text { think that in } \\
\text { your community } \\
\text { poverty has . . ." }\end{array}$} & Decreased & 12 & 3 & 1 & 16 & 16 & 1 & 2 & 18 \\
\hline & Not changed & 4 & 5 & 7 & 16 & 5 & 5 & 4 & 14 \\
\hline & Increased & 5 & 6 & 45 & 56 & 15 & 9 & 44 & 67 \\
\hline & Total & 21 & 15 & 53 & 89 & 35 & 15 & 50 & 100 \\
\hline
\end{tabular}

Source: Calculations based on EDAM4-IS and EDAM 2012.

Notes: Only households who answered both questions were included (3,480 households in 2017 and 3,436 in 2012). Cells correspond to the percentage of the population. 


\section{COMPARING MONETARY MEASURES ACROSS EDAM3-IS (2013) AND EDAM4-IS (2017)}

There have been many changes in the poverty measurement methodology among the various household consumption surveys implemented Djibouti (see Box 1.2). This hinders the ability to make straightforward comparisons of data from multiple rounds of surveys, as is typically done in other contexts. Comparing welfare over time and understanding whether the living standards of the Djiboutian population have improved over time requires making strong assumptions in the production of estimates. In this subsection, an attempt is made to study the evolution of poverty by adjusting the welfare aggregates and poverty lines over the years to make them comparable. The results must be considered at best illustrative and not conclusive of the evolution of monetary welfare in Djibouti.

There are several reasons why welfare and poverty rates in 2017 are not comparable to those in 2013. The key points related to the noncomparability of data are as follows:

1. Complementarity: The EDAM-BC survey was administered only in Djibouti city in 2013. However, to produce national estimates, data from EDAM3IS conducted in 2012 was used to supplement the expenditure information for regions and rural areas. The process that was used to implement this adjustment is unclear.

\section{Food consumption: For EDAM-BC 2013, a} log or diary was used instead of recall to collect consumption data. At the same time, information on a much more detailed list of articles was collected during the data collection (it was possible to register more than 200 food items). In EDAM4-IS 2017, consumption of 100 food items was collected using a seven-day recall period. As noted in Backiny-Yetna, Steele, and Djima (2014) and Ahmed Brzozowski, and Crossley (2006), these differences in the data collection process may lead to differences in the actual data collected.
3. Nonfood consumption: Like the food aggregate, there were significant differences in the data collection method and the level of detail of nonfood items. For EDAM-BC 2013, a log or diary was used to collect consumption data instead of recall, which was used in EDAM4-IS. In EDAM-BC 2013, more than 500 nonfood items were collected at different recall periods. This included expenditures on health, education, electricity, and water. However, in EDAM4-IS, these expenditures were moved to different sections and hence were better placed in the questionnaire.

4. Durables: In EDAM-BC 2013, the purchase value of durable goods acquired by the household during the reference year was included in the welfare aggregate. In contrast, the welfare measure obtained in EDAM4 incorporated an estimate of the flow of services from the current market value of each durable good. To account for this difference, expenditures on durables in both 2013 and 2017 are not included.

5. Temporal adjustments: Welfare and poverty lines are estimates in current prices for each survey round and represent the cost of basic needs at the time of implementation. Adjustments are required to take into account differences over time in the cost of living in the country.

There is no bulletproof way to convincingly address all the points just noted. Instead, this exercise provides a set of alternative assumptions that would lead to the estimation of pseudo-comparable welfare aggregates and poverty lines for both 2013 and 2017. This yields four imperfect approaches:

Approach 1: Using data from EDAM-BC 2013, a basic cost of needs approach was adopted to define food and total poverty lines in 2013. A similar methodology was used in EDAM4-IS 2017, and the poverty lines were defined based on the consumption basket of the Djiboutian population in 2017. In 
order to make poverty lines comparable, the food poverty line in 2017 is adjusted by 11.3 percent and the nonfood part is adjusted by 0.54 percent, corresponding to temporal adjustments between May 2013 and May 2017.

Approach 2: The poverty line of 2017 is used and the food part of the welfare aggregate in 2013 is adjusted by 11.3 percent and the nonfood part is adjusted by 0.54 percent, corresponding to temporal adjustments between May 2013 and May 2017.

Approach 3: In order to make poverty lines comparable, the food poverty line in 2017 is adjusted by 11.3 percent and the nonfood part is adjusted by 0.54 percent, corresponding to temporal adjustments between May 2013 and May 2017. There is no consensus in the literature as to the magnitude as well as the direction of the difference with respect to diary and recall as a mode of collecting food expenditures. While some research reports higher expenditures using a diary method, others report the opposite.
Thus, the food expenditures in 2013 are adjusted by increasing them by 10 percent.

Approach 4: Following the same adjustments is approach 3, the final approach allows the food expenditures in 2013 to be adjusted downward. Food expenditures in this approach are adjusted by decreasing them by 5 percent.

Figure 1.16 presents the results for poverty rates in Djibouti city of all four approaches. To the extent that the welfare aggregates are comparable, it is found that the extreme poverty rate seems to have dropped in Djibouti city between 2013 and 2017, irrespective of the approach applied. Under approaches 2 and 4, there appears to have been a drop of about 5 percentage points, whereas under approach 3 the decrease is of about 2 percentage points. Considering all the caveats, this may be interpreted as suggestive evidence that, similar to the results shown in the section on nonmonetary indicators, the living standards of the Djiboutian population may have improved slightly in the past few years.

\section{FIGURE 1.16 Comparison of Poverty Rates between 2013 and 2017, Djibouti City}

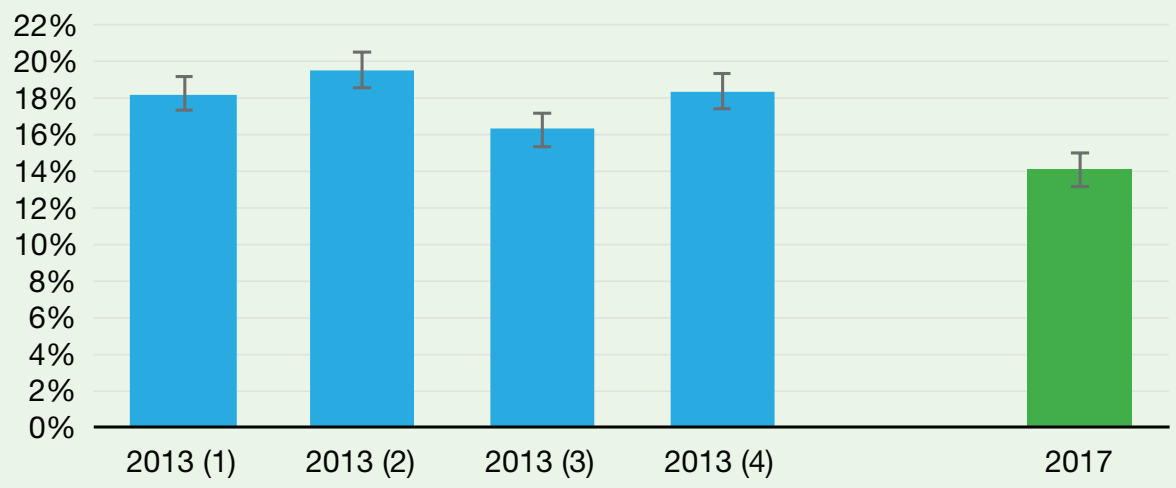

Source: Calculations based on EDAM3-BC and EDAM4-IS.

Notes: The approach used for 2013 estimation is labeled in parenthesis. See text for explanation of the approaches. In approach 1, the food poverty and the nonfood poverty lines in 2017 are adjusted separately, corresponding to temporal adjustments between May 2013 and May 2017. In approach 2, the welfare aggregate of 2013 is temporally adjusted separately for food and nonfood parts, and the poverty line of 2017 is used. In approach 3, food expenditures are increased by 10 percent. In addition, the food poverty and the nonfood poverty lines in 2017 are adjusted separately, corresponding to temporal adjustments between May 2013 and May 2017. In approach 4, food expenditures are decreased by 5 percent In addition, the food poverty and the nonfood poverty lines in 2017 are adjusted separately, corresponding to temporal adjustments between May 2013 and May 2017. Vertical bars show confidence intervals. 


\section{INEQUALITY IN DJIBOUTI}

To provide a better view of welfare and development in the country, it is important to understand the depth of inequality. As discussed in the literature, there are several reasons to worry about inequality. For instance, inequality can be associated with lower growth, and policies that tackle inequality may turn into the main drivers of poverty reduction, especially as economies reach higher levels of development (Olinto, Lara Ibarra, and Saavedra-Chanduvi 2014; Marrero and Serven 2018; Brueckner and Lederman 2015). In order to continue promoting poverty reduction at the pace needed to meet SDG 1, it will be as important to enact policies that help tackle inequality as policies that boost economic growth. Inequality has also been shown to be correlated with negative well-being perceptions, to lead to social tensions (Cramer 2003), and in some cases be concurrent with low mobility (Dang and lanchovichina 2018). While the disparities in levels of consumption presented so far provide evidence that there are certain segments of the population that continue to live in extreme poverty and have lower outcomes in other nonmonetary indicators, it is still important to assess the magnitude of some of these systemic and structural barriers to evaluate how excluded certain vulnerable groups are.

We begin by showing (traditional) indicators related to monetary poverty, before presenting results on the population's subjective perception about well-being. As a complement, we also discuss inequality form the angle of disparities in access to opportunities for children. The section concludes with an in-depth look at the gaps in well-being between the poor of urban and nonurban areas.

\section{MONETARY INEQUALITY}

The welfare aggregate obtained from EDAM4 is helpful in understanding monetary inequality in Djibouti. Following common practice, we use per capita consumption to explore differences in consumption levels across the population, as opposed to the per adult equivalent measure that was used to measure poverty in the earlier sections. There are wide disparities in the levels of wellbeing of Djiboutian population. Figure 1.17 shows the annual consumption per capita by decile. The population of the richest decile has an estimated per capita consumption level that is more than 16 times the average household consumption in the first decile. In addition, the richest decile has a consumption twice as high per capita as the 9th decile. Figure 1.18 also highlights these disparities in consumption per capita geographically. Mirroring high poverty rates, rural areas have the lowest consumption per capita, less than half of the national average. Djibouti city has a high consumption per capita, although disparities exist. The fourth and the fifth districts of the capital city together make up the area of Balbala, which has the lowest consumption per capita.

\section{FIGURE 1.17 Annual Consumption per Capita, per Decile}

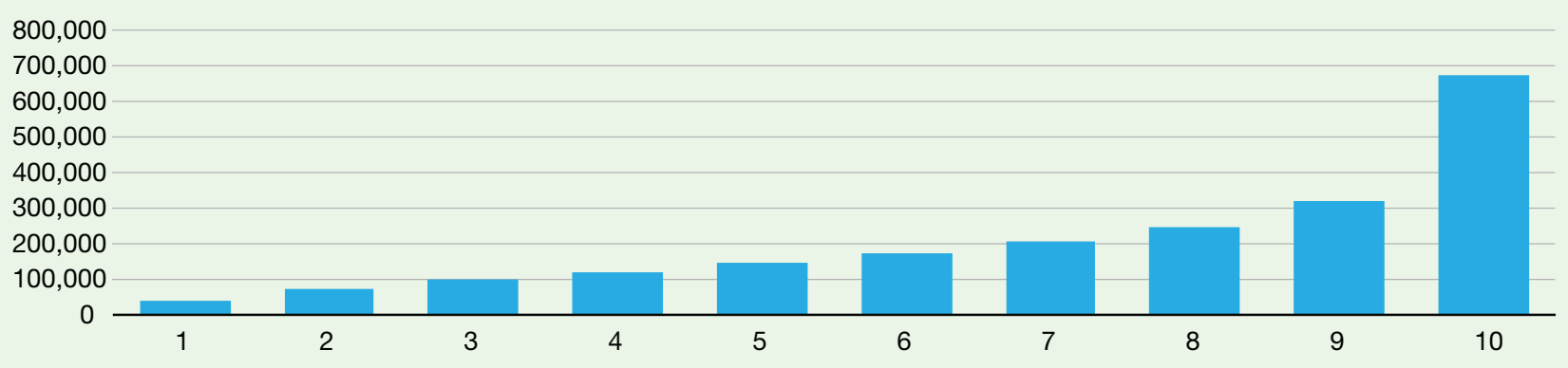

Source: Calculations based on EDAM4-IS.

Note: Deciles are calculated based on per capita consumption. 


\section{FIGURE 1.18 Annual Consumption per Capita, across Regions and Districts of Djibouti City (DF)}

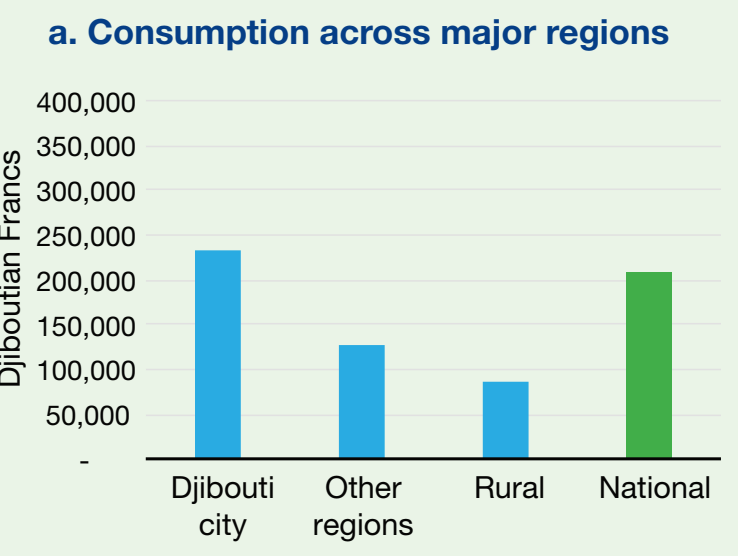

Source: Calculations based on EDAM4-IS.

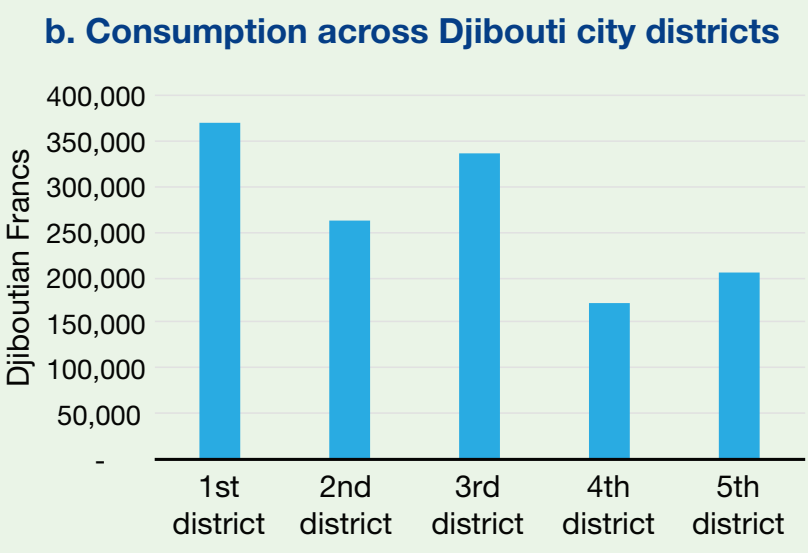

The Gini coefficient of the consumption per capita distribution is estimated at 0.42 (Table 1.14). It is notable that, compared to the capital city, the rest of the country has higher levels of inequality - probably linked to the marked differences between the main cities in the regions and the welfare levels in the region's rural areas. Within regions, Tadjourah and Dikhil show the largest monetary inequality as measured by the Gini coefficient. Also, these regions show the largest disparities between the 90th and the 10th percentile of consumption per capita. In Tadjourah, households in the 90th percentile have a consumption level 8.2 times higher than those in the 10th percentile. In Dikhil, this ratio stands at 7.6.

We make an attempt to study the evolution of inequality by adjusting the welfare aggregates between 2013 and 2017 to make them comparable for Djibouti city only. In EDAM-BC 2013, the purchase value of durable goods acquired by the household during the reference year was included in the welfare aggregate. In contrast, the welfare measure obtained in EDAM4 incorporated an estimate of the flow of services from the current market value of each durable good. To account for this difference, expenditures on durables in both 2013 and 2017 are not included in the welfare aggregate for the purpose of this analysis. Next, the food part of the welfare aggregate in 2013 is adjusted by 11.3 percent and the nonfood part is adjusted by 0.54 percent, corresponding to temporal adjustments between May 2013 and May 2017. Nevertheless, the results presented must be considered as illustrative and not conclusive of the evolution of inequality in Djibouti. We find a very slight decline in the Gini coefficient in 2017 in Djibouti city as compared to in 2013 (Table 1.14).

A decomposition of inequality using the Theil index shows that the majority of inequality in Djibouti is coming from disparities in consumption in the capital city. With a nationallevel Theil index estimated at 0.326, inequality within Djibouti city explains about 78 percent of this inequality. Inequality between the capital, other urban areas, and the rural areas explain about 5 percent of total inequality. ${ }^{19}$ Focusing only in the capital, districts 2 and 5 explain the largest share of inequality in Djibouti city, representing 23.7 percent of total inequality each. This results from the combination of (relatively) high population shares, high share of total aggregate consumption, and high inequality.

19 This does not imply that inequality is low in each of the regions, but that its contributions to total inequality are low 
TABLE 1.14 Indicators of Inequality

a. By location

\begin{tabular}{l|c|c|c|c|c|} 
& National & Djibouti city & Other regions & Other urban & Rural \\
\hline Gini & 0.42 & 0.40 & 0.42 & 0.34 & 0.38 \\
\hline p90/p10 & 6.70 & 5.51 & 8.20 & 5.51 & 6.18 \\
\hline p90/p50 & 2.53 & 2.52 & 2.83 & 2.23 & 2.42 \\
\hline p10/p50 & 0.38 & 0.46 & 0.35 & 0.41 & 0.39 \\
\hline p75/p25 & 2.52 & 2.34 & 3.04 & 2.27 & 2.43 \\
\hline
\end{tabular}

b. By region

\begin{tabular}{l|c|c|c|c|c|c|} 
& Djibouti city & Ali Sabieh & Dikhil & Tadjourah & Obock & Arta \\
\hline Gini & 0.40 & 0.33 & 0.42 & 0.52 & 0.38 & 0.30 \\
\hline p90/p10 & 5.51 & 6.52 & 7.68 & 8.27 & 7.51 & 5.62 \\
\hline p90/p50 & 2.52 & 2.24 & 2.56 & 2.79 & 3.09 & 2.47 \\
\hline p10/p50 & 0.46 & 0.34 & 0.33 & 0.34 & 0.41 & 0.44 \\
\hline p75/p25 & 2.34 & 2.80 & 2.92 & 2.90 & 3.08 & 2.47 \\
\hline
\end{tabular}

c. Comparison of Gini coefficient over time, Djibouti city

\begin{tabular}{l|l|l} 
& 2017 & 2013 \\
\hline Gini coefficient & 0.396 & 0.406 \\
\hline
\end{tabular}

Source: Calculations using EDAM3-BC and EDAM4-IS.

Notes: p90/p10 shows the ratio of per capita consumption of individuals from the 90th percentile to those from the 10th. Percentiles are calculated based on per capita consumption

\section{FIGURE 1.19 Gini Coefficient across the World, circa 2015}

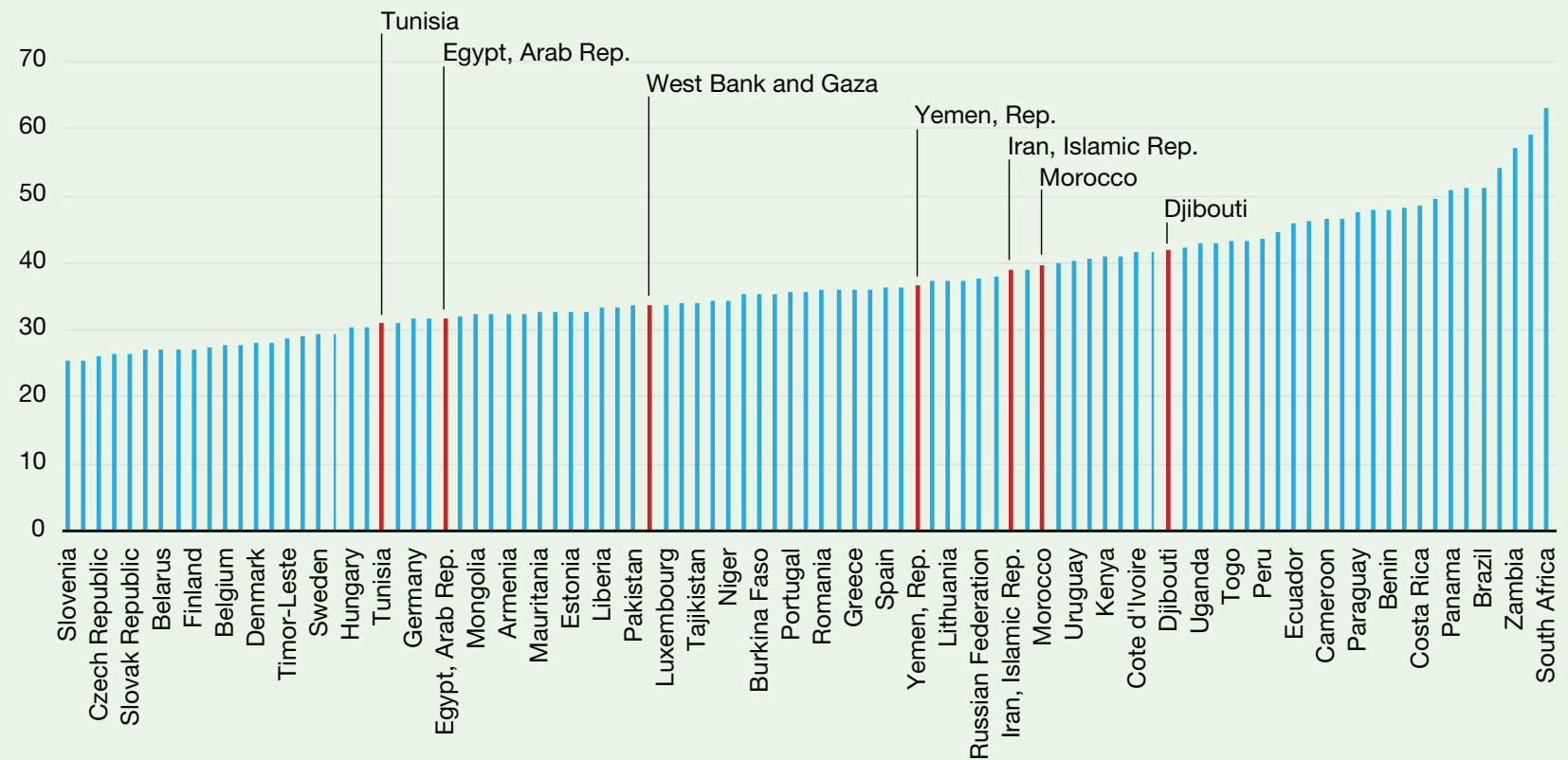

Source: WDI, accessed October 19, 2018; and EDAM4-IS. 
Using consumption data from EDAM4, we calculate the Gini coefficient for Djibouti and compare it to Gini coefficient for 95 countries as obtained from the World Development Indicators website (Figure 1.19). The coefficients are obtained from country surveys circa 2015. Djibouti is in the 71st place out of the 95 countries shown. Monetary inequality in the country, as measured by the Gini coefficient, is higher than that of other Middle East and North Africa (MENA) countries and Ethiopia. Uganda has a similar estimated Gini (0.43).
The high monetary inequality indexes, as well as the disparities between urban and rural areas, provide suggestive evidence that the benefits from economic growth might be reaped by only certain segments of the population in Djibouti. As far as the evolution of inequality is concerned, there are no comparable consumption or income indicators over time that would allow a study. Nevertheless, changes in access to services and dwelling characteristics (as seen in the subsection on trends in well-being) could shed some light in this regard. Table 1.15

\section{TABLE 1.15 Access to Services, By Quantiles}

\begin{tabular}{l|c|c|c|c|c|c||c|c|}
\multicolumn{1}{l|}{} & \multicolumn{2}{c|}{$\begin{array}{c}\text { Access to } \\
\text { electricity }\end{array}$} & \multicolumn{2}{c|}{ Access to water } & \multicolumn{2}{c|}{$\begin{array}{c}\text { Appropriate } \\
\text { garbage disposal }\end{array}$} & \multicolumn{2}{c|}{$\begin{array}{c}\text { Access to public } \\
\text { sanitation network }\end{array}$} \\
\hline Quantiles & $\mathbf{2 0 1 2}$ & $\mathbf{2 0 1 7}$ & $\mathbf{2 0 1 2}$ & $\mathbf{2 0 1 7}$ & $\mathbf{2 0 1 2}$ & $\mathbf{2 0 1 7}$ & $\mathbf{2 0 1 2}$ & $\mathbf{2 0 1 7}$ \\
\hline 1 & $9 \%$ & $13 \%$ & $63 \%$ & $67 \%$ & $41 \%$ & $43 \%$ & $4 \%$ & $14 \%$ \\
\hline 2 & $33 \%$ & $45 \%$ & $86 \%$ & $91 \%$ & $59 \%$ & $79 \%$ & $11 \%$ & $23 \%$ \\
\hline 3 & $60 \%$ & $71 \%$ & $93 \%$ & $97 \%$ & $72 \%$ & $85 \%$ & $17 \%$ & $30 \%$ \\
\hline 4 & $80 \%$ & $81 \%$ & $94 \%$ & $98 \%$ & $78 \%$ & $90 \%$ & $20 \%$ & $29 \%$ \\
\hline 5 & $91 \%$ & $92 \%$ & $95 \%$ & $99 \%$ & $87 \%$ & $93 \%$ & $28 \%$ & $35 \%$ \\
\hline Total & $55 \%$ & $60 \%$ & $86 \%$ & $90 \%$ & $67 \%$ & $78 \%$ & $16 \%$ & $26 \%$ \\
\hline
\end{tabular}

Source: Calculations based on EDAM4-IS and EDAM 2012.

Notes: Quantiles are calculated based on per capita consumption. Access to electricity is defined as the use of electricity as the main source of lighting. Access to water is defined as the availability of water in the household in the form of running water (ONEAD indoor connection), direct connection from a borehole, ONEAD outdoor connection by pipe, public fountain and drilling (with a pump). Access to water in 2017 had one additional category that was not included in 2012-direct connection from a borehole. Appropriate garbage disposal is defined as availability of garbage collector-OVD (public dump), availability of garbage collector-private, and garbage deposited in a designated place. Access to public sanitation network was elaborated in 2017 to include public sanitation networks (trench, open concrete channel/slab, river network), and sanitation networks directly linked to the collective network from the house.

presents the evolution of nonmonetary indicators along the 2012 and 2017 consumption distribution points.

There seem to be large gains in access to electricity and appropriate garbage disposal in the middle deciles, while improvements in access to water are found throughout the consumption distribution. The highest gains in access to public sanitation network are found in the lower and middle deciles up until decile 9. The findings show that nonmonetary indicators saw improvements across the distribution without uniquely benefitting the richest.

Perceptions among members of the population about their own welfare and how they place themselves in the consumption distribution are closely tied to the perceptions around inequality. As far as the self-perceived welfare is concerned, as one moves from the bottom 20 percent (bottom quintile), or the poorest households, to the top 20 percent (top quintile), or the richest households, the declared welfare category in which the household places itself improves as well (Figure 1.20). For example, 39 and 44 percent of the bottom quintile perceive themselves to be very poor and poor, respectively. On the other hand, 62 percent of the top 20 percent perceive themselves to be middle class, while only 14 percent consider themselves to be rich or very rich. Thus, there seems to be some coherence between the distribution of the population across income groups according to both objective and subjective measures of welfare. 


\section{FIGURE 1.20 Self-Reported Welfare Category, by Quintiles of Consumption per Capita (percent)}

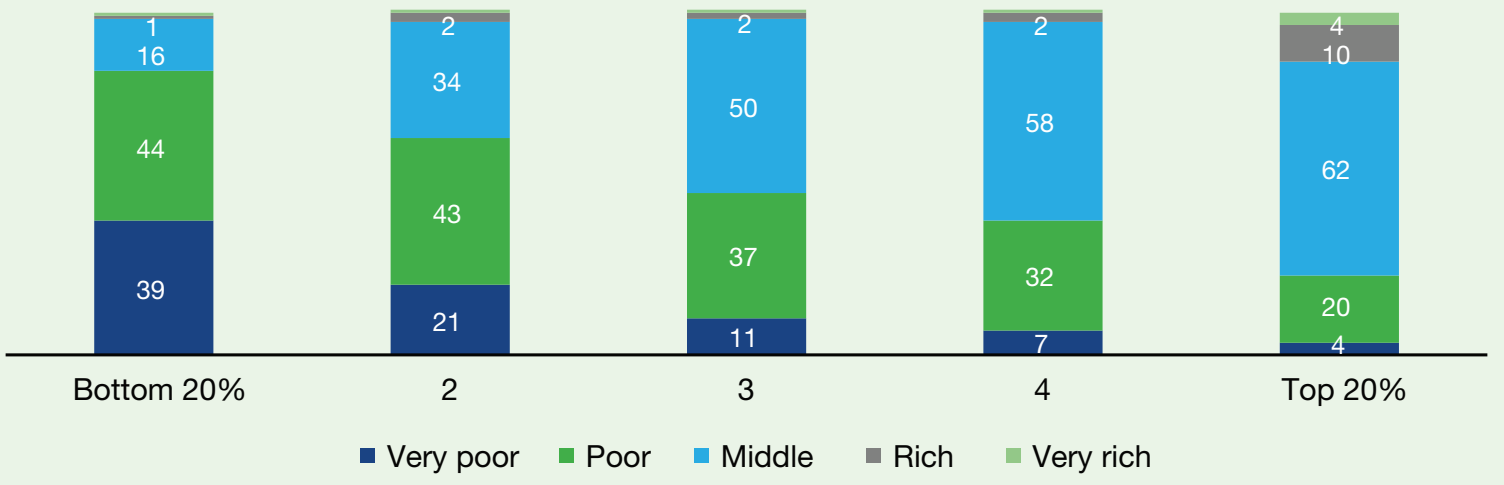

Source: Calculations based on EDAM4-IS.

Notes: Bottom 20 percent represents the first quintile of the consumption per capita distribution.

\section{DEPRIVATION IN DJIBOUTI: HUMAN OPPORTUNITY INDEX}

In addition to the conventional measures of well-being, such as poverty and inequality, it is worth investigating access to opportunities and resources among the vulnerable to assess mobility or the chances that they have to escape poverty and achieve outcomes at par with the rest of the population. Labor markets have been found to be crucial for mobility, in addition to access to essential services early on in life such as health, education, and infrastructure (Krishnan et al. 2016). The existence of inequality in opportunities may help explain the disadvantage that certain groups face that may determine outcomes later on in life.

To complement the view on inequality in Djibouti, we estimate the human opportunity index $(\mathrm{HOI})$ using the EDAM4-IS data, in line with the widely applied methodology found in the literature (Paes de Barros et al. 2009; Ferreira et al. 2008; Krishnan et al. 2016). This index rests on the principle that the circumstances into which a child is born should not determine his or her access to opportunities, where opportunities are basic goods or services that everyone would agree should be universal. Access (measured by coverage rates) paints only part of the picture of how a certain good or service is distributed across the population, especially when a particular subgroup of the population is consistently left out of coverage. The $\mathrm{HOl}$ is an index that starts with the coverage rate of a good or a service and applies a correction that reflects the extent to which coverage is equally distributed across different subgroups of the population (defined by circumstances like gender or location). The more that certain subgroups have lower coverage than the average, the higher the penalty and the lower the $\mathrm{HOI}$.

Table 1.16 provides a list of indicators chosen as the opportunities for children in Djibouti and the circumstances used to create the subgroups of interest. We follow the literature (Ferreira et al. 2008; Krishnan et al. 2016; Narayan et al 2018) in defining the opportunities set. Certainly, these should not be taken as a comprehensive list of the opportunities that should be available to a child to achieve his or her potential in life. The opportunities considered for the $\mathrm{HOl}$ estimation fall into three main categories: education, basic housing services, and 
household poverty. For education, we consider three opportunities: the ability to read and write, attendance or enrolment in school, and achievement of at least primary education. For basic housing services, access to a safe and improved water source, improved sanitation facilities (water closet with flush or latrine with slab, and not shared with other households), and electricity are the opportunities assessed. Water and sanitation are key drivers of public health, as they are known to reduce the incidence of diarrhea and its long-term consequences, such as malnutrition. Finally, we study the opportunity of a child to be raised in a family that is not multidimensionally poor, defined as a deprivation score less than 0.33. All the opportunities are analyzed for children ages 6 to 14 years, inclusive. The age reference for literacy is 10 to 14 years of age and completion of primary education is 12 to 16 years.

\section{TABLE 1.16 Opportunities and Circumstances Used in Human Opportunity Index Calculation}

\begin{tabular}{|c|c|c|}
\hline Category & Opportunity & Description \\
\hline \multicolumn{3}{|c|}{ Opportunities } \\
\hline \multirow[t]{3}{*}{ Basic housing services } & Water & Dwelling has improved water access (children ages 6-14 years) \\
\hline & Sanitation & Dwelling has improved sanitation access (children ages $6-14$ years) \\
\hline & Electricity & Dwelling has electricity (children ages $6-14$ years) \\
\hline \multirow[t]{3}{*}{ Education } & Literacy & Child can read and write (children ages 10-14 years) \\
\hline & Attending school & Child is currently attending school (children ages 6-14 years) \\
\hline & $\begin{array}{l}\text { Completed primary } \\
\text { education }\end{array}$ & $\begin{array}{l}\text { Child completed at least elementary school (children ages 12-16 } \\
\text { years) }\end{array}$ \\
\hline Household poverty & $\begin{array}{l}\text { Not multidimensionally } \\
\text { poor }\end{array}$ & $\begin{array}{l}\text { Child is not in a multidimensionally poor household (children ages } \\
6-14 \text { years) }\end{array}$ \\
\hline \multicolumn{3}{|c|}{ Circumstances } \\
\hline Child characteristics & Gender & Binary variable equals 1 if child is male \\
\hline \multirow[t]{3}{*}{ Household characteristics } & $\begin{array}{l}\text { Children in the } \\
\text { household }\end{array}$ & Number of members ages $0-14$ years living in the same household \\
\hline & Elderly presence & $\begin{array}{l}\text { Binary variable equals } 1 \text { if there is at least one household member } \\
\text { age } 65 \text { years or older }\end{array}$ \\
\hline & Single parent household & Binary variable equals 1 if household head's partner is not present \\
\hline \multirow[t]{3}{*}{ Head of household characteristics } & Age & Age of household head (years) \\
\hline & Educational attainment & $\begin{array}{l}\text { Education of father broken into four categories by level of } \\
\text { attainment }\end{array}$ \\
\hline & Public worker & $\begin{array}{l}\text { Binary variable equals } 1 \text { if household head works in the public } \\
\text { sector }\end{array}$ \\
\hline \multirow[t]{2}{*}{ Location } & Rural & Binary variable equals 1 if household is located in a rural community \\
\hline & Region & Series of binary variables that refer to region of residence \\
\hline Socioeconomic status & Consumption quintile & $\begin{array}{l}\text { Household consumption per capita mapped to a quintile of the } \\
\text { consumption per capita distribution in the country }\end{array}$ \\
\hline
\end{tabular}


We use a list of circumstances (that is, characteristics of a child that he or she cannot control) categorized into five main groups: child characteristics, household characteristics, household head's (or father's) characteristics, location, and socioeconomic status. The gender of the child is the first circumstance used. For household's characteristics, three circumstances are looked at: the number of children ages 0-14 years, the presence of at least one elderly member (age 65 years or older), and whether the household is headed by a single parent. For characteristics of the head of household, age and employment in public sector are used, as well as the educational attainment of the child's father. For location, urban or rural and region of residence are the circumstance groups. Socioeconomic status, defined as the wealth quintile (per capita expenditures) that a child is born into, is the last circumstance group.
Among the seven opportunities analyzed, improved water access has the highest coverage rate and $\mathrm{HOI}$ (Figure 1.21). The second highest "scores" are found in literacy, as 85 percent of all children in Djibouti ages 10-14 years are literate, with a corresponding inequality penalty of 4 percent. School attendance is still widely available among Djiboutian children (ages 6-14), with a coverage rate of 82 percent. In education, the lowest scores are found in completion of primary education, with a coverage of 68 percent and with access broadly distributed across all circumstance groups. In terms of dwelling facilities, access to improved sanitation and access to electricity are, not only limited, but unequally distributed among the population. Access to electricity as a basic service has the second highest penalty of circumstance groups out of all opportunities analyzed in this report, reaching an $\mathrm{HOI}$ of just 44 percent. Finally, about two-thirds of children are not "MPI poor," but there are large differences across circumstance groups: the $\mathrm{HOI}$ is only 51 percent.

\section{FIGURE 1.21 Coverage Rates and Human Opportunity Index for Children's Opportunities}

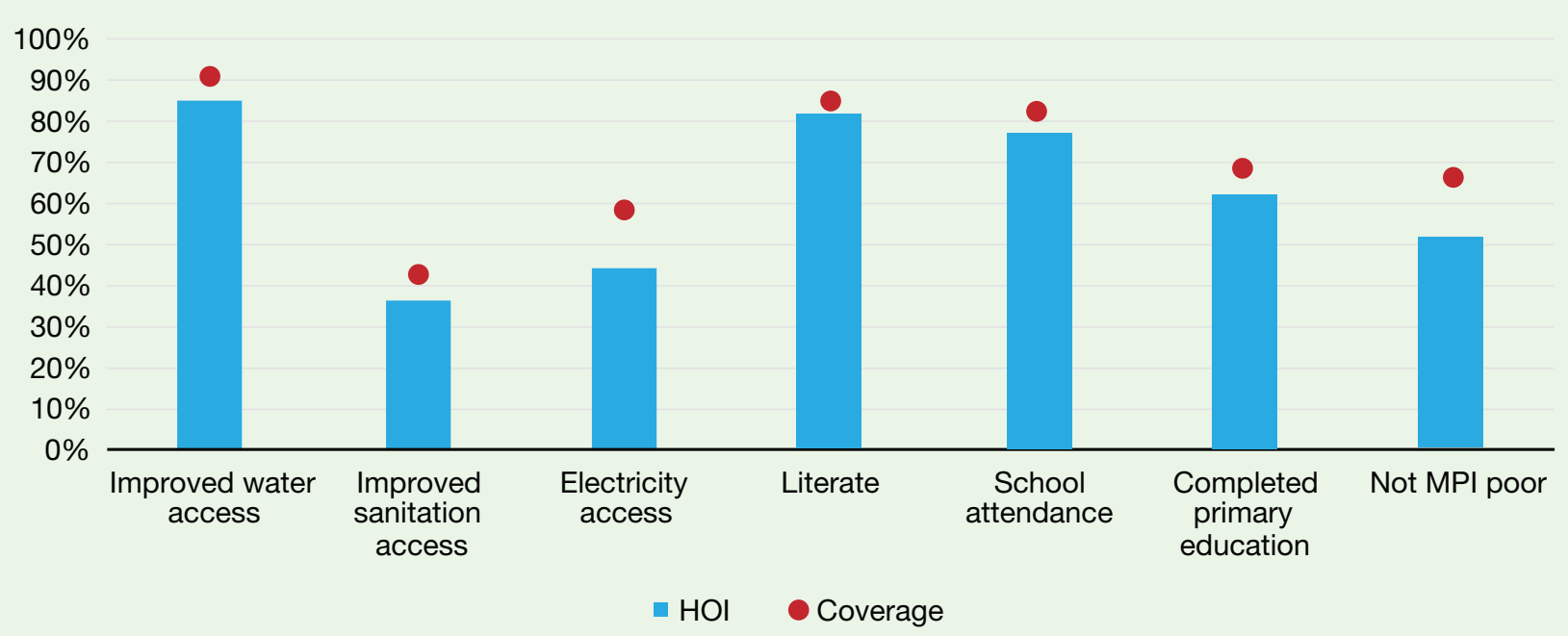

Source: Calculations based on EDAM4-IS.

Notes: Definition of opportunities in Table 1.16. 


\section{FIGURE 1.22 Inequality Decomposition of Disparities in Access to Opportunities}

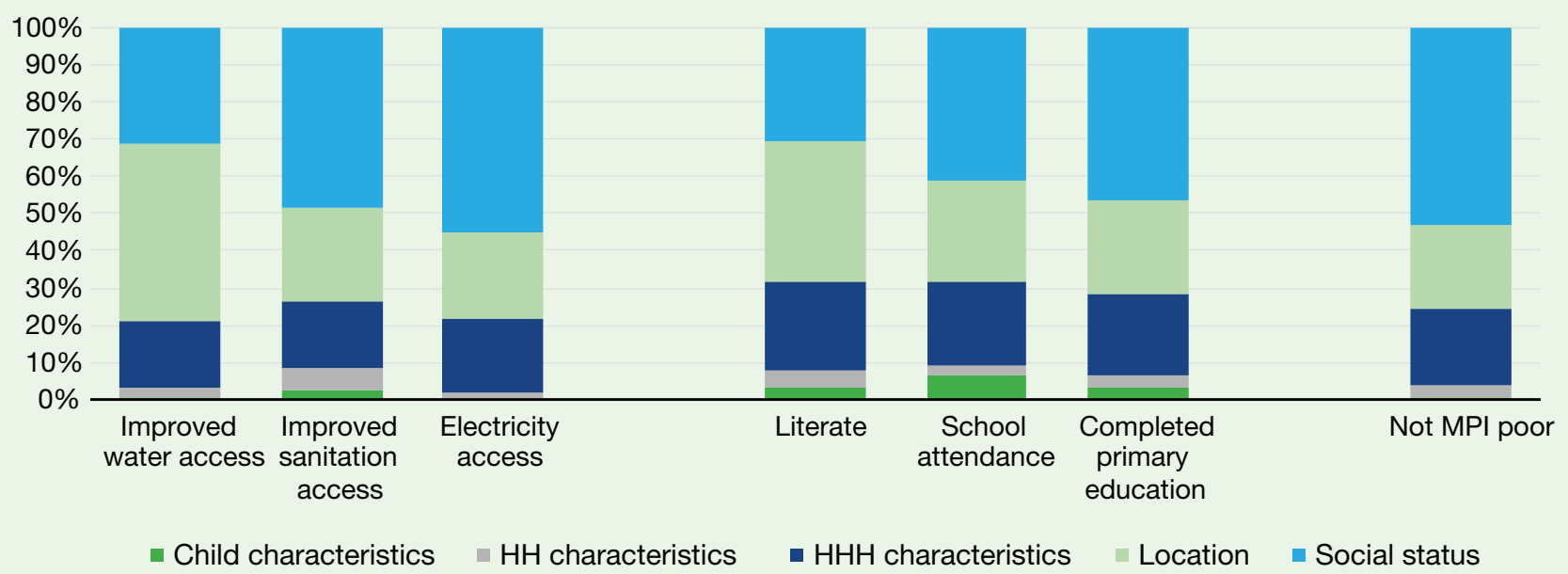

Source: Calculations based on EDAM4-IS.

Notes: Definition of opportunities in Table 1.16. $\mathrm{HH}=$ household; $\mathrm{HHH}=$ head of household.

To better understand the nature of the inequalities in the distributions of opportunities, a decomposition of the HOl's D-index is estimated to explain the marginal contribution of each circumstance to the overall inequality of opportunity. ${ }^{20}$ In general, socioeconomic status tends to explain the largest variation in inequality, followed by location and head of household characteristics (Figure 1.22). Child characteristics (gender) and household characteristics often explain little of the inequality in opportunity. However, inequality in literacy and school attendance are explained by household characteristics for 24 and 22 percent of their observed inequality, respectively. Socioeconomic status explains about 49 percent or more of inequality in access to sanitation, 55 percent in access to electricity, 53 percent in multidimensional poverty, and 46 percent completion of primary school. Location is the biggest determinant for lack of improved water access, and it explains between a third and a fourth of overall inequality in children's opportunities.
Improvements in educational outcomes such as school attendance and primary school completion appear to be linked to the income level of the household. Thus, efforts that improve economic opportunities - and hence the income-generating capacity of households - are likely to have second order effects on improving educational outcomes of those children and improving their potential for future income generation. Finally, improvements in provision of services in harder to reach rural areas in regions is an important policy action going forward.

\section{COMPARING THE URBAN POOR AND NONPOOR IN THE CAPITAL: THE CASE OF BALBALA}

The community of Balbala, comprising the fourth and fifth districts of Djibouti city, has experienced important transformations in recent years, including a major influx of people from both inside and outside the country. This demographic change can partly explain the proliferation of slums and, as described from anecdotal evidence, an increase in the demand for a wide range of services. An

20 Broadly speaking, the D-index denotes the percentage of goods and/or services that would have to be redistributed so that all circumstance groups would attain the same coverage. 
analysis of geospatial data via a building footprint-drawing exercise suggests that the population in these districts is denser than in other districts of Djibouti city. In addition, as shown in the analysis so far, there are marked disparities within the capital: the fourth and fifth districts show the lowest levels of consumption per capita, the highest poverty rates, and the highest poverty gaps (that is, the extreme poor are on average much further away from the poverty line than poor in other districts).

Other nonmonetary indicators provide further evidence of welfare gaps in this urban area. Figure 1.23 shows that households in Balbala are relatively more deprived than those in other areas of the city. Household groups in this commune are more likely to reside in a dwelling with dirt floors. They are less likely to own such assets as a refrigerator. Households in this area could also be more at risk to shocks. As evidenced by the consequences of tropical storm Sagar in May 2018, households in the capital are at risk of suffering from floods. Among households that self-report residing in an area that is prone to flooding, those in Balbala have a high risk of flooding occurring inside their home.
With poverty rates between 15.8 percent (fifth district) and 18.3 percent (fourth district), the Balbala community is host to about 37 percent of the poor population of the country. Thus, it is important to better understand the characteristics of the poor who reside in this area and to understand how they fare compared to the nonpoor residents in the neighborhood and in Djibouti city. We also contrast these characteristics with those of the poor and nonpoor population in rural areas to compare the opportunities in these two areas separately. Populations living in rural areas have lower consumption per capita on average and lack many amenities; there is a strong correlation between welfare and the prominence of rural population in the interior regions of the country. Since the urban environment is typically more affluent than rural areas, regions with a high proportion of the population living in rural areas have been shown to have weaker monetary and nonmonetary indicators when compared to more urbanized regions.

Table 1.17 presents a series of characteristics of the poor and nonpoor populations, differentiating among those living in Balbala, those in Djibouti city outside Balbala, and those

\section{FIGURE 1.23 Household Characteristics by District in Djibouti City}

\section{a. Percentage of households with dirt floors}

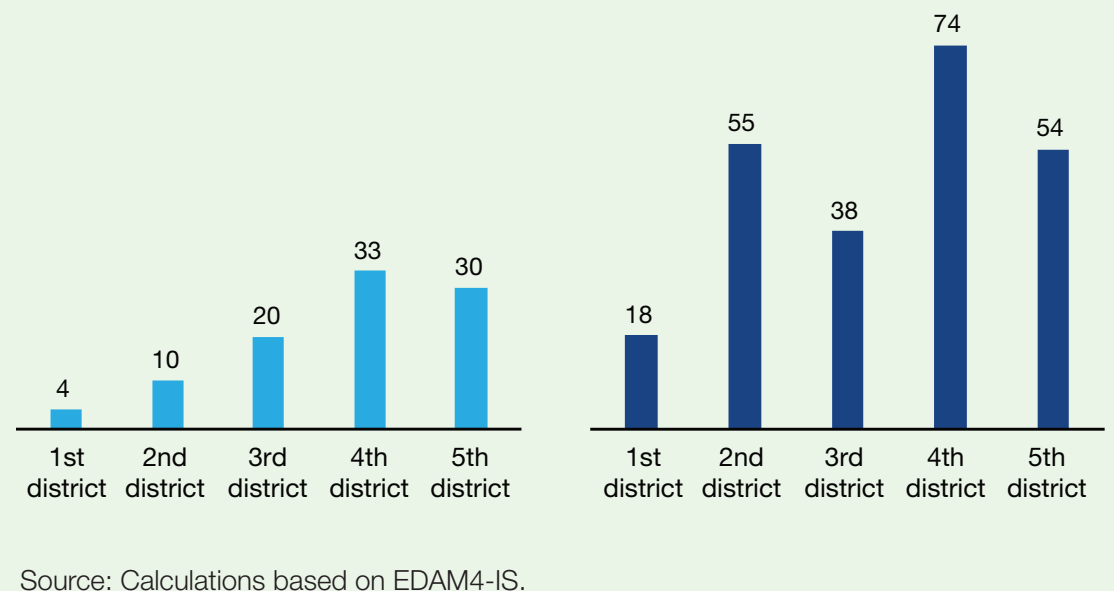

\section{b. Percentage reporting risk of flooding inside home}

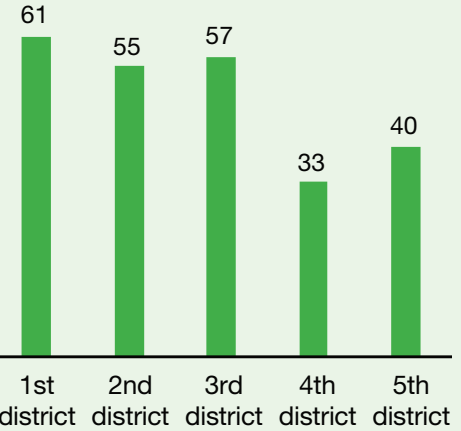


living in rural areas. The poor in Balbala appear to share characteristics with the poor elsewhere in the country. In particular, the educational attainment and formality of jobs of the household heads of the extreme poor population living in Balbala is similar to those residing in rural areas. The average consumption per capita among the poor in Balbala is much lower than the nonpoor in Balbala and also lower than that in rural areas. The deprivation score among poor urban households is also closer to the levels of the monetary poor in rural areas than to the deprivation score of their neighbors.

Nevertheless, the poor in Balbala appear to be more attached to the labor market and have higher access to certain services than the poor in rural areas. The percentage of the heads who are employed among the poor population

\section{TABLE 1.17 Characteristics of Poor and Nonpoor, by Area of Residence}

\begin{tabular}{|c|c|c|c|c|c|c|}
\hline & \multicolumn{3}{|c|}{ Nonpoor population } & \multicolumn{3}{|c|}{ Extreme poor population } \\
\hline & $\begin{array}{l}\text { Districts } \\
1-2-3\end{array}$ & Balbala & Rural & $\begin{array}{l}\text { Districts } \\
1-2-3\end{array}$ & Balbala & Rural \\
\hline Dependency ratio* & 0.71 & 0.87 & 1.08 & 0.75 & 0.82 & 1.35 \\
\hline $\begin{array}{l}\text { Percentage of those age } 15 \text { or more in labor } \\
\text { force }\end{array}$ & $48 \%$ & $46 \%$ & $41 \%$ & $49 \%$ & $41 \%$ & $33 \%$ \\
\hline Percentage of individuals employed ${ }^{* \star}$ & $29 \%$ & $25 \%$ & $22 \%$ & $13 \%$ & $12 \%$ & $13 \%$ \\
\hline Head has no education & $44 \%$ & $61 \%$ & $81 \%$ & $87 \%$ & $87 \%$ & $94 \%$ \\
\hline Head has at least secondary education & $19 \%$ & $15 \%$ & $3 \%$ & $4 \%$ & $2 \%$ & $1 \%$ \\
\hline Head is employed & $57 \%$ & $61 \%$ & $41 \%$ & $31 \%$ & $42 \%$ & $26 \%$ \\
\hline $\begin{array}{l}\text { Head is employed in public sector (as a \% of all } \\
\text { employed) }\end{array}$ & $43 \%$ & $48 \%$ & $45 \%$ & $32 \%$ & $46 \%$ & $27 \%$ \\
\hline $\begin{array}{l}\text { Head is employed in private formal sector (as a } \\
\% \text { of all employed) }\end{array}$ & $19 \%$ & $10 \%$ & $5 \%$ & $2 \%$ & $3 \%$ & $4 \%$ \\
\hline Access to water & $99 \%$ & $99 \%$ & $66 \%$ & $92 \%$ & $97 \%$ & $41 \%$ \\
\hline Access to sanitation & $48 \%$ & $54 \%$ & $23 \%$ & $28 \%$ & $32 \%$ & $10 \%$ \\
\hline Access to electricity & $90 \%$ & $68 \%$ & $10 \%$ & $59 \%$ & $18 \%$ & $3 \%$ \\
\hline $\begin{array}{l}\text { Household lives less than one kilometer away } \\
\text { from an elementary school }\end{array}$ & $39 \%$ & $41 \%$ & $41 \%$ & $41 \%$ & $47 \%$ & $37 \%$ \\
\hline Children ages 6-14 enrolled in school & $84 \%$ & $87 \%$ & $69 \%$ & $70 \%$ & $79 \%$ & $53 \%$ \\
\hline $\begin{array}{l}\text { Household lives less than one kilometer away } \\
\text { from any health facility }\end{array}$ & $26 \%$ & $25 \%$ & $15 \%$ & $28 \%$ & $29 \%$ & $10 \%$ \\
\hline Average consumption per capita (DF) & 323,598 & 212,859 & 151,326 & 69,392 & 67,669 & 49,051 \\
\hline Deprivation score & 0.13 & 0.16 & 0.44 & 0.47 & 0.50 & 0.83 \\
\hline
\end{tabular}

Source: Calculations based on EDAM4-IS.

Note: Access to electricity is defined as the use of electricity as the main source of lighting. Access to water is defined as the availability of water through an ONEAD indoor connection, direct connection from a borehole, ONEAD outdoor connection by pipe, public fountain and drilling (with a pump). Access to sanitation is defined as unshared access to a water closet with flush, or latrine with slab. Private sector comprises all branches of activity except public administration and others (international organizations, military bases, and unspecified categories). Within the private sector, employers, contractors and independent workers are considered working in the formal sector when they have accounting records, a trading license (commonly referred to as "patente") and registration in the chamber of commerce. Within the private sector, salaried individuals, family helpers and apprentices are considered working in the formal sector if the worker has a contract and is registered in social security. All remaining individuals working in the private sector are considered as working in the informal sector.

* Only households with at least one working age (15-64) individual are included. ** Includes all individuals 15 years and older. 
in Balbala is 42 percent, while only a quarter of poor rural household heads are employed. By virtue of being in the capital, the poor in Balbala perform better in terms of access to services than the rural poor: poor households in the capital have better coverage rates of water, sanitation, and electricity and more families live close to an elementary school and health facility. While access to water does not seem like a concern among the Balbala poor, access to electricity and sanitation are much lower than among the nonpoor. Expansion of electricity access in this area should remain a primary concern. Access to primary schools within one kilometer is nearly similar for the poor and nonpoor in the capital and rural areas. About 47 percent of the poor in Balbala live within one kilometer of the school. The urban poor children ages 6-14 years have relatively high rates of school attendance, while only 53 percent of the rural poor children ages of 6-14 are likely to go to school.

Other data sources can help better capture the (simply defined) access to certain services by the population of the capital city. Evidence from geospatial data shows the catchment areas of primary schools and hospitals in

\section{MAP 1.1 Catchment Areas of Primary Schools in Djibouti City (One Kilometer)}

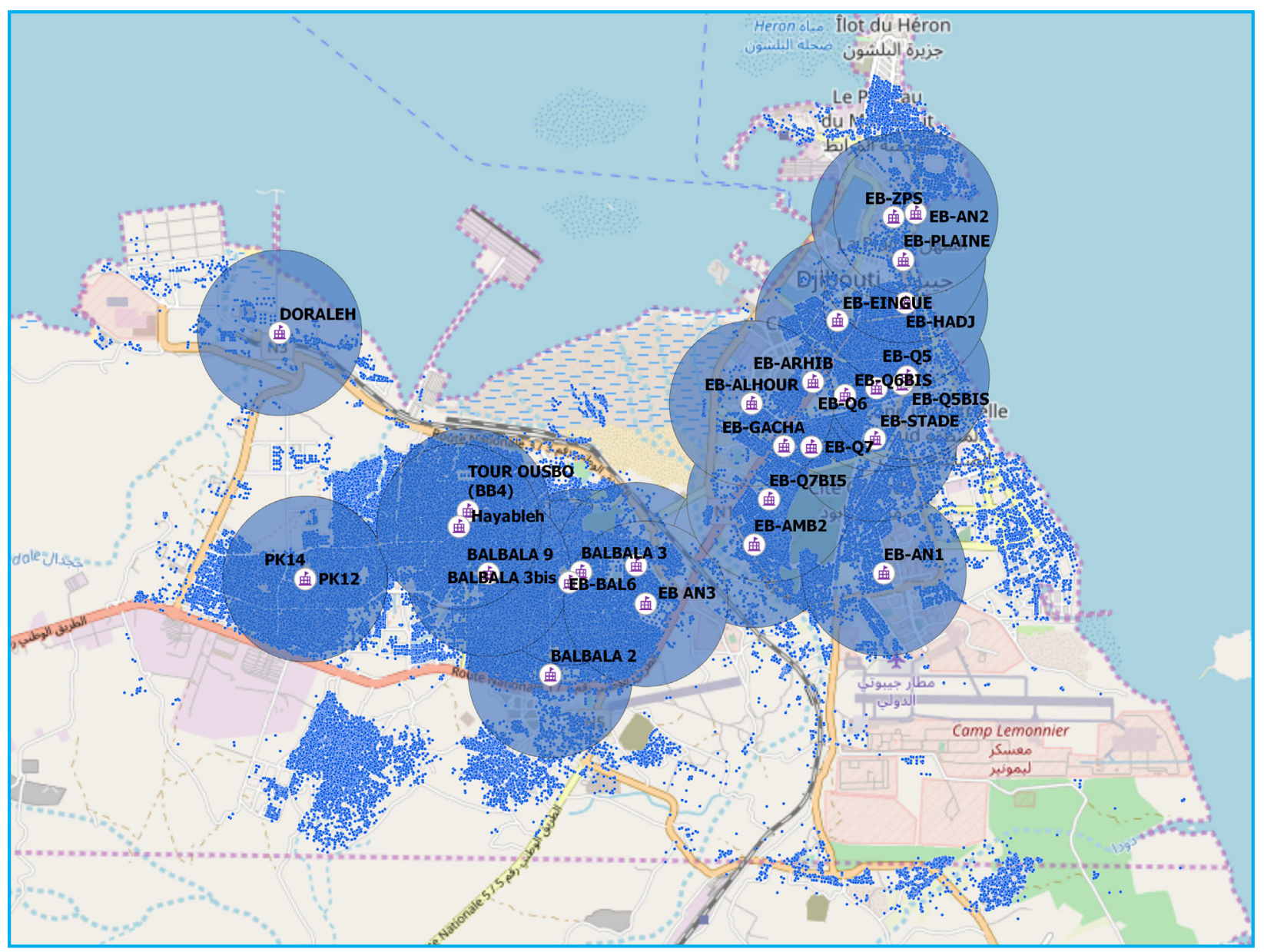

Note: Data on primary schools is obtained from the website of the Ministère de l'Education Nationale et de la Formation Professionnelle (accessed December 27, 2018). Data for dwellings (marked in blue) is obtained from the building footprint of Djibouti produced by the World Bank. 
Djibouti city in the radius of one kilometer (Map 1.1 and Map 1.2). The majority of the city dwellings are covered by at least one primary school (80.6 percent) and hospital (71.3 percent). However, the estimated density (population served) of these facilities is expected to be high in Djibouti city and may thus call for attention in examining whether these areas are underserved and consequently if the quality of service delivery in these areas is affected. For schools, this is less likely to be a problem as a result of the introduction of double classes in public schools in the capital. Using an alternate catchment area of 1.5 kilometers would increase the coverage of public primary schools and hospitals to 89.7 percent and 86.9 percent, respectively. These elements point to the need to boost coverage in certain areas of the capital that host poor and vulnerable populations. It would also be important to consider improvements in service delivery (if the areas are found to be underserved) as well as strategies to encourage parents to have children stay in school longer.

\section{MAP 1.2 Catchment Areas of Hospitals in Djibouti City (One Kilometer)}

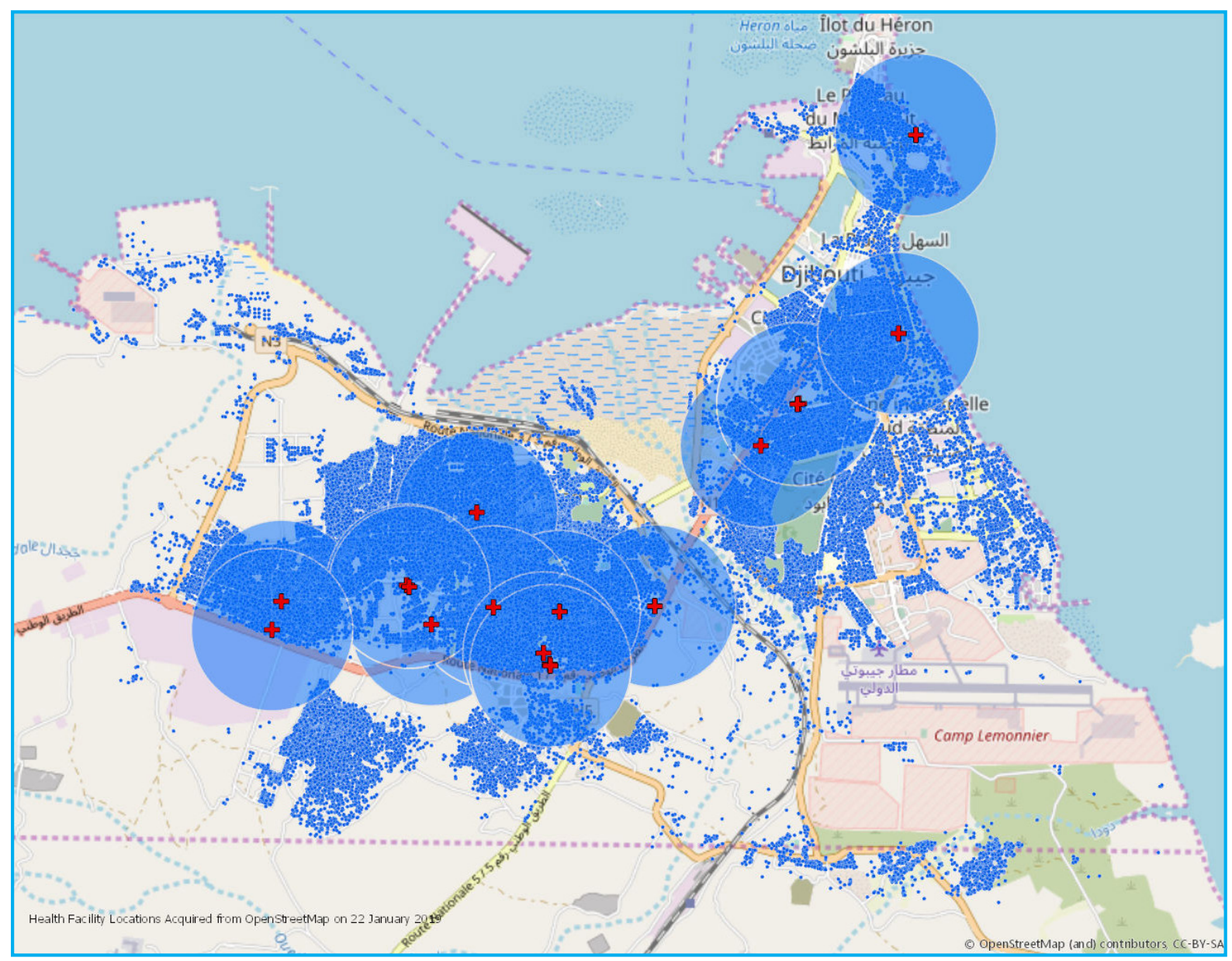

Note: Data on hospitals is obtained from OpenStreetMap, https://www.openstreetmap.org. Military hospitals and doctor's clinics have been left out. Data for dwellings (marked in blue) are obtained from the building footprint of Djibouti produced by the World Bank. 
Rural and urban poor face a distinct set of concerns, and a separate and targeted set of policies must be thought out for each of these subgroups of population. The urban poor have much lower consumption than others in their community and have much worse education and employment outcomes. In urban areas, especially in Balbala, the quality of service delivery may be poor due to the high density of population served in these areas. Meanwhile, rural areas require a comprehensive strategy that invests in the provision of access to infrastructure and amenities. Households in these areas suffer from low access to services such as electricity, water, and sanitation. Electricity access is especially a concern to be addressed, as only 6 percent of the rural population has access. Finally, open defecation rates are high in regions and coverage of health facilities is low.

There is one more aspect of location that is important to highlight in the Djiboutian context. Location plays a major role as it poses challenges to the implementation of public investments such as building of schools and clinics or the distribution of transfers to vulnerable populations. The lack of access to several services is evident in rural areas of Djibouti, but a realistic government strategy to expand coverage of basic services will need to find innovative ways to reach the populations in the poorest regions: most of the population residing in the regions live far apart from each other. We illustrate this by looking at Tadjourah and Dikhil, which have the highest poverty rates in the country.
Each has an area of about 7,000 square kilometers. Using geospatial data, we conduct the following exercise. First, we identify all the buildings via satellite imagery. Second, using these building as proxies for dwellings or inhabited spaces, we create a one-kilometer radius around each dwelling. Third, we create clusters of dwellings to represent inhabited areas, like communities or villages. To build these clusters, we draw a one-kilometer radius around each dwelling and then all the radii where their areas overlap. For instance, if two dwelling are near each other, they will form a cluster shaped like a peanut. And fourth, we calculate the dwelling density (number of dwellings per square kilometer) for all the clusters identified.

Map 1.3 shows the results of this exercise for the regions. In Tadjourah, the region with the highest poverty and lowest coverage rates of certain services, about 60 percent of dwellings are in extremely low-density areas (one building per square kilometer) and almost three quarters (73 percent) are in very low-density areas (two buildings or less per square kilometer). Meanwhile, in Dikhil, where extreme poverty is 53 percent, these shares are 77 and 86 percent, respectively. As a comparison, Djibouti city has all dwellings $(80,818)$ under one cluster with an estimated density of 293.3 buildings per square kilometer. Achieving universal coverage of basic services in rural areas will certainly require additional resources, but they will have to be coupled with a well-crafted strategy to reach the neediest in an efficient manner. 


\section{MAP 1.3 Clusters and Density of Clusters for Regions Outside Djibouti City}

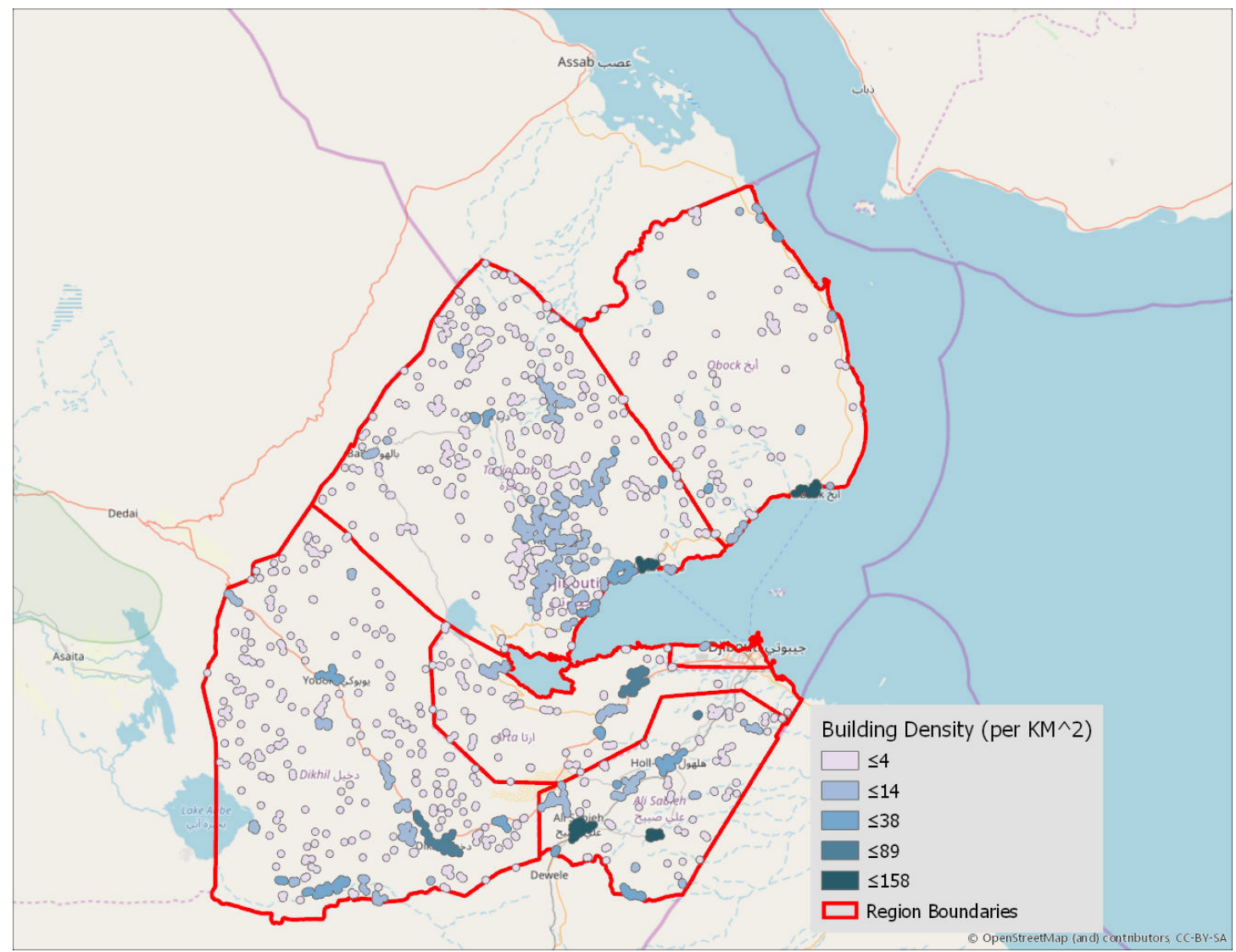

Source: Calculations made using geospatial data created by the World Bank. The underlying map is taken from OpenStreetMap. Clusters refer to groups of one-kilometer-radius neighborhoods around all buildings identified through a building footprint exercise. Djibouti city cluster not shown. 


\section{REFERENCES}

Ahmed, N., M. Brzozowski, and T. F. Crossley. 2006. "Measurement Errors in Recall Food Consumption Data." IFS Working Papers 06/21. Institute for Fiscal Studies, London.

Anker, R. 2011. "Engel's Law around the World 150 Years Later." Political Economy Research Institute Working Paper 247. Amherst, MA.

Backiny-Yetna, P., D. Steele, and I. Y. Djima. 2014. The impact of Household Food Consumption Data Collection Methods on Poverty and Inequality Measures in Niger. Washington, DC: World Bank.

Borgen Project. 2017. "Ethiopia-Djibouti Water Pipeline." Borgen blog. Seattle, WA. December. https:// borgenproject.org/tag/ethiopia-djibouti-water-pipeline/.

Brueckner, M., and D. Lederman. 2015. Effects of Income Inequality on Aggregate Output. Washington, DC: World Bank.

Chakravorty, U., M. Pelli, and B. Ural Marchand. 2014. "Does the Quality of Electricity Matter? Evidence from Rural India." Journal of Economic Behavior and Organization, 107, pp.228-247.

Chandrasekhar, S., and S. Amin. 2012. "Looking beyond Universal Primary Education: Gender Differences in Time Use among Children in Rural Bangladesh." Asian population studies, 8(1), 23-38.

Chowdhury, S. K. 2010. "Impact of Infrastructures on Paid Work Opportunities and Unpaid Work Burdens on Rural Women in Bangladesh." Journal of International Development 22 (7): 997-1017.

Cramer, C. 2003. "Does Inequality Cause Conflict?" Journal of International Development 15 (4): 397-412.

Dang, H. A. H., and E. lanchovichina. 2018. "Welfare Dynamics with Synthetic Panels: The Case of the Arab World in Transition." Review of Income and Wealth 64: S114-S144.
Deaton, A., and S. Zaidi. 2002. Guidelines for Constructing Consumption Aggregates for Welfare Analysis. Vol. 135. Washington, DC: World Bank.

Dinkelman, T. 2011. "The Effects of Rural Electrification on Employment: New Evidence from South Africa." American Economic Review 101 (7): 3078-108.

DISED (Direction de la Statistiques et des Etudes Démographiques). 2018. Résultats de la Quatrième Enquête Djiboutienne Auprès de Ménages pour les Indicateurs Sociaux (EDAM4-IS). Djibouti city: DISED. http://www.dised.dj/Rapport1_resultats_EDAM4.pdf.

Ferreira, F. H., J. R. Molinas Vega, R. Paes de Barros, and J. Saavedra Chanduvi. 2008. Measuring inequality of Opportunities in Latin America and the Caribbean. Washington, DC: World Bank.

Ferreira, Francisco, and Carolina Sánchez-Páramo. 2017. "A Richer Array of International Poverty Lines." Let's Talk Development, World Bank blog. Washington, DC. http://blogs.worldbank.org/developmenttalk/richer-arrayinternational-poverty-lines.

IMF (International Monetary Fund). 2017. “Djibouti 2016 Article IV Consultation-Press Release; Staff Report; and Statement by the Executive Director for Djibouti." IMF Country Report no. 17/87. Washington, DC: IMF. Jacobs, Andrew, and Jane Perlez. 2017. "U.S. Wary of Its New Neighbor in Djibouti: A Chinese Naval Base." New York Times. February 25. https://www.nytimes. com/2017/02/25/world/africa/us-djibouti-chinese-navalbase.html.

Krishnan, N., G. Lara Ibarra, A, Narayan, S. Tiwari, and T. Vishwanath. 2016. Uneven Odds, Unequal Outcomes: Inequality of Opportunity in the Middle East and North Africa. Washington, DC: World Bank. 
Maasho, Aaron. 2011. "Ethiopia Signs Djibouti Railway Deal with China." Reuters. December 17. https://www. reuters.com/article/ethiopia-railway/ethiopia-signs-djiboutirailway-deal-with-china-idUSL6E7NH07M20111217?feedT ype=RSS\&feedName=industrialsSector

Marrero, G. A., and L. Serven. 2018. "Growth, Inequality, and Poverty: A Robust Relationship?" The World Bank.

Meseret, Elias. 2016. “Ethiopia's New Coastal Rail Link Runs through Restive Region." Associated Press. October 5. https://www.voanews.com/a/ethiopia-new-coastalrail/3537554.html

Narayan, Ambar, Roy Van der Weide, Alexandru Cojocaru, Christoph Lakner, Silvia Redaelli, Daniel Gerszon Mahler, Rakesh Gupta N. Ramasubbaiah, and Stefan Thewissen. 2018. Fair Progress?: Economic Mobility Across Generations Around the World. Washington, DC: World Bank. https://openknowledge.worldbank.org/ handle/10986/28428.

Olinto, P., G. Lara Ibarra, and J. Saavedra-Chanduvi. 2014. Accelerating Poverty Reduction in a Less Poor World: The roles of Growth and Inequality. Washington, DC: World Bank.

Paes de Barros, Ricardo, Francisco H. G. Ferreira, Jose R. Molinas Vega, and Jaime Saavedra Chanduvi. 2009. Measuring Inequality of Opportunities in Latin America and the Caribbean. Washington, DC: World Bank. https:// openknowledge.worldbank.org/handle/10986/2580.

Ravallion, M. 1998. "Poverty Lines in Theory and Practice." LSMS Working Paper 133. World Bank: Washington DC.

UNHCR (United Nations High Commissioner for Refugees). https://www.unhcr.org/djibouti.html

Van de Walle, D., M. Ravallion, V. Mendiratta, and G. Koolwal. 2017. "Long-term Gains from Electrification in Rural India." World Bank Economic Review 31 (2): 385-411.
Washington Group on Disability Statistics. n.d. http:// www.washingtongroup-disability.com/washington-groupquestion-sets/

WDI (World Development Indicators). n.d. Database. Washington, DC: World Bank. https://datacatalog. worldbank.org/dataset/world-development-indicators.

World Bank. n.d. "Tables, Charts, and Technical Notes." Global Consumption Database. http://datatopics.

worldbank.org/consumption/detail.

World Bank. 2008. The Welfare Impact of Rural Electrification: A Reassessment of the Costs and Benefits; An IEG Impact Evaluation. Washington, DC: World Bank.

World Bank. 2018a. Poverty and Shared Prosperity 2018: Piecing Together the Poverty Puzzle. Washington, DC: World Bank. 


\section{HUMAN CAPITAL AND LABOR MARKET}

A key objective of a poverty reduction strategy in Djibouti should be to unleash the potential of its (current and future) labor force, by providing people with skills to obtain or generate good jobs that allow them to grow economically. Understanding the labor market opportunities of the Djiboutian workforce requires looking into the population's education, as well as their market outcomes. The framework developed in Lopez-Calva and Rodríguez-Castelán (2016) argues that the capacity of an individual (or the household she belongs to) to generate income is based on the assets (or all kinds of capital) and opportunities that she owns, and her ability to use them to obtain returns. Of key interest, then, is how human capital (measured, for instance, by educational attainment) is accumulated in the population and how the population is able to reap benefits from it. In addition, earnings from labor is integral to economic growth and to escaping poverty. As shown in Azevedo et al. (2013) for a broad set of countries, Barros et al. (2006) in Brazil, and several other studies in the literature, labor income is often associated with more and better paying jobs and is the biggest contributor to changes in poverty. Thus, it is expected that a sustainable approach to generate income and eradicate poverty in the country is to promote a welleducated labor force that is competitive in the global arena and that this workforce can grow in a system welcoming private sector investments.

There is suggestive evidence that the government of Djibouti (GoD) has made important strides in investing in its population and boosting its educational attainment. Nonetheless, the concentration of economic growth in capital-intensive sectors has missed the opportunity to unleash the potential of the improvements in educational attainment of the Djiboutian labor force. In this chapter, we provide analytics of a snapshot of the labor market in Djibouti. We start with a brief look at the human capital of the labor force, followed by an analysis of the labor outcomes. Finally, we present some findings on the types of firms existing in Djibouti to shed some light on the labor demand side. A brief discussion of the policies concludes.

\section{HUMAN CAPITAL: EDUCATIONAL OUTCOMES IN DJIBOUTI}

Across the country's regions, educational outcomes in Djibouti follow a pattern similar to that found in welfare and other nonmonetary indicators. Using self-declared information from EDAM4-IS, an estimate of literacy rates, or the ability to read and write among individuals age 15 years and older, is calculated. In 2017, a bit more than half (53 percent) of the population over 15 years of age of Djibouti could read and write (Figure 2.1). Literacy rates vary by gender, with nearly three-fifths of all men being literate as compared to 43 percent of women. Geographic disparities in literacy rates are also evident-59 percent of the population in the capital city is literate as opposed to 29 percent in the regions, with wide disparities across regions. The literacy rates are lowest in the region of Tadjourah, where only about a fifth of the population can read and write, followed closely by Obock and Dikhil. Similar regional trends are also observed for men and women, with women having lower literacy rates than men in every region. 
Looking at another indicator of education, defined as the percentage of the population age 15 years and older that has completed at least primary schooling (Figure 2.2), we find that about 40 percent of the population has completed primary schooling. This number stands at 44 percent in the capital city and is lowest in the regions of Tadjourah and Obock, at about 15 percent. Differences in primary schooling completion across regions seen here may be explained by these differences in spending on education. This might also point to education being a normal good in Djibouti, wherein spending on the good increases as income increases. Gender disparities are also present in this indicator, while following the same pattern of regional disparities. About a third of Djiboutian women have finished primary education compared to almost half of the men. This gap is present in every region of the country, with Tadjourah and Obock showing the smallest differences (although probably due to the low overall rate).

\section{FIGURE 2.1 Literacy Rates among People Age 15 Years and Older, 2017 (percent)}

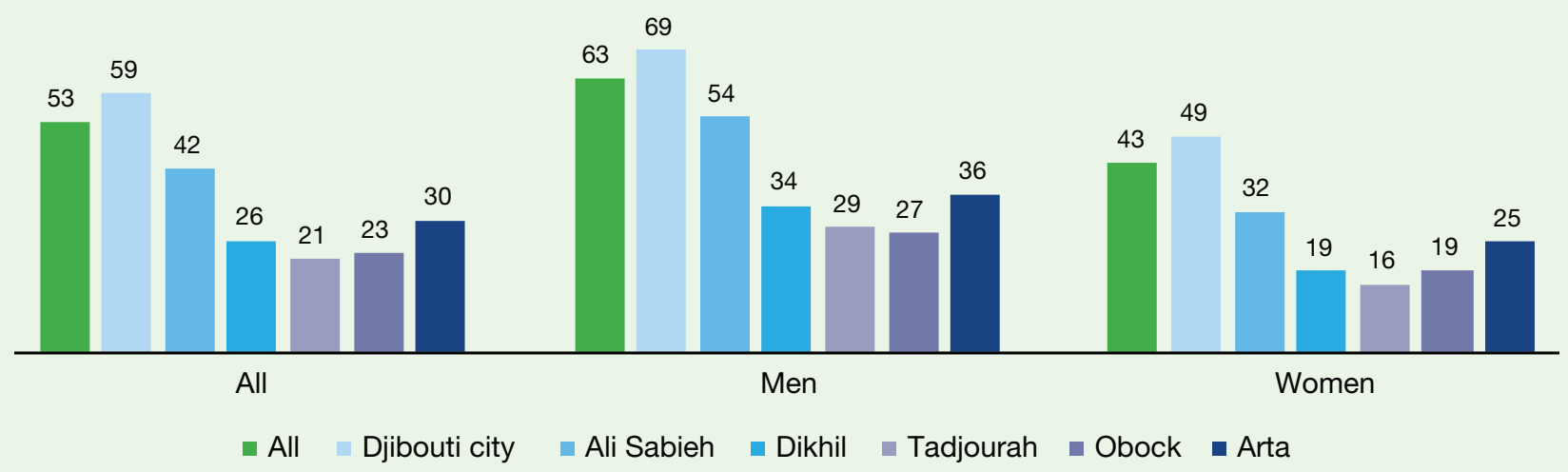

Source: Calculations based on EDAM4-IS.

FIGURE 2.2 Percentage of Population Age 15 Years and Older with at Least Primary Education, 2017

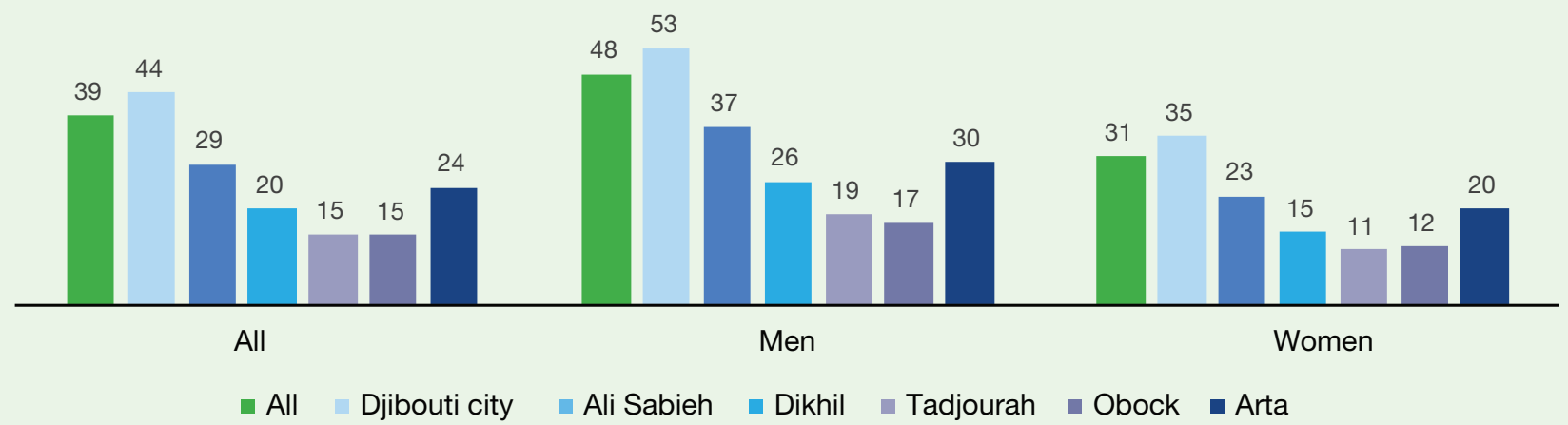

Source: Calculations based on EDAM4-IS. 


\section{INTERGENERATIONAL TRANSFORMATION IN DJIBOUTI}

Behind the results of low aggregate literacy rates, there is some evidence of an educational transformation underway in Djibouti. For instance, in 2010, the GoD spent 12.3 percent of its total expenditure (equivalent to 4.49 percent of GDP) in education. ${ }^{21}$ While more recent estimates are not available, other indicators suggest that the GoD has made significant efforts to increase access to schooling in recent years. The number of public primary schools increased from 84 in 2004-5 to 136 in 2016-17 (DISED 2012a, 2017a). Further, the number of public middle and secondary schools also increased threefold, from 11 in 2004-05 to 36 in 2016-17 (DISED 2012a, 2017a). As higher schooling is likely to lead to higher earnings (Ashenfelter and Krueger 1994; Card and Krueger 1992; Duflo 2001; Heckman et al. 2006; Psacharopoulos and Patrinos 2018), this increased availability of access to schooling holds vast potential for poverty reduction in the medium and long terms.
Some of these efforts appear to be bearing fruit as the younger cohorts perform much better on a host of educational outcomes and women seem to be catching up to men, but certain groups of the population are being left behind. Comparing literacy rates across age cohorts, findings reveal that the younger cohorts of ages 10-14 years and 15-24 years have remarkably higher literacy rates as compared to older cohorts of 25 years and older (Figure 2.3). The cohort of 15-24 years has a literacy rate of 80 percent, significantly higher than the national average of 53 percent but still lower than the average of the MENA region of 91 percent for the same cohort (The World Bank, 2018c). Another interesting finding is that the gap in literacy rates among men and women is closing for younger cohorts. Among the population aged 25-39 years and older, there is a 26 percentage point difference in literacy rate between men and women, while this gap is only 10 percentage points and not quite 2 percentage points for those age 15-24 years and 6-14 years old, respectively.

\section{FIGURE 2.3 Literacy Rates, 2017 (percent)}

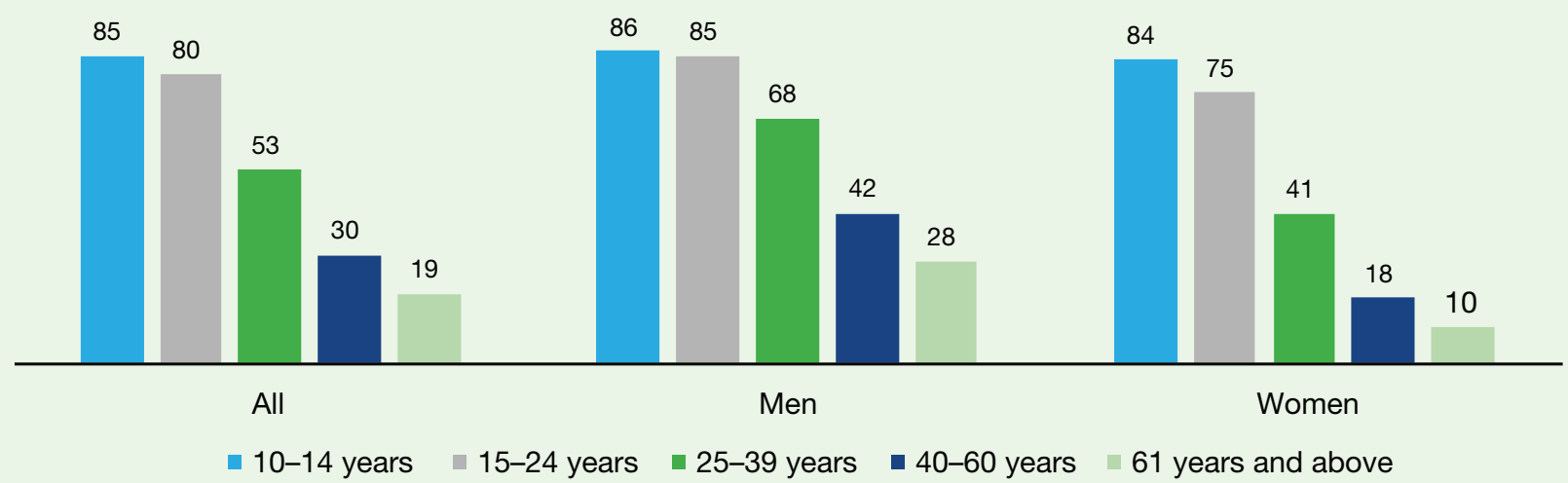

Source: Calculations based on EDAM4-IS.

21 These expenditures represented a decrease from previous years. In 2010, the GoD spent 22.5 percent of its total expenditure (or 8.4 percent of GDP) in education See WDI, https://data.worldbank.org/indicator/SE.XPD.TOTL.GD.ZS?locations=DJ, accessed December 27, 2018. 


\section{FIGURE 2.4 Educational Attainment by Age Cohort, 2017}

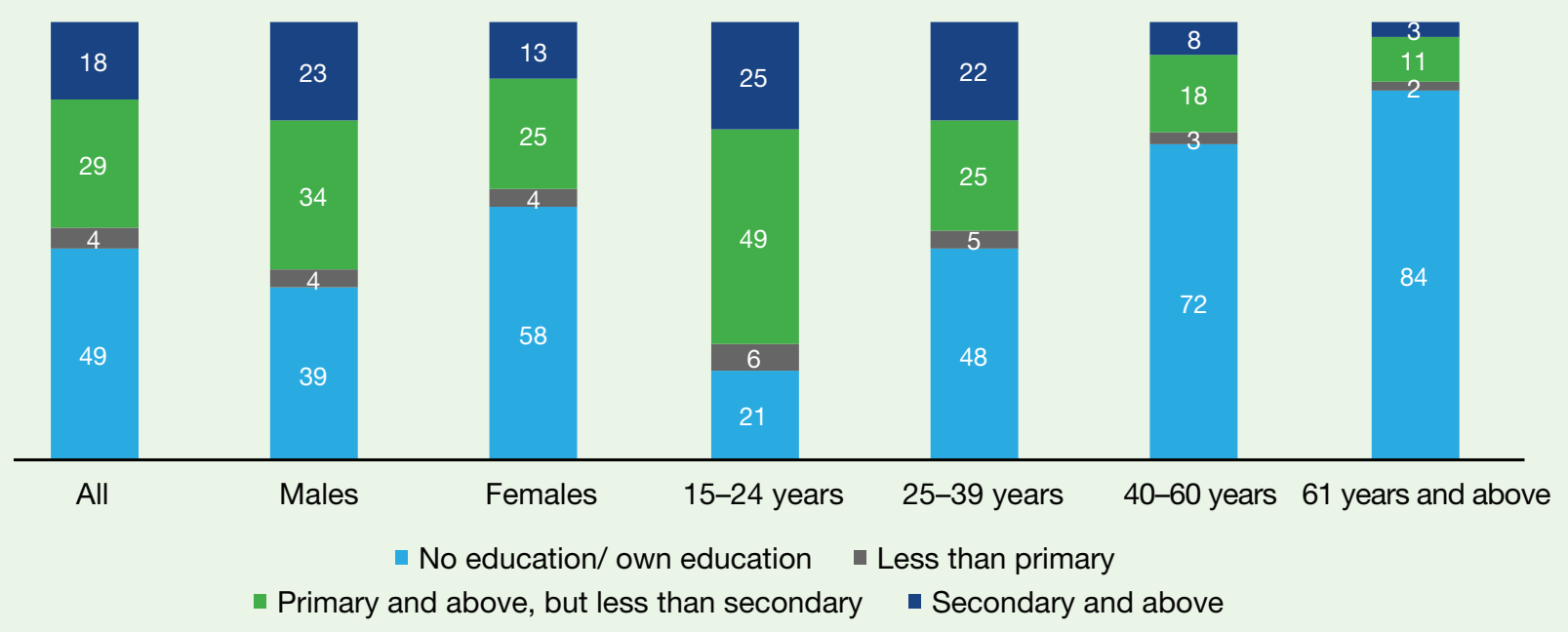

Source: Calculations based on EDAM4-IS.

Note: Only individuals older than the age of 15 years are included

Figure 2.4 shows similar results on educational attainment. About 49 percent of those age 15-24 years have completed at least primary education, and this percentage deteriorates dramatically with age. Among those age 40 years and older, three-fourths have no education. Another interesting finding is that the percentage of population with less than primary education is relatively small and is not changing much across age cohorts. Thus, it seems that the transition of education runs from no education to primary education or more. Women are more likely to have no education whatsoever and only 38 percent have completed at least primary education, as opposed to 57 percent of the men.

Another noteworthy finding is that nearly 81 percent of the children ages 6-14 were enrolled in school in 2017. In the regions outside Djibouti city, this percentage is 71 percent. There is, thus, an indication that the Djiboutian population considers education to be important for its children, and this may have consequences for Djibouti's human capital stock in the future. Among children ages 6-14 going to school, 96 percent have been or are going to a French public school. On the other hand, approximately one out of three people ages 11-39 years has never been to school. The results are worse for women (39 percent) and the population outside Djibouti city (52 percent). As per EDAM4, the main reason cited by respondents for never going to school is found to be lack of interest, while the fact of being a woman is cited as the second most important reason.

The concept of economic mobility rests on the idea that access to opportunity depends little on one's starting point and that an individual has the opportunity to improve his or her economic status over time. In developing countries, a large body of research has focused on the intergenerational transmission of poverty and mobility out of it. For example, Gong et al. (2012) show that the relative placement of children in the income distribution is a result of their parent's income in urban China. Further, they establish that link between the two runs through the channel of education and occupation, among others. Many emerging economies such as South Africa, Brazil, Chile, and China appear to have low levels of intergenerational mobility due to high inequality that persists in these countries (Gong, Leigh, and Meng, 2012; 
Nunez and Miranda 2010; Piraino 2015). In addition, it can be contended that education can play a pivotal role in lifting people out of poverty, and consequently, breaking its intergenerational transmission. While we cannot establish a link between parents' and children's income due to the unavailability of such disaggregated data, we can explore the intergenerational mobility of education.

Based on the results noted, there is evidence that an intergenerational movement to higher education levels in Djibouti has taken place. Indeed, the percentage of individuals (age 25 years and older) with higher educational qualifications than their father is 36 percent in Djibouti (Figure 2.5). A third of individuals over the age of 25 years whose father has no education have attained some form of education (Table 2.1). However, certain disparities remain among men and women. The poor women are found to be the most immobile group; 87 percent of them have no improvements in educational outcomes with respect to their father's. Almost all fathers in this subgroup have no education, and about 10 percent of poor women attain some education when their father has none. Poor men follow the lead with a corresponding number of 78 percent. The most upwardly mobile group comprises nonpoor men -53 percent of them have educational attainment higher than their father's. To better understand the gaps among these groups, international benchmarks can be obtained from a recent study (Narayan et al. 2018) on intergenerational educational mobility that provided estimates of upward mobility for close to 150 economies. ${ }^{22}$ Upward mobility among Djiboutian nonpoor men is around the median of the distribution with such countries as China, Egypt, and Hungary. Poor women's mobility is close to the bottom and similar to those in Mali and South Sudan.

Some of these results point to Djibouti becoming well placed to reap the benefits of high economic growth it has been experiencing over the past decade. A key challenge will be to ensure that all groups of the population are capable of participating in a more developed economy

\section{FIGURE 2.5 Educational Mobility of Individuals 25 Years and Older Compared to Their Fathers' (percent)}

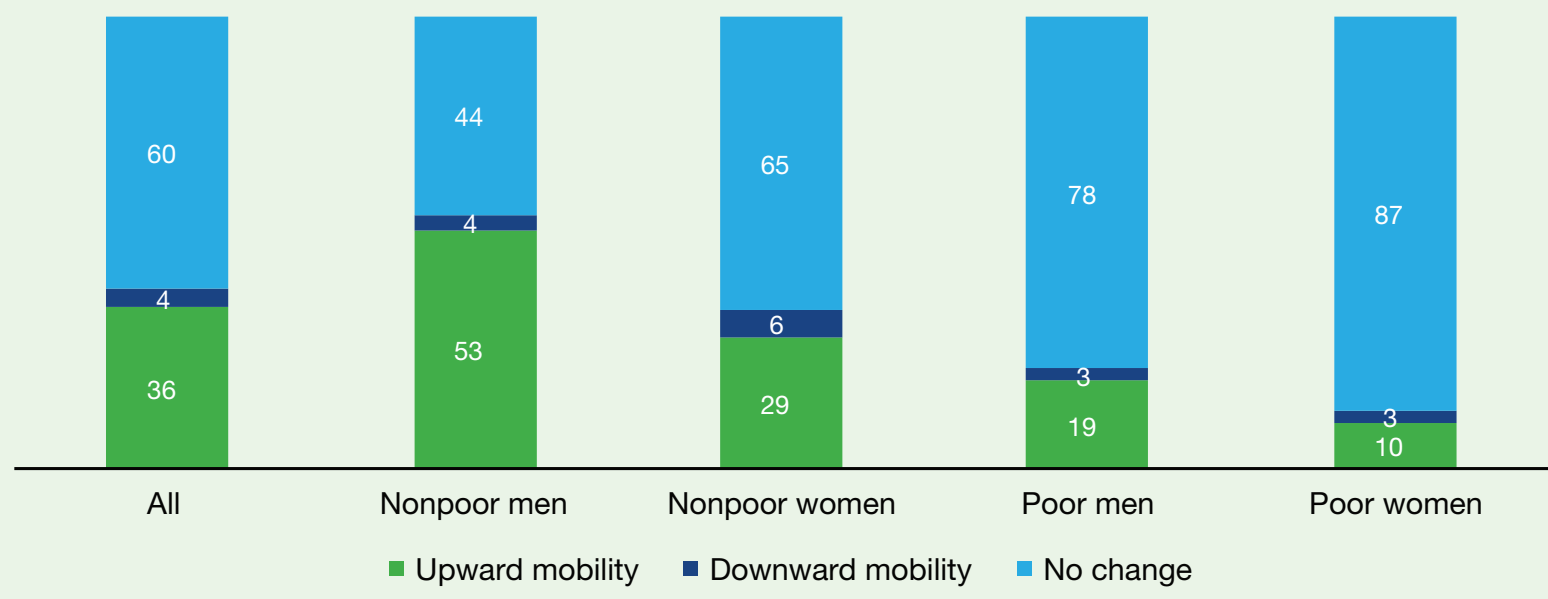

Source: Calculations based on EDAM4-IS.

Notes: We use educational attainment as divided into four categories: no education, primary education or less, between primary education and secondary education, and secondary education or more. If the educational attainment of the child is higher than that of the father, he or she is considered upwardly mobile. Data on education of self or father were missing for 7 percent of all individuals.

22 To obtain a comparable estimate within the estimates from Narayan et al. (2018), we use the Global Database on Intergenerational Mobility. In particular, we obtain the average estimated absolute upward mobility (across all available cohorts) for fathers and all children for each country. 


\section{TABLE 2.1 Education Transition Matrices of Individuals 25 Years and Older Based on Their Father's Education}

\begin{tabular}{|c|c|c|c|c|c|}
\hline \multirow[b]{2}{*}{ All } & \multicolumn{5}{|c|}{ Father's education } \\
\hline & $\begin{array}{c}\text { No } \\
\text { education }\end{array}$ & $\begin{array}{l}\text { Primary } \\
\text { or less }\end{array}$ & $\begin{array}{l}\text { More than } \\
\text { primary or } \\
\text { secondary }\end{array}$ & $\begin{array}{l}\text { More than } \\
\text { secondary }\end{array}$ & Total \\
\hline No education & 57 & 3 & 0 & 0 & 61 \\
\hline Primary or less & 12 & 1 & 0 & 0 & 14 \\
\hline More than primary or secondary & 14 & 2 & 1 & 0 & 17 \\
\hline More than secondary & 6 & 1 & 1 & 1 & 8 \\
\hline Total & 88 & 8 & 2 & 1 & 100 \\
\hline
\end{tabular}

\begin{tabular}{|c|c|c|c|c|c|}
\hline \multirow[b]{2}{*}{ Poor women } & \multicolumn{5}{|c|}{ Father's education } \\
\hline & $\begin{array}{c}\text { No } \\
\text { education }\end{array}$ & $\begin{array}{c}\text { Primary or } \\
\text { less }\end{array}$ & $\begin{array}{l}\text { More than } \\
\text { primary or } \\
\text { secondary }\end{array}$ & $\begin{array}{l}\text { More than } \\
\text { secondary }\end{array}$ & Total \\
\hline No education & 87 & 2 & 0 & 0 & 89 \\
\hline Primary or less & 7 & 0 & 0 & 0 & 7 \\
\hline More than primary or secondary & 3 & 0 & 0 & 0 & 3 \\
\hline More than secondary & 0 & 0 & 0 & 0 & 0 \\
\hline Total & 97 & 3 & 0 & 0 & 100 \\
\hline
\end{tabular}

Source: Calculations based on EDAM4-IS. Data on education of self or father were missing for 7 percent of all individuals.

and reaping returns of increased educational attainment in the labor market. Certain groups of the population appear to already be ahead of the curve and surpassing the educational levels of their parents. However, stronger efforts will be needed for growth to be truly inclusive and all groups to prosper along with the country's growth.

Finally, it is important to note that this section on human capital takes a narrow view on educational attainment. There are two main reasons. First, there are no data on the extent of actual learning obtained via the educational system in Djibouti. Learning, as opposed to obtaining a certificate, could be a better measure of the skills obtained by an individual and her potential to be a productive part of the economy. Typical proxies for quality of learning, including such international tests as the Programme for
International Student Assessment or Trends in International Mathematics and Science Study, have not been conducted in Djibouti. Second, there is mixed evidence of improvements in other human capital indicators, such as health. Regarding this more long-term view of human capital investments, it is harder to evaluate the implemented policies in recent years. For instance, projections for infant mortality show a continuous decline, reaching 51.5 in 2017 from 80.3 in 2000. However, indicators on stunting rates appear to be unchanged and wasting rates appear to have increased between 1996 and 2012 (World Bank 2018a). There are no health indicators available with more recent surveys. ${ }^{23}$ With these in mind, it must be clear that the gains in education may not fully translate into gains in productivity among the Djiboutian labor force.

23 Information on the government's expenditure on health dates from 2015. According to WDI (accessed February 13, 2019), the domestic general government health expenditure represented 2.4 percent of GDP in 2015. 


\section{LABOR MARKET OUTCOMES}

The high rates of economic growth that Djibouti has experienced in recent years could have spillover effects in the form of job creation and hence contribute to poverty reduction. Economic well-being is intrinsically tied to employment, and this is more so for the poor. In chapter 1 , a strong correlation was found between poverty status and labor force outcomes. In this section, it is shown that labor force outcomes are also highly correlated with location, gender, and age. We provide a snapshot of labor force outcomes in Djibouti in 2017, followed by an exploration of the links between education and employment outcomes. For education to break the intergenerational transmission of poverty, the underlying assumption is that improved education outcomes must translate into better employment outcomes. We also give a closer look at those employed, the sectors of employment, and wages in these sectors. Labor force participation rates in Djibouti are low (Table 2.2). Overall, among the population 15 years and older, about 45 percent participate in the labor market - a ratio practically unchanged from the earlier estimate of 46.3 percent in 1996 (World Bank 1997), despite the positive economic growth during the past 20 years. Similar to the patterns found in other MENA countries, labor force participation in Djibouti shows substantial variation across gender and age. Men's labor force participation stands at 59 percent, whereas for women it is only 32 percent. Less than a third of individuals in the 15-24 age range participate in the labor market. Among people in prime age working years (25-39 and 40-60), the participation rate is 55 and 53 percent, respectively.

Figure 2.6 shows the distribution of the population of working age (15 years and older) across gender and age cohorts. It appears that women and the youngest cohort of 15-24 years are less likely to be active in the labor force. Among those who are active in these two groups, a large percentage remain unemployed. For example, 13 percent of those

\section{TABLE 2.2 Characteristics of the Population by Poverty Status and Location}

\begin{tabular}{l|c|c|c|c|c|c|c|} 
& \multicolumn{4}{|c|}{ Gender } & \multicolumn{4}{c|}{ Age group (in years) } \\
\cline { 3 - 8 } & Overall & Male & Female & $15-24$ & $\mathbf{2 5 - 3 9}$ & $\mathbf{4 0 - 6 0}$ & $\mathbf{6 1 +}$ \\
\hline Labor force participation & $44.7 \%$ & $58.5 \%$ & $31.5 \%$ & $28.6 \%$ & $55.3 \%$ & $53.4 \%$ & $15.8 \%$ \\
\hline
\end{tabular}

Source: Calculations based on EDAM4-IS.

Notes: Only the population 15 years and older is included.

\section{FIGURE 2.6 Distribution of Population in the Labor Market (percent)}

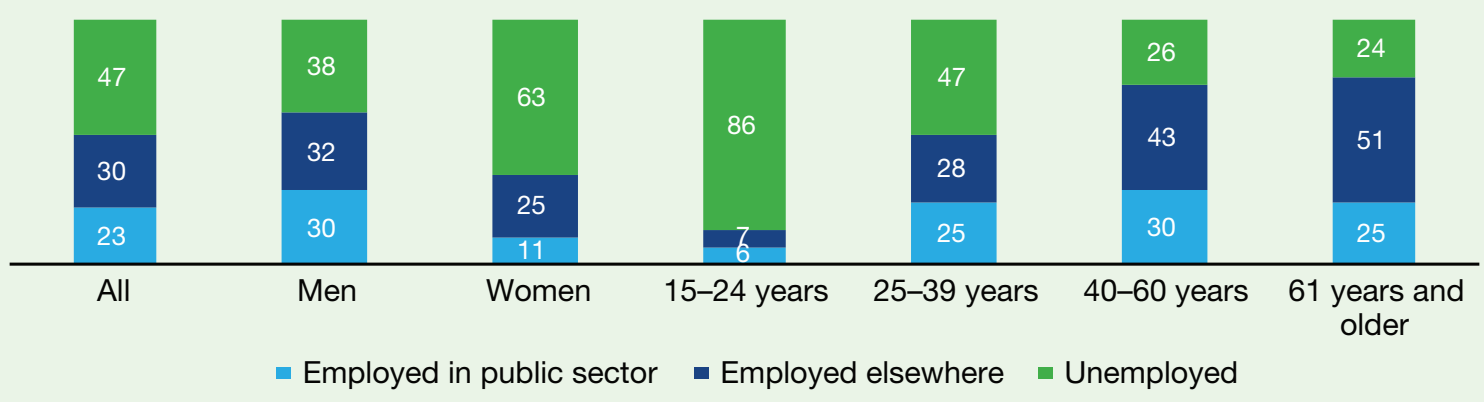

Source: Calculations based on EDAM4-IS.

Notes: Only the population 15 years and older is included. Public sector includes those employed declaring public administration as the main branch of activity. 
active among the youngest cohort are employed. About 62 percent of all active working age men are employed, and 30 percent are employed in the public sector. What is striking is that even though the population ages 15-24 years have higher educational attainment than the older cohorts, a large percentage of those active among them strive to find a job.

Based on educational attainment, employment rates are highest for individuals with no education and those with secondary education or more (Figure 2.7). This pattern is observed for both men and women, although the former have much higher level of employment rate as compared to women. Seniority and years of experience also seem to increase the probability of being employed. About 74 percent in the age range of 40-60 years are employed, while this number stands at 53 percent for individuals ages 25-39 years. It seems that the high education levels among 15-24 years old have not translated to employment opportunities yet. We study the population ages 15-24 year in a bit more detail to explore this finding.

\section{FIGURE 2.7 Employment Rate among Labor Market Participants, by Educational Attainment}
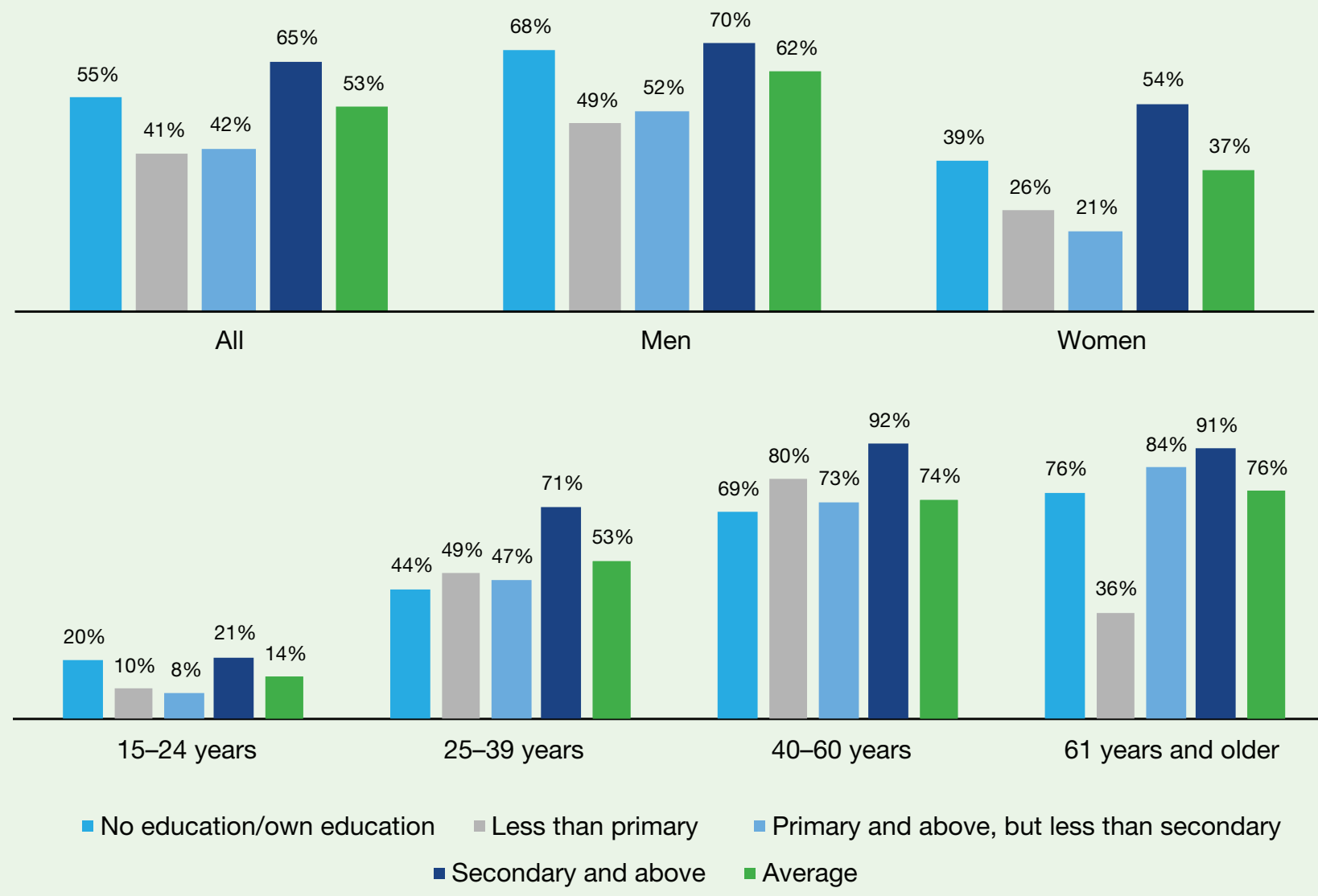

Source: Calculations based on EDAM4-IS.

Notes: Employment rate is defined as those employed among those active in the labor force. Both employed and unemployed individuals are considered active in the labor force. 
With the lowest employment shares, it is worth exploring how the youth (15-24 years old) in Djibouti occupy their time. We do this by distinguishing among four activities: studying, employed or in training, unemployed (within those seeking a job), and neither studying nor employed, nor in training, nor unemployed (NEET). Nationally, about
45 percent of those ages 15-24 years are studying, 22 percent are unemployed, 5 percent are employed, and 28 percent are NEET (Figure 2.8). Meanwhile, a third of young women are NEET. Youth in the regions have worse outcomes: about 43 percent are NEET and thus are disengaged from any productive activity.

\section{FIGURE 2.8 Distribution of Youth Ages 15-24 Years across Education and Labor Force Activities}
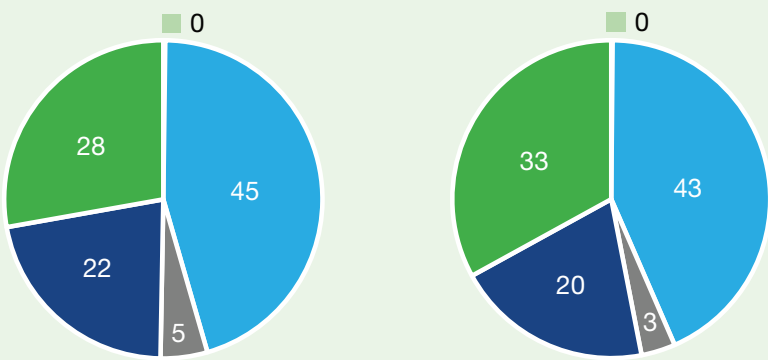

Employed/training and studying

- Studying Employed/ in training

- Unemployed nEET

Source: Calculations based on EDAM4-IS.

Note: NEET refers to youth not in employment, education or training neither unemployed (those individuals who are seeking a job).

One of the reasons for not seeking participation in the labor market could be that more women are in school for a longer period of time (as noted in the findings related to education mobility). Table 2.3 present the reasons for not wanting to find employment for men and women in the age group of 15-24 years. Indeed, studying is cited as one of the key reasons, however less so by men in 2017 as compared to 2012. As compared to 2012, more women are out of the labor force in 2017 and more of them also seem to report family obligations as the key reason. Thus, not only are women less likely to participate in the labor force in 2017 than men, this phenomenon is becoming worse over time for them but not for men. Better education outcomes for young women do not seem to be translating to higher labor market attachment rates for them.

TABLE 2.3 Reasons for Not Wanting to Find Employment, among the Youth 15-24 Years Old (percent)

\begin{tabular}{|c|c|c|c|c|}
\hline & \multicolumn{2}{|c|}{2017} & \multicolumn{2}{|c|}{2012} \\
\hline & Males & Females & Males & Females \\
\hline In the labor force & 32 & 26 & 33 & 33 \\
\hline \multicolumn{5}{|l|}{ Out of the labor force: } \\
\hline Studying & 44 & 40 & 53 & 42 \\
\hline Family obligations & 7 & 19 & 4 & 13 \\
\hline Others & 11 & 11 & 9 & 9 \\
\hline Missing & 6 & 5 & 1 & 4 \\
\hline Total & 100 & 100 & 100 & 100 \\
\hline
\end{tabular}

Source: Calculations based on EDAM 2012 and EDAM4-IS.

Note: Students seeking employment are counted as part of the labor force. Trainees without other activity are counted out of the labor force. Shares may differ slightly from Figure 2.8. 
For the 53 percent of the population employed nationally, a dual market is the norm, with the public sector being a major employer, on one side, and informal jobs or working in informal firms, on the other. Table 2.4 shows that public administration is the branch of activity for close to half of the employed population (44 percent). Services follow with nearly 27 percent of those employed. We divide the sector of employment into public administration (when the main branch of activity is public administration) and private (when the main branch of activity is anything except the public administration, with exceptions). Within the private sector, we distinguish between formal and informal private sector jobs. Within the private sector, employers, contractors and independent workers are considered working in the formal sector when they have accounting records, a trading license (commonly referred to as "patente") and registration in the chamber of commerce. Within the private sector, salaried individuals, family helpers and apprentices are considered working in the formal sector if the worker has a contract and is registered in social security. All remaining individuals working in the private sector are considered as working in the informal sector. The findings indicate that most of the private sector jobs are informal, with 46 percent of those employed engaging in them. Among the women who are employed, this number is even higher at 63 percent.

\section{TABLE 2.4 Distribution of Employed Individuals by Branch of Activity and Sector of Employment (percent)}

\begin{tabular}{|c|c|c|c|c|}
\hline & $\begin{array}{l}\text { Private } \\
\text { informal }\end{array}$ & Private formal & $\begin{array}{c}\text { Public } \\
\text { Administration }\end{array}$ & Total \\
\hline \multicolumn{5}{|c|}{ Overall population } \\
\hline Agriculture & 1.3 & 0.2 & 0.0 & 1.5 \\
\hline Manufacturing & 4.1 & 0.9 & 0.0 & 5.0 \\
\hline Services & 24.0 & 3.4 & 0.0 & 27.4 \\
\hline Public administration & 0.0 & 0.0 & 43.8 & 43.8 \\
\hline Other & 16.9 & 5.5 & 0.0 & 22.4 \\
\hline Total & 46.3 & 9.9 & 43.8 & 100.0 \\
\hline \multicolumn{5}{|c|}{ Women's population } \\
\hline Agriculture & 0.9 & 0.2 & 0.0 & 1.1 \\
\hline Manufacturing & 0.5 & 0.3 & 0.0 & 0.8 \\
\hline Services & 48.8 & 1.8 & 0.0 & 50.5 \\
\hline Public administration & 0.0 & 0.0 & 31.1 & 31.1 \\
\hline Other & 13.0 & 3.6 & 0.0 & 16.6 \\
\hline Total & 63.1 & 5.8 & 31.1 & 100.0 \\
\hline
\end{tabular}

\section{Source: Calculations based on EDAM4-IS.}

Notes: Includes 3,139 individuals that answered to all corresponding questions. Private sector comprises all branches of activity except public administration-agriculture, manufacturing, services (including private administration), and others (international organizations, military bases, and unspecified categories). Within the private sector, employers, contractors and independent workers are considered working in the formal sector when they have accounting records, a trading license (commonly referred to as "patente") and registration in the chamber of commerce. Within the private sector, salaried individuals, family helpers and apprentices are considered working in the formal sector if the worker has a contract and is registered in social security. All remaining individuals working in the private sector are considered as working in the informal sector. 
Outside of the public sector, the services account for the majority of the jobs available. In a country with tropical desert on the coast and in the north, and semidesert in the south-central highlands, the agricultural sector plays a minor role in employing people. The services sector takes the lion's share of employment both formally and informally. About a quarter of the employed population has an informal job in the services sector. In this group, the most common occupation is in sales (beignets, fruits, vegetables, cereals, and other fresh food), accounting for 29 percent of those employed. Half of employed women are working informally in the services sector. Among them, 59 percent sell similar kinds of products.
Regarding the size of the firm that the employed individuals work, we find that firms in the public and formal private sectors are large, many employing more than 20 individuals (Table 2.5). On the other hand, firms in the informal private sector are predominantly one-person firms, pointing to largely self-employed individuals working by themselves. The numbers for women are even higher, with nearly 47 percent of those employed working by themselves. Thus, most of the private sector in Djibouti is in the informal sector, while this sector is more dominant for women.

\section{TABLE 2.5 Distribution of Employed Individuals by Firm Size and Sector of Employment (percent)}

\begin{tabular}{|c|c|c|c|c|}
\hline & $\begin{array}{l}\text { Private } \\
\text { informal }\end{array}$ & Private formal & $\begin{array}{c}\text { Public } \\
\text { administration }\end{array}$ & Total \\
\hline Firm size & \multicolumn{4}{|c|}{ Overall population } \\
\hline 1 & 20.8 & 0.6 & 1.1 & 22.5 \\
\hline $2-3$ & 8.7 & 0.5 & 2.2 & 11.4 \\
\hline $4-5$ & 4.8 & 1.1 & 2.7 & 8.6 \\
\hline $6-10$ & 3.0 & 1.0 & 3.3 & 7.3 \\
\hline $11-20$ & 3.3 & 1.1 & 5.1 & 9.6 \\
\hline More than 20 & 6.6 & 6.1 & 27.9 & 40.6 \\
\hline Total & 47.3 & 10.4 & 42.3 & 100 \\
\hline Firm size & \multicolumn{4}{|c|}{ Women's population } \\
\hline 1 & 46.8 & 0.7 & 0.5 & 48.0 \\
\hline $2-3$ & 8.8 & 0.3 & 2.4 & 11.5 \\
\hline $4-5$ & 3.8 & 0.9 & 2.8 & 7.5 \\
\hline $6-10$ & 1.7 & 0.1 & 2.5 & 4.3 \\
\hline $11-20$ & 0.7 & 0.3 & 4.1 & 5.1 \\
\hline More than 20 & 3.6 & 3.6 & 16.4 & 23.5 \\
\hline Total & 65.4 & 5.9 & 28.7 & 100.0 \\
\hline
\end{tabular}

Source: Calculations based on EDAM4-IS.

Notes: Sample includes 2,806 individuals with complete information. Private sector comprises all branches of activity except public administration-agriculture, manufacturing, services (including private administration), and others (international organizations, military bases, and unspecified categories). Within the private sector, employers, contractors and independent workers are considered working in the formal sector when they have accounting records, a trading license (commonly referred to as "patente") and registration in the chamber of commerce. Within the private sector, salaried individuals, family helpers and apprentices are considered working in the formal sector if the worker has a contract and is registered in social security. All remaining individuals working in the private sector are considered as working in the informal sector. 
The public sector has an enormous appeal to highly qualified individuals, with important implications for the pool of private sector workers (Table 2.6). The distribution of educational attainment among public sector workers is varied: 26 percent don't have any formal education, 25 percent have only primary, and close to half of the public employees (45 percent) have at least a secondary education. Moreover, the public administration hires 7 out of every 10 Djiboutian workers with at least secondary education. Thus, the pool of available talent in the private sector is constituted of a population in which individuals with low skills are overrepresented.

The strong pull from the public sector appears to be a result of its higher wages (Table 2.7). It seems that salaried individuals working in the public administration get paid more than in the private sector. Earnings in the informal private sector, which employs the largest share of those employed, seem to be the lowest. There is also a small segment of the population that works in the formal private sector, drawing high wages. To understand the return to being employed in the public sector as well as to education, we use a regression-based framework, accounting for sector of work, number of years of work experience, and frequency of payment of wages (Table 2.8). We find that each year of formal education is associated with an increase in wages by 7.8 percent. Controlling for public sector work provides similar results. It also seems that working in the public sector is associated with higher wages, as it carries a premium of 18 percent, even after controlling for other worker's characteristics. The result also holds when the premia is estimated using categorical variables for educational attainment.

\section{TABLE 2.6 Distribution of Employed individuals by Educational Attainment and Sector of Employment (percent)}

\begin{tabular}{l|c|c|c|c|} 
& & & Public & Total \\
\hline No education/own education & Private informal & Private formal & administration & 44.8 \\
\hline Less than primary & 30.8 & 2.5 & 11.5 & 4.2 \\
\hline Primary but less than secondary & 2.5 & 0.4 & 1.3 & 23.3 \\
\hline Secondary and above & 9.1 & 3.2 & 11.0 & 27.6 \\
\hline Total & 3.9 & 3.9 & 19.9 & 100 \\
\hline
\end{tabular}

Source: Calculations based on EDAM4-IS.

Notes: Sample includes 3,132 individuals with complete information. Private sector comprises all branches of activity except public administration-agriculture, manufacturing, services (including private administration), and others (international organizations, military bases, and unspecified categories). Within the private sector, employers, contractors and independent workers are considered working in the formal sector when they have accounting records, a trading license (commonly referred to as "patente") and registration in the chamber of commerce. Within the private sector, salaried individuals, family helpers and apprentices are considered working in the formal sector if the worker has a contract and is registered in social security. All remaining individuals working in the private sector are considered as working in the informal sector.Cells show the percentage of the working population. 


\section{TABLE 2.7 Wages Earned in Private and Public Sector by Status of Employment}

\begin{tabular}{|c|c|c|c|}
\hline & Private informal & Private formal & $\begin{array}{c}\text { Public } \\
\text { administration }\end{array}$ \\
\hline \multicolumn{4}{|c|}{ Employer or self-employed } \\
\hline Sample size & 822 & 58 & 402 \\
\hline Mean monthly wages (DF) & 89,829 & 232,452 & 101,171 \\
\hline Mean wage per hour (DF) & 1,698 & 1,843 & 2,226 \\
\hline \multicolumn{4}{|l|}{ Tacheron (contractor) } \\
\hline Sample size & 186 & - & - \\
\hline Mean monthly wages (DF) & 77,123 & - & - \\
\hline Mean wage per hour (DF) & 2,646 & - & - \\
\hline \multicolumn{4}{|l|}{ Salaried } \\
\hline Sample size & 367 & 233 & 892 \\
\hline Mean monthly wages (DF) & 78,170 & 98,632 & 106,187 \\
\hline Mean wage per hour (DF) & 892 & 1,283 & 1,396 \\
\hline \multicolumn{4}{|l|}{ All } \\
\hline Sample size & 1492 & 300 & 1313 \\
\hline Mean monthly wages (DF) & 84,221 & 118,442 & 104,161 \\
\hline Mean wage per hour (DF) & 1,599 & 1,349 & 1,698 \\
\hline
\end{tabular}

Source: Calculations based on EDAM4-IS.

Note: The private sector comprises all branches of activity except public administration-agriculture, manufacturing, services (including private administration), and others (international organizations, military bases and unspecified categories). Within the private sector, employers, contractors and independent workers are considered working in the formal sector when they have accounting records, a trading license (commonly referred to as "patente") and registration in the chamber of commerce. Within the private sector, salaried individuals, family helpers and apprentices are considered working in the formal sector if the worker has a contract and is registered in social security. All remaining individuals working in the private sector are considered as working in the informal sector. A group of 117 workers were identified in an "Other" status of employment in the informal private sector only and are not shown due to the small sample size and lack of comparator groups.

Djibouti's high economic growth rate has not translated into the creation of a dynamic formal private sector. The most dominant sector of employment in Djibouti is the informal private sector, employing 46 percent. This is closely followed by the public sector, with 43 percent of those employed. Informal private jobs are more concentrated among women and tend to be largely one-person firms. Informal jobs may be considered unappealing because of lower salaries than in the public sector, low job security, and the absence of job protection and social security. For the country as a whole, the informal sector is unlikely to drive development, as informal jobs are largely low-skill jobs with low productivity. The workers engaged in informal jobs, however, may represent an untapped mass of potential entrepreneurs facing obstacles such as high government regulation. 
TABLE 2.8 Returns to Education

\begin{tabular}{|c|c|c|c|c|}
\hline & \multicolumn{4}{|c|}{ Dependent variable: log of wages } \\
\hline & [1] & [2] & [3] & [4] \\
\hline \multirow[t]{2}{*}{ Years of education } & $0.078^{\star \star *}$ & $0.073^{\star \star \star}$ & & \\
\hline & $(0.001)$ & $(0.001)$ & & \\
\hline \multirow[t]{2}{*}{ Works in public sector } & & $0.180^{\star \star \star}$ & & $0.184^{\star \star \star}$ \\
\hline & & $(0.006)$ & & $(0.006)$ \\
\hline \multirow[t]{2}{*}{ Work experience } & $0.018^{* \star \star}$ & $0.018^{\star \star \star}$ & $0.019^{\star \star \star}$ & $0.019^{* \star *}$ \\
\hline & $(0.001)$ & $(0.001)$ & $(0.001)$ & $(0.001)$ \\
\hline \multirow[t]{2}{*}{ Less than primary education } & & & $0.158^{\star \star \star}$ & $0.152^{\star \star \star}$ \\
\hline & & & $(0.014)$ & $(0.014)$ \\
\hline \multirow[t]{2}{*}{ Primary but less than secondary education } & & & $0.386^{\star \star \star}$ & $0.354^{\star \star \star}$ \\
\hline & & & $(0.008)$ & $(0.008)$ \\
\hline \multirow[t]{2}{*}{ Secondary education and above } & & & $1.064^{\star \star \star}$ & $0.997^{\star \star *}$ \\
\hline & & & $(0.009)$ & $(0.009)$ \\
\hline \multirow[t]{2}{*}{ Constant } & $13.008^{\star \star \star}$ & $13.025^{\star \star \star}$ & $13.086^{\star \star \star}$ & $13.098^{\star \star \star}$ \\
\hline & $(0.015)$ & $(0.015)$ & $(0.015)$ & $(0.015)$ \\
\hline $\mathrm{R} 2$ & 0.214 & 0.225 & 0.214 & 0.225 \\
\hline
\end{tabular}

Source: Calculations based on EDAM4-IS.

Notes: Standard errors in parentheses. ${ }^{\star \star *} p<0.01,{ }^{* *} p<0.05,{ }^{*} p<0.1$. Other variables in the regression include square of work experience and frequency of payment of wages. Public sector includes those employed declaring public administration as the main branch of activity. Private sector comprises all branches of activity except public administration-agriculture, manufacturing, services (including private administration), and others (international organizations, military bases, and unspecified categories).

The literature also emphasizes the importance of a healthy formal sector. One of the key arguments is that formal firms are the driver of economic development, while informal firms are a by-product of poverty (Rauch 1991; La Porta and Schleifer 2014). In this literature, as an economy modernizes, formal firms grow, and informality becomes less prevalent. Countries with an abundance of informal firms suffer from low aggregate productivity, too. As countries develop, more workers transition from the informal to the formal sector. Thus, efforts encouraging the growth of the formal sector in Djibouti may be important to stimulate job-driven growth. While the expansion of a formal sector is good for development, informality is found to be correlated to the poverty status of individuals in
Djibouti. Evidently, poverty rates are six times higher when the household head is employed in the informal private sector as compared to the formal private sector (Table 2.9). Individuals living in households where the head is employed in the informal private sector also spend more on health-related expenses, pointing to their vulnerability to health shocks. In addition, Table 2.10 displays the share of each type of income in the total household income for the population as a whole and the bottom 20 percent. About 31 percent of the income for the bottom 20 percent comes from formal and public sector work, while this share stands at 51 percent for an average Djiboutian. This contrast shows that the poor depend heavily on informal sector work, more so than an average Djiboutian. 


\section{TABLE 2.9 Characteristics by Sector of Employment of Household Heads}

\begin{tabular}{|c|c|c|c|}
\hline & $\begin{array}{l}\text { Private } \\
\text { informal }\end{array}$ & Private formal & $\begin{array}{c}\text { Public } \\
\text { administration }\end{array}$ \\
\hline Average monthly wages of head (DF) & 87,081 & 121,576 & 101,077 \\
\hline Extreme poverty rate & $18 \%$ & $3 \%$ & $11 \%$ \\
\hline Extreme poverty rate when poverty line is $5 \%$ higher & $20 \%$ & $6 \%$ & $12 \%$ \\
\hline Extreme poverty rate when poverty line is $10 \%$ higher & $22 \%$ & $6 \%$ & $13 \%$ \\
\hline Percentage of household experienced a health problem & $28 \%$ & $24 \%$ & $27 \%$ \\
\hline Health expenses as a percentage of total: average & $3 \%$ & $2.5 \%$ & $1.9 \%$ \\
\hline Health expenses as a percentage of total: 90th percentile & $7.2 \%$ & $6.7 \%$ & $4.9 \%$ \\
\hline
\end{tabular}

Source: Calculations based on EDAM4-IS.

Notes: Wage information is available for 2,415 individuals and 1,531 heads. The rest of the sample of heads includes 1,996 individuals with complete information. Private sector comprises all branches of activity except public administration-agriculture, manufacturing, services (including private administration), and others (international organizations, military bases, and unspecified categories). Within the private sector, employers, contractors and independent workers are considered working in the formal sector when they have accounting records, a trading license (commonly referred to as "patente") and registration in the chamber of commerce. Within the private sector, salaried individuals, family helpers and apprentices are considered working in the formal sector if the worker has a contract and is registered in social security. All remaining individuals working in the private sector are considered as working in the informal sector. Cells show the percentage of the working population.

\section{TABLE 2.10 Share of Various Income Sources in Total Income}

\begin{tabular}{l|c|c|} 
& Overall & Bottom 20\% \\
\hline Share of informal private labor income & $37 \%$ & $40 \%$ \\
\hline Share of formal private labor income & $8 \%$ & $2.5 \%$ \\
\hline Share of public labor income & $41 \%$ & $21.5 \%$ \\
\hline Share of transfers & $10.5 \%$ & $20.1 \%$ \\
\hline Share of revenue from agricultural economic activity & $3.8 \%$ & $14.3 \%$ \\
\hline
\end{tabular}

Source: Calculations based on EDAM4-IS.

Notes: Only households that reported income and have complete information are included (2,426 and 532 households, respectively). Bottom 20 percent is calculated based on the full distribution of consumption per adult equivalent. Private sector comprises all branches of activity except public administration-agriculture, manufacturing, services (including private administration), and others (international organizations, military bases and unspecified categories). Within the private sector, employers, contractors and independent workers are considered working in the formal sector when they have accounting records, a trading license (commonly referred to as "patente") and registration in the chamber of commerce. Within the private sector, salaried individuals, family helpers and apprentices are considered working in the formal sector if the worker has a contract and is registered in social security. All remaining individuals working in the private sector are considered as working in the informal sector. 
There are also obstacles in the demand side of the labor market that prevent the continuous development of a dynamic formal private sector. Some insights can be directly obtained from the perceptions of the firms conducting business in the country. According to the enterprise survey conducted in 2013, ${ }^{24}$ high tax rates were found to be a hindrance for 15 percent of the small and medium firms. The low educated workforce was a constraint declared by 13 percent of medium-size firms and 28 percent of large firms. About 35 percent of the large firms also reported the paucity and quality of electricity as a constraint. Yet another barrier to running a business smoothly was corruption, which was declared by 14 percent of small firms and 15 percent of large firms. About 43 percent of firms believe they needed to give gifts to secure a government contract, and this percentage was higher among larger firms at 66 percent.

Other findings from the survey include 50 percent reporting electricity being the main problem. Firms were found to be suffering from about 1.3 power outages in a typical month, leading to losses of about 2.8 percent of sales, with (slightly) higher losses being suffered by medium-size firms (20-99). The average number of days needed to get an electric connection was found to be 34.1 (small firms took 25 days; medium-size firms took about 57.6 days, and large firms took about 28 days). At the same time, the average number of days needed to get a water connection was 16.1. Finally, just less than half of firms (47.1 percent) believe that the court system in Djibouti is fair, impartial, and uncorrupted.

Firm usage of Internet is relatively high (40.7 percent) with respect to the MENA region (36.2 percent) and other lower middle-income countries (36.9 percent)-although differences exist between small firms (1-19 workers) at 35 percent and large firms (100 or more workers) at 74.9 percent. The use of email to communicate with clients and suppliers is also higher in Djibouti (71.6 percent) than other countries in the MENA region (50) and other lower middle-income counties (64.8 percent). Meanwhile, the percentage of full-time female workers is very low: 26.6 percent, even lower than the average of lower middleincome countries (32.4 percent).

Access to credit did not seem to be an issue, as 30.5 percent of all firms have a bank loan or line of credit. The rate is 23.6 percent among small firms, 35.9 percent among large firms, and highest among the medium firms at 44.7 percent. The average rate is much higher than that found in MENA: 19.8 percent (but slightly lower than in lower middle-income economies' 34.7 percent). Not surprisingly, 91.6 percent of firms have a checking and/ or savings account, including 87.7 percent of small firms reporting so.

Djibouti has made tremendous strides in the "doing business" (DB) arena in the past few years. As per the DB 2014 report (World Bank 2014), Djibouti was in 160th place of all countries evaluated. Several areas of improvement were identified: starting a business (a rank of 127), getting electricity (144), registering property (133) and getting credit (180), among others. Of particular attention to starting a business were the costs associated with startup (184.7 percent of income per capita between all the permits needed) and those to get electricity: 180 days at a cost of 7,487 percent of income per capita.

In the DB 2019 report (World Bank 2019), Djibouti made significant strides, jumping 55 places and placing itself on 99th place (as opposed to 154th a year before). The largest gains came from changes in protecting minority investors, registering property and getting electricity. Other improvements were seen in insolvency and starting a business. Dealing with construction permits was the only index in which a decrease was observed (ranking fell from 84 to 101).

24 Source: World Bank Enterprise Survey 2013.

The sample comprised 266 formal nonagricultural private firms. Public utilities, government services, health care, and financial services sectors are not included in the sample." 
Regarding the indicator related to starting a business, there were improvements in the number of procedures and time required to get the entire process done. It is notable, however, that the actual cost of opening a business increased when compared to DB 2018: it was estimated at 35 percent of income per capita, whereas the latest indicator is 41.9 percent. These costs reflect typically spending DF 90,000 on a lawyer to draft the company's articles, DF 29,000 needed for registration fees, name registration, service fee of the Guichet unique (one stop shop), registration of the articles of association (including DF 1,000 per page for the stamp duty), as well as DF 7,000-10,000 needed to create the company seal, letterhead, and books. It is true that this cost has come down substantially: it was estimated to be 184 percent of income per capita in the DB 2014, but it is still higher than the MENA average (22.6 percent) and that of Organisation of Economic Co-ordination and Development (OECD) high-income countries (3.1 percent).

The price of electricity seems to have slightly decreased in the past few years. There are four procedures required to get electricity now (lower than the MENA average of 4.7), and there has been a substantial improvement in the number of days required to secure electricity: down from 125 days to 52 (also lower than 72.4 MENA average). In addition, there has been an improvement in the relative cost of setting up the electricity service: 941.8 percent of income per capita (from 5,974 percent a year ago), although this is higher than MENA (479.9) and OECD high-income (64.2) averages. Costs are accrued from paying the estimate and obtaining external works from Electricité de Djibouti, signing the supply contract, and obtaining the final connection. It is notable that the reliability of supply and transparency score of 0 has not moved and is much lower than 4.2 in MENA and 7.5 in OECD. Some improvements have been found in the ability to conduct business over time in Djibouti, but many concerns persist and make it difficult for the formal private sector to boom, in line with the high economic growth of the past few years.

Overall, even though the youth have higher educational attainment and women are catching up to men, these population groups are still the least attached to the labor market. The most dominant sectors of employment in Djibouti are the informal private sector and public sector, which together employ 90 percent of the population. Salaries are higher in the public and formal sector as compared to the informal private sector too. For the country as a whole, the informal sector is unlikely to drive development, as the jobs are largely low-skill jobs with low productivity. The workers engaged in informal jobs may represent potential entrepreneurs who face obstacles such as high government regulation. Thus, to develop the labor market and absorb the increasingly educated population, obstacles in the labor demand side should also be addressed and policies to boost the formal sector must be promoted. 


\section{REFERENCES}

Ashenfelter, O., and A. Krueger. 1994. Estimates of the Economic Return to Schooling from a New Sample of Twins. The American Economic Review. Vol. 84, No. 5 (Dec., 1994), pp. 1157-1173

Azevedo, J. P., G. Inchauste, S. Olivieri, J. Saavedra, and H. Winkler. 2013. Is Labor Income Responsible for Poverty Reduction? A Decomposition Approach. Washington, DC: World Bank.

Barros, R. P. D., M. D. Carvalho, S. Franco, and R. Mendonça, R. 2006. Uma análise das principais causas da queda recente na desigualdade de renda brasileira. No 1203, Discussion Papers, Instituto de Pesquisa Econômica Aplicada- IPEA.

Card, D., and A. B. Krueger. 1992. "Does School Quality Matter? Returns to Education and the Characteristics of Public Schools in the United States." Journal of political Economy 100 (1): 1-40.

DISED (Direction de la Statistiques et des Etudes Démographiques). 2012a. Annuaire Statistique 2012.

DISED. 2012b. EDAM 3-IS. Djibouti: DISED.

DISED. 2017a. Annuaire Statistique 2017. Djibouti: DISED.

DISED. 2017b. EDAM4-IS. Djibouti: DISED.

Duflo, E. 2001. "Schooling and Labor Market Consequences of School Construction in Indonesia: Evidence from an Unusual Policy Experiment." American Economic Review 91 (4): 795-813.

Gong, H., A. Leigh, and X. Meng. 2012. "Intergenerational Income Mobility in Urban China." Review of Income and Wealth 58 (3): 397-592.
Heckman, J. J., L. J. Lochner, and P. E. Todd. 2006. "Earnings Functions, Rates of Return and Treatment Effects: The Mincer Equation and Beyond." Handbook of the Economics of Education 1: 307-458.

La Porta, R., and A. Shleifer. 2014. "Informality and Development." Journal of Economic Perspectives 28 (3): 109-26.

López-Calva, L. F., and C. Rodríguez-Castelán, 2016. Pro-Growth Equity: A Policy Framework for the Twin Goals. Washington, DC: World Bank.

Ministere de l'Education Nationale et de la Formation Professionnelle. 2018. "Cartographie des ecoles de base." http://qgiscloud.com/Destini/projet_ETS_djibouti/ ?bl=mapnik\&st=\&l=ecole-djibouti\%2Cregion-djibouti\&t =projet_ETS_djibouti\&e=4790662\%2C1291018\%2C4810 982\%2C1300946.

Narayan, Ambar, Roy Van der Weide, Alexandru Cojocaru, Christoph Lakner, Silvia Redaelli, Daniel Gerszon Mahler, Rakesh Gupta N. Ramasubbaiah, and Stefan Thewissen. 2018. Fair Progress?: Economic Mobility Across Generations Around the World. Washington, DC: World Bank. https://openknowledge.worldbank.org/ handle/10986/28428.

Nunez, J. I., and L. Miranda, L. 2010. "Intergenerational Income Mobility in a Less-Developed, High-Inequality Context: The Case of Chile." B. E. Journal of Economic Analysis and Policy 10 (1)

Piraino, P. 2015. "Intergenerational Earnings Mobility and Equality of Opportunity in South Africa." World Development 67: 396-405. 
Psacharopoulos, G., and H. A. Patrinos. 2018. "Returns to Investment in Education: A Decennial Review of the Global Literature." Education Economics 26(5): 445-458.

Rauch, J. E. 1991. "Modelling the Informal Sector Formally." Journal of development Economics 35 (1): 33-47.

WDI (World Development Indicators). Database. Washington, DC: World Bank. https://datacatalog. worldbank.org/dataset/world-development-indicators.

World Bank. 1997. Djibouti. Crossroads of the Horn of Africa. Poverty Assessment Report 16543-DJl. Washington, DC: World Bank.

World Bank. 2014. Doing Business. Washington, DC: World Bank.

World Bank. 2019. Doing Business. Washington, DC: World Bank.

UNESCO Institute for Statistics. 2018a. "Literacy Rate, Adult Total (\% of People Ages 15 and Above)." World Bank Open Data. https://data.worldbank.org/indicator/SE.ADT. LITR.ZS.

UNESCO Institute for Statistics. 2018b. "Literacy Rate, Youth Total (\% of People Ages 15-24)." World Bank Open Data. https://data.worldbank.org/indicator/SE.ADT.1524. LT.ZS.

World Bank. 1997. Djibouti: Crossroads of the Horn of Africa. Poverty Assessment Report 16543-DJI. Washington, DC: World Bank. http://documents. worldbank.org/curated/en/557421468748480282/ Djibouti-Crossroads-of-the-Horn-of-Africa-povertyassessment
World Bank. n.d. "Tables, Charts, and Technical Notes." Global Consumption Database. http://datatopics. worldbank.org/consumption/detail.

World Bank. 2018a. Economic Transformation in Djibouti: Systematic Country Diagnostic. Washington, DC: World Bank.

World Bank. 2018b. Poverty and Shared Prosperity 2018: Piecing Together the Poverty Puzzle. Washington, DC: World Bank.

World Bank. 2018c. World Development Report 2018: Learning to Realize Education's Promise. Overview booklet. Washington, DC: World Bank.

World Bank and OECD (Organization for Economic Cooperation and Development). 2018. "GDP Growth (Annual \%)." World Bank Open Data. https://data.worldbank.org/ indicator/NY.GDP.MKTP.KD.ZG. 


\section{SELECTED TOPICS TO INFORM PUBLIC POLICY IN DJIBOUTI}

Chapter 3 provides a compilation of short notes that exploit recent data to address current policy questions relevant to the Djiboutian context. The EDAM4 provides a very recent snapshot of the population (as of 2017) that allows us to run simulations of the potential impact of certain policy actions and at the same time better understand the current state of certain populations in the country and identify their future needs.

The first section, "Introducing competition to the telecom sector," presents an overview of the telecom sector in Djibouti. It describes the current state of affairs, challenges in access and coverage, and the take-up of telecom services among the population. Based on international experiences, the section runs a hypothetical scenario in which the sector is opened to new competitors. Using a World Bank tool, we present the potential implications for welfare of the price changes that are expected to accompany higher competition.

The second section, "Improved targeting of social programs," discusses the use of recent data as one of the targeting tools to help support the most vulnerable in Djibouti. Proxy means test (PMT) approaches have been used in the country for several years, with the previous model being defined in 2013. However, with the availability of new data, coupled with an updated view of the welfare landscape in the country and the recognized needs of social programs, we are able to identify and better serve the poorest among the Djiboutian population. The section presents the development of a PMT model using EDAM4 data and discusses its performance. The section concludes with a simulation of the potential benefits for poverty reduction by the expansion of a social program that uses PMT as its primary targeting mechanism.

Finally, in the third section, "Nomads and pastoralists," we discuss nomadism in Djibouti. According to the Djibouti census of 2009, about 20 percent of the population was found to be nomadic. Since this is a significant percentage of the Djiboutian population, it is important to know more about the well-being of this population and implications they may have for public policy.

\section{INTRODUCING COMPETITION TO THE TELECOM SECTOR}

The rise of digital technologies and the digital economy offers a once-in-a-generation opportunity to unlock new pathways for rapid economic growth, economic mobility, innovation, job creation, and access to quality services that would have been unimaginable even a decade ago. The accelerating pace of technology diffusion, the convergence of multiple technologies, and the emergence of global platforms are disrupting traditional development models. Digital technologies are expanding access to global markets, changing business models, and delivering enormous productivity gains. Digitization is expanding access to basic needs and services. In 2016, the global digital economy was worth $\$ 11.5$ trillion, or 15.5 percent of global gross domestic product (GDP). It is expected to reach 25 percent in less than a decade, far outpacing the growth of the 'traditional' economy. 
The information communications technology (ICT) sector holds enormous potential for welfare improvements by creating and enabling more jobs and economic opportunities, improving labor productivity, and generating more consumer surplus (World Bank 2016). Through these channels, continuous development of ICT services holds enormous potential for economic growth and poverty alleviation. While the Internet could be an effective force of development, it also poses potential risks. Some of the key risks highlighted in the report are the risk of concentration of market power as well as greater inequality among the nation's population, manifested by the digital divide. Further, issues such as privacy, cybersecurity, and Internet governance need to be kept in mind as approaches to regulate the Internet are considered. Djibouti is particularly well placed to take advantage of the digital economy. The country has a regional comparative advantage as the landing site of the undersea fiber optic ICT cables. The full potential of this geostrategic position does not seem to have been exploited, however. The development of the sector has been driven by the economic strategy of Djibouti Telecom (DT) - the single national fixed and mobile operator to provide ICT services. ${ }^{25}$ DT has a monopoly in all telecommunications markets, including those that are typically open to competition such as mobile and data services. It represents a significant portion of the economy, with revenues accounting for up to 6 percent of GDP (World Bank 2015).

DT's strategy is outward oriented, selling much of its capacity on the international market, mainly to Ethiopia. The operator has banked on the country's geostrategic position between the Middle East and Africa to successfully become a reliable offeror of connectivity between the two regions for global communications carriers. Unfortunately, this approach has not been equally matched by efforts to expand broadband access and use in the domestic market. DT's relatively cheap bandwidth is not widely offered to consumers and businesses locally, leaving the domestic market in shortage.

\section{FIGURE 3.1 Selected ICT World Rankings for MENA and SSA countries}

\section{ITU, ICT \\ Development Index Ranking 2016}

\section{UN, e-government ranking 2016}

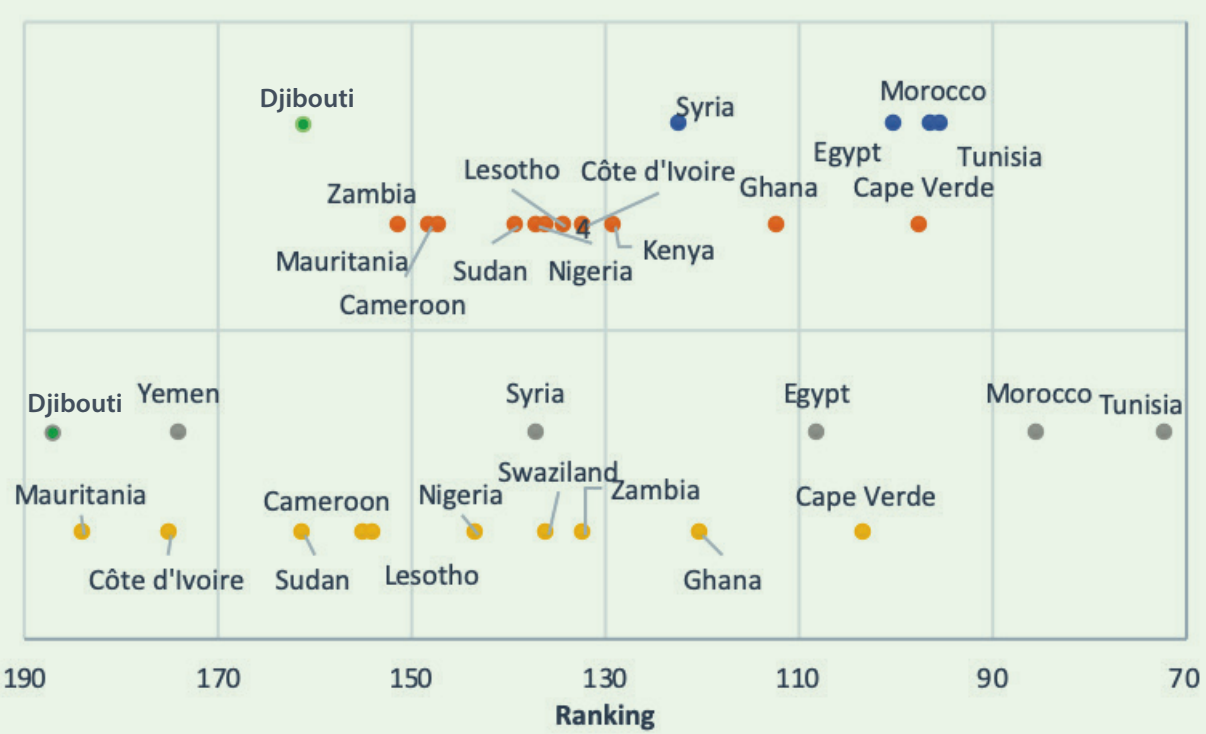

Source: ITU 2017; UNDESA 2017.

Notes: MENA countries in blue, SSA countries in orange. Djibouti's 2016 rank shown in green.

25 The only two other countries in the world with a single operator are Ethiopia and Cuba. North Korea introduced a second mobile operator in 2015. 
A lack of competition to drive service delivery, productivity, and innovation could be one reason for the poor performance in the sector. In 2016, Djibouti ranked 161 st out of 175 countries in the ICT Development Index published by the United Nations International Telecommunications Union (ITU 2017), the last place among lower middle-income countries (Figure 3.1). More worryingly, the country has fallen in the rankings over the past five years. Another ranking, provided by the United Nations Department of Economic and Social Affairs (UNDESA), provides a similar conclusion when evaluating the country's e-government: Djibouti was ranked 187th out of 193 countries in 2016, and its ranking has dropped since 2010. ${ }^{26}$ Finally, GSMA (Global System Mobile Association) estimates that the unique mobile subscription penetration represents less than 30 percent of the total population in 2018-lagging the Sub-Saharan Africa (SSA) average of 45 percent and the MENA average of 64 percent.

Unfortunately, the (under)performance of the ICT sector has significant macroeconomic effects on the economy and poverty reduction (World Bank 2016). For example, in rural Peru, the expansion of mobile network coverage boosted household real consumption by 11 percent (Beuermann, McKelvey, and Vakis 2012). The ICT sector has a great capability to enable job creation and innovation in the private sector, with the corresponding increase in economic opportunities for the population. Moreover, the Internet is also an enabler of higher labor productivity by means of lowering information and search costs. For example, the introduction of mobile phones in the grain markets of Niger led to farmers obtaining grain price information over the phone, thereby reducing search costs by 50 percent (Aker 2010) and reduced dispersion of grain prices across markets by 10 percent (Aker and Mbiti 2010). People's perceptions also reveal that the Internet has led to an increase in consumer welfare by making several products and services available digitally. From the standpoint of both the government and the private sector, the Internet can bring major benefits in the provision and delivery of services. Digital identification can also improve participation of and help for the disadvantaged groups in the country to become integrated. The advantages of a well-developed ICT sector are manifold and transformational.

\section{PROVISION OF ICT SERVICES IN DJIBOUTI}

The sluggish development of the ICT sector and limited availability of digital services have differential effects across the income distribution. The subgroup of the population that is most affected by the sectoral environment is expected to be the (mostly poor) rural population of Djibouti. Despite having one of the highest proportions of urban population among the lower middle-income countries in MENA and SSA (with about 85 percent of the population), mobile broadband coverage in Djibouti in 2018 remains below the regional average (at about 76 percent) and far lower than many MENA or SSA countries that have a smaller share of urban population (GSMA 2018). This low national coverage rate implies that the vast majority of the rural population (which account for 23 percent of the total population) have no mobile broadband coverage in Djibouti.

Further evidence of the disparities of access can be found in the recent EDAM4, conducted in 2017. Results from the survey show the extent of the digital gap between the richest population and the poorest population. Eightynine percent of the households in the richest quintile (the 20 percent of households with the highest consumption levels) own a least one mobile phone, a figure similar to the households in the third quintile, where 81 percent own

26 The recent launch of the e-government site by the Agence Nationale des Systèmes d'Information de l'État is not likely to be captured in this ranking. 
at least one mobile phone. However, the figure drops to 70 percent for the second quintile, and 41 percent for poorest quintile (the bottom 20 percent). The discrepancy is higher in relative terms for computer ownership: whereas 27 percent of the households in the top quintile own a computer, there are virtually no households in the bottom 20 percent that own one (Figure 3.2). As the richest households are mostly located in urban areas and the poorest households are mostly located in rural areas, there is a geographical digital divide between the urban population, where 70 percent of the households own at least one mobile phone, and the rural population, where only 25 percent of the households own a mobile phone (Figure 3.3).

The lack of mobile phone infrastructure (and associated coverage) in rural areas-combined with less than optimal transport infrastructure and low penetration of telephone service-helps explain why a large share of the rural population remains offline. Only one-third of the rural population is less than 10 minutes away from a location where a phone call can be made, compared to twothirds of the urban population. Even worse, a third of the

\section{FIGURE 3.2 Digital gap between the richest and poorest households by quintile}

\begin{tabular}{|c|c|}
\hline National average & $10 \%$ \\
\hline Richest quintile & $27 \%$ \\
\hline 4th quintile & $9 \%$ \\
\hline 3rd quintile & $3 \%$ \\
\hline 2nd quintile & $70 \%$ \\
\hline Poorest quintile & $\begin{array}{ll}0 \% & 41 \%\end{array}$ \\
\hline
\end{tabular}

Source: Calculations based on EDAM4-IS.

\section{FIGURE 3.3 Digital gap between urban and rural households}

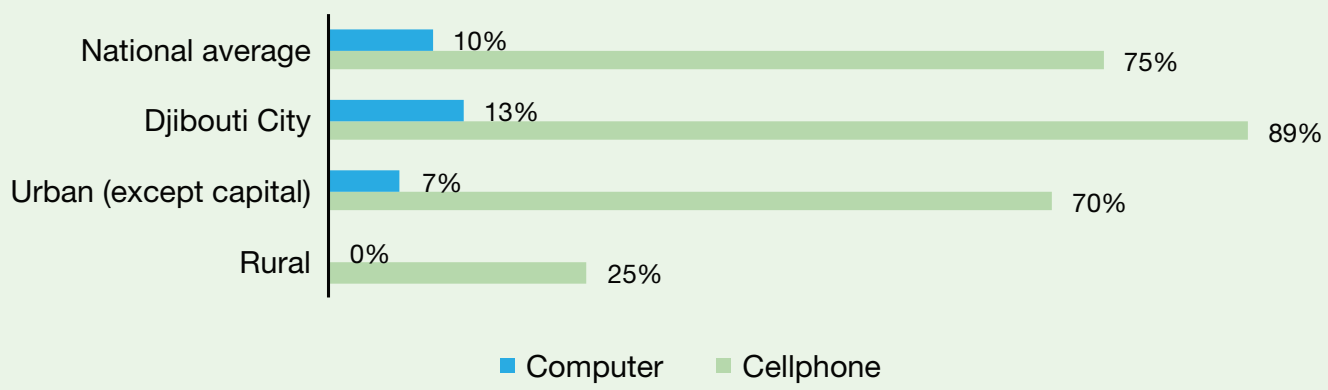

Source: Calculations based on EDAM4-IS. 
rural population are more than an hour away from such infrastructure, compared to less than 5 percent for the urban population (Figure 3.4).

Affordability also appears to play an important role in explaining the low coverage of ICT services. Gelvanovska, Rogy, and Rossotto (2014) estimated that the price of fixed broadband in Djibouti would absorb roughly the whole income of the poorest 60 percent of the population. Currently, the cost of a basic asymmetric digital subscriber line (ADSL) package (3 megabits per second, or Mbps) in Djibouti is about DF 90,000-100,000 per year (Table 3.1). This is higher than the estimated average annual consumption per capita of the bottom 20 percent of the population, and roughly equal to the estimated yearly per

\section{FIGURE 3.4 Travel Distance from Telephone Service Infrastructure}

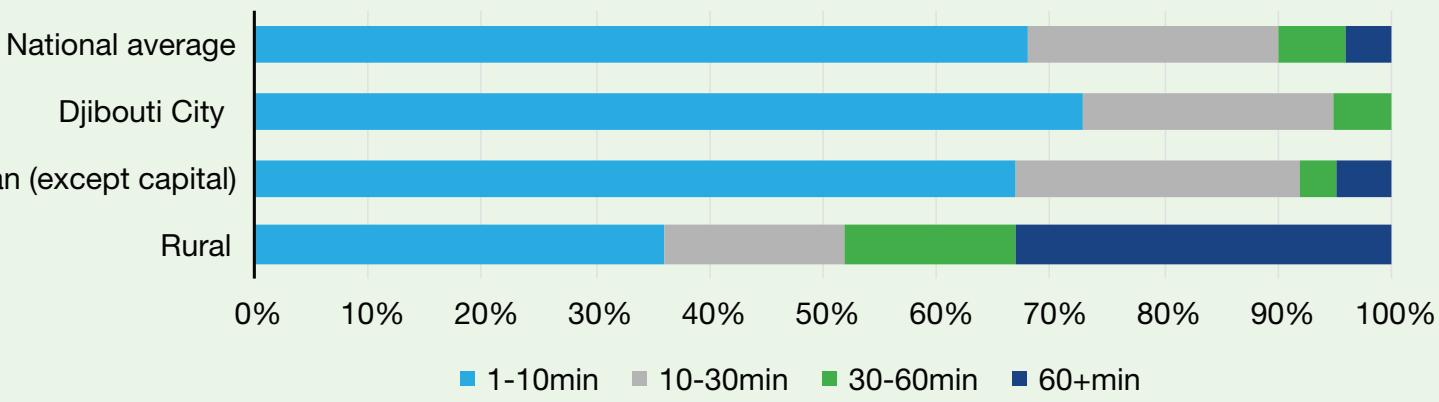

Source: Calculations based on EDAM4-IS.

capita consumption of the third decile of the population

(Table 3.2). A 4 Mbps Internet package would instead be equivalent to the yearly consumption for an individual belonging to the fifth decile of the population. The cost for the fastest ADSL service (6 Mbps) is roughly equal to the consumption level of an individual belonging to the average household in the ninth decile. ${ }^{27}$ It is notable that the prices from 2018 are substantially lower than the costs before; according to ITU (2018), DT had cut the price of an entrylevel plan by 70 percent between 2016 and $2017 .{ }^{28}$

\section{TABLE 3.1 Djibouti Telecom Costs, by Service (Djiboutian francs, DF)}

\begin{tabular}{l|c|c|c|c}
\multicolumn{5}{c}{ ADSL for private use* } \\
Available plans & $\mathbf{3}$ Mbps & $\mathbf{4}$ Mbps & $\mathbf{5}$ Mbps & $\mathbf{6}$ Mbps \\
\hline Monthly plan & 9,000 & 14,000 & 18,000 & 25,000 \\
\hline Yearly plan (15\% discount) & 91,800 & 142,800 & 183,600 & 255,000 \\
\hline
\end{tabular}

Source: Djibouti Telecom, http://www.djiboutitelecom.dj/particulier-internet-adsl-particulier.html, accessed November 22, 2018.

* Internet for particuliers (private individual).

27 To put this estimate in context, in 2018, the Broadband Commission for Sustainable Development agreed on a target for 2025 for entry-level broadband services at less than 2 percent of monthly gross national income (GNI) per capita. The current estimate for Djibouti for a fixed-broadband basket is 9.8 percent of GNI per capita (ITU 2018).

28 The price drop was accompanied by a reduction in the cap (from 50 gigabits to 30 gigabits per month) and the speed (from 3 to 1 Megabytes/s). 


\section{TABLE 3.2 Average per Capita Consumption (DF by Quintile)}

\begin{tabular}{l|c|} 
Quintile & Average per capita consumption (annual) \\
\hline 1 & 56,182 \\
\hline 2 & 108,506 \\
\hline 3 & 156,757 \\
\hline 4 & 224,548 \\
\hline 5 & 496,690 \\
\hline National & 208,224 \\
\hline
\end{tabular}

Source: Calculations based on EDAM4-IS.

\section{POTENTIAL IMPACT OF A NEW ENTRANT ON RETAIL PRICES IN DJIBOUTI}

While there is a broad consensus that regulatory reform in telecommunications is beneficial for businesses and individual consumers, it is very difficult to assess ex ante the evolution of the performances of the sector with expected changes in firm ownership, regulatory framework, and market structure (especially with the introduction of a second operator in a monopolistic market). Boylaud and Nicoletti (2001) conducted a study on Organization for Economic Co-operation and Development (OECD) countries and concluded that the gains in the reduction of mobile prices were linked to the number of competitors (proxied by the share of new entrants or by the number of competitors), the market shares of the competitors, the prospect of competition (as proxied by the number of years remaining before liberalization), the specificities of the national markets, and other factors (effect of ownership, economic structure, technology, and price rebalancing).

In 2002, the European Commission released a report on the dynamics of the telecommunications sector in the European Union after market liberalization (EC 2002).
Findings suggest that new entrants usually do charge less than incumbent operators, ${ }^{29}$ but it is not clear the extent to which potential reductions in quality of service (such as a lower national mobile coverage or a lower quality of customer care) affect the overall benefits of consumers.

More recent studies have focused on the effect of market concentration on retail prices. For example, Genakos, Valletti, and Verboven (2015) focused on the link between measures of market concentration and prices paid by end users in mature OECD markets. They conclude that one additional competitor is associated to a price reduction of approximately 8.6 percent (ranging from 7.9 percent to 15.9 percent, depending on numerous factors). At the same time, the authors caution that impacts from entry and mergers of different firm sizes could not be reliably established. A study published by the British regulator Ofcom in 2016 contains a cross-country econometric analysis of the effects of the number of mobile networks on prices, and the effects of "disruptive" entry in mature OECD markets (Ofcom 2016). ${ }^{30}$ It finds that an increase in the number of mobile networks reduces prices by 7.3 to 9.2 percent. It also finds that where a disruptive player is present, prices are lower by 10.7 to 12.4 percent. This brings the total effect of disruptive new entry to 17.2 to 20.5 percent.

29 For national calls, the study finds that operators charged up to 56 percent less in the United Kingdom, 46 percent less in France, and 35 percent less in Germany.

30 A disruptive player is defined by Ofcom as a player that presents the following behavior: (i) introduction of new innovative services which supersede others, (ii) introduction of new production technologies that increase efficiency for existing services, and (iii) aggressive behavior where the player competes vigorously and prioritizes gaining market share above other considerations such as profits or cost recovery in the short or even medium term. 
Even though the introduction of a new mobile entrant will surely have an impact on the performance of the sector and potentially decrease retail prices significantly, it is difficult to quantify this effect ex ante. Based on crosscountry empirical analysis, the decrease in retail prices induced by a new entrant ranges from 10 to 20 percent (in mature markets), and up to 35 to 56 percent (in developing markets, that is, the mobile market situation in the European Union in the early 2000s). ${ }^{31}$

The following cases from international experience can provide hints at the potential effects in the Djiboutian context. The examples listed come from countries with a comparable population, and that have been able to develop a controlled sector by introducing a second mobile operator alongside the incumbent:

\section{Cabo Verde-Population 500,000 and two telecom operators: Cabo Verde Telecom and T+.} Following an unsuccessful bidding process in 2004 for the second mobile license, the government began direct negotiations with a foreign investor (Alexander Group Telecommunications), which launched the $\mathrm{T}+$ operator in 2005 on a limited scale. The treasury benefited from the sale of the second license, which was purchased for the equivalent of US\$ 2 million (about CVEsc 180 million in local currency). In 2007, the second operator finally launched its mobile services on the island of Santiago, which is home to about half of the population, and the single penetration of mobile subscribers (percentage of the population with at least one mobile line) doubled in two years, from 21 percent in 2007 to 40 percent in 2009.

\section{Bahrain-Population 1.2 million and three telecom operators: Bahrain Telecommunication Company, Zain Bahrain and Viva. The second} operator, Zain Bahrain, is 55 percent owned by the Kuwaiti operator Zain Group, which obtained a license in 2003. The third operator is Saudi and obtained his license in 2009 and was fully operational in 2011. Additional licenses generated approximately US\$33 million (approximately BD 83 million in local currency) and approximately US\$500,000 in annual spectrum fees. The introduction of the third operator boosted competition and increased subscriber penetration from 65 percent in 2010 to 91 percent in 2009.

\section{Brunei-Population 393,162 and two telecom} operators: DST-Group and B-mobile. The second operator (B-mobile) was a joint venture between the local fixed operator TelBru and a local conglomerate (QAF Comserve) and launched its operation in 2005. The amount of the second license is not disclosed, but the introduction of competition boosted single subscriber penetration from 47 percent in 2005 to 67 percent in 2007.

\section{Mauritius-Population 1.3 million and three telecom operators: Emtel, Cellplus, and MTML.} The first two mobile operators launched their GSM (Global System of Mobile) services in 1996 (Cellplus) and 1999 (Emtel), so that competition in Mauritius was already effective in the early 2000s. The third operator obtained its license in 2005. Because competition between the first two operators was already fierce, with strong mobile growth and lower prices, the introduction of the third operator had a minor impact on the market.

To further explore the potential effects of changes to the structure of the ICT sector, we conduct the following thought exercise. In the presence of more competition, what could be the potential effects on prices in telecommunication services in Djibouti? And, what would be the potential effects in terms of increased welfare for households? The results of this simulation are presented in the next section.

31 Another example is the entry of AT\&T in Mexico, where a decrease of about 13 percent in the price of mobile services was experienced. 


\section{SIMULATING INCREASED COMPETITION IN THE ICT SECTOR IN DJIBOUTI}

We use the EDAM4 data from 2017 to explore the ICT sector in Djibouti and conduct a simulation on the potential benefits of market forces in decreasing the prices of ICT services. We present basic summary statistics on expenditures related to the sector. Next, we discuss the methodology and the tool used for simulations, before presenting the findings.

We identify as "consumer of telecom services" the households that responded having spent money during the past month on fees on phone services (fixed or mobile), bought mobile "credit," used a phone booth, and/or paid a monthly contract for phone (fixed or mobile) or Internet services. The relatively low penetration of telecommunication services among the Djiboutian population partly explains why only about 22 percent of the population is found to be a telecom user, with this share being driven mostly by purchase of cards of credit for mobile phone minutes. Moreover, there are marked differences in usage rates across the consumption distribution. Among the poorest decile, less than 5 percent of the population declared having expenditures on telecom services. This rate increases, with the level of consumption reaching 23 percent around the middle of the distribution and to about 35 percent among the top 10 percent (Table 3.3). Expenditures on telecom services also appear to be correlated with the level of consumption, with users in the top 10 percent of the distribution spending more than 10 times the level of expenditures of those in the bottom 10 percent. It is notable that users devote similar shares of their total expenditures to telecom services.

\section{TABLE 3.3 Summary Statistics on Telecom Expenditures and Users}

\begin{tabular}{|c|c|c|c|c|c|c|c|}
\hline $\begin{array}{l}\stackrel{0}{0} \\
\text { Q }\end{array}$ & 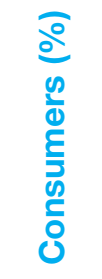 & 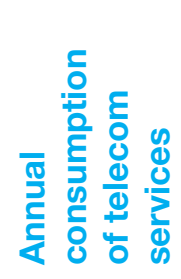 & 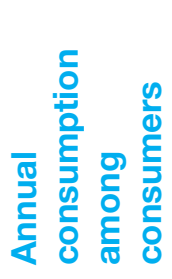 & 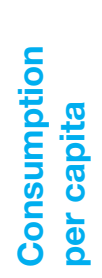 & 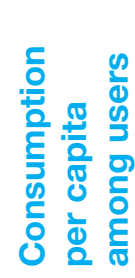 & 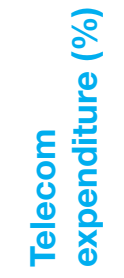 & 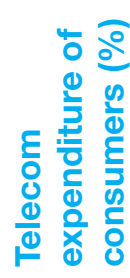 \\
\hline 1 & $4.1 \%$ & 166 & 4,009 & $0.0 \%$ & $1.2 \%$ & 40,491 & 50,457 \\
\hline 2 & $13.1 \%$ & 1,004 & 7,668 & $0.2 \%$ & $1.3 \%$ & 71,982 & 74,627 \\
\hline 3 & $16.6 \%$ & 1,570 & 9,468 & $0.2 \%$ & $1.1 \%$ & 97,836 & 99,662 \\
\hline 4 & $22.2 \%$ & 2,401 & 10,800 & $0.2 \%$ & $1.1 \%$ & 119,223 & 120,107 \\
\hline 5 & $22.9 \%$ & 6,946 & 30,367 & $0.4 \%$ & $1.9 \%$ & 143,328 & 143,115 \\
\hline 6 & $22.8 \%$ & 4,557 & 19,967 & $0.4 \%$ & $1.6 \%$ & 170,249 & 169,540 \\
\hline 7 & $27.2 \%$ & 5,034 & 18,504 & $0.4 \%$ & $1.4 \%$ & 203,287 & 202,935 \\
\hline 8 & $25.3 \%$ & 7,525 & 29,757 & $0.4 \%$ & $1.7 \%$ & 245,532 & 247,397 \\
\hline 9 & $29.2 \%$ & 17,411 & 59,569 & $0.7 \%$ & $2.4 \%$ & 318,732 & 324,248 \\
\hline 10 & $34.6 \%$ & 21,704 & 62,762 & $0.6 \%$ & $1.8 \%$ & 672,770 & 699,677 \\
\hline Overall & $21.8 \%$ & 6,822 & 31,299 & $0.4 \%$ & $1.6 \%$ & 208,224 & 266,367 \\
\hline
\end{tabular}

Source: Calculations based on EDAM4-IS.

Note: Deciles based on the distribution of consumption per capita. The coefficient of variation of telecom usage was 20 percent or higher in deciles 1 and 2 (grayed out) and thus may be interpreted with caution. 


\section{TABLE 3.4 WELCOM Simulations}

\begin{tabular}{l|c|c|} 
& Elasticity =-1.5 & Elasticity = -2.5 \\
\hline Price change & $22.2 \%$ & $13.3 \%$ \\
\hline Welfare gains (DF per year) per user & \multicolumn{2}{|l}{} \\
\hline Quintile 1 & n.a. & n.a. \\
\hline Quintile 2 & 828 & 276 \\
\hline Quintile 3 & 1,792 & 597 \\
\hline Quintile 4 & 2,290 & 763 \\
\hline Quintile 5 & 7,347 & 2,449 \\
\hline
\end{tabular}

Source: Calculations based on EDAM4-IS.

Note: Quintiles based on the distribution of consumption per capita. Results for the bottom quintile were 594 and 198, respectively, but are not shown as it is considered that there is too little information (i.e. sample sizea coefficient of variation of 18 percent) to draw reliable estimates.

To conduct the simulation, we apply the World Bankdeveloped tool on welfare and competition (WELCOM). The tool allows the simulation of the distributional effects of changes in market competition through its impact on prices. In short, the tool (i) estimates the expected change in prices resulting from the increased competition, by assuming that after new entrants come into the sector competition pushes prices toward the marginal cost (the result in perfectly competitive markets); (ii) identifies all users of telecom services; and (iii) applies the estimated price decrease to households that are currently users of telecom services as an estimate of their gain in welfare. $^{32}$ Given the lack of guidance in the literature on an appropriate price elasticity for telecom services, we run the simulations assuming a price elasticity of -1.5 and -2.5 to provide a range of results. To note is that in both cases the simulations assume that the demand for communications services is elastic, since in monopolistic markets the firm optimizes its output in the elastic section of the demand curve. Thus, we present the results for the simulation where the opening of the sector leads to a drop in the market share of the incumbent firm to half of the market. That is, we simulate the expected effects in the short or medium term after the opening of the sector.
Table 3.4 presents the main results from the simulations. As expected, both simulations show a decrease in price after a new entrant establishes itself in the telecom sector. In the scenario where individuals are assumed to be less responsive to price changes, the price of telecom service experiences a drop of 22 percent, whereas when individuals are more responsive, the price drops by 13 percent. In terms of welfare gains, they follow the patterns of consumption observed above, with richer individuals spending more on telecom services than poorer individuals. Thus, richer households reap more of the benefits of a decrease in prices. Under the lower elasticity scenario, an individual in a household that uses telecom services in the second quintile is estimated to experience a welfare gain of DF 828. In the same scenario, an individual in the top 20 percent would gain DF 7,347. The welfare gains are lower across the distribution corresponding to the lower price change in the scenario of an elasticity of -2.5 .

The welfare gains are low with respect to the overall level of consumption in each quintile, and thus are not conducive to tangible changes in poverty or inequality. It is important to highlight that the results presented are limited, as they can simulate the potential welfare gains

32 For a more detail description of the methodology, see Araar et al. (2018). 
only among current telecom users. In a context such as Djibouti, an equally important question would be, what would happen to the individuals that are not currently consuming these items (due to several reasons, including affordability or coverage)? That is, given an expected drop in price and an associated welfare gain, should we expect more people to adopt and use telecom services?

We attempt to answer this question by conducting the following thought exercise. First, we run a probit model to look at the predictors of telecom usage among the Djiboutian population. We use as covariates a series of household characteristics, household head characteristics, dwelling characteristics, location variables, the household's consumption level, as well as the usage of telecom services among households in the same primary sampling units (PSUs). We estimate the probit via a stepwise regression and find that consumption level and access within the PSU are highly correlated with telecom usage.
Second, we simulate the increase in the probability of using telecom services by assuming that all nonusers would (potentially) benefit from the average welfare gains just described based on the quintile of consumption that they currently belong to. Table 3.5 illustrates that there are limited potential gains in the extensive margin (that is, take up of telecom services). Using the low elasticity as benchmark, households in the fifth quintile would be 0.0014 percentage points more likely to use telecom services (assuming all other covariates constant). The probability of take up is correlated with households' consumption, but differences are not significant. This result is likely due to the small gains in the short run. Higher effects could be expected as competition leads to larger drops in prices in the long run. Besides the further drop in prices due to more competition, other indirect effects such as having neighbors who take up telecom services could also have an impact on individual take up.

\section{TABLE 3.5 Estimated increase in probability of using telecom services due to welfare gains}

\begin{tabular}{l|c|c|} 
& Elasticity $=\mathbf{- 1 . 5}$ & Elasticity $=\mathbf{- 2 . 5}$ \\
\hline Quintile 1 & n.a. & n.a. \\
\hline Quintile 2 & 0.0003 & 0.0001 \\
\hline Quintile 3 & 0.0006 & 0.0002 \\
\hline Quintile 4 & 0.0008 & 0.0003 \\
\hline Quintile 5 & 0.0014 & 0.0005 \\
\hline
\end{tabular}

Source: Calculations based on EDAM4-IS.

Note: Results shown in percentage points. Quintiles based on the distribution of consumption per capita. Results for the bottom quintile are not shown as it is considered that there is too little information (i.e sample size) to draw reliable estimates.

\section{CONCLUSION}

In this section we bring some insights as to the hypothetical gains to the population that an opening of the telecom sector could bring about in Djibouti. The ICT sector is currently believed to be below its potential, thus limiting the access to such services and, somewhat indirectly, preventing more spaces for the private sector in Djibouti to become bigger players in the economy. From a relatively narrow angle of welfare gains to households, the simulations presented here hint at important gains due to the expected price decreases following increased competition in the sector. More work is needed to fully understand the implications of changes to the telecom sector in Djibouti. The huge potential the sector holds for contributing to the development of the country should be enough incentive to pursue this important agenda. ${ }^{33}$

33 The EDTIC survey conducted in 2018 by DISED is expected to provide additional insights on the sector. 


\section{IMPROVED TARGETING OF SOCIAL PROGRAMS}

Djibouti's approach to expanding social safety nets (SSN) has been increasingly aligned to poverty reduction and building of human capital. This focus is in contrast to other MENA countries in the region whose primary motivation for reform has been driven by efforts to rebalance generalized subsidies on commodities (mainly energy products) with more targeted transfers to households. ${ }^{34}$ Djibouti has made efforts in recent years to invest in adaptive SSNs and incentivize households to invest in human development. Until recently, most SSN programs had been established in the wake of drought shocks and were largely donor-driven initiatives (such as World Food Program, UNICEF, Food and Agriculture Organization, Islamic Development Bank,
USAID, and the Norwegian Refugee Council), which were mainly focused on providing food to vulnerable populations. At present, the scale and funding of an integrated SSN program remains inadequate to protect most poor and vulnerable groups.

Nonetheless, expenditure on SSNs in Djibouti remains low. While the MENA as a region spends, on average, 1 percent of GDP on SSNs, Djibouti spends only 0.2 percent of GDP (as of 2014). Within the region, only two other countries (Jordan and Egypt) spend less as a percentage of GDP. Meanwhile Iraq, the West Bank and Gaza, and Syria all spend above the global average (Figure 3.5).

\section{FIGURE 3.5 Social Assistance Expenditure as a Percentage of GDP}

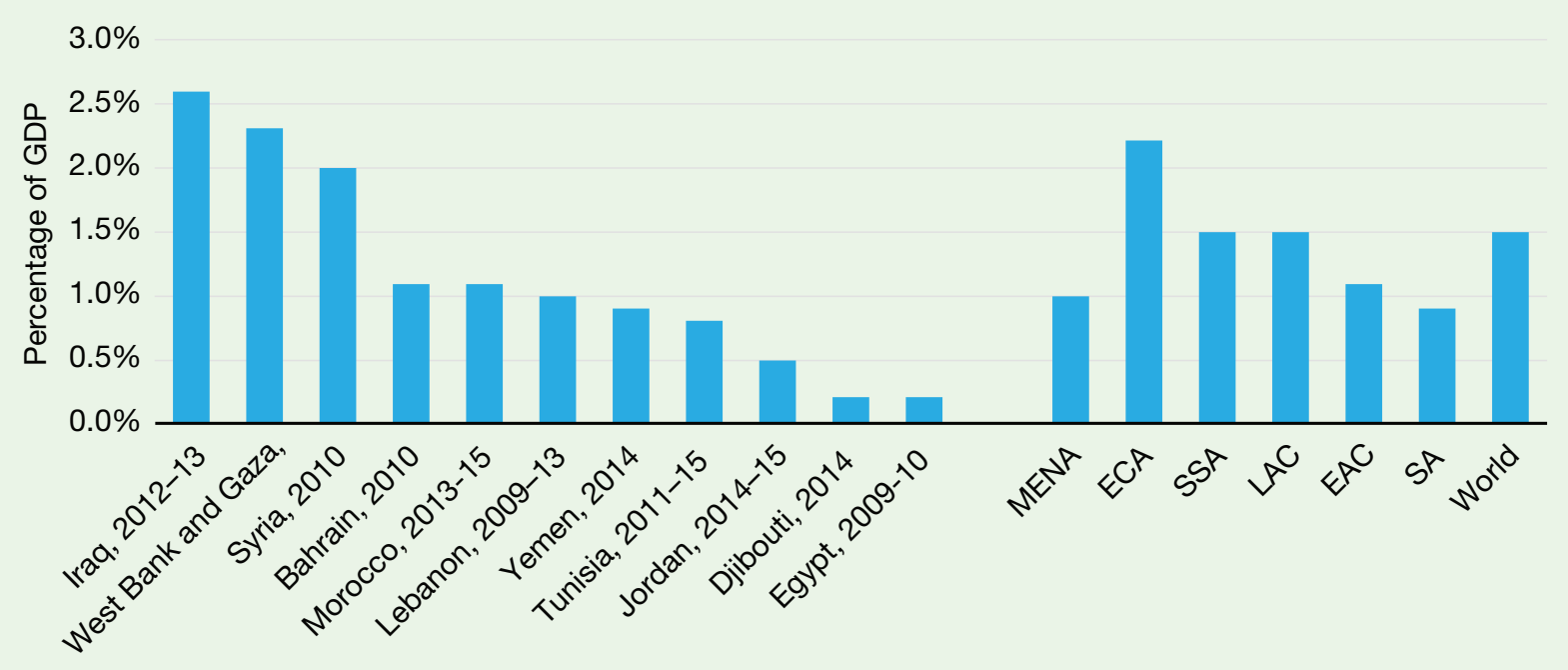

Source: Report calculations and ASPIRE database.

Note: Calculated individual programs expenditure as a percentage of that year's GDP (real GPD) and aggregated all programs by country. Data are administrative data collected from country counterparts. MENA stands for Middle East and North Africa, ECA stands for Europe and Central Asia, SSA stands for Sub-saharan Africa, LAC stands for Latin America and Carribean, EAC stands for East Asia and SA stands for South Asia.

34 In the MENA region, generalized price subsidies have been a major part of the social contract between governments and the people. Large-scale subsidies are still pervasive, including in foods and fuels. Yet generalized subsidies are both costly and usually badly targeted. This is especially the case with energy products. Only 7 percent of fuel subsidy spending in poor countries benefits the poorest quintile of households, while 43 percent benefit the richest quintile. For example, in 2008, the poorest 40 percent of the population in Egypt received only 3 percent of gasoline subsidies (Sdralevich et al. 2014). Globally, the IEA estimates that only 8 percent of subsidies accrue to the poorest fifth of the population (IEA 2012). 
Accompanying this relatively low spending on SSNs, Djibouti's programs are also fragmented, and donor driven. The low level of spending in SSNs is not channeled efficiently. Djibouti has nine different safety net programs (Table 3.6). Most of these programs are cash transfer programs (either conditional or not). The high fragmentation of these programs leaves significant scope for improvement through consolidation and better use of the resources. The most prominent SSN program in Djibouti is the Programme National Solidarite Familiale (PNSF), a conditional cash transfer program that makes up more than one-third of the available SSN budget. Besides regular cash assistance, beneficiaries of the PNSF are also eligible for a heavily subsidized medical insurance under the Programme d'Assistance Sociale de Santé.

Djibouti has begun laying the groundwork for a social protection system through the national expansion of the PNSF and the establishment of a social registry. PNSF currently serves approximately 3,000 households. The program has, however, the potential to be the cornerstone of a country-owned and adaptive social protection system. The emphasis is now on the scaling up of PNSF to cover a greater share of the poor population. The scale-up will build on the capacity development from recent projects, the development of the social registry, and a management information system. To that end, creating the fiscal space and investing in the institutional and capacity building to establish a country-owned SSN system in Djibouti is becoming a key priority for GoD.

The GoD plans to reinforce its social protection system by expanding the PNSF by 5,000 households. In particular, the expansion is expected to target households outside the capital and in subprefectures selected due to their high level of need. Furthermore, PNSF includes soft conditionalities related to participation in community-level behavioral change communication sessions. Thus, besides the direct support for increased consumption, the program will aim to nudge beneficiaries toward building their human capital. Finally, the expansion of PNSF will be supported by incorporating elements of targeting based on proxy means testing. Here we present the results of an analytical exercise using the EDAM4-IS data to build a prediction model that can be used (i) to estimate the consumption level of a households and (ii) as input for the determination of whether a household is eligible for certain social programs. The following sections describe the findings of this exercise.

\section{TABLE 3.6 Social Safety Net Programs in Djibouti}

\begin{tabular}{l|l|c|} 
Program name & Program type & Expenditure (US\$) \\
\hline Zakat & UCT &.. \\
\hline Food distribution Program & Food, in-kind assistance, and near-cash transfers &.. \\
\hline Scholarships for education & Other Social Assistance Programs &.. \\
\hline School feeding program & Food, in-kind assistance, and near-cash transfers &.. \\
\hline Food voucher (July-September) & UCT & 500,000 \\
\hline University students (canteen and transport subsidy) & CCT & 929,600 \\
\hline $\begin{array}{l}\text { Social Assistance Pilot Program on Labor and } \\
\text { Human Capital }\end{array}$ & Public works & $1,381,623$ \\
\hline Peri-urban voucher program & Food, in-kind assistance, and near-cash transfers &.. \\
\hline Programme National Solidarite Familiale & Rural and urban cash transfer program & $1,521,000$ \\
\hline
\end{tabular}

Source: Compiled from GoD data.

Note: $\mathrm{UCT}$ = unconditional cash transfer; $\mathrm{CCT}$ = conditional cash transfer. 


\section{A PROXY MEANS TEST (PMT) APPLICATION USING EDAM4-IS}

In 2013, the first PMT formula was used by the Secreatariat d'Etat des Affaires Sociales to help in its targeting efforts and identify the most vulnerable population groups in Djibouti. Given the strong economic growth observed in the country in recent years, it is thus important to explore whether an updating of the formula is required to better reflect the current conditions of poor households in Djibouti. It is thus fortunate that in 2017, the DISED conducted EDAM4 to update the profile of welfare and poverty in the country. Such recent data can provide a wealth of information for such an exercise.

While PMT models are known to have limitations, there are contexts in which the application of this approach is warranted. ${ }^{35}$ Given Djibouti's high level of informality and weakly integrated information systems, a PMT model can be an informative tool to help achieve the objective of finding the most vulnerable population. In this section, we describe the estimation of a predictive model that can help identify vulnerable households by collecting data on a short list of observable characteristics. We first describe the methodology of the PMT, followed by the estimated model. We conclude by describing the performance of the model.

\section{METHODOLOGY}

Consumption per capita is the welfare aggregate used to measure and predict poverty. An ordinary least squares estimator is used to predict the natural logarithm of consumption per capita on the set of explanatory variables. Formally, the model is specified as

$\ln W_{i}=\alpha+X_{i j} \beta_{j}+\varepsilon_{i}$

where $W_{i}$ is the log of consumption per capita per household (welfare aggregate), $X_{i j}$ is a vector of characteristics of $\mathrm{j}$ variables (poverty predictors) for $\mathrm{i}$ households, $\beta_{j}$ are the coefficients (weights) of the poverty proxies, $\alpha$ is the constant, and $\varepsilon_{i}$ the error term.

The goal of the exercise is to maximize the R-squaredthe explanatory power of the model-and to minimize the inclusion (leakage) and exclusion (undercoverage) errors.

Table 3.7 presents the different possible performance scenarios. Households will be successfully targeted (S1 and S2) when poor and nonpoor households are beneficiaries and nonbeneficiaries, respectively. On the other hand, when poor households are nonbeneficiaries because predicted as nonpoor and conversely, nonpoor household beneficiaries, these will incur exclusion (E1) and inclusion (E2) errors, respectively. From this set of possibilities, the following concepts are defined. Coverage rate is the ratio of beneficiaries to total population $\left(\mathrm{M} 1 / \mathrm{N}^{*} 100\right)$. Leakage rate is the ratio of inclusion error to total beneficiaries (E2/M1*100). Undercoverage rate is the ratio of exclusion error to total poor (E1/N1*100). Performance of the models is tested by comparing undercoverage and leakage rates between PMT.

From a practical point of view, other considerations need to be taken into account in choosing a particular PMT model. One objective, for instance, could be to raise the welfare of

\section{TABLE 3.7 Inclusion and Exclusion Errors}

\begin{tabular}{l|l|l|c|} 
& Poor & Nonpoor & Total \\
\hline Beneficiary & Successful targeting (S1) & Inclusion error (E2) & M1 \\
\hline Nonbeneficiary & Exclusion error (E1) & Successful targeting (S2) & M2 \\
\hline Total & N1 & N2 & N \\
\hline
\end{tabular}

35 See the discussion in Brown, Ravallion, and Van de Walle (2018) on PMT for nine African countries. 
the poor, in which case minimizing the exclusion error can be give more weight in the decision. On the other hand, officials may be interested in keeping costs of the program contained and thus may choose to focus on minimizing the errors of inclusion. Certainly, the administrative costs of implementing one (or many) PMT models in an effective way should also be taken into account.

\section{THE MODEL}

A first attempt at defining the PMT model was done by applying the 2013 PMT specification to the EDAM4IS data. However, such an approach results in higher undercoverage (exclusion error) and lower national coverage today than in 2013. This is not surprising, as the context and environment in Djibouti has changed since EDAM3-IS, resulting in a weaker performance of the 2013 PMT. A revision of the model, which was previously very accurate, is necessary to account for the progress and change Djibouti has experienced since 2013. The reestimation of the 2017 PMT tested the old covariates, as well as new correlates (that aid as proxies) of consumption (and in turn of poverty). The simplest approach to the reestimation would be to repopulate the 2013 PMT with new data in order to update the beta coefficients. However, this would limit the potential of the probability model to accurately predict current levels of welfare. Therefore, a new model is estimated with EDAM4-IS data.

The revised 2017 PMT models include a range of poverty predictors from five categories of household-level indicators. The choice of predictors is determined by two factors: (i) the correlation with consumption per capita, which is important for accurate predictions, and (ii) the verifiability of the predictor by social workers who conduct home visits, which is important to determine the accuracy of the information imputed in the PMT formula. The different categories of predictors assessed to determine probability of poverty are the following: household characteristics, such as household size and dependency ratio; dwelling characteristics, such as materials used to construct walls and roofs, as well as access to basic services like electricity, improved sanitation, and water; characteristics of the head of household, such as education level and employment status; location, such as region of residence; and ownership of durable goods, such as televisions, refrigerators, radios, and so forth. Most of these indicators are difficult to falsify or unlikely to be falsified. Unannounced household visits by social workers also limit the ability to falsify information.

We find that ownership of durable goods, such as cell phones, televisions, refrigerators, bicycles, mattresses, and radios, is associated with higher predicted welfare. Household demographic indicators such as size and dependency ratio - the ratio of children and elders to adults - are negatively correlated with welfare. Large households with a high prevalence of financially dependent children and elders are not surprisingly predicted poorer. The poorer regions of Dikhil and Tadjourah are associated with higher poverty likelihood. Educated heads of household and those working in the public sector are less likely to be poor. Households living in villas or apartment buildings are less likely to be poor compared to those living in tents, makeshift accommodation, ordinary housing (no camps, makeshift dwellings etc.), or collective housing.

\section{PERFORMANCE}

The myriad possible combinations of the groups of variables mentioned demand that we set up an approach to select the most accurate and robust PMT model. The common default is to estimate a national PMT model using a nationally representative household survey. However, given the strong heterogeneity between urban and rural communities, estimating two distinct models for each environment may be desirable. PMT predictors, such as dwelling characteristics (for example, materials used to build roof, walls, and floors), are not easily comparable across regions. Thus, following consultations with partners and government representatives, we present here the results from a single national model and a regional model that combines two separate PMT formulae for rural and urban households. ${ }^{36}$

36 A third model for three distinct regions was also estimated, resulting in City of Djibouti PMT, Other Urban Areas PMT (including only regional capital cities), and a Rural PMT. However, for logistical reasons, such an approach was not favored. 
Conventionally, the performance of a PMT model can be evaluated by measuring predictions errors. ${ }^{37}$ Two indicators are of key interest. First, the exclusion error or undercoverage occurs when households are flagged as nonbeneficiaries by the PMT formula, but in reality a more detailed observation of their consumption level would have put them below the eligibility threshold (which many times implies that they are poor). Second, the inclusion error, or leakage rate, refers to the households that are classified as beneficiaries to the program due to a low PMT score, when in fact they may not be poor or their real consumption levels are above what a given program considers to be the eligibility threshold. These rates were simulated at different levels of the consumption per capita distribution (deciles), as well as the 25th and 35th percentile, as these are close to the national extreme and global poverty rates estimated by DISED (21 percent and 36 percent, respectively). ${ }^{38}$
Table 3.8 compares the performance indicators of two models. One is a national model that applies one formula to the entire country. The second model allows the formula to vary between urban and rural areas and is labeled "flexible." The results on performance indicators are presented at the aggregate (national) level for ease of comparison. There are no significant differences between the exclusion and inclusion errors of the two models, nor does one appear to be clearly preferable to the other. As a rule of thumb, the PMT models are assessed based on their performance at the 30th percentile. It is, however, also interesting to use as guidance of performance the 35th percentile. The reason is that, in the case of Djibouti, this level is qualitatively similar to poverty in per capita terms, the upper official poverty rate, and provides relatively more desirable levels for the performance indicators. Assuming that the population of interest in concentrated in the bottom 30 or 35 percent of the distribution, the

\section{TABLE 3.8 Performance of National and Flexible Model}

\begin{tabular}{l|c|c|c|c|c|c|}
\multicolumn{1}{|c|}{} & \multicolumn{3}{c|}{ National } & \multicolumn{3}{c}{ Flexible } \\
\hline Percentile & Coverage & Exclusion & Inclusion & Coverage & Exclusion & Inclusion \\
\hline 10 & $8.5 \%$ & $41.7 \%$ & $31.5 \%$ & $8.4 \%$ & $42.3 \%$ & $31.1 \%$ \\
\hline 20 & $17.1 \%$ & $35.0 \%$ & $23.9 \%$ & $16.6 \%$ & $35.5 \%$ & $22.2 \%$ \\
\hline 25 & $23.8 \%$ & $29.1 \%$ & $25.4 \%$ & $22.9 \%$ & $30.9 \%$ & $24.5 \%$ \\
\hline 30 & $27.3 \%$ & $28.1 \%$ & $21.1 \%$ & $27.8 \%$ & $27.5 \%$ & $21.8 \%$ \\
\hline 35 & $33.3 \%$ & $24.8 \%$ & $20.6 \%$ & $32.6 \%$ & $25.1 \%$ & $19.6 \%$ \\
\hline 40 & $39.3 \%$ & $21.6 \%$ & $20.1 \%$ & $38.8 \%$ & $21.6 \%$ & $19.0 \%$ \\
\hline 50 & $50.4 \%$ & $16.4 \%$ & $17.0 \%$ & $49.7 \%$ & $17.1 \%$ & $16.4 \%$ \\
\hline 80 & $61.4 \%$ & $12.4 \%$ & $14.4 \%$ & $61.7 \%$ & $12.4 \%$ & $14.8 \%$ \\
\hline 90 & $72.4 \%$ & $9.0 \%$ & $12.1 \%$ & $72.6 \%$ & $8.8 \%$ & $12.0 \%$ \\
\hline
\end{tabular}

Source: Calculations based on EDAM4-IS.

Notes: Flexible refers to countrywide indicators obtained by putting together predictions of an urban and a rural model.

37 Each specification was obtained using stepwise regression in STATA. Multicollinearity among regressors on the final specifications was formally tested using the variance inflation factor (VIF) ratio. No multicollinearity was detected, given that all indicators had a ratio below 5. Mean VIF for the three models (national, urban, and rural, respectively) stood at 1.75, 1.35, and 1.64.

38 Poverty rates from DISED are based on an adult equivalent scale. In results not shown, comparable models have been produced to estimate performance based on an adult equivalent scale. The GoD will have to take into consideration potential differences of these models in defining the targeting criteria of programs that will use the PMT. 
national model appears to be slightly better in terms of exclusion, while the flexible model performs better in terms of inclusion. A targeting at the 35th percentile would lead in the national (flexible) model to an undercoverage rate of
24.8 percent (25.1 percent) and a leakage of 20.6 percent (19.6 percent). These as well as those at the rates for the 30th percentile are-empirically - low rates of error when compared to other settings (Figure 3.6).

\section{FIGURE 3.6 Errors of Inclusion and Exclusion for PMT Model in Djibouti Compared to Other Countries (cutoff point at 30th percentile)}

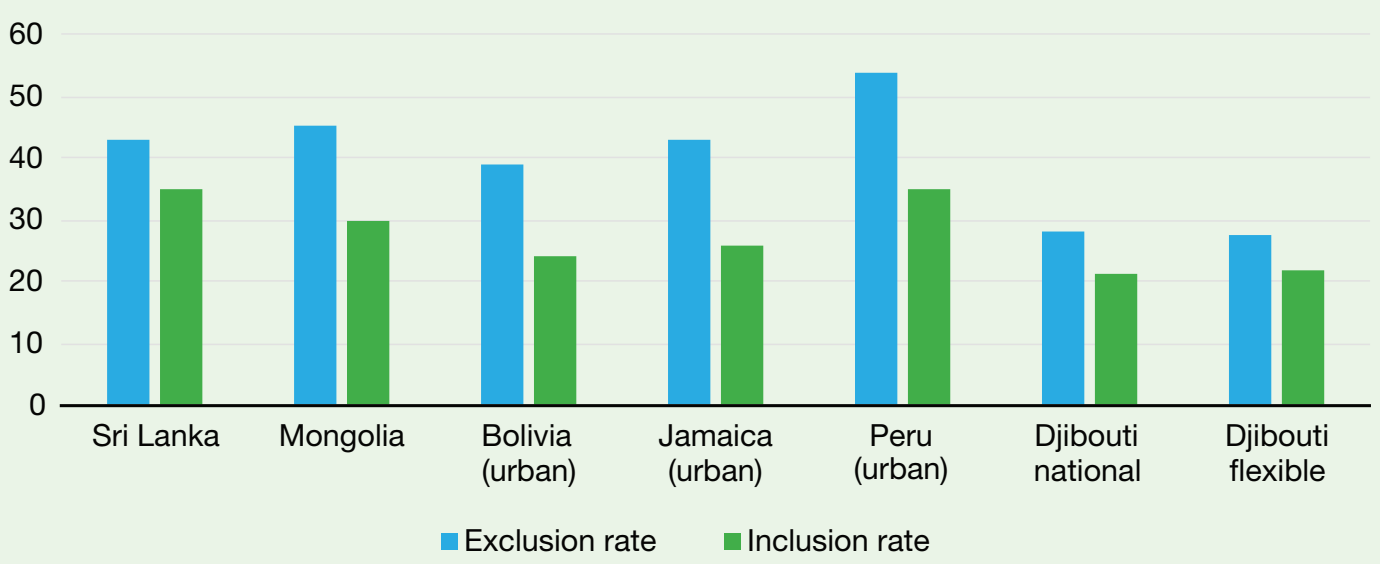

Source: Calculation based on EDAM4-IS (Djibouti); and compilation in Atamanov et al. 2015 from Grosh and Baker 1995, Narayan and Yoshida 2005, and Araujo and Cararro n.d.

\section{ADDITIONAL PERFORMANCE INDICATORS OF THE PMT MODEL}

\section{Performance in population subgroups}

Overall, homogeneity is greater among households in rural settings than households in urban regions-performance among rural communities is therefore expected to be more accurate than among urban families. A common concern by partners on the ground is the failure of PMT models to predict poverty accurately for small and large households. This concern is tested by assessing the performance of the specifications described above for different subsets of the population. ${ }^{39}$ The focus is on three groups: small households defined as household sizes below or equal the 10th percentile (that is, three members), large households as those above or equal to the 90th percentile (that is, ten members), and small and elderly households (defined as those with at least 1one elderly member -60 or more years old-in a two-person household at most). These households account for 13 percent, 13 percent, and 1 percent of the population sample, respectively. Poverty incidence among these groups is, respectively, 16 percent, 29 percent, and 21 percent (the national poverty rate being 21 percent).

39 Additional estimations were done following the flexible model PMT, in which the household size was included as a series of dummy variables instead of using it in continuous form. The idea was to allow the prediction model to nonparametrically estimate differences in consumption across households of different sizes and that differences could vary between smaller and larger households. This econometric specification worsened exclusion and inclusion errors. 
As a sensitivity analysis, we present performance indicators of the flexible PMT specification for these three subgroups (Table 3.9). ${ }^{40}$ There is no clear evidence suggesting that the PMT would significantly underperform in these population subgroups. For instance, using these results, we find that rates of exclusion are lower for all three populations of concern than among the overall population. At the 35th percentile, undercoverage is 23.2 percent for small households, 15.1 percent for large households, and 16.5 percent for small-elderly households, whereas it is 25.1 percent at the population level. Notably, leakage rates are higher, especially in the case of large households (30.2 percent), compared to the national average of 19.6 percent.

\section{Performance in the bottom of the distribution}

Following Grosh and Baker (1995), we further test the desirability of an alternative to reduce measured exclusion errors by using the poorer segment of population to run the predictive PMT model. The argument is that by focusing on the poorest half of the population as the basis for the formula (and assuming that richer individuals and households are unlikely to apply to a social program), the approach can lead to much lower exclusion errors. Certainly, the assumption that no one from above the program cutoff would apply for benefits will not apply cannot be guaranteed.

The national and flexible models were re-estimated by fitting only the bottom 55 percent of the population (a truncated model). This specification included 35 variables (instead of the more than 50 in the previous models). Table 3.10 shows the results obtained from (i) the reestimation of both national and flexible models to only the bottom 55 percent of the population, (ii) using the typical cutoff of 35th percentile, and (iii) showing the results of whether

\section{TABLE 3.9 Performance of Flexible Model for Subsets of Population}

\begin{tabular}{|c|c|c|c|c|c|c|}
\hline & \multicolumn{2}{|c|}{ Small households } & \multicolumn{2}{|c|}{ Large households } & \multicolumn{2}{|c|}{ Small, elderly Households } \\
\hline Percentile & $\begin{array}{c}\text { Under- } \\
\text { coverage }\end{array}$ & Leakage & $\begin{array}{c}\text { Under- } \\
\text { coverage }\end{array}$ & Leakage & $\begin{array}{c}\text { Under- } \\
\text { coverage }\end{array}$ & Leakage \\
\hline 10 & $50.1 \%$ & $39.1 \%$ & $29.6 \%$ & $43.6 \%$ & $61.9 \%$ & $58.6 \%$ \\
\hline 20 & $34.2 \%$ & $33.1 \%$ & $19.2 \%$ & $26.0 \%$ & $14.2 \%$ & $36.1 \%$ \\
\hline 25 & $30.6 \%$ & $28.5 \%$ & $18.2 \%$ & $35.1 \%$ & $18.4 \%$ & $29.9 \%$ \\
\hline 30 & $25.5 \%$ & $25.1 \%$ & $13.8 \%$ & $32.4 \%$ & $18.2 \%$ & $23.0 \%$ \\
\hline 35 & $23.2 \%$ & $23.0 \%$ & $15.1 \%$ & $30.2 \%$ & $16.5 \%$ & $25.4 \%$ \\
\hline 40 & $19.2 \%$ & $21.1 \%$ & $6.7 \%$ & $25.0 \%$ & $9.8 \%$ & $24.4 \%$ \\
\hline
\end{tabular}

Source: Calculations based on EDAM4-IS.

\section{TABLE 3.10 Errors of Exclusion and Inclusion for Truncated Model with Predictions for the Whole and for the Restricted Sample}

\begin{tabular}{l|c|c|c|c|}
\multirow{2}{*}{} & \multicolumn{2}{|c|}{ Anyone applies to the program } & Only bottom 55\% applies to the program \\
\cline { 2 - 5 } & Exclusion & Inclusion & Exclusion & Inclusion \\
\hline National model & $11 \%$ & $34 \%$ & $11 \%$ & $23 \%$ \\
\hline Flexible model & $11 \%$ & $34 \%$ & $11 \%$ & $23 \%$ \\
\hline
\end{tabular}

Source: Calculations based on EDAM4-IS.

40 Results for the national model are qualitatively the same. 
the assumption on richer households being able to apply to (and be considered for receiving benefits from) a given social program using the PMT formula. ${ }^{41}$ Restricting the sample to the bottom 55 percent of the population and using the truncated model generates errors of exclusion of 11 percent regardless of our assumption on who is able to apply to the program. This implies that the program would miss about 1 actual poor person from 10. Errors of inclusion are between 23-34 percent.

If we need to compare between the models presented earlier and the truncated model, it is necessary to make sure we select a cut-off point producing approximately similar program participation rates (and thus the identical budget). Aiming for a total participation of 32 percent, the relevant cutoff for the national/flexible models is the 35th percentile, whereas for the truncated model it is the 25th percentile. Thus, if we predict errors using these cut-offs, we find that exclusion (inclusion) rates under the national and flexible models are about 25 percent (20-21 percent). Meanwhile, the truncated model (and a cut-off of a 25th percentile) would lead to an exclusion rate of 16-18 percent and an inclusion rate of 33 percent. Therefore, the truncated model performs better in terms of targeting poor people but has higher leakage.

The performance indicators associated with the PMT models presented here indicate that there is no clear "winner" in terms of providing the least errors across all dimensions. It is therefore crucial for implementing agencies to incorporate additional considerations based on their mandate to further scrutinize the model on the ground in the context of Djibouti and to decide on the approach to follow or whether additional filters are need as "inclusion criteria" or "categorical targeting" (for example, female-headed households, widowed-headed households, and so forth).

\section{SIMULATING AN EXPANSION OF PNSF}

Using information from the PMT that allows a differentiation between the urban and rural settings (model 2 without truncation), we run the following hypothetical scenario of an expansion of the PNSF to illustrate the potential of the application of a PMT model. In particular, we assume the following:

- The PNSF is rolled out nationally using the PMT model from above to identify and rank (based on households' needs) potential beneficiaries.

- We use the EDAM2017 data to obtain a PMT score for all households (that is, we assume that all households apply to the PNSF program and get a score). Households with the most needs (the lowest scores) are then ranked first.

The PNSF is assumed to expand to 5,000 households nationally.

- The PNSF provides about US\$56 per household per month to the new identified beneficiaries. ${ }^{42}$

- The program is rolled out and effective as of September 2018.

- There are no behavior responses (changes to the labor decisions or consumption patterns for instance) as a result of receiving the program.

Under these assumptions, new beneficiaries find themselves with a higher level of consumption per adult equivalent than under a situation before the program expanded. This then leads to an increase in welfare and decrease in poverty. Table 3.11 presents the results. Overall, there is a 0.6 percentage point decrease in poverty in the country as a whole, but with substantial

41 Tests using the VIF ratio were also performed in each mode for multicollinearity. The ratios were 1.62, 1.27, and 1.53 for the national, urban, and rural models, respectively.

42 Figures from 2016 suggest that each PNSF beneficiary household received approximately DF 80,302 per year (US\$37.7 per month). There were 3,362 households receiving the program in 2018. There are few households in the EDAM4 that declare currently receiving PNSF benefits. In the simulation, we assume they keep their current benefits. The simulated benefits for new beneficiaries are about DF 120,000 per year per household. 


\section{TABLE 3.11 Simulation Results on Poverty Rate after Hypothetical Expansion of PNSF}

\begin{tabular}{l|c|c|}
\multicolumn{1}{c|}{} & Ex ante & After expansion \\
\hline Djibouti city & $13.6 \%$ & $13.5 \%$ \\
\hline Ali-Sabieh & $27.2 \%$ & $25.5 \%$ \\
\hline Dikhil & $52.9 \%$ & $49.3 \%$ \\
\hline Tadjourah & $65.4 \%$ & $60.9 \%$ \\
\hline Obock & $40.4 \%$ & $39.9 \%$ \\
\hline Arta & $31.6 \%$ & $31.1 \%$ \\
\hline Total & $21.1 \%$ & $20.5 \%$ \\
\hline
\end{tabular}

Source: Calculations based on EDAM4-IS.

variation across regions. In particular, poverty in Tadjourah decreases by 4.5 percentage points. Poverty in the capital city decreases only slightly. This result may directly follow from the fact that higher levels of deprivation are found in regions that are heavily rural and thus under the simulation get much higher priority under the new PNSF.

We also simulate an alternative scenario assessing the impact of a hypothetical expansion of the PNSF under a mixed implementing strategy. In this second simulation eligibility is based on using both the PMT and geographical targeting. We simulate this scenario as the logistics and administrative costs of running a PMT nationally may be too high. In light of pervasive poverty in rural areas, a randomly assigned assistance package in rural communities coupled with PMT-targeting in the capital city could potentially reduce costs. Meanwhile, applying a PMT targeting in a zone with high population density such as the capital, may be cost-effective.

Using the same PMT model (model 2 without truncation), we run the following hypothetical scenario:

The PNSF is assumed to expand to 5,000 households.

- The PNSF provides about US\$56 per household per month to the identified beneficiaries.
We assume there are no behavior responses (changes to the labor decisions or consumption patterns for instance) as a result of receiving the program.

- The PNSF is randomly assigned among rural households based on the percentage of poor population living in either rural areas or in the city of Djibouti. This implies, for instance, that if 20 percent of poor households live in Dikhil, then 1,000 (20 percent of 5,000) households in Dikhil will randomly receive the PNSF expansion. However, the PNSF expansion for the city of Djibouti will be based on the percentage of poor households living there but selected through the PMT scores generated by the model, where the lowest scores are ranked first and assuming all households apply to the program.

Table 3.12 presents the results from the second simulation. Under the assumptions and conditions just outlined, beneficiaries of the PNSF expansion have a higher level of consumption per adult equivalent than before the expansion. This leads to an overall decrease in poverty nationally and regionally. Poverty is reduced by 0.7 percentage points in the country as a whole. Similar to the first simulation, there are substantial differences across regions. Tadjourah experiences the largest percentage point decrease in poverty (4.1 percentage points) and Obock the highest percentage decrease (9 percent as the result of a 3.6 percentage point drop in poverty). 


\section{TABLE 3.12 Simulation Results on Poverty Rate after Alternative Hypothetical Expansion of PNSF}

\begin{tabular}{l|c|c|} 
& Ex ante & After expansion \\
\hline Djibouti city & $13.6 \%$ & $13.4 \%$ \\
\hline Ali-Sabieh & $27.2 \%$ & $26.1 \%$ \\
\hline Dikhil & $52.9 \%$ & $50.5 \%$ \\
\hline Tadjourah & $65.4 \%$ & $61.3 \%$ \\
\hline Obock & $40.4 \%$ & $36.8 \%$ \\
\hline Arta & $31.6 \%$ & $29.1 \%$ \\
\hline Total & $21.1 \%$ & $20.4 \%$ \\
\hline
\end{tabular}

Source: Calculations based on EDAM4-IS.

Compared to the results from a PMT-exclusive targeting, the national poverty rate is reduced slightly less under a mixed strategy, but this difference is not statistically significant. From a regional perspective, poverty in Djibouti city, Ali-Sabieh, Dikhil, and Tadjourah is not reduced as much under the second simulation. In light of these findings, and with consideration to costs, we observe that a mix of PMT and geographical targeting shows promising results. However, it is up to the Secrétariat d'Etat chargé des Affaires Sociales to evaluate the most efficient approach to distributing benefits in rural areas given the known high levels of poverty.

\section{CONCLUSION}

This section note presents a preliminary analysis of the application of PMT models to the Djiboutian case. The models use recent data collected in 2017 from the EDAM4 and thus help to capture the livelihoods of Djiboutians as accurately as possible. The results presented here show that PMT models appear to perform well in line with inclusion and exclusion errors that have been found in other settings. However, the different applications of the PMT methodology did not allow to find a specification that was superior to other tests across all indicators.
The potential of the PMT models and the results presented here to inform the design of policies is still high. Despite the shortcomings known of PMT models, there is great potential for the use of such models to improve targeting in Djibouti, especially as the GoD seeks to expand its SSN and increases the focus of SSN towards the most vulnerable. ${ }^{43}$ Additional analyses could help complement the results presented here. In particular, the next analytical steps could be expanded in at least two ways. First, it would be helpful to conduct a comparison between the population of current beneficiaries of PNSF and the population that was used in estimating the PMT models. Should the demographic and economic characteristics be significantly different between the survey population and, say, the pool of households that will be recertified to a program, caution should be used in the application of a new PMT model to "out-of-sample" populations. Second, more analysis should be done to explore the implications of official poverty rates being expressed in adult equivalent terms and PMT models in per capita terms. The eligibility definition and criteria should follow the most informative strategy for the government and should be taken into account for the classifications of vulnerability in the analytical exercises.

43 A back of the envelope calculation suggests that PNSF, the largest SSN program, reaches only 3 percent of households (in a context where about a fifth of household are considered extreme poor). 


\section{NOMADS AND PASTORALISTS}

About 20 percent of the Djiboutian population was found to be nomadic in 2009, with about 56 percent living in the regions of Dikhil and Tadjourah, according to the Djibouti census of 2009. Given its large share and the fact that Djibouti has experienced persistent droughts over the past decade, it becomes important to study the welfare of this population, as nomads' livelihoods may have come under threat. In this section, we explore the current status of nomadism in Djibouti and the vulnerability that nomads may face. We refer to Lara Ibarra, Weiser, and MartinezCruz (2018) for a review of nomadism, climate risk, and the links between them.

Nomadic people (or nomads) are persons without a fixed place of usual residence who move from one site to another

\section{MAP 3.1 Major Livestock Migration Routes in Djibouti}

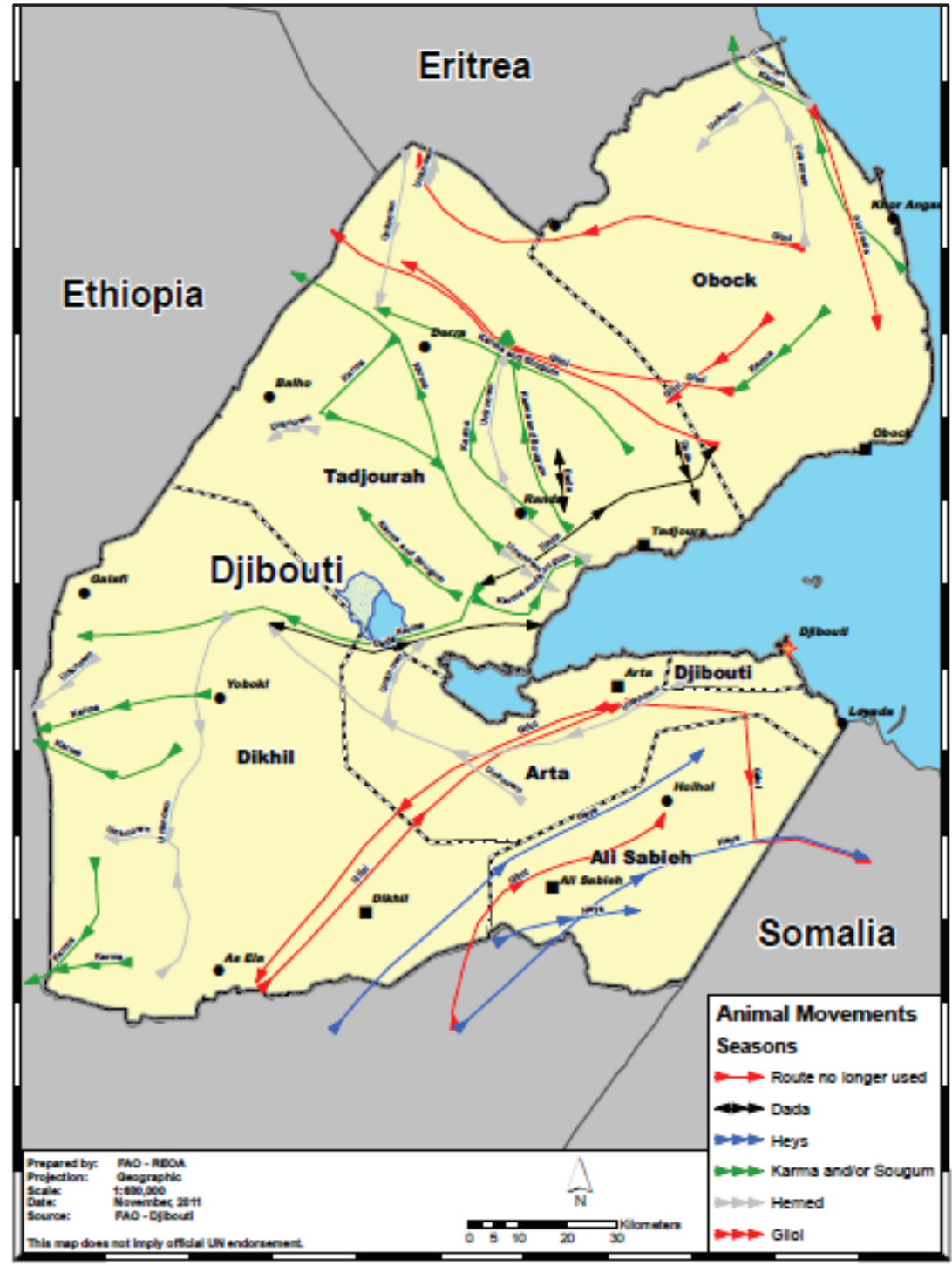

Source: FAO 2011. 
in certain seasons or periods, usually according to wellestablished patterns of geographical mobility (UN 1998). They also usually return to their original location at different times in a year. Nomads can be classified into three types: hunter-gatherers, whose livelihood depend on wild plants; pastoralists, who raise herds of animals and move with them; and peripatetic nomads, who subsist by practicing a trade from place to place. Nomadism is not to be confused with migration, as the latter entails a long-term or permanent move from one place to another (Tanabe 2015).

Estimates from a report by the United Nations (UN 2009) place the nomadic population in the world at 200 million, found in different parts of the world and across continents. Among other reasons, nomadic populations have become a vulnerable group due to the dramatic changes in weather conditions and exacerbated risk from climate change. For instance, Tao et al. (2015) argue that in recent decades climate change has had significant impacts on the lakes in the Mongolian Plateau, which are the source of livelihood for the Mongolian nomadic population. As is observed in Djibouti, Sheik-Mohamed and Velema (1999) argue that annual rainfall in the Sahara Desert or semiarid areas like the Sahil and northeastern Africa is expected to become even more varied. This is likely to have an effect on the potential of the pastoralists to sustain their activities. It is also argued that climate change may have positive effects at local levels, while having negative effects in others (Byg and Salick 2009; Martinez-Cruz, Juárez-Torres, and Guerrero 2017). Nevertheless, in summary, nomads are more likely to be affected negatively from climate change, for instance, in Sub-Saharan Africa (Schlenker and Lobell 2010).

Nomadism in Djibouti takes the form of pastoralism, in which individuals raise herds of animals and travel with them. Map 3.1 highlights the key routes taken by nomads in Djibouti circa 2011. The season of Heys/ Dada rains runs normally from October to February and the season of Karan/Karma rains runs normally from July to September. As in other parts of the world, nomads in Djibouti are no exception at being increasingly vulnerable to climate change, due their direct dependence on weather conditions to earn income. Figure 3.7 shows that temperatures in Djibouti are becoming more extreme over time. Temperatures in January have been dropping and those in July have been increasing. With the series of droughts in Djibouti in the past decade along with temperature changes, the livelihoods of pastoralists have come under a serious threat.

\section{FIGURE 3.7 Average Temperature in Djibouti (Celsius)}

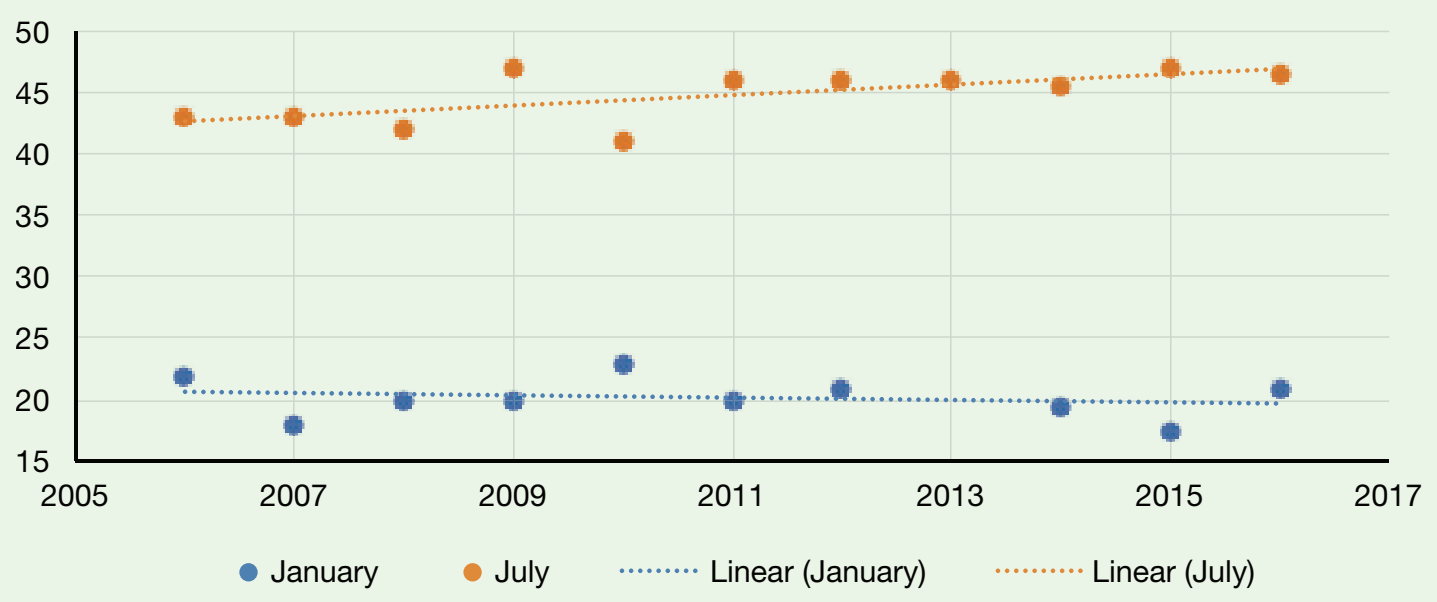

Source: World Bank Climate Change Knowledge Portal. http://sdwebx.worldbank.org/climateportal/index.cfm?page=country_historical_climate, accessed October 19, 2018. 
The pastoralist population was covered in the latest survey of EDAM4-IS for the first time in the EDAM history. With this survey information, a simple yet informative profile of this population can be provided. Figure 3.8 shows a snapshot of the population in Djibouti engaged in animal rearing and in pastoralism. We find that ownership and rearing of livestock is highly prevalent in Tadjourah and Obock. About 55 percent of the population owns and/or rears animals, mostly goats, in these two regions. About 15 percent own camels, while sheep are more commonly owned and/or reared in Ali Sabieh and Arta. Of those that own any of the four most common animals (goats, camels, sheep, or cattle), questions on the practice of transhumance were asked in EDAM4-IS. A subset of those who practice transhumance in neighboring countries or in further distant areas within Djibouti are defined as pastoralists. Figure 3.9 shows that 15 percent of the population of Obock practices transhumance, the highest in the country. Both Tadjourah and Obock have about 3 percent of the population as pastoralists. Overall, outside of Djibouti city, about 6 percent of the population is found to practice transhumance.

Part of the explanation of this low percentage of pastoralists observed, as compared to the census of Djibouti in 2009, could be due to successive droughts that Djibouti has been facing over the past decade (see Box 1.1 for more detail). The resilience strategies developed by the nomadic populations against the negative effects of the drought have been (i) to migrate to regions, sometimes beyond the country's borders, or (ii) to settle around villages or other points, abandoning traditional transhumance in favor of nearby pastures. In fact, in 2009, the GoD adopted the National Strategy for Food and Nutrition Security (Décret n²009-0113/PRE). In volume 1 of this report, it is mentioned that, due to drought,

\section{FIGURE 3.8 Percentage of Population Owning and/or Raising Animals}

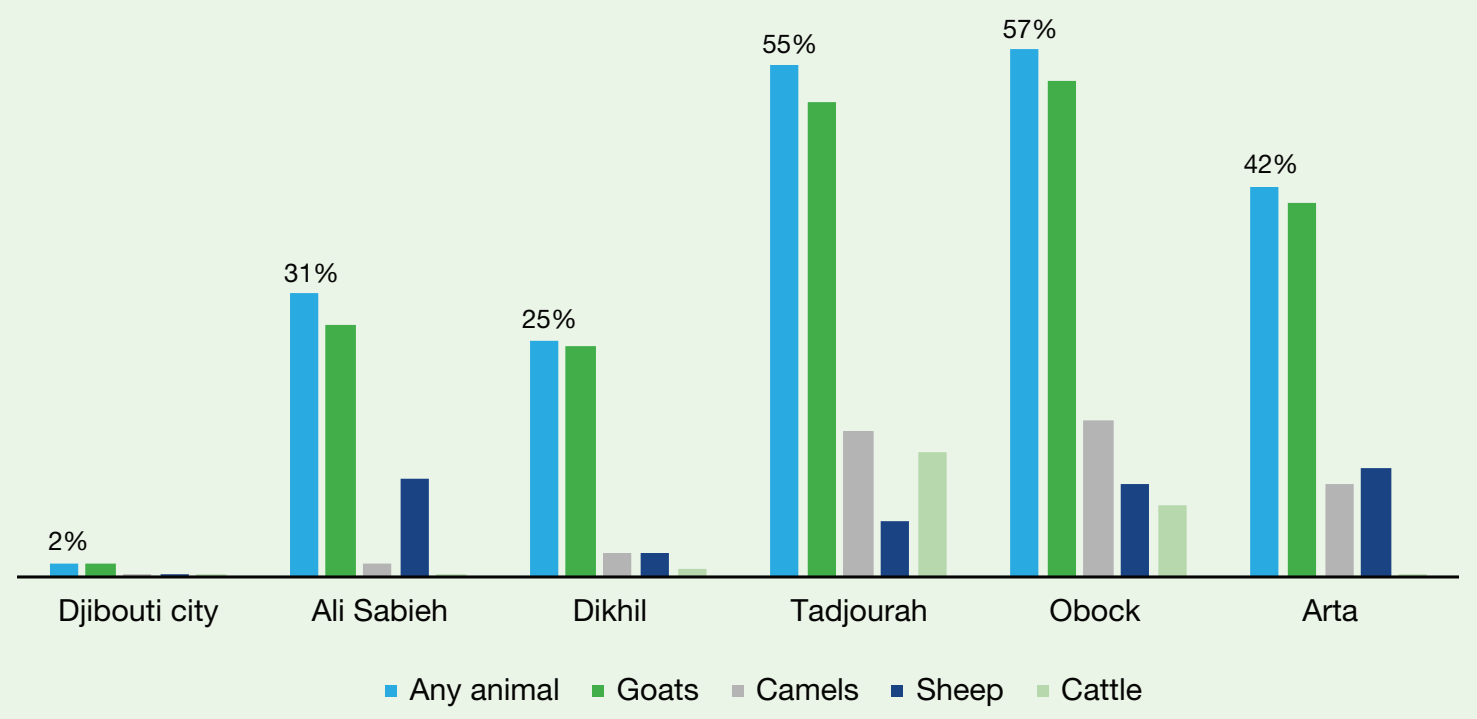

Source: Calculations based on EDAM4-IS 


\section{FIGURE 3.9 Percentage of Population Practicing Transhumance and Is Pastoralist}

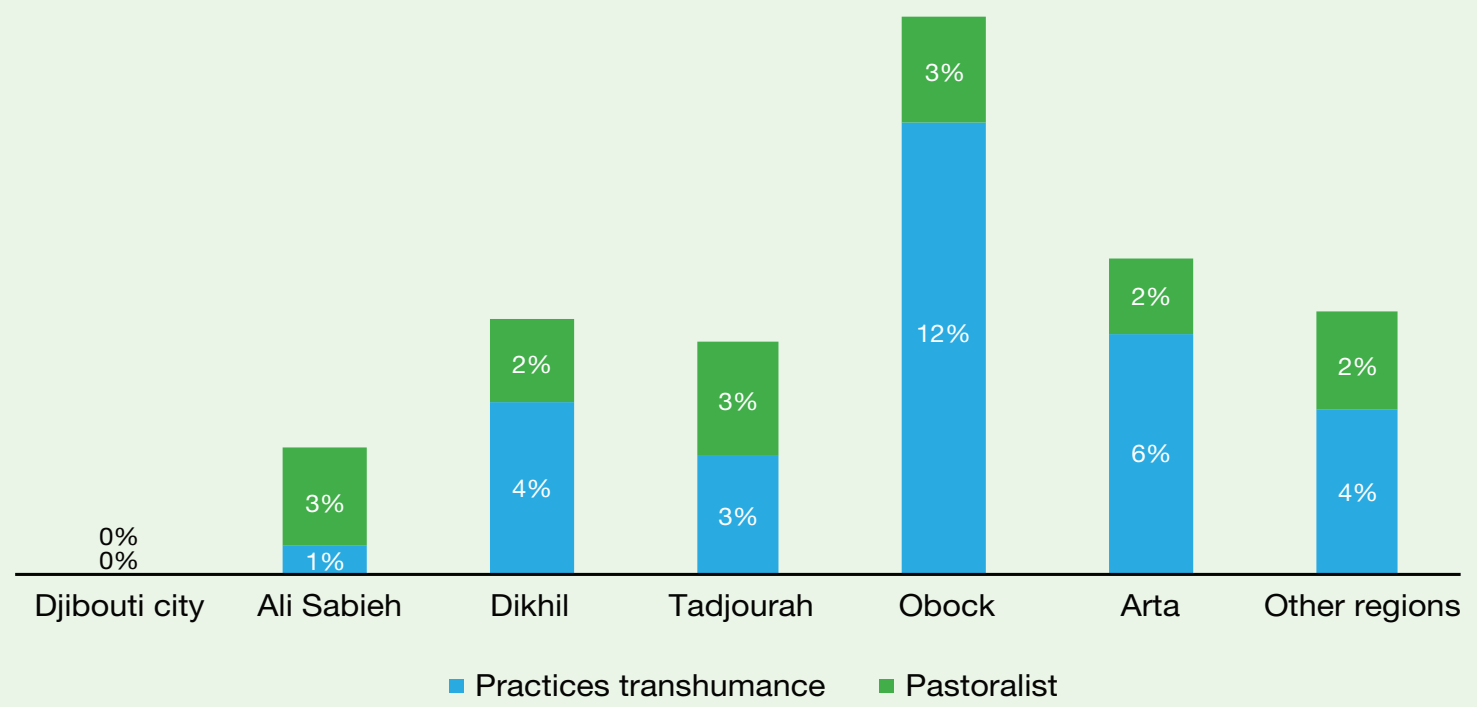

Source: Calculations based on EDAM4-IS.

Notes: The percentage of population practicing transhumance out of all surveyed refers to those practicing transhumance to rear goats, camels, sheep, or cattle in the neighborhood. Pastoralist are defined as those practicing transhumance of goats, camels, sheep, or cattle either in other countries or within the country but outside of the neighborhoods.

"nomadic pastoralists are led to move their animals . . . in the interior of the country, especially to high-altitude pastures and to other countries in the region. . . . More substantial and more regular humanitarian aid to Ethiopian pastoralists has helped set up pastoralists in Ethiopia, whose home lands were traditionally in Djibouti. Therefore, there is a double hemorrhage of the rural population." This phenomenon led to the substantial downward revision of DISED's estimation of the nomadic population when estimating the framework of EDAM4 (DISED 2018).

Estimates from consumption expenditure show that the welfare of this subgroup is much worse than the population as a whole (Figure 3.10). The poverty rates among those who practice transhumance and those who are pastoralists are higher, especially in Ali Sabieh and Dikhil. When we compare characteristics of the households that practice transhumance to those that do not in the regions, interesting findings emerge. We find that while they live in households of similar size, the dependency ratio is higher in households that practice transhumance. Table 3.13 shows that the demographic characteristics of households' heads are similar, but educational outcomes of household members vary significantly. Only 7 percent of individuals living in households that practice transhumance are literate as compared to 31 percent in other households in regions. The former also have only 0.5 years of schooling on an average compared to 2.8 years. These low levels of education and literacy would make 


\section{FIGURE 3.10 Extreme (Monetary) Poverty Rate among Various Population Groups}

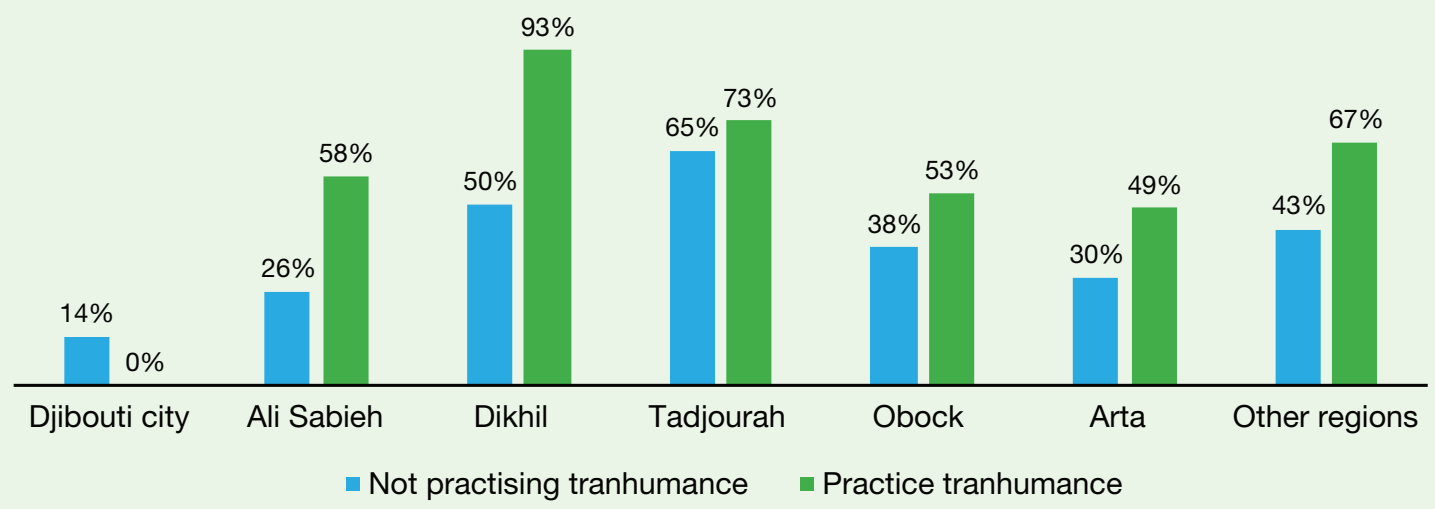

Source: Calculations based on EDAM4-IS.

Notes: The percentage of population practicing transhumance out of all surveyed refers to those practicing transhumance to rear goats, camels, sheep, or cattle.

TABLE 3.13 Characteristics of Households in the Regions That Practice Transhumance and Those That Do Not

\begin{tabular}{l|c|c|} 
& $\begin{array}{c}\text { Households that practice } \\
\text { transhumance }\end{array}$ & $\begin{array}{c}\text { Households that do not practice } \\
\text { transhumance }\end{array}$ \\
\hline Household size & 5.2 & 5.4 \\
\hline Dependency ratio $(\%)^{*}$ & 137.1 & 120.9 \\
\hline
\end{tabular}

Household head characteristics

\begin{tabular}{l|c|c|}
\hline Age** & 46.8 & 45.9 \\
\hline Married & $80.8 \%$ & $82.7 \%$ \\
\hline Female & $76.0 \%$ & $74.9 \%$ \\
\hline Individual characteristics & \multicolumn{2}{|c|}{} \\
\hline Literate (15 years and older) & $7.1 \%$ & $30.8 \%$ \\
\hline Years of education (15 years and older) & 0.55 & 2.8 \\
\hline
\end{tabular}

Source: Calculations based on EDAM4-IS.

Notes: The percentage of population practicing transhumance out of all surveyed refers to those practicing transhumance to rear goats, camels, sheep, or cattle. The sample consists of households in the regions only, out of which 181 households practice transhumance and 2,258 do not.

* Only households with at least one working age (15-64) individual are included.

** The sample comprises 4,359 household heads. For the remaining households, the age of the household head is unknown. 
assimilation in the labor force difficult for households that practice transhumance. All these findings point further to the vulnerability of this subgroup of the population and lend support to the recommendation that this subgroup requires attention.

The report by the United Nations (UN 2009) argues that pastoralism has proven to be a very effective livelihood in drylands. The strategies employed by pastoralists to subsist in these parts of the world have been shown to be sustainable for the environment and been found to be economically feasible. Pastoralist livelihoods have also promoted biological and floral diversity in regions where the practitioners travel. In some cases, efforts have been made by national agencies and international organizations to improve the livelihoods of nomads and have met with failure. For example, in an effort to promote transition to alternative livelihoods, desert tourism was promoted among the Tuareg people in Algeria and the Bedouin people in Jordan. This economic activity did not bring the expected economic gains but has disturbed the livelihood of these groups (Chatelard 2005; Hobbs and Tsunemi 2007). It, thus, becomes imperative to protect this vulnerable group, especially in light of the everpersistent threat of climate change. Equally important, the statistical systems in Djibouti must redouble efforts to observe this population. The upcoming population census (expected to be conducted in 2020) is an opportunity that should not be missed to improve our understanding of this important subgroup. It would also be worthwhile to investigate resilience strategies that could be employed by this population as well as the policy actions that may facilitate the promotion of these strategies and alternative livelihoods. 


\section{REFERENCES}

Aker, J. C. 2010. "Information from Markets Near and Far: Mobile Phones and Agricultural Markets in Niger." American Economic Journal: Applied Economics 2 (3): 46-59.

Aker, J. C., and I. M. Mbiti. 2010. "Mobile Phones and Economic Development in Africa." Journal of Economic Perspectives 24 (3): 207-32.

Araujo, C. and Carraro, L. n.d. A proxy-Means Test Exercise for the Selection of Beneficiaries of Poverty Targeted Programs in Mongolia. Washington, DC: World Bank.

Araar, A., E. Malasquez, S. Olivieri, and C. RodriguezCastelan. 2018. WELCOM User Manual. Washington, DC: World Bank.

Atamanov, A., C. Castaneda, D. Jolliffe, D. Krayem, and H. Sayed. 2015. Updating the Proxy Means Testing Formula in Lebanon. Technical report. Washington, DC: World Bank.

Beuermann, D. W., C. McKelvey, and R. Vakis. 2012. "Mobile Phones and Economic Development in Rural Peru." Journal of Development Studies 48 (11): 1617-28.

Boylaud, Olivier, and Giuseppe Nicoletti. 2001. "Regulation, Market Structure, and Performance in Telecommunications." OECD Economic Studies, 2001(1), 99-142.

Brown, C., M. Ravallion, and D. Van de Walle. 2018. A Poor Means Test? Econometric Targeting in Africa. Journal of Development Economics 134 (September): 109-24.

Byg, A., and J. Salick. 2009. "Local Perspectives on a Global Phenomenon: Climate Change in Eastern Tibetan Villages." Global Environmental Change 19 (2): 156-66.
Chatelard, G. 2005. Desert Tourism as a Substitute for Pastoralism? Tuareg in Algeria and Bedouin in Jordan. In Nomadic societies in the Middle East and North Africa: entering the 21st century. Chatty, D. (Ed.), Brill Academic Publishers, Netherlands, 710-736.

DISED. 2018. Résultats de la Quatrième Enquête Djiboutienne Auprès de Ménages pour les Indicateurs Sociaux (EDAM4-IS). Djibouti city: DISED. http://www. dised.dj/Rapport1_resultats_EDAM4.pdf.

EC (European Commission) 2002. Eighth Report from the Commission on the Implementation of the Telecommunications Regulatory Package, 3/12/2002 COM(2002) 695 final, SEC(2002) 1329. Brussels: EC.

FAO (UN Food and Agriculture Organization). 2011. Major Livestock Migration Routes in Djibouti. Map. Rome: Italy.

Gelvanovska, N., M. Rogy, and C. M. Rossotto. 2014. Broadband Networks in the Middle East and North Africa: Accelerating High-Speed Internet Access. Washington, DC: World Bank.

Genakos, Valletti, Verboven. 2015. Evaluating Market Consolidation in Mobile Communications. Brussels: Centre on Regulation in Europe (CERRE). $<<$ Au: Full names of authors needed.>>

Grosh, M., and J. Baker. 1995. "Proxy Means Tests for Targeting Social Programs: Simulations and Speculation." Living Standards Measurement Study Working Paper 118. World Bank: Washington, DC.

GSMA (Global System Mobile Association). 2018. The Mobile Economy Middle East \& North Africa. 
Hobbs, J. J., and F. Tsunemi. 2007. "Soft Sedentarization: Bedouin Tourist Stations as a Response to Drought in Egypt's Eastern Desert." Human Ecology 35 (2): 209-22.

IEA (International Energy Agency). 2012. World Energy Outlook. Paris: IEA.

ITU (United Nations International Telecommunications Union). 2017. "ICT Development Index 2017."

Geneva: ITU. http://www.itu.int/net4/ITU-D/

idi/2016/\#idi2016countrycard-tab\&DJl.

ITU. 2018. Measuring the Information Society Report. Vol. I. Geneva: ITU.

Lara Ibarra, Gabriel, Christina Weiser, and Adan MartinezCruz. 2018 "Estimating the Value of Housing Services of Nomadic Populations." Photocopy. Washington, DC: World Bank.

Martínez-Cruz, A. L., M. Juárez-Torres, and S. Guerrero. 2017. "Assessing Impacts from Climate Change on local Social-Ecological Systems in Contexts Where Information Is Lacking: An Expert Elicitation in the Bolivian Altiplano." Ecological Economics (137): 70-82.

Narayan, A., and N. Yoshida. 2005. "Proxy Means Test for Targeting Welfare Benefits in Sri Lanka." South Asia Region PREM Working Paper Series SASPR-7. World Bank: Washington, DC.

Ofcom. 2016. A Cross-Country Econometric Analysis of the Effect of Disruptive Firms on Mobile Pricing. London: Ofcom.

Schlenker, W., and D. B. Lobell. 2010. "Robust Negative Impacts of Climate Change on African Agriculture."

Environmental Research Letters 5 (1): 014010.
Sdralevich, M. C. A., M. R. Sab, M. Y. Zouhar, and G. Albertin. 2014. Subsidy Reform in the Middle East and North Africa: Recent Progress and Challenges Ahead. Washington, DC: International Monetary Fund.

Sheik-Mohamed, A., and J. P. Velema. 1999. "Where Health Care Has no Access: The Nomadic Populations of Sub-Saharan Africa." Tropical Medicine and International Health 4 (10): 695-707.

Tanabe, Jennifer. 2015. "Nomad." New World Encyclopedia. St. Paul, MN: Paragon House. http://www.newworldencyclopedia.org/p/index. php?title=Nomad\&oldid=989416.

Tao, S., J. Fang, X. Zhao, S. Zhao, H. Shen, H. Hu, Z. Tang, Z. Wang, and Q. Guo. 2015. "Rapid Loss of Lakes on the Mongolian Plateau." Proceedings of the National Academy of Sciences 112 (7): 2281-2286.

UN (United Nations). 1998. "Recommendations on Statistics of International Migration," revision 1. Statistical Papers Series M, 58. New York: United Nations. https://unstats.un.org/unsd/publication/SeriesM/ SeriesM_58rev1e.pdf.

UN. 2009. State of the World's Indigenous Peoples. New York: UN. https://www.un.org/development/desa/ indigenouspeoples/publications/state-of-the-worldsindigenous-peoples.html.

UNDESA (United Nations Department of Economic and Social Affairs). 2016. 2016 E-Government for Sustainable Development. New York: UN.

World Bank. 2015. Telecommunications Sector in Djibouti: Finding the Path to Growth. Washington, DC: World Bank.

World Bank. 2016. World Development Report 'Digital Dividends'. Washington, DC: World Bank. 


\section{NOTE ON EDAM4-IS 2017 AND SAMPLING}

This appendix presents a more detailed description of the Fourth Djibouti Household Survey for the 2017 Social Indicators. ${ }^{44}$ The EDAM4-IS survey was deployed in two phases. The first was conducted in April-May 2017 and ended before the Ramadan period. The second phase of the data collection was implemented in NovemberDecember 2017.

\section{THE DJIBOUTI HOUSEHOLD SURVEY (EDAM4-IS)}

The 2017 EDAM questionnaire covered the following topics:

1. Characteristics of household members (demographics and nationality)

2. Education

3. Health

4. Employment

5. Characteristics of housing

6. Possession of assets and durables

7. Food expenses (consumed at home and meals taken outside)

8. Nonfood expenditure

9. Sources of revenue (private and public transfers)

10. Shocks and survival mechanisms

11. Perceptions of poverty

12. Governance

13. Access to services

14. Income from farming activities
The EDAM4-IS questionnaire is the result of an adaptation of the traditional EDAM questionnaires with the aim of deepening the measurement and analysis of poverty and well-being. Compared to earlier surveys, the revisions that were incorporated into the EDAM4-IS questionnaire include the following:

1. The collection of a list of 100 food items that account for the majority of the products in the Djibouti household consumption basket

2. Information on transfers from public and private sources in more detail

3. Information on the purchase and present value of durable goods collected to account for the flow of services

4. Specific modules for income from economic activities

5. Information on nationality and migration (following recommendations from International Organization for Migration)

6. Information on education, health, and housing expenditures better placed in the questionnaire to improve collection of data (a comprehensive module on water and sanitation services was integrated following the direct request of the National Office of Water and Sanitation of Djibouti, or ONEAD).

44 The information presented here draws extensively from DISED (2018). Additional information is available in DISED's microdata catalog. http://www.dised.dj/djibnada/index.php/catalog/12. 
By comparing the collection of data on food consumption, and using lessons learned from international experience, a recall period of consumer goods expenditure of seven days was applied. Also, expenses on purchases and food donations consumed outside the home were captured for all household members age five years and older. Specific questions on the consumption of tobacco and other similar products were also included in the questionnaire.
To better capture the welfare derived from durable goods, information was collected on assets owned by the household, their values at the time of purchase, the length of time have been owned, and the estimation of their current value.

Last, unlike the previous EDAM and EBC surveys, the coverage of EDAM4-IS 2017 was extended to nomadic households.

\section{SAMPLING AND EXTRAPOLATION COEFFICIENTS OF THE EDAM4-IS}

The main database and maps for the compilation of the EDAM4 frame are those of the General Census of Population and Housing of Djibouti 2009. The census enumeration areas (EAs) or primary sampling units (PSUs) sampling frame is stratified by region, urban area, and rural area for most national surveys. Although the urban and rural areas of each region are individual sampling strata to improve the efficiency of the sample design, the total results for other urban and rural areas is limited at the national level.
A stratified two-stage sampling model was used for EDAM4. In the first step, EA samples were systematically selected with size-proportional probabilities within each stratum. Fifteen survey strata have been defined: the five districts of Djibouti city, and each of the five regions of the interior of the country divided in urban and rural areas. Before proceeding to draw sample households at the second stage, an update of the household listings of the sample EAs was carried out in April 2017. At the second

\section{TABLE A.1 Enumeration Areas (EAs) Selected in the Sampling}

\begin{tabular}{|c|c|c|c|c|c|}
\hline \multirow[b]{2}{*}{ Region } & \multirow{2}{*}{$\begin{array}{c}\text { Total } \\
\text { Total EAs }\end{array}$} & \multicolumn{2}{|c|}{ Urban } & \multicolumn{2}{|c|}{ Rural } \\
\hline & & Total EAs & Selected EAs & Total EAs & Selected EAs \\
\hline \multicolumn{6}{|l|}{ Djibouti city } \\
\hline District 1 & 74 & 74 & 42 & - & - \\
\hline District 2 & 120 & 120 & 42 & - & - \\
\hline District 3 & 38 & 38 & 38 & - & - \\
\hline District 4 & 156 & 156 & 42 & - & - \\
\hline District 5 & 142 & 142 & 42 & - & - \\
\hline Ali Sabieh region & 46 & 27 & 16 & 19 & 18 \\
\hline Dikhil region & 64 & 20 & 9 & 44 & 25 \\
\hline Tadjourah region & 57 & 12 & 4 & 45 & 30 \\
\hline Obock region & 45 & 8 & 8 & 37 & 26 \\
\hline Arta region & 51 & 10 & 8 & 41 & 26 \\
\hline Totals & 793 & 607 & 251 & 186 & 125 \\
\hline
\end{tabular}


stage, a systematic random sample of 12 households was selected in each EA sample (or cluster) for Djibouti city and 15 households per EA for other regions. In the case of rural samples, the sample of 15 households was to include both sedentary and nomadic households. Given the large percentage of nomadic households in rural areas according to the published results of the 2009 census (more than 50 percent), this sampling procedure had to provide a sufficient sample of nomadic households for analysis at the national level. In total, the sample of EDAM4 includes 376 EAs (251 in urban areas, 125 in rural areas). The table A.1 shows EDAM4's EAs distribution.

\section{DATA COLLECTION}

Due to the limited time available for data collection prior to Ramadan, which began on May 27, 2017, it was decided to cover the sample for Djibouti city in two phases.

For the first phase, before Ramadan, a subsample of 84 of 206 EAs for Djibouti city was selected to obtain reliable results for this area. For the other regions, all sample groups were surveyed in the first phase. The $84 \mathrm{EA}$ samples in Djibouti city for the first phase were allocated to the districts in proportion to the number of households. Data collection for the first phase ran from April 27 to May 26, 2017.
The remaining 122 sample EAs for Djibouti city were surveyed during the second phase, from October to November 2017, to provide reliable district-level survey results from the combined data for both phases.

The final size of the sample is 4,474 households distributed as given in table A.2.

\section{SAMPLING WEIGHTS}

For sample estimates from the 2017 EDAM4 data to be representative of the population, it will be necessary to multiply the data by a sampling weight or an expansion factor. The base weight for each sample household is equal to the inverse of its selection probability (calculated by multiplying the probabilities at each sampling stage).

Based on the two-stage stratified sample design, the overall probability of selection for the 2017 EDAM sample households can be expressed as follows:

$$
p_{h i}=\frac{n_{h} M_{h i}}{M_{h}} \times \frac{m_{h i}}{M_{h i}^{\prime}}
$$

where:

$P_{h i}=$ overall sampling probability for households selected for EDAM4 in the i-th group of samples in stratum $\mathrm{h}$

$n_{h}=$ number of sample clusters selected in stratum $\mathrm{h}$ for EDAM4

\section{TABLE A.2 Sample Distribution by Region}

\begin{tabular}{l|c|} 
Region & Households interviewed \\
\hline Djibouti city & 2,035 \\
\hline Ali Sabieh & 495 \\
\hline Dikhil & 496 \\
\hline Tadjourah & 493 \\
\hline Obock & 475 \\
\hline Arta & 480 \\
\hline Djibouti country & 4,474 \\
\hline
\end{tabular}

Source: Calculations based on EDAM4-IS 
$M_{h i}=$ total number of households in the i-th sample group in stratum $\mathrm{h}$ of the sampling frame based on the 2009 Djibouti census (partially updated)

$M_{h}=$ total number of households in stratum $\mathrm{h}$ of the frame

$m_{h i}=12$ or $15=$ number of sample households selected for EDAM4 in the i-th group of samples in stratum $\mathrm{h}$

$M_{h i}^{\prime}=$ total number of households in the new list for the i-th group of samples in stratum $\mathrm{h}$

The base weight for sample households of EDAM4 is the inverse of this probability of selection, expressed as follows:

$$
W_{h i}=\frac{1}{p_{h i}}=\frac{M_{h} M_{h i}^{\prime}}{n_{h} M_{h i} m_{h i}}
$$

$W_{h i}=$ base weight for sample households EDAM4 in the $\mathrm{i}$-th group of samples in stratum $\mathrm{h}$

After the collection of EDAM4 data, the base weights were adjusted to account for noninterviews, as follows:

$$
W_{h i}^{\prime}=W_{h i} \frac{m_{h i}}{m_{h i}^{\prime}}
$$

Where:

$W_{h i}^{\prime}=$ adjusted weight for sample households EDAM4 in the $\mathrm{i}$-th group of samples in stratum $\mathrm{h}$

$m_{h i}^{\prime}=$ number of sampled households completing interviews in the $\mathrm{i}$-th group of samples in stratum $\mathrm{h}$
DOES THE EDAM REPRESENT THE ACTUAL DJIBOUTIAN POPULATION?

Given the implementation of the EDAM4, an important implication is that there may exist a difference between the population that is represented in the survey and the overall population in the country. Current estimates of the Djiboutian population are about 1 million but include subgroups of the population such as homeless and refugees that are not part of the survey. Moreover, they are based on extrapolations of the distribution of the population from the 2009 Census that may overestimate the evolution of the nomadic population. This difference may raise concerns on the ability of the survey to be representative of the country's population.

Table A.3 presents a selection of indicators that may help allay these concerns. The survey results are compared with results using other sources, specifically administrative data on schooling from the Ministry of National Education and Professional Training in Djibouti (MENFOP) and Enquete Djiboutienne sur l'emploi, le secteur informel et la consummation, or EDESIC 2015 (DISED 2015). The indicators on the percentage of students enrolled in various years of primary school is strikingly similar in EDAM4-IS and official data from MENFOP in 2016-17. Using indicators on education and access to services, we see that survey results from EDAM4-IS are similar to those obtained from EDESIC 2015, published by DISED. This validation exercise provides confidence in terms of the sampling methodology and the representation of the survey. 
TABLE A.3 Comparison of Selected Indicators between EDAM4 and DISED Published Data

\begin{tabular}{|c|c|c|}
\hline & EDAM4-IS & Other sources \\
\hline \multicolumn{3}{|l|}{ Percentage of students enrolled in: } \\
\hline 1st year of school & 20 & 19 \\
\hline 2nd year of school & 18 & 19 \\
\hline 3rd year of school & 18 & 19 \\
\hline 4th year of school & 19 & 18 \\
\hline 5th year of school & 25 & 25 \\
\hline Percentage of students in public primary school who are girls & 46 & 47 \\
\hline Access to water & 90 & 86 \\
\hline Access to electricity & 60 & 58 \\
\hline Open defecation & 12 & 14 \\
\hline Gross enrolment ratio, primary (children ages 6-10 years) & 96 & 94 \\
\hline Literacy rate among men ( 15 years and older) & 69 & 67 \\
\hline Literacy rate among women ( 15 years and older) & 49 & 53 \\
\hline Median age & 22 & 20 \\
\hline
\end{tabular}

Source: Calculations based on EDAM4-IS, and DISED 2017.

Note: Access to electricity reflects the use of electricity as the main source of lighting. Access to water reflects the availability of water in running water (ONEAD indoor connection), direct connection from a borehole, ONEAD outdoor connection by pipe, public fountain and borehole (with a pump). 


\section{REFERENCES}

DISED (Direction de la Statistiques et des Etudes

Démographiques). 2015. Enquete Djiboutienne sur

l'emploi, le secteur informel et la consummation, 2015.

Djibouti: DISED.

DISED. 2017. Annuaire Statistique 2017. Djibouti: DISED.

DISED. 2018. Résultats de la Quatrième Enquête

Djiboutienne Auprès de Ménages pour les Indicateurs

Sociaux (EDAM4-IS). Djibouti city: DISED. http://www.

dised.dj/Rapport1_resultats_EDAM4.pdf. 


\section{NOTE ON POVERTY MEASUREMENT METHODOLOGY}

The calculation of poverty rate and other associated measures entails the construction of a consumption aggregate as a measure of welfare and a poverty line representing the minimum welfare level below which a person is deemed to be poor. The methodology used for each of these is discussed in turn.

\section{THE AGGREGATE OF CONSUMPTION AS A MEASURE OF WELL-BEING}

The measure of standard of living used depends either on the consumption or income of a household. The choice between consumption and income depends on many factors, such as the availability of data, the design of the survey, as well as the context of the country. For example, in the case of a country like Djibouti, the recording of income is difficult because of the underreporting as well as the presence of an informal sector of employment. Thus, consumption is considered as a better approximation of well-being. Subsequently, temporal adjustments must be made to household consumption to ensure that poverty measures are comparable across different data collection periods. The size and composition of the household also play an important role and need to be adjusted.

In defining the consumption aggregate, its four groups of components are considered (Deaton and Zaidi 2002): (i) expenditures on food products, (ii) nonfood expenditures, (iii) consumer durables, and (iv) rent and housing. In the sections that follow, estimation of each of these components is discussed. Aggregating these four components will determine nominal household expenditures. Subsequently, decisions on price deflators, the time deflator, and household composition adjustments to obtain the value of consumption that will be used as the basis for determining poverty rates are presented.

\section{EXPENDITURES ON FOOD PRODUCTS}

The value of consumption expenditure incurred for each food in the preceding seven days has been reported by households in the EDAM4, 2017 and is directly used in the consumption aggregate. The survey includes a very detailed list of 100 foods divided into 12 groups. Food consumption data include the value and quantity of food purchased as well as the amount of food produced at home and foods that may have been acquired through nonmonetary transactions such as donations, barter or trade, and so forth. These three modes of acquisition are used to construct a measure of household food consumption expenditure.

Another section of the questionnaire focused on food consumed outside the home by each household member over the age of five in the preceding seven days. This includes all meals taken outside the house, such as at restaurants. This section also recorded the value of the meals received as a gift. The aggregation of data from these two components provides us with a measure of 
total food consumption expenditure. This expense is then converted into an annual expense.

Figure B.1 shows that the top 10 foods that are consumed by the Djiboutian population. About 90 percent of the population consumes imported rice, followed closely by spaghetti and sugar. The average expenditures on each of these 10 food products is also presented. Not surprisingly, average expenditure on mutton is the highest among these products. Table B.1 disaggregates food expenditure by food-item group and by quintiles of the per capita

\section{FIGURE B.1 Percentage of Population Consuming and Mean Annual Expenditure (DF) by Food Product}

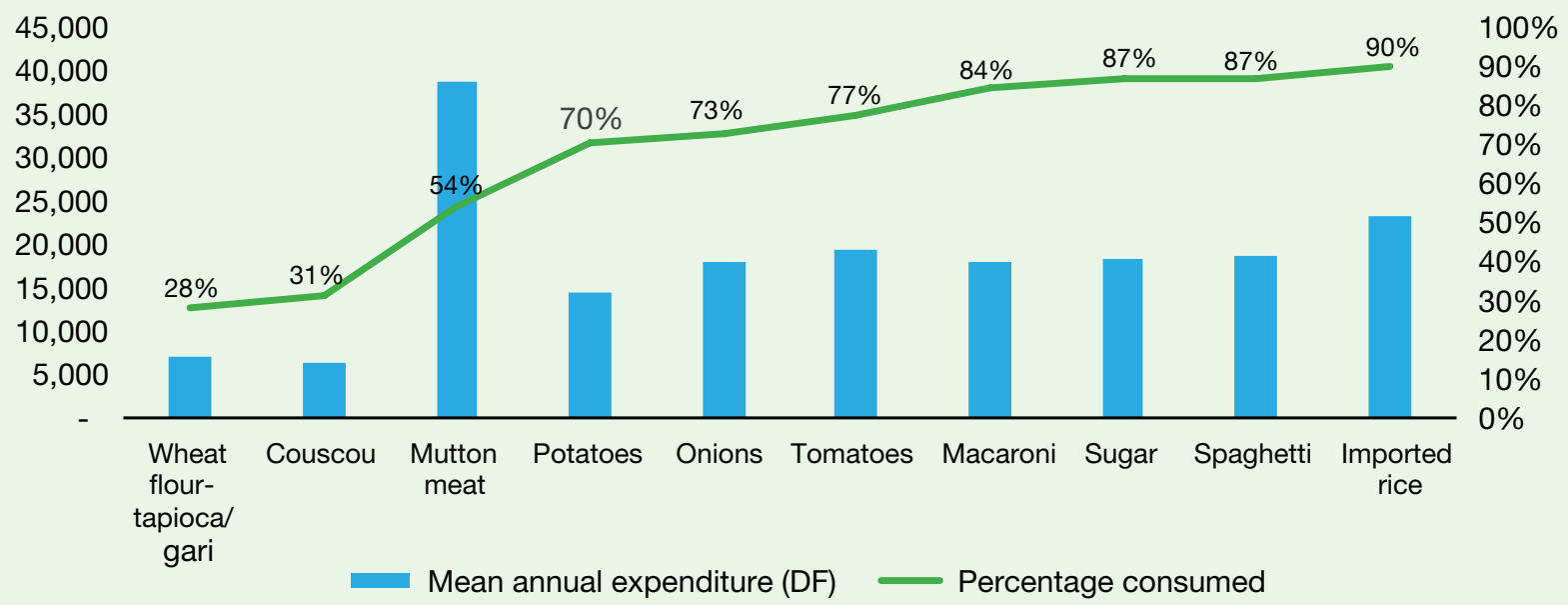

Source: Calculations based on EDAM4-IS.

TABLE B.1 Shares of Food Group to Total Food Consumption Expenditure by Quintile

\begin{tabular}{|c|c|c|c|c|c|c|}
\hline & Poorest & & & & Richest & \multirow[b]{2}{*}{ Total } \\
\hline & 1 & 2 & 3 & 4 & 5 & \\
\hline Cereals & $30 \%$ & $18 \%$ & $14 \%$ & $12 \%$ & $10 \%$ & $17 \%$ \\
\hline Pasta and bread & $18 \%$ & $20 \%$ & $19 \%$ & $17 \%$ & $12 \%$ & $17 \%$ \\
\hline Meat & $5 \%$ & $11 \%$ & $14 \%$ & $16 \%$ & $16 \%$ & $12 \%$ \\
\hline Fish & $1 \%$ & $2 \%$ & $3 \%$ & $3 \%$ & $6 \%$ & $3 \%$ \\
\hline Milk products and eggs & $3 \%$ & $6 \%$ & $7 \%$ & $8 \%$ & $11 \%$ & $7 \%$ \\
\hline Oil and butter & $8 \%$ & $6 \%$ & $6 \%$ & $5 \%$ & $5 \%$ & $6 \%$ \\
\hline Fruits & $1 \%$ & $3 \%$ & $3 \%$ & $4 \%$ & $6 \%$ & $3 \%$ \\
\hline Vegetables & $11 \%$ & $14 \%$ & $14 \%$ & $13 \%$ & $12 \%$ & $13 \%$ \\
\hline Canned vegetables & $2 \%$ & $2 \%$ & $2 \%$ & $2 \%$ & $2 \%$ & $2 \%$ \\
\hline Tubers and plantains & $3 \%$ & $4 \%$ & $4 \%$ & $4 \%$ & $3 \%$ & $4 \%$ \\
\hline Sugar and condiments & $8 \%$ & $6 \%$ & $6 \%$ & $5 \%$ & $5 \%$ & $6 \%$ \\
\hline Others & $12 \%$ & $10 \%$ & $9 \%$ & $10 \%$ & $12 \%$ & $11 \%$ \\
\hline Total & $100 \%$ & $100 \%$ & $100 \%$ & $100 \%$ & $100 \%$ & $100 \%$ \\
\hline
\end{tabular}

Source: Calculations based on EDAM4-IS. 
distribution of food expenditure. As expected, the share of staple foods (bread and cereals) to total food expenditure declines the higher the overall value of food consumption, and it is matched by an opposite increase in relatively more nutrient-rich food such as meat, milk products, and fruits. In table B.2, various characteristics of the food basket of the Djiboutian population are presented.

\section{TABLE B.2 Djibouti's Food Basket}

\begin{tabular}{|c|c|c|c|c|}
\hline & $\begin{array}{l}\text { Percentage } \\
\text { consuming }\end{array}$ & $\begin{array}{l}\text { Daily expenditure } \\
\text { (DF) }\end{array}$ & $\begin{array}{c}\text { Daily expenditure } \\
\text { per adult } \\
\text { equivalent (DF) }\end{array}$ & Unit cost (DF) \\
\hline Cereals & $7 \%$ & 57 & 13 & n.a. \\
\hline Pasta and bread & $17 \%$ & 87 & 18 & n.a. \\
\hline Meat & $7 \%$ & 157 & 36 & n.a. \\
\hline Fish & $6 \%$ & 103 & 25 & n.a. \\
\hline Milk products & $9 \%$ & 150 & 36 & n.a. \\
\hline Eggs & $7 \%$ & 53 & 13 & n.a. \\
\hline Oil and butter & $16 \%$ & 64 & 15 & n.a. \\
\hline Fruits & $12 \%$ & 48 & 11 & n.a. \\
\hline Vegetables & $20 \%$ & 28 & 7 & n.a. \\
\hline Canned vegetables & $10 \%$ & 69 & 17 & n.a. \\
\hline Tubers and plantains & $0 \%$ & 67 & 21 & n.a. \\
\hline Sugar and condiments & $4 \%$ & 58 & 14 & n.a. \\
\hline Others & $21 \%$ & 29 & 7 & n.a. \\
\hline Imported rice & $90 \%$ & 70 & 16 & 161 \\
\hline Couscous & $31 \%$ & 56 & 12 & 166 \\
\hline Wheat flour: tapioca & $28 \%$ & 69 & 17 & 130 \\
\hline Macaroni & $84 \%$ & 59 & 13 & 191 \\
\hline Spaghetti & $87 \%$ & 58 & 13 & 188 \\
\hline Mutton meat & $54 \%$ & 194 & 45 & 1095 \\
\hline Onions & $73 \%$ & 67 & 15 & 176 \\
\hline Tomatoes & $77 \%$ & 69 & 15 & 233 \\
\hline Potatoes & $70 \%$ & 56 & 12 & 130 \\
\hline Sugar & $87 \%$ & 58 & 13 & 162 \\
\hline
\end{tabular}

Source: Calculations based on EDAM4-IS.

Notes: n.a. $=$ not applicable. 


\section{EXPENDITURE ON NONFOOD PRODUCTS}

Total consumption expenditures from nonfood items are calculated by aggregating expenditures for various goods and services. These expenses are recorded in different sections of the questionnaire; the reference period, therefore, differs. Major groups of goods and services include fuel, vehicle use, transportation and communication, games, books and recreational services, personal care products and services, home repairs, appliances, clothing and footwear, textiles, glassware, tools and nondurable goods, music equipment, video and computer (excluding durable goods), jewelry, watches and personal items, tourism, insurance and other services, energy expenditures and public services, education expenditures, and health expenditures. Each of these expenses is annualized using a factor corresponding to the recall period. For example, the previous month's expenses are multiplied by 12 .

Finally, expenditures for tobacco products, drugs, and alcohol consumed in the preceding seven days for each household member older than 12 years are also added to the nonfood expenditure aggregate. These products include cigarettes, cigars, shisha, chewing tobacco products, alcoholic beverages, and other drugs. The quantity of these products received in donations, exchanges, and so forth is also captured in the questionnaire and included in the consumption aggregate after obtaining an estimate of the unit value from the information on individuals' purchases. These expenses are then converted into annual expenditures using a factor of 52 (weeks).

Health expenditures are often irregular expenditures, and a choice must be made about their inclusion in the aggregate of well-being. On the one hand, some types of health expenditures improve the well-being of individuals and are discretionary. However, other types of health expenditure (for example, for the sick) could be a necessity and necessarily linked to a loss of well-being. Deaton and Zaidi (2002) recommend calculating the elasticity of health expenditures relative to total expenditures. The higher the elasticity, the higher the case for its inclusion in the consumption aggregate.

Using the information from the health section, the following regression is performed:

$$
\ln (\text { healthexp })=\beta \ln (\text { hhexp })_{h}+\epsilon_{h}
$$

where healthexp includes all per capita household expenses related to health and hhexp includes all per capita household expenses except health. The estimated $\beta$ is 1.46. Thus, it is considered appropriate to include health expenditures in the aggregate of well-being.

Deaton and Zaidi's (2002) recommendation on education spending is also noted: education spending could be considered an investment and not necessarily an increase in well-being. An estimation similar to (1) for education expenditures is done. The estimate found is 1.34 , and it is concluded that these expenditures should also be included in the calculation of the consumption aggregate. ${ }^{45}$

According to good practices in measuring poverty, household consumption expenditure excludes irregular expenditures. These include spending on celebrations such as Eid, weddings, and other ceremonies. These expenses are incurred a few times or once in a lifetime; therefore, including them in the year in which they were made would lead to underestimation of poverty and overestimation of inequality. Charitable donations and assistance (cash or in-kind) to family and friends were also excluded because they do not contribute directly to the well-being of the household.

\section{DURABLE GOODS}

The aggregate of well-being used in the previous EDAMs (2002, 2012, and 2013) included the cost of acquisition of durable goods. In other words, the total purchase value of durable goods acquired in the preceding year has been included in the consumption aggregate. However, it can be argued that such an expenditure is an investment and not a consumption, as households are likely to

45 If we exclude health expenditures from the welfare aggregate, the poverty rates remain largely unaffected. (The extreme poverty rate is 21 percent and the overall poverty rate is 35.7 percent). 
benefit from these purchases over a long period of time.

Therefore, including them as consumption in the reference period can lead to an overestimation of well-being and bias the inequality indices obtained from the distribution of consumption. In line with current good practices, information on the purchase value, the present value, and the number of years of possession of a durable goods is used to include the "flow of service" of durable goods as a component of household welfare.

The flow of service, or "use value," is the value of services provided by durable goods to households over a period of time. A standard approach involves estimating the "user cost" of durable goods. The purchase price reflects the value of the durable good over its entire life, but it is preferred to capture the flow of services provided by the durable good during the reference period. The user cost has potentially two components: (i) the opportunity cost of the locked-in funds in the durable good (captured by the interest rate) and (ii) the temporal depreciation (in rare cases, appreciation) of the good itself. The depreciation rate is based on the date and cost of acquisition of the good, combined with assumptions about the current value of the item.
The standard approach is to impute the cost of use as follows:

$$
U C=\left(p_{t}\left(r_{t}-\pi_{t}+\delta\right)\right) /(1-\delta)
$$

where

$p_{t}=$ purchase price of durable good,

$r_{t}=$ nominal interest rate

$\pi_{t}=$ inflation rate, and

$\delta=$ depreciation rate.

A detailed inventory of 45 durable goods was obtained from the asset possession section of the questionnaire. The final list of durable goods included in the welfare aggregate came from those in which at least 60 households provided information on the purchase value, the present value, and the number of years the household had owned the good. These criteria allowed enough variation to obtain a reliable depreciation rate for each asset. Table B.3 shows the durable goods included in the final calculation and the estimated corresponding

\section{TABLE B.3 Durable Goods Included in the Consumption Aggregate}

\begin{tabular}{l|c|}
\multicolumn{1}{l|}{ Name of article } & Depreciation rate \\
\hline Satellite dish/ digital & $-8.2 \%$ \\
\hline Wardrobe/ dresser & $-5.9 \%$ \\
\hline Air conditioner & $-6.8 \%$ \\
\hline Iron & $-10.9 \%$ \\
\hline Bed (bed + mattress) or mattress & $-8.3 \%$ \\
\hline Washing machine & $-5.9 \%$ \\
\hline Mixer & $-7.6 \%$ \\
\hline PC/ laptop* & $-15.0 \%$ \\
\hline Radio & $-19.4 \%$ \\
\hline Gas stove (kerosene) & $-10.5 \%$ \\
\hline Refrigerator / Freezer & $-5.9 \%$ \\
\hline Living room furniture (armchairs and coffee table) & $-8.3 \%$ \\
\hline Mobile phone* & $-20.0 \%$ \\
\hline Television & $-6.8 \%$ \\
\hline
\end{tabular}

Source: Calculations based on EDAM4-IS.

Notes: * The depreciation rates for these items were taken from United Policy Holders website. 
depreciation rate. It is worth noting that for most goods, the information provided by households has closely followed the depreciation rates used by some insurance companies. There are two items for which households tended to underestimate the depreciation rate: computers and mobile phones. This is understandable, given the relatively recent availability of these items. Thus, the rates of these goods for this exercise have been replaced by those found on the United Policy Holders website.

To estimate equation (2), data from the Red Sea Bank of Africa site was obtained, in which the nominal annual return for a savings account was 1.59 percent. Finally, the inflation used for the calculation was -0.58 percent. This is based on a deflation rate calculated between 2016 and 2017 .

\section{RENT AND HOUSING SERVICES}

Among the components of measures of well-being, housing services are a key element. When consumption is used as a measure of well-being, as is the case in most developing countries, housing services should appropriately capture the utility generated by the consumption of housing amenities (Deaton and Grosh 2000). This estimate of the flow of services received by households must be comparable between households. If two households with the same number of members and the same age structure reside in a house with similar characteristics, both should be measured as having the same flow of housing services.

A natural choice to capture the value of the service market of any home could be the rent paid by its tenant. For homeowners, or households who received their housing for free (as an in-kind benefit) the rent is unknown. In EDAM4IS, households living in owner-occupied dwellings are encouraged to self-report the rental price of the dwelling if the household were to rent it. However, this self-declared rent may be an imperfect indicator of the real rental value of housing. Owners or in-kind occupants may not be fully aware of the rental market conditions where they reside. Their responses may also reflect what is known as "owner pride," the tendency to overstate the rental value of the residence that the owner currently occupies because of his or her personal attachment to it. Thus, a hedonistic semilogarithmic model to estimate a rental value for owners and in-kind occupants was used. The approach used to estimate the hedonic model is as follows.

Information on rents paid by a subset of the population, namely, tenants as well as self-reported rent by owners and in-kind dwellers, is used. Following Freeman (1993), it is argued that the rent paid by a tenant (In (rent)) can be expressed in terms of its characteristics (Xh), neighborhood characteristics (Nh), and location (Lh). The following formula is adopted:

$$
\ln (\text { rent })=\alpha+\beta X_{h}+\gamma L_{h}+\epsilon
$$

The variable on the left is the log of the rent paid by households living in rented dwellings, the self-reported rent by occupants of the service dwellings and the owners occupying their homes. This analysis is performed separately for Djibouti city and other regions. The housing characteristics, such as type of housing, type (or materials) of floor, type of wall, type of ceiling, source of lighting, water source, type of toilet, number of rooms, services to dispose of wastewater, garbage system, and a sewage disposal system are controlled for. Finally, some household characteristics such as size (and square), employment status, type of job, and type of business where the head of household is employed; and $\mathrm{Q}$ is the residual term are also included in the regression. The estimated coefficients are then applied to owner-occupied and in-kind dwellers' housing characteristics to produce a predicted value of their implicit rent: ${ }^{46}$

$$
\text { rent_ } \widehat{\text { lmpllclt }}=\exp (\hat{\alpha}+\hat{\beta} X+\hat{\gamma} L)
$$

To obtain the final imputed rent, a Smearing correction (Duan 1983) based on the average residue of the regression is performed. As a sensitivity analysis, the rent at the national level using the fixed effects of the region is estimated. The imputed final values did not differ qualitatively (extreme poverty rate changed to 21.3 percent and overall poverty rate changes to 35.9 percent). The results of the hedonic model are provided in table B.4.

46 Rent was found to be missing for 27 households and thus was imputed as the mean rent of the PSU. 


\section{TABLE B.4 Results of the Estimation of Hedonic Model}

\begin{tabular}{|c|c|c|}
\hline Variable & $\begin{array}{c}\text { (1) } \\
\text { Djibouti city }\end{array}$ & $\begin{array}{c}\text { (2) } \\
\text { Other regions }\end{array}$ \\
\hline Occupancy status-Owner & $\begin{array}{c}0.134^{\star \star \star} \\
-0.039\end{array}$ & \\
\hline Occupancy status - Free housing & $\begin{array}{c}-0.072 \\
-0.08\end{array}$ & $\begin{array}{l}-0.506^{\star \star \star} \\
-0.082\end{array}$ \\
\hline Type of accommodation-apartment in a building & $\begin{array}{c}0.815^{\star \star \star} \\
-0.108\end{array}$ & $\begin{array}{c}0.713^{\star \star \star} \\
-0.259\end{array}$ \\
\hline Type of accommodation-Single villa & $\begin{array}{l}0.278 \\
-0.23\end{array}$ & $\begin{array}{l}-0.429^{*} \\
-0.222\end{array}$ \\
\hline Type of accommodation - Villa with floor (duplex) & $\begin{array}{c}-0.407^{\star \star} \\
-0.176\end{array}$ & $\begin{array}{c}-0.373^{\star \star \star} \\
-0.109\end{array}$ \\
\hline Household size & $\begin{array}{l}-0.037^{\star} \\
-0.022\end{array}$ & $\begin{array}{l}0.017^{\star} \\
-0.01\end{array}$ \\
\hline More than two rooms & $\begin{array}{c}0.234^{\star * *} \\
-0.042\end{array}$ & $\begin{array}{c}0.557^{\star \star \star} \\
-0.062\end{array}$ \\
\hline Building materials -Wood/board & $\begin{array}{l}-0.241^{\star} \\
-0.139\end{array}$ & $\begin{array}{c}-0.323^{\star * *} \\
-0.099\end{array}$ \\
\hline Roof materials-Wood & & $\begin{array}{c}-0.233^{\star \star} \\
-0.101\end{array}$ \\
\hline Roof materials-Beton & $\begin{array}{c}0.341^{\star \star *} \\
-0.118\end{array}$ & $\begin{array}{l}-0.429^{\star} \\
-0.253\end{array}$ \\
\hline Roof materials-Straw & $\begin{array}{c}0.283^{\star \star} \\
-0.134\end{array}$ & $\begin{array}{l}-0.114 \\
-0.125\end{array}$ \\
\hline Lighting source-Lamp oil (kerosene) & $\begin{array}{l}-0.086 \\
-0.062\end{array}$ & $\begin{array}{c}-0.400^{\star \star \star} \\
-0.087\end{array}$ \\
\hline Lighting source-Generator & $\begin{array}{c}-0.533^{\star \star \star} \\
-0.064\end{array}$ & $\begin{array}{c}-0.375^{\star \star \star} \\
-0.064\end{array}$ \\
\hline Source of water-Direct connection from a borehole & & $\begin{array}{c}-0.328^{\star \star *} \\
-0.109\end{array}$ \\
\hline Source of water-ONEAD external hose connector & $\begin{array}{c}-0.306^{\star * \star} \\
-0.043\end{array}$ & $\begin{array}{c}-0.437^{\star \star \star} \\
-0.074\end{array}$ \\
\hline Source of water-Public fountain & $\begin{array}{c}-0.385^{\text {}} \\
-0.14\end{array}$ & $\begin{array}{c}-0.480^{\star \star \star} \\
-0.075\end{array}$ \\
\hline Source of water-Drilling (then with pump) & & $\begin{array}{c}-0.583^{\star \star \star} \\
-0.096\end{array}$ \\
\hline Source of water-Wells without pump & $\begin{array}{l}-0.394 \\
-0.258\end{array}$ & $\begin{array}{c}-0.875^{\star \star \star} \\
-0.102\end{array}$ \\
\hline Source of water-Traditional wells & $\begin{array}{c}-0.963 \\
-0.73\end{array}$ & $\begin{array}{c}-0.377^{\star \star} \\
-0.156\end{array}$ \\
\hline Toilet-Toilet without flush & $\begin{array}{c}-0.101^{\star \star} \\
-0.05\end{array}$ & $\begin{array}{l}-0.065 \\
-0.075\end{array}$ \\
\hline Toilet-Single latrine (single pit with concrete slab or local materials and hole) & $\begin{array}{l}-0.343^{\star \star \star} \\
-0.052\end{array}$ & $\begin{array}{l}0.272^{\star \star \star} \\
-0.075\end{array}$ \\
\hline
\end{tabular}




\begin{tabular}{|c|c|c|}
\hline Variable & $\begin{array}{c}\text { (1) } \\
\text { Djibouti city }\end{array}$ & $\begin{array}{c}\text { (2) } \\
\text { Other regions }\end{array}$ \\
\hline Toilet-Hole in the ground with rudimentary fence & $\begin{array}{l}-1.374^{\star \star \star} \\
-0.075\end{array}$ & $\begin{array}{l}0.291^{\star \star \star} \\
-0.084\end{array}$ \\
\hline Toilet-open & $\begin{array}{l}-1.282^{\star \star \star} \\
-0.148\end{array}$ & \\
\hline Garbage disposal-Dropped in a special place & & -0.067 \\
\hline Garbage disposal-Burn & $\begin{array}{l}-0.260^{\star \star \star} \\
-0.062\end{array}$ & $\begin{array}{l}-0.099 \\
-0.069\end{array}$ \\
\hline Wastewater disposal-Covered wells or pit & $\begin{array}{l}-0.332^{\star \star \star} \\
-0.06\end{array}$ & $\begin{array}{l}-0.156 \\
-0.124\end{array}$ \\
\hline Wastewater disposal-On the street or in nature & & $\begin{array}{l}-0.276^{\star \star} \\
-0.118\end{array}$ \\
\hline \multicolumn{3}{|l|}{ Region dummy - Ali Sabbieh } \\
\hline Region dummy-Dikhil & & $\begin{array}{c}0.363^{\star \star \star} \\
-0.069\end{array}$ \\
\hline Region dummy - Tadjourah & & $\begin{array}{l}0.251^{* *} \\
-0.101\end{array}$ \\
\hline Region dummy-Obock & & $\begin{array}{l}0.361^{\star \star \star} \\
-0.081\end{array}$ \\
\hline Region dummy-Arta & & $\begin{array}{l}0.379^{* \star *} \\
-0.082\end{array}$ \\
\hline Employment of the head-Salaried senior executive, engineer and related & $\begin{array}{l}0.456^{\star \star \star} \\
-0.152\end{array}$ & $\begin{array}{l}0.548^{\star *} \\
-0.232\end{array}$ \\
\hline Employment of the head-Medium executive officer, officer & & $\begin{array}{l}0.271^{\star *} \\
-0.109\end{array}$ \\
\hline Employment of head-(Employee) other employee/(employee) worker & $\begin{array}{c}0.178^{\star \star \star} \\
-0.046\end{array}$ & $\begin{array}{c}0.103 \\
-0.064\end{array}$ \\
\hline Employment of head- (Employee) laborer & $\begin{array}{l}-0.158 \\
-0.109\end{array}$ & $\begin{array}{c}0.178 \\
-0.142\end{array}$ \\
\hline Unemployment of head of household & $\begin{array}{c}0.085 \\
-0.054\end{array}$ & $\begin{array}{c}0.051 \\
-0.063\end{array}$ \\
\hline Chef's employment sector-NGO/International Organization/collectives/ others & $\begin{array}{c}0.229^{\star \star \star} \\
-0.079\end{array}$ & $\begin{array}{l}0.168^{\star} \\
-0.095\end{array}$ \\
\hline Constant & $\begin{array}{c}3.602^{\star \star \star} \\
-0.082\end{array}$ & $\begin{array}{c}2.517^{\star \star \star} \\
-0.12\end{array}$ \\
\hline Observations & 1,764 & 1,081 \\
\hline R-squared & 0.57 & 0.675 \\
\hline
\end{tabular}

Source: Calculations using EDAM4-IS. Notes: Standard deviation shown in parentheses. ${ }^{* * *} p<0.01,{ }^{* *} p<0.05$, ${ }^{*} p<0.1$. The results are displayed for the selected variables. Other variables included in the regression are the type of dwelling, the source of water, the employment of the head of household, the sector of employment of the head, the garbage disposal, the square of the household size. 
There is a consensus that the details of the approach used in estimating a hedonic model depends on the context of the country and the data available. The hedonic regression will vary depending on the groups of observations (renters, owners, and so forth) that end up included in the estimation. Thus, due to the reasons mentioned, rent declared by tenants and self-reported rent by owners may yield very different answers due to owner's pride and other reasons. Three alternatives to explore the robustness of our chosen approach (and its implications for welfare and poverty measurement) are considered.

First, one could estimate the hedonic model from equations 3 and 4 using reported rent information for tenants only. However, given the low number of tenants in Djibouti (only 19 percent of all dwellings are rented nationally, and the numbers are even lower in the regions at an average of
8 percent), creating a distribution of rents that is based on a few observed characteristics. Thus, this approach is not followed. A second alternative is to estimate the above hedonic model using only self-reported rent information for owners and in-kind dwellers (and exclude rent reported by tenants). Sensitivity analysis based on this approach is conducted and did not find any significant changes to measures of well-being or poverty rates (the extreme poverty rate changed to 19.7 percent and the overall poverty rate changed to 34.4 percent). In the third approach, the estimated coefficients from equation 3 are applied to not only owner-occupied and in-kind dwellers' but also tenant's housing characteristics to produce a predicted value of rent. Using this approach, no significant changes to measures of well-being or poverty rates are found (the extreme poverty rate changed to 20.6 percent and the overall poverty rate change to 35.6 percent).

\section{ANALYSIS OF THE CONSUMPTION AGGREGATE}

The consumption aggregate is finally obtained by aggregating food expenditure and nonfood expenditures, together with user cost of consumer durables and housing.

The relative importance of each of these classes as it varies by quintiles of the per capita total expenditure distribution is show in table B.5 In general, as one would expect from Engel's law, ${ }^{47}$ the share of food items to the total tends to decline for quintiles higher up in the total expenditure distribution. The share of expenditure on housing is high across all quintiles of per capita expenditure. As it is further discussed in the section on defining the poverty line, variations in the composition of the consumption aggregate along the distribution of total expenditure imply that the composition of the consumption

\section{TABLE B.5 Share of Consumption Aggregate Components, by Quintile}

\begin{tabular}{c|c|c|c|c|c|}
\multicolumn{2}{c|}{ Quintile } & Food & Nonfood & Housing & Durables \\
\hline Poorest & 1 & $53.9 \%$ & $19.7 \%$ & $26.3 \%$ & $0.2 \%$ \\
\hline & 2 & $46.1 \%$ & $25.1 \%$ & $28.3 \%$ & $0.4 \%$ \\
\hline & 3 & $41.1 \%$ & $27.1 \%$ & $31.1 \%$ & $0.7 \%$ \\
\hline Richest & 5 & $39.6 \%$ & $28.4 \%$ & $31.1 \%$ & $0.8 \%$ \\
\hline
\end{tabular}

Source: Calculations based on EDAM4-IS.

Note: Quintiles are calculated based on per capita consumption

47 Engel's law is an empirical observation in economics that states as income rises, the proportion of income spent on food falls, even if the level of expenditure on food rises. 
bundle defining basic needs should be estimated on a subsample of "relatively poor" households.

\section{HOUSEHOLD COMPOSITION}

For each household, food, nonfood, services of durable goods, and housing flows are aggregated to arrive at annual consumption expenditures. Since consumption varies within the household according to demographic composition, it is important to define a measure of well-being for an individual household member. One of the simplest ways to do this is to divide consumption expenditure by household size and express the aggregate well-being in per capita terms. The main advantage of this approach is that it is easy to communicate and understand. The disadvantage is that such a correction may be inappropriate because the preferences of household members are not homogeneous and there are economies of scale associated with certain goods and services.

In the report "Measuring Poverty and Inequality" (DISED 2014), for the purposes of adjustment of household composition, an equivalent scale is used. The construction of an equivalence scale is theoretically the most appropriate method for moving from family welfare to individual wellbeing. The Food and Agriculture Organization equivalence scale (also used by Afristat) is applied, which assigns weight to each household member by age group and sex (table B.6).

\section{TABLE B.6 Scales for an Equivalent Adult}

\begin{tabular}{l|c|c|} 
& Males & Females \\
\hline 0-1 years & 0.27 & 0.27 \\
\hline 1-3 years & 0.45 & 0.45 \\
\hline 4-6 years & 0.61 & 0.61 \\
\hline 7-9 years & 0.73 & 0.73 \\
\hline $10-12$ years & 0.86 & 0.73 \\
\hline $13-15$ years & 0.96 & 0.83 \\
\hline $16-19$ years & 1.02 & 0.77 \\
\hline 20-50 years & 1.00 & 0.77 \\
\hline 51 years and more & 0.86 & 0.79 \\
\hline
\end{tabular}

Source: DISED 2014

\section{TEMPORAL AND SPATIAL ADJUSTMENT}

Intertemporal price adjustments account for differences in the prices of goods that form the aggregate of well-being over time. As usual, for the intertemporal adjustment of prices, inflation rates constructed from the consumer price index are used. More precisely, the values obtained from the second phase in November 2018 and in December 2017 are adjusted with a factor of 0.9898 and 0.9992, respectively, to make the real values comparable to the values captured in the first phase in May 2017 (corresponding to deflation rate observed during this period of -1.02 percent and -0.71 percent, respectively).

Another factor to consider is the difference in the cost of living across space. One way to account for difference in the cost of living is to perform a spatial price adjustment. Deaton and Zaidi (2002) recommend using the Paasche price index at the household level for spatial price adjustment. Using this approach, it is found that the poverty rate in Djibouti city declines from 13.6 percent to 11.7 percent, causing the poverty for Djibouti as a country to decline from 21.1 percent to 19.8 percent. 


\section{ESTIMATION OF POVERTY LINE}

The poverty line is estimated to represent, according to the norms of a given society, the cost for a household to achieve a level of well-being considered the minimum necessary and which allows it to satisfy its food and nonfood needs. The data from EDAM4 were used to determine-from the level of consumption (per adult equivalent) considered the minimum necessary and whether a household's consumption expenditures are below this threshold-if the household can be deemed poor. Although a similar exercise was conducted in 2014 by DISED and African Development Bank, the improvements incorporated into the EDAM4 questionnaire change the methodology for calculating household consumption. The availability of a recent consumption basket of Djiboutian households contributed to the decision to define a new poverty line for 2017. The threshold is a new baseline for poverty monitoring in Djibouti and will be used as a reference for future EDAM analyses.

To construct poverty lines, the absolute concept to calculate the poverty line is used. ${ }^{48}$ The cost-of-basicneeds approach is used, ${ }^{49}$ which consists of estimating a food component and a nonfood component of the poverty line. The food component is based on the calculation of a food threshold that guarantees a minimum level of energy intake of 2,115 kilocalories per day. ${ }^{50}$ For the construction of the nonfood component of the poverty line, the Ravallion (1998) method was applied to construct two nonfood poverty lines, which are explained in turn.

\section{ESTIMATION OF THE FOOD POVERTY LINE}

The estimation of absolute poverty thresholds is typically based primarily on the assessment of a cost of food energy requirements. The food threshold is defined as the product of the minimum caloric intake that a basket of food consumption must guarantee by the unit cost of acquiring a kilocalorie. It is, thus, given by the following equation:

$$
z_{\alpha}=C * \operatorname{COST} * 365
$$

where $\mathrm{C}$ is the minimum daily input required for the dietary needs of an active adult (2,115 kilocalories), COST is the average unit cost of a kilocalorie. The steps to calculate each of these is discussed in turn.

Step 1: Set the minimum caloric intake. The minimum caloric intake of this basket of consumption must allow the daily activities of an average individual to be carried out. DISED has estimated 2,115 kilocalories a day is a good reference for the caloric needs of the population.

\section{Step 2: Calculate the unit cost of acquiring a}

kilocalorie. To calculate the unit cost of acquiring a kilocalorie, one needs to identify the food calories and the cost or price associated with each product covered in EDAM4-IS. In addition, a reference population must be identified for whom the unit cost of a kilocalorie will be calculated.

48 Poverty lines typically follow one of two main approaches. A first approach considers that the poverty line is an absolute concept, indicating the level of consumption needed to meet just minimum food and nonfood needs. The second approach interprets the poverty line as a relative concept, so poverty is understood as a situation of relative deprivation. The actual values of the relative poverty lines increase with the economic (and social) conditions of the country.

49 The cost-of-basic-needs approach has been used in DISED (2014).

50 Although lower than the thresholds used in other African countries, this level was considered appropriate in the current Djiboutian context. 
The choice of a reference population must ensure that its consumption basket is closest to the population living near the poverty line, but at the same time, that such basket of consumption can reach a sufficient nutritional level.

Using EDAM-BC 2013, DISED (2014) determined the reference population as follows: instead of using the population between the second and fourth deciles, which is a common method, the entire population was chosen as the reference. According to DISED's estimates, the population between the second and fourth decile "consumes a basket of food products whose nutrient intake, mainly protein, is low. Therefore, their consumption does not reflect a minimum caloric intake required but rather the low income that does not allow them to buy food of reasonable quality." The approach followed for the current exercise also took the entire population as a reference, where average caloric consumption per adult equivalent stands at 1,791 calories (the distribution is shown in figure B.2). It is also found that consumption of the second and fourth deciles are low: this population consumes only 15 food products on average, resulting in 1,444 kilocalories per day per equivalent adult. This result suggests that calculating the unit cost of a kilocalorie using the consumption of the population from the second to the fourth decile would lead to an average value of the cost that would underrepresent the real cost of a basket that provides a desirable minimum caloric intake. The consumption basket of the reference population (entire population) identified is used and this forms the basis for the calculation of food poverty line.

\section{FIGURE B.2 Distribution of per Adult Equivalent Daily Intake of Calories}

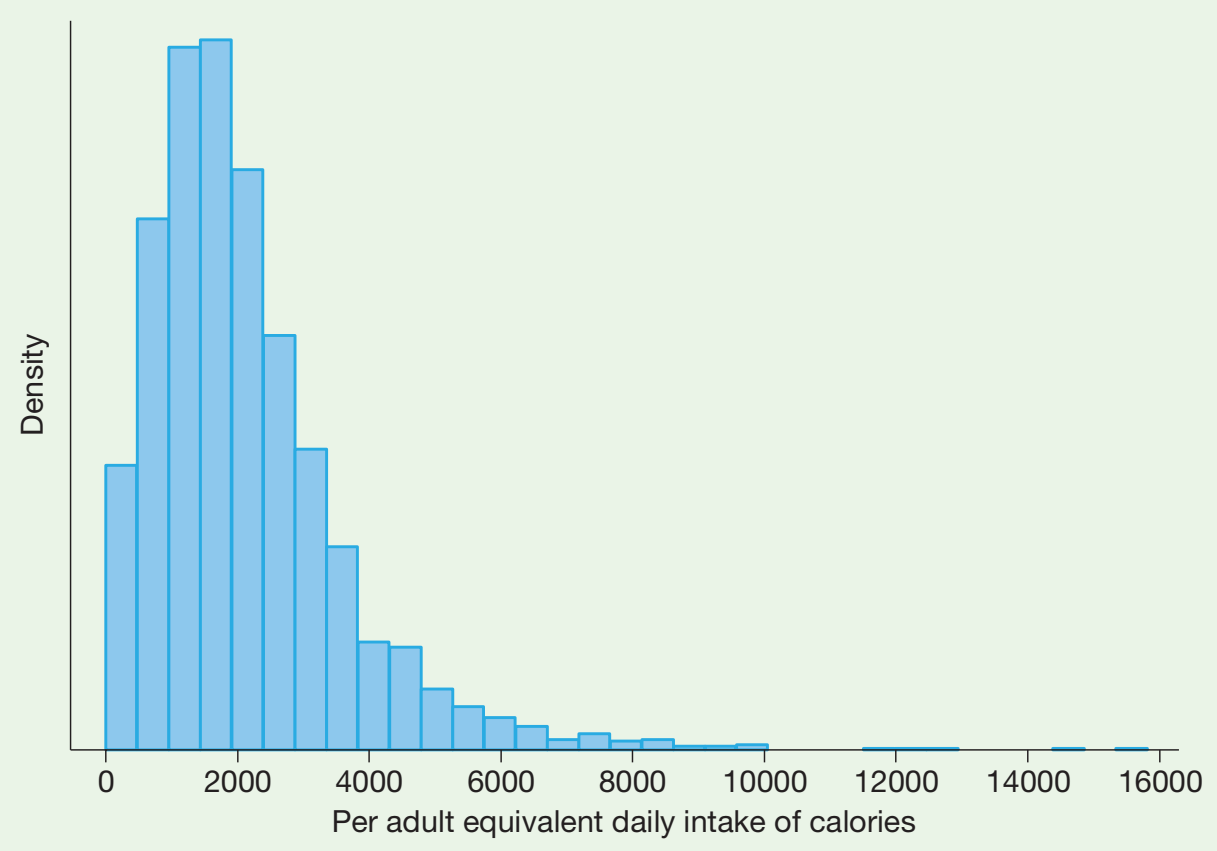

Source: Calculations based on EDAM4-IS. 
It is necessary to obtain the caloric composition of each food product covered in EDAM4 in Djibouti to calculate the unit cost of a kilocalorie. Since food caloric data are not available specifically for Djibouti, a table was constructed for Djibouti from the Food and Agriculture Organization's table prepared for the West Africa (FAO 2012) and for North African countries (Tunisian National Table). This has been done keeping in mind the food products that are mainly consumed in Djibouti. ${ }^{51}$

The next step to calculate the unit cost of acquisition of a kilocalorie is to establish the price of each product. Out of 100 food products in EDAM4-IS, all the necessary information could be gathered for 44 products. The price paid (as a proxy for the unit cost) based on the quantity purchased and the amount paid that was entered in the survey is then calculated. In addition, this price can be allocated by kilogram or liter. ${ }^{52}$ Djiboutian households spend 81 percent of food expenditure on these 44 products. The remaining 56 products were not included because they did not satisfy one of the following criteria: (i) there is a credible mapping between the product and calorie intake (for example, in food group codes such as "cookies, pastries and croissants"); (ii) consumption was reported mainly in nonstandard units and could not be transformed into kilograms or liters; and (iii) the number of households reporting consumption of the food product was low.

\section{FOOD POVERTY THRESHOLD}

With these elements, the level of annual expenditure (per equivalent adult) needed to meet the minimum nutritional needs of 2,115 kilocalories using the cost-of-basicneeds approach is determined. The median unit cost of the calorie is used to determine the food component of the poverty line. The average unit cost of a kilocalorie is estimated at DF 0.103 in 2017 and the estimated food poverty line is DF 79,480 .

\section{EXTREME POVERTY THRESHOLD}

The extreme poverty line includes a food component and a nonfood component. The nonfood component of the extreme poverty line is calculated by looking at households whose total consumption expenditure is equal to the food poverty line. Households for which these two are equal choose to divide their consumption between food and nonfood items. It follows that these households consider that spending on nonfood items will boost their level of satisfaction. The expenditure corresponding to these nonfood products is therefore considered indispensable.

To estimate this extreme poverty line, Ravallion's (1998) method of estimating a Engel function is done. It shows the relationship between the budgetary part of food expenditure $\left(w_{\alpha}\right)$, consumption per adult equivalent $(y)$ normalized by the food poverty line $\left({ }^{Z} \alpha\right)$, and the deviation of household size $\left(n^{h}\right)$ from the average household size, as follows:

$w_{\alpha}^{i}=\alpha+\beta \ln \left(\frac{y^{i}}{z_{\alpha}}\right)+\gamma\left[\ln \left(\frac{y^{i}}{z_{\alpha}}\right)\right]^{2}+\delta\left(n^{h}-\bar{n}\right)+\vartheta_{\alpha}^{i}$

The quantile regression approach is used to estimate the coefficient in equation (2) for the entire country in order to calculate the unique food and nonfood poverty lines for the entire country. Table B.7 shows the estimated value of the parameters of equation (2).

The budget coefficient is found to be 0.59 or 59.4 percent for the country. The income coefficient of effect describes income elasticity - this elasticity is less than 1. That means that spending on food is a necessity expense.

When the household consumption per adult equivalent is exactly equal to the food poverty line and the household size is equal to the average household size, the part of the household budget devoted to food consumption is given

51 The reliability of the data source has been verified in the poverty calculations performed in previous years by DISED.

52 All the information needed to transform the different acquisition units was collected and analyzed. Using detailed product data and the most common prices collected by DISED, a map of most units could be made in kilograms or liters. This is the key to being able to map the quantities of calories consumed by households. 


\section{TABLE B.7 Estimation of the Engel Curve Coefficients in 2017}

\begin{tabular}{l|c|c|c|c|} 
& Coefficient & Standard deviation & $\mathrm{t}$ & $\mathrm{P}>\mathrm{t}$ \\
\hline Income effect & -0.101 & 0.007 & -15.33 & 0 \\
\hline Income effect squared & -0.009 & 0.003 & -2.98 & 0.003 \\
\hline Household size & -0.020 & 0.002 & -13.43 & 0 \\
\hline Constant & 0.594 & 0.005 & 120.28 & 0 \\
\hline
\end{tabular}

Source: Calculations based on EDAM4-IS.

by $\alpha$ (according to equation (2)). Thus, the nonfood poverty line can be deduced as follows:

$z_{n a}^{l o w}=(1-\alpha) z_{\alpha}$

Thus, a relationship between the food poverty line $\left({ }^{Z} \alpha\right)$ and the extreme poverty line $\left(z^{l o w}\right)$ is given as follows:

$z^{\text {low }}=z_{\alpha}+z_{\text {na }}^{\text {loe }}=(2-\alpha) z_{\alpha}$

Finally, this nonfood poverty line is added to the food poverty line to calculate the extreme poverty line. The extreme poverty line reflects the bare minimum necessary to have sufficient nutritional intake to survive.

\section{OVERALL POVERTY THRESHOLD}

The overall poverty line also includes a food component (as previously defined) and a nonfood component that are calculated by determining the total consumption of households whose food consumption expenditure is equal to the food poverty line. This ensures that households can achieve the caloric intake equal to the minimum as defined by the food poverty line without forgoing consumption to nonfood products.
The overall nonfood poverty line can be calculated using equation (3) for $y=z^{\text {haut }}$ and a food budget share equal to $Z_{\alpha} / Z^{\text {haut: }}$

$\frac{z_{\alpha}}{z^{\text {haut }}}=\alpha+\beta \ln \left(\frac{z^{\text {haut }}}{z_{\alpha}}\right)+\gamma\left[\ln \left(\frac{z^{\text {haut }}}{z_{\alpha}}\right)\right]^{2}$

Finally, this overall nonfood poverty line is added to the food poverty line to calculate the overall poverty line. Using the 2017 EDAM4 survey and the baseline consumer basket that guarantees 2,115 kilocalories per day per adult, the extreme poverty line of 2017 equals DF 306 per day and the overall poverty line is estimated at DF 415 per day. Using the extreme poverty line, table B.8 presents results at different levels of aggregation.

Other alternatives of poverty lines to explore the robustness of our chosen approach (and its implications for welfare and poverty measurement) are considered. First, the poverty line used for 2013 is used and adjusted with inflation experienced between May 2013 and May 2017 (3.84 percent). The consequent poverty line gives poverty rates that do not differ qualitatively from the official results (extreme poverty rate of 18.3 percent and overall poverty rate of 36.5 percent). Second, the poverty line 
of 2013 is used and adjusted with inflation experienced between May 2013 and May 2017 for food expenditures and nonfood expenditures separately (11.3 percent inflation for the food part and 0.54 percent deflation for the nonfood part). Using the resulting poverty thresholds, the extreme poverty rate stands at 19.4 percent and overall poverty rate of 37 percent. Finally, since the data were collected in two phases, in May 2017 and NovemberDecember 2017, some concern was expressed regarding the role of seasonality. To test this, restricting to phase one only (conducted in May 2017), it is found that the results on poverty do not differ from the official ones qualitatively (resulting in an extreme poverty rate of 23.4 percent and overall poverty rate of 39.4 percent).

\section{TABLE B.8 Extreme Poverty Rate and Corresponding Standard Errors and}

Confidence Intervals

\begin{tabular}{l|c|c|c|c|} 
& \multicolumn{1}{|c|}{ Estimate } & Standard error & \multicolumn{2}{|c|}{$95 \%$ confidence interval } \\
\hline National & $21.1 \%$ & 0.90 & 19.40 & 22.90 \\
\hline Regions & $45.0 \%$ & 1.30 & 42.50 & 47.50 \\
\hline Djibouti city & $13.6 \%$ & 1.10 & 11.40 & 15.80 \\
\hline Rural & $62.6 \%$ & 1.30 & 59.90 & 65.20 \\
\hline Other urban & $14.8 \%$ & 2.00 & 10.80 & 18.80 \\
\hline Ali Sabieh & $27.2 \%$ & 2.30 & 22.60 & 31.70 \\
\hline Dikhil & $52.9 \%$ & 2.70 & 47.60 & 58.10 \\
\hline Tadjourah & $65.4 \%$ & 2.60 & 60.30 & 70.60 \\
\hline Obock & $40.4 \%$ & 2.90 & 34.80 & 46.10 \\
\hline Arta & $31.6 \%$ & 2.70 & 26.40 & 36.80 \\
\hline 1st district & $4.7 \%$ & 2.20 & 0.40 & 9.00 \\
\hline 2nd district & $9.8 \%$ & 1.80 & 6.20 & 13.30 \\
\hline 3rd district & $8.5 \%$ & 1.80 & 5.00 & 12.00 \\
\hline 4th district & $18.3 \%$ & 2.30 & 13.70 & 22.90 \\
\hline 5th district & $15.8 \%$ & 2.30 & 11.40 & 20.20 \\
\hline
\end{tabular}

Source: Calculations based on EDAM4-IS. 


\section{REFERENCES}

Deaton, Angus, and Margaret Grosh. 1998. Consumption. In Designing Household Survey Questionnaires for Developing Countries: Lessons from Ten Years of LSMS Experience Edited by: Grosh, M. and Glewwe, P. mimeo, Ch.17

Deaton, A., and S. Zaidi. 2002. Guidelines for Constructing Consumption Aggregates for Welfare Analysis.

Washington, DC: World Bank.

DISED (Direction de la Statistiques et des Etudes

Démographiques). 2014. "Mesures de la pauvreté et des inégalités." Photocopy. Djibouti: DISED.

Duan, Naihua. 1983. "Smearing Estimate: A

Nonparametric Retransformation Method." Journal of the American Statistical Association 78 (383): 605-10.

FAO (UN Food and Agriculture Organization). 2012. West African Food Composition Table. Rome: FAO. http://www. fao.org/3/i2698b/i2698b00.pdf.

FAO. 2007. Tunisian National Table. Rome: FAO.

Freeman, A. Myrick. 1993. The measurement of Environmental and Resource Values Resources for the Future." Washington, DC: World Bank.

Ravallion, M. 1998. "Poverty Lines in Theory and Practice." LSMS Working Paper 133. World Bank: Washington DC.

United Policy Holders. Depreciation Schedule - residential personal property. https://www.uphelp.org/library/ resource/depreciation-schedule-residential-personalproperty 
CHALLENGES TO INCLUSIVE GROWTH A POVERTY AND EQUITY ASSESSMENT OF DJIBOUTI 



